\title{
WestVirginiaUniversity
}

THE RESEARCH REPOSITORY @ WVU

Graduate Theses, Dissertations, and Problem Reports

2004

\section{Behavior of FRP wrapped concrete cylinders}

Renee R. Rajappa

West Virginia University

Follow this and additional works at: https://researchrepository.wvu.edu/etd

\section{Recommended Citation}

Rajappa, Renee R., "Behavior of FRP wrapped concrete cylinders" (2004). Graduate Theses, Dissertations, and Problem Reports. 1881.

https://researchrepository.wvu.edu/etd/1881

This Thesis is protected by copyright and/or related rights. It has been brought to you by the The Research Repository @ WVU with permission from the rights-holder(s). You are free to use this Thesis in any way that is permitted by the copyright and related rights legislation that applies to your use. For other uses you must obtain permission from the rights-holder(s) directly, unless additional rights are indicated by a Creative Commons license in the record and/ or on the work itself. This Thesis has been accepted for inclusion in WVU Graduate Theses, Dissertations, and Problem Reports collection by an authorized administrator of The Research Repository @ WVU. For more information, please contact researchrepository@mail.wvu.edu. 


\title{
BEHAVIOR OF FRP WRAPPED CONCRETE CYLINDERS
}

\author{
Renee R. Rajappa \\ Thesis submitted to the \\ College of Engineering and Mineral Resources at \\ West Virginia University in \\ partial fulfillment of the requirements \\ for the degree of
}

Master of Science

in

Civil Engineering

\author{
P.V. Vijay, Ph.D., Chair \\ Hota GangaRao, Ph.D., Co-chair \\ Cho Eung Ha, Ph.D.
}

Department of Civil and Environmental Engineering

\author{
Morgantown, West Virginia \\ 2004
}

Keywords: Confinement, CFRP, Concrete Columns, Composite Wrap, Strengthening,

Rehabilitation, Deformability Factor, Ductility,

Aging, Infrared Thermography, Bond

Copyright 2004 Renee R. Rajappa 


\section{ABSTRACT \\ BEHAVIOR OF FRP WRAPPED CONCRETE CYLINDERS}

\section{Renee Rajappa}

In this research, increases in strength, stiffness and ductility due to external wrapping of Carbon Fiber Reinforced Polymer (CFRP) sheets on plain and steel reinforced concrete cylinders were studied. The research focused on behavior of plain and wrapped concrete cylinders with respect to parameters such as: 1) concrete compressive strength $\left.\left(f_{c}^{\prime}\right) ; 2\right)$ fiber orientation of CFRP wrap $\left(0^{\circ}, 45^{\circ}\right.$ and $\left.\pm 45^{\circ}\right)$; 3 ) cylinder size (3"x 6", 4"x 8", 6"x 12"); 4) number of CFRP wraps $(1,3,6) ; 5)$ wrapping height and location (top and bottom, middle); 6) degree of fabric wetting; and 7) degree of bonding fabric onto concrete. The mechanical properties evaluated include confinement related increase in axial strength/stiffness, energy absorption (deformability factor), and failure modes. The experimental results were correlated to analytical models consisting of terms representing lateral confining/radial pressure generated by the wrap in hoop direction.

The mechanical properties were compared to those of non-wrapped specimens. An increase in strength of 1.5 - 3 times and hoop strain of $10-20$ times was noticed. The increase in axial strength of 3"x 6" concrete cylinder per layer of wrap for 1, 3 and 6 layer wrapped cylinder was $29 \%, 43.7 \%$ and $33.93 \%$, respectively. Cylinders completely bonded with wrap showed 1.52 times increase in strength whereas cylinders with $31.8 \%$ and $21.2 \%$ bond showed 1.48 times and 1.23 times increase in strength, respectively. Thus the small delaminations or discontinuities in bonding that may be caused during hand or machine wrapping of column specimens are not critical and do not affect the confinement related strength increase. Deformability factor or energy absorption of specimen wrapped with 3 wraps of $0^{\circ}$ fiber direction showed 12 times increase and specimens with $\pm 45^{\circ}$ wrap showed 9 times increase compared to non-wrapped specimens.

Aging of wrapped and non-wrapped cylinders with and without internal steel reinforcement and carbon strip specimens was studied by subjecting them to elevated temperature $\left(175^{\circ} \mathrm{F}\right)$ and freeze-thaw $\left(-20^{\circ} \mathrm{F}\right.$ to $\left.120^{\circ} \mathrm{F}\right)$ condition. Wrapped cylinders showed a maximum decrease in strength of $12 \%$ in elevated temperature aging and $5 \%$ in freeze thaw aging. Further Aging is underway for both conditions.

Non-destructive infrared thermography tests were done to study the interfacial bond between concrete and wrap. Thermograms were recorded to identify the presence of localized delaminations in the wrapped specimens. Infrared thermography was also used to examine delamination size increase in aged specimens, and no detectable growth was observed with thermography. 


\section{DEDICATION}

This Thesis is dedicated to my Family, Teachers and Friends

who have made it possible for me to complete my

Masters Degree in $\mathrm{WVU}$ 


\section{ACKNOWLEDGEMENTS}

First of all I would like to thank my professors Dr. Vijay, my Chair and Dr. Hota, my Cochair for their guidance and encouragement throughout the period of my Masters study and research. I am sincerely thankful for their patience and time during my research work at CFC, WVU. I am thankful for the valuable suggestions of Dr. Cho, a member of my thesis committee. I am thankful to the CFC for funding this research and giving me an opportunity to work in this team.

I am thankful to Jerry Nester, David Turner and Douglas F. Cutlip for their help in the laboratory. I am thankful to all my colleagues in B62 who have helped me throughout, especially Raghu, Vijay, Praveen, Deepika, Aneesh, Meru and Sachin. I would like to extend thanks to my friends, Sam, Kedhar and Balaji who always helped me with testing. I would also like to thank my roommates and my friend Archana, for making my stay in Morgantown a very pleasant and memorable one.

I am thankful to my family, who made me realize the importance of advanced studies. Their support and love gave me the motivation to do my best. 


\section{TABLE OF CONTENTS}

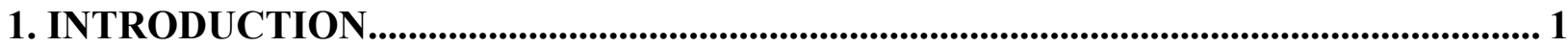

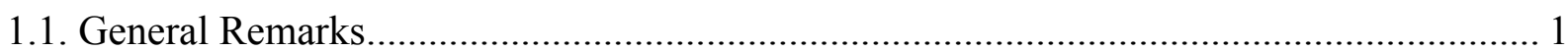

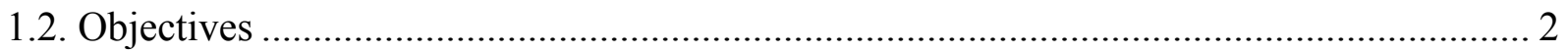

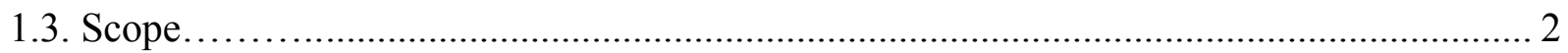

1.3.1. Concrete Cylinders Confinement................................................................. 3

1.3.2. Tests to Determine Effect of Number of Wraps .............................................. 4

1.3.3. Tests to Determine Effects due to Cross Sectional Area of Concrete ............... 5

1.3.4. Tests Conducted to Determine Effect of Wrap Position and Height ................. 6

1.3.5. Confinement effects due to Partial Fabric Wetting.......................................... 7

1.3.6. Confinement effects due to degree of Bonding Fabric on Concrete.................. 7

1.3.7. Accelerated Aging Tests ....................................................................... 8

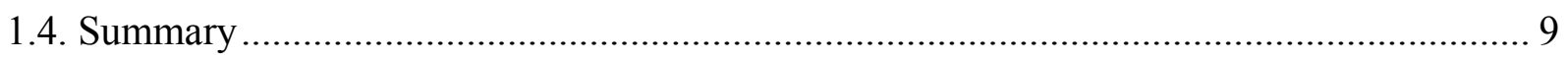

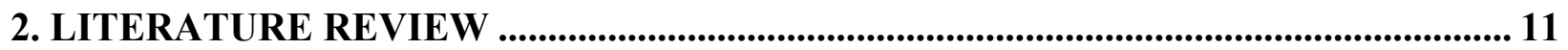

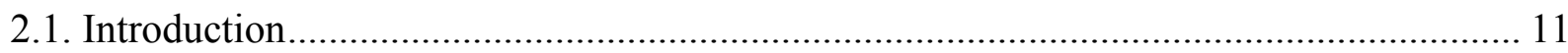

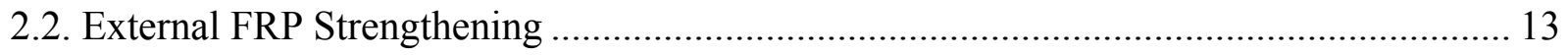

2.3. Aging of FRP Strengthened Structures....................................................................... 16

2.4. Methods of wrapping and Types of FRP wrap .......................................................... 19

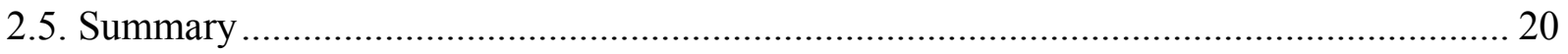

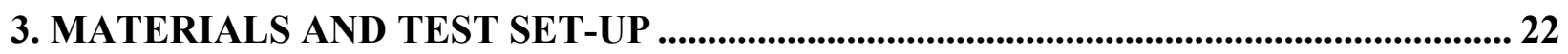

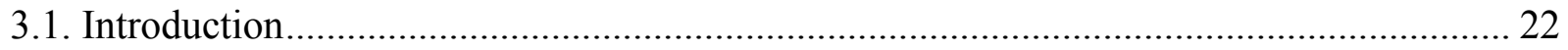

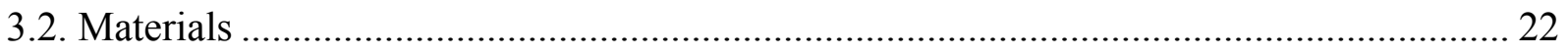

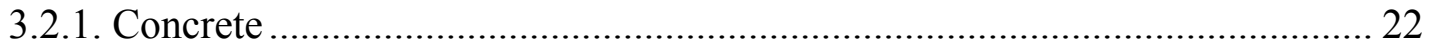

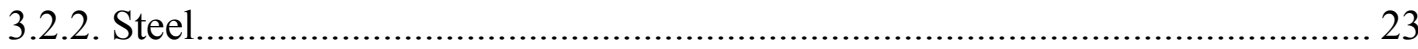




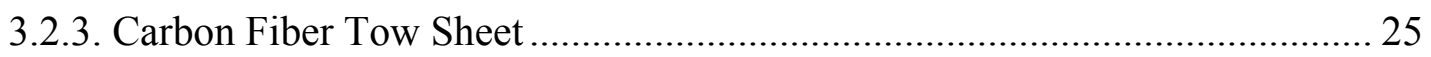

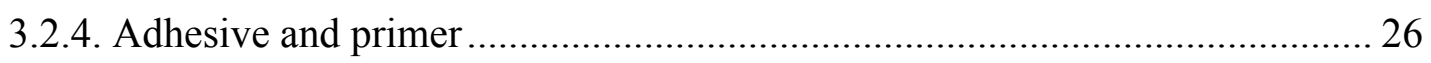

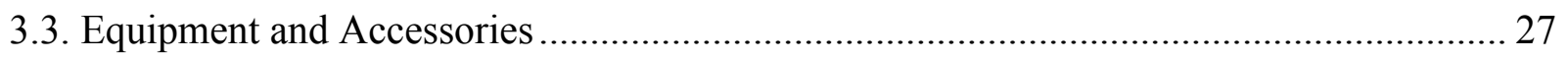

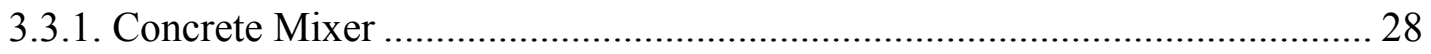

3.3.2. Universal Compression-Testing Machine....................................................... 28

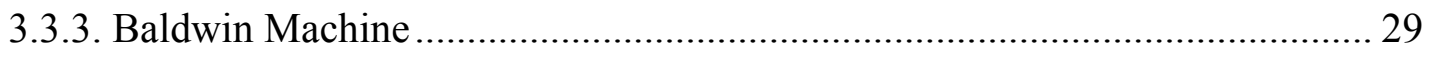

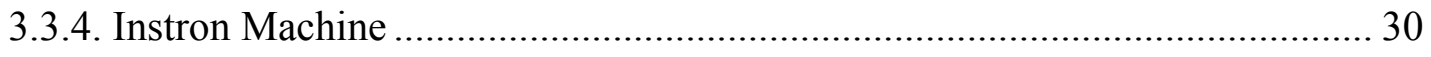

3.3.5. Data Acquisition, Strain Gauges, Load cell and LVDT ................................. 31

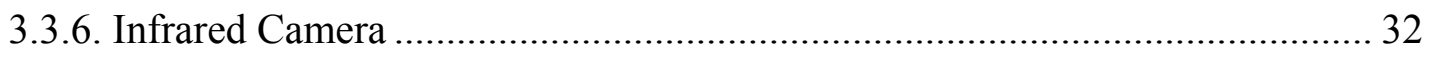

3.3.7. Environmental Chamber for Freeze Thaw Cyclic Aging ............................... 34

3.3.8. Elevated Temperature Bath for Aging ....................................................... 35

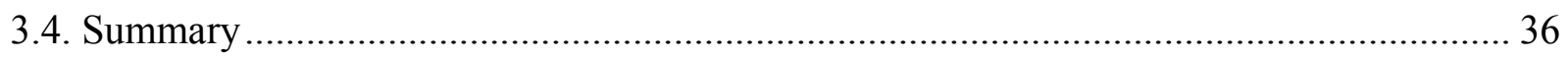

4. TEST SPECIMEN AND TEST PROCEDURE ........................................................................ 37

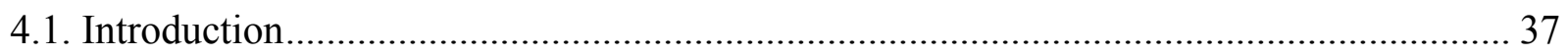

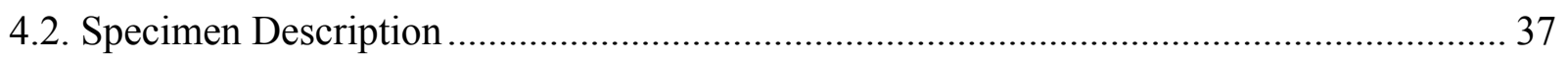

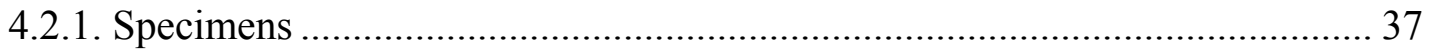

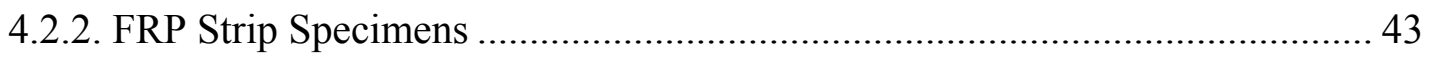

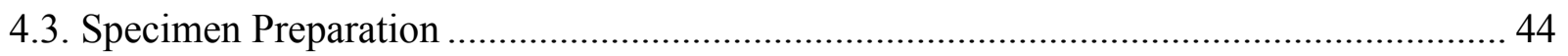

4.3.1. Casting and Curing of Concrete Cylinders .................................................... 44

4.3.2. Wrapping of Cylinders............................................................................. 45

4.3.3. Preparation of FRP Strip Specimens............................................................. 49

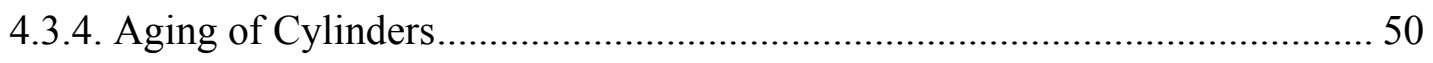

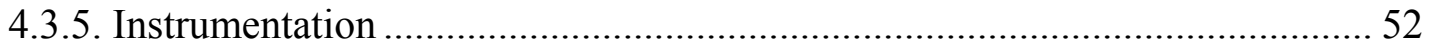

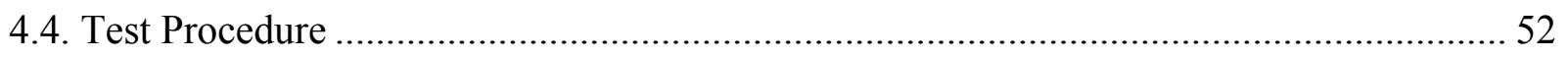


4.4.1. Axial Compression Tests .............................................................................. 53

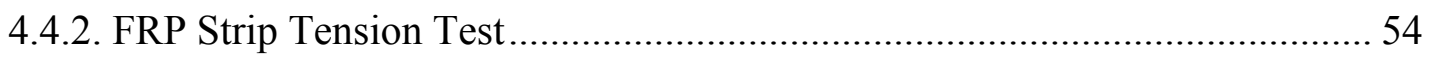

4.4.3. Infrared Thermography Test.................................................................... 54

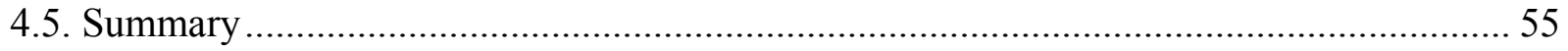

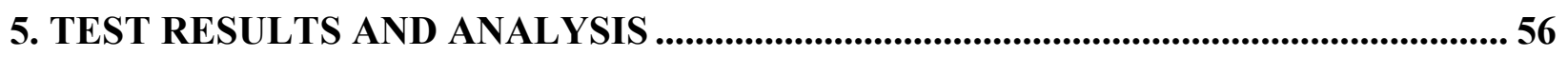

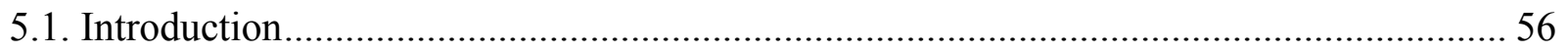

5.2. Axial Compression Tests to Determine Effect of Confinement ........................................ 56

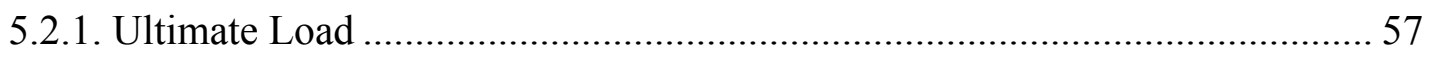

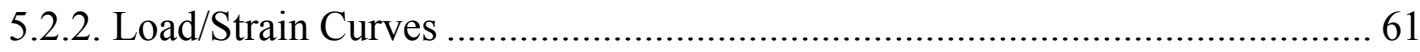

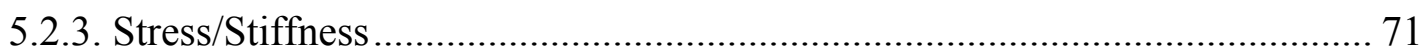

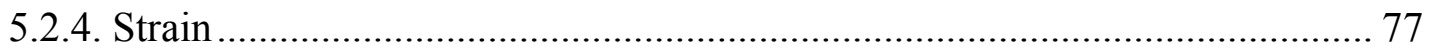

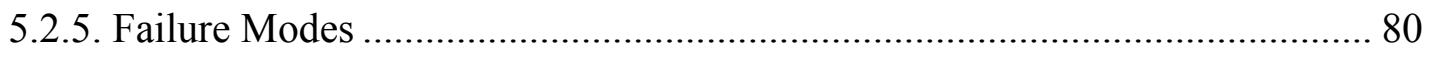

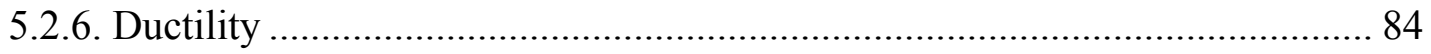

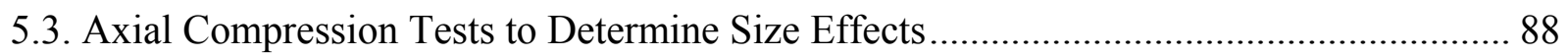

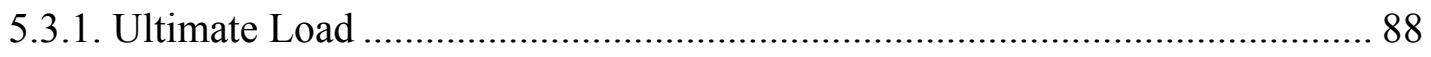

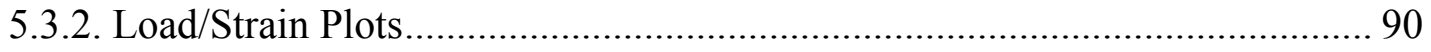

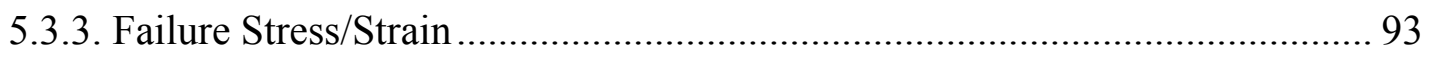

5.4. Axial Compression Tests to Determine the Effect of Number of Layers........................... 94

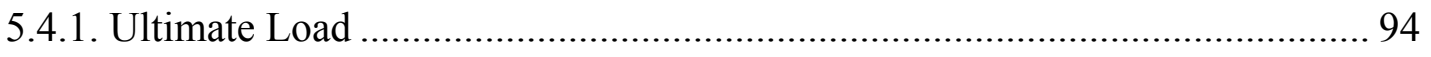

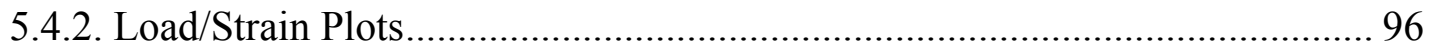

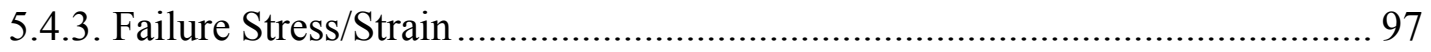

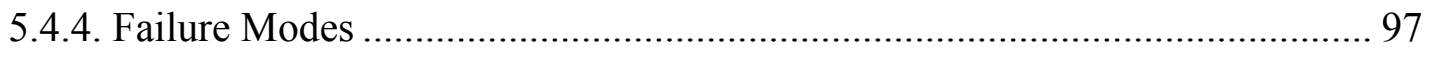

5.5. Axial Compression Tests to Determine Effects of Height and Position of Wrap ........... 100

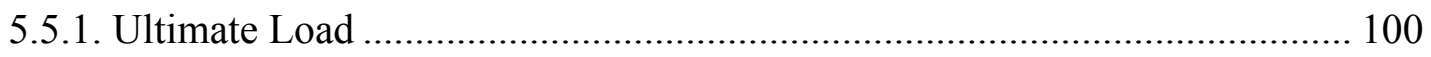




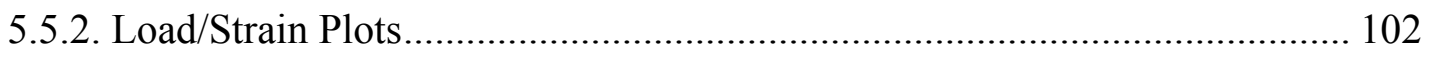

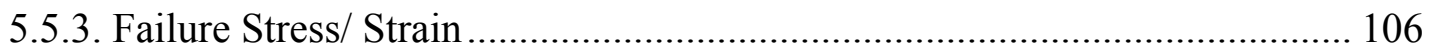

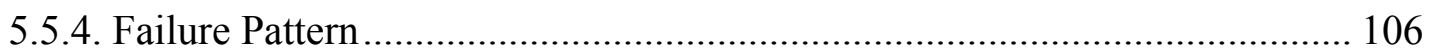

5.6. Axial Compression Tests to Determine Effect of Fiber Wetting...................................... 110

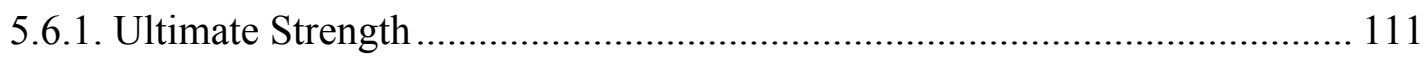

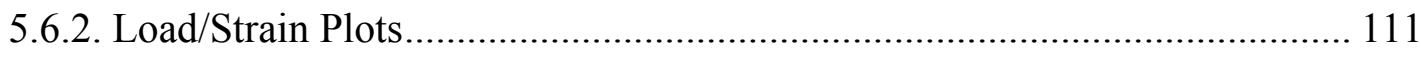

5.6.3. Maximum Stress/Strain and Energy ………………................................. 115

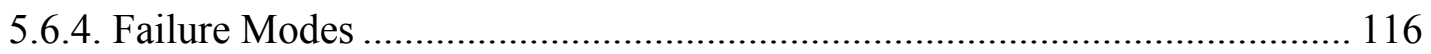

5.7. Axial Compression Tests to Determine Effect of Degree of Fabric Bonding to Concrete

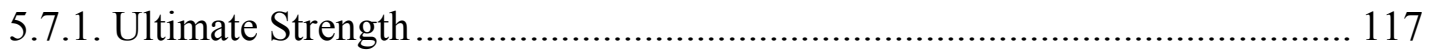

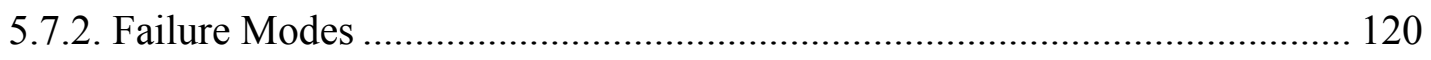

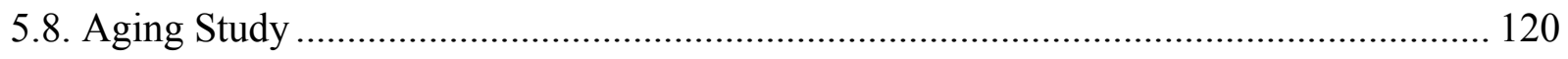

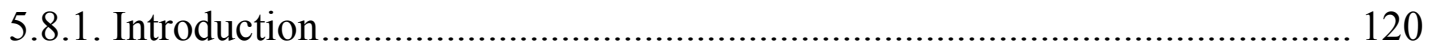

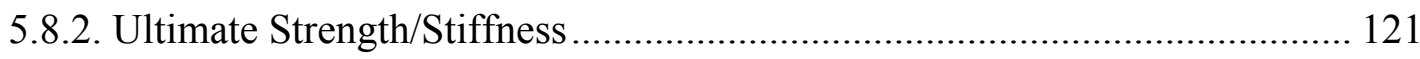

5.8.3. Stress/Strain Comparison.......................................................................... 124

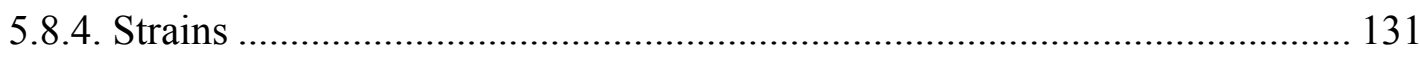

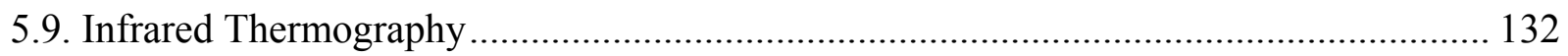

5.9.1. Thermal Mapping/Profiling .................................................................... 132

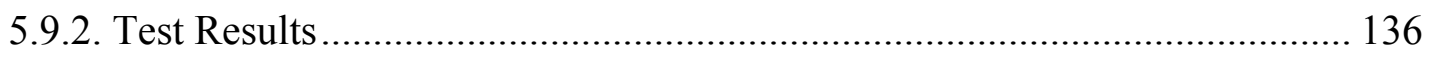

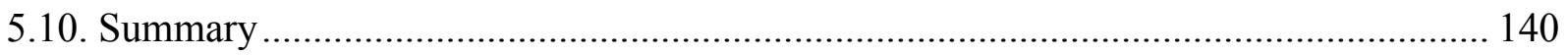

6. ANALYTICAL EVALUATION................................................................................................. 141

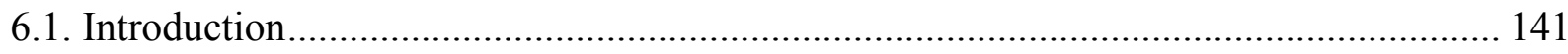

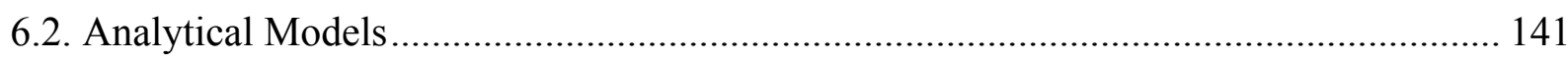


6.2.1. Model I.

6.2.2. Model II

6.2.3. Model III 145

6.2.4. Model IV

6.2.5. Model V 148

6.2.6. Model VI 151

6.3. Comparison of Experimental and Analytical Results 152

6.4. Discussions 157

7. CONCLUSIONS AND RECOMMENDATIONS.

7.1. Introduction 158

7.2. Effect of Confinement 159

7.2.1. Ultimate Load

7.2.2. Axial and Hoop Failure Strain 159

7.2.3. Stiffness 160

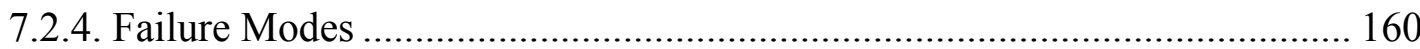

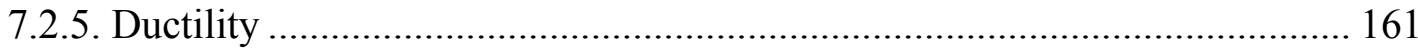

7.3. Size Effect due to Concrete Cross Section ............................................................. 161

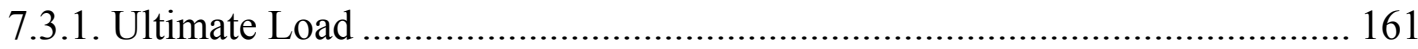

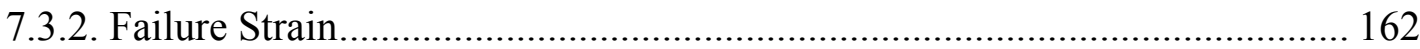

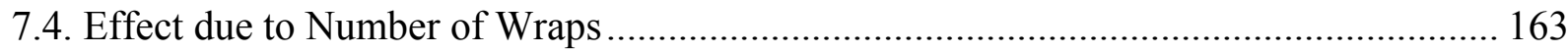

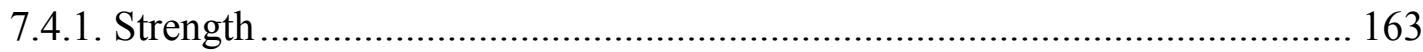

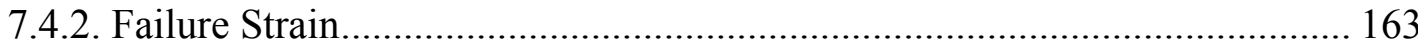

7.5. Effects of Wrapping Height and Location ........................................................ 164

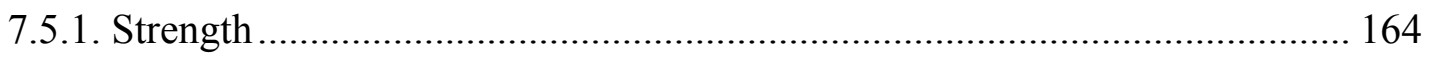


7.5.2. Strain 164

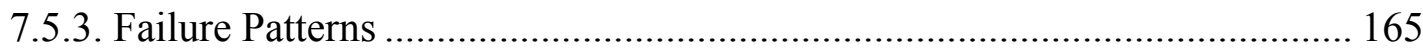

7.6. Effect of Degree of Fabric Wetting ......................................................................... 165

7.6.1. Strength ...................................................................................................... 165

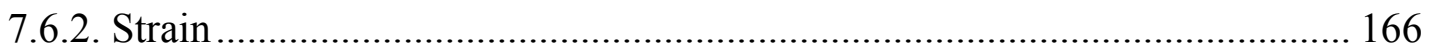

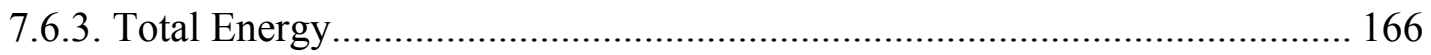

7.7. Degree of wrap Bonding/Contact with Concrete............................................................ 167

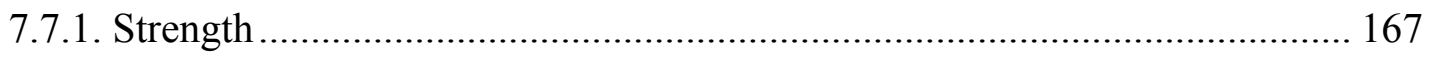

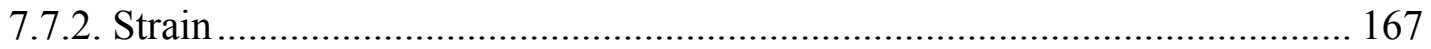

7.8. Axial Compression Tests to determine the Effects of Aging ......................................... 167

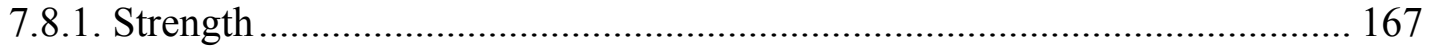

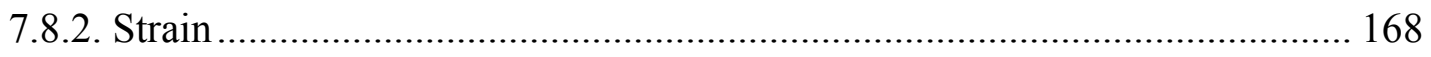

7.8.3. Strength/Stiffness of Strip Specimens ........................................................ 168

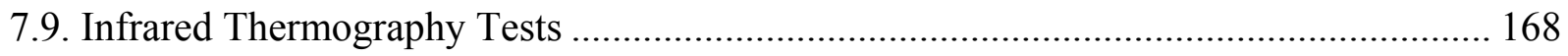

7.10. Analytical and Experimental Comparison ................................................................. 168

7.11. Recommendations for Future research ................................................................... 169

8. REFERENCES.................................................................................................................... 170 


\section{LIST OF TABLES}

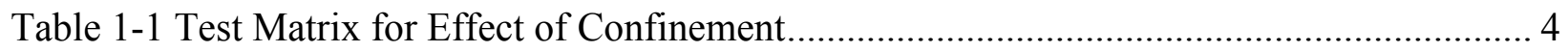

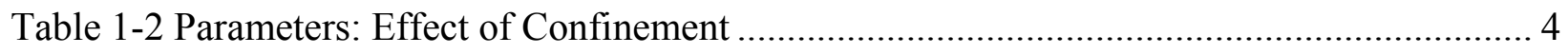

Table 1-3 Test matrix for effect of Increased Number of Carbon Wraps....................................... 5

Table 1-4 Parameters: Effect of Number of Wraps ............................................................... 5

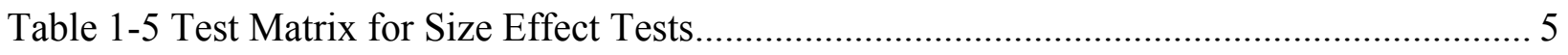

Table 1-6 Parameters: Effect of Concrete Cross Sectional Area ................................................. 6

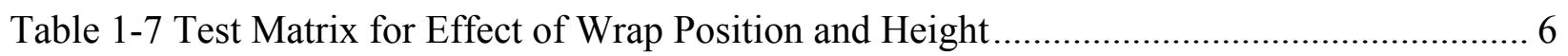

Table 1-8 Parameters: Effect of Wrap Position and Height …………........................................ 6

Table 1-9 Test Matrix for Effect of Partial Fabric Wetting ............................................................. 7

Table 1-10 Parameters: Effect of Partial Fabric Wetting........................................................... 7

Table 1-11 Test Matrix for Effect of Degree of Bonding Fabric to Concrete ................................. 8

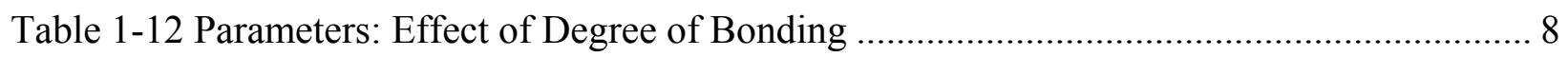

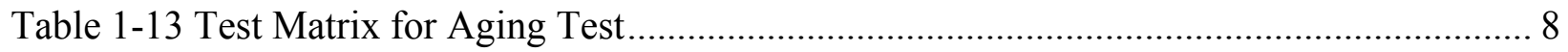

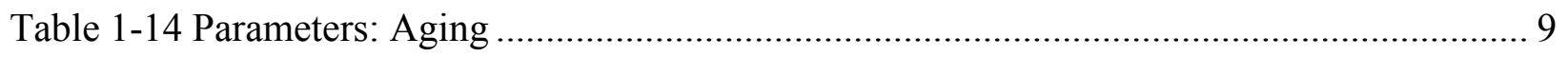

Table 2-1 Rehabilitation Techniques ................................................................................. 19

Table 2-2 Qualitative Comparison between Fibers (Ref. Meier and Winistorfer, 1995) ............. 20

Table 3-1 Properties of Carbon Fiber Tow Sheet reported by Manufacturer (Tonen Co.,

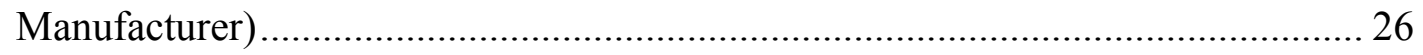

Table 3-2 Properties of Epoxy Resin reported by Manufacturer................................................... 27

Table 4-1 Test Specimens -Confinement Effects and Aging .................................................... 38

Table 4-2 Test Specimens - Effect of Size, Number of Wraps and Partial Wrapping .................. 40

Table 4-3 Test Specimens - Partial Wetting and Bond ............................................................... 43

Table 5-1 Strength of Control Specimens (Effect of Confinement) ……….................................. 57 
Table 5-2 Comparison of Axial Strength of Plain and Reinforced Cylinders with Control Specimens of Batch 1(Effect of Confinement) ................................................. 59

Table 5-3 Comparison of Axial Strength of Plain and Reinforced Cylinders with Control

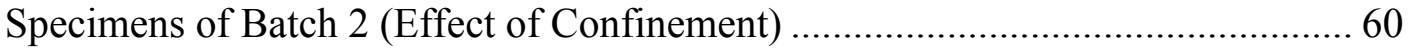

Table 5-4 Maximum Stress of Batch $1\left(f_{c}{ }^{\prime}=4500 \mathrm{psi}\right)$ Specimens....................................... 71

Table 5-5 Maximum Stress of Batch $2\left(f_{c}^{\prime}=8000 \mathrm{psi}\right)$ Specimens......................................... 72

Table 5-6 Stiffness of Batch $1\left(f_{c}{ }^{\prime}=4500\right.$ psi $)$ Specimens .............................................. 73

Table 5-7 Stiffness of Batch $2\left(f_{c}{ }^{\prime}=8000\right.$ psi $)$ Specimens ............................................... 74

Table 5-8 Axial Stress Values at 0.0008, 0.002 and 0.003 Axial Strain for Batch $1\left(f_{c}{ }^{\prime}=\right.$

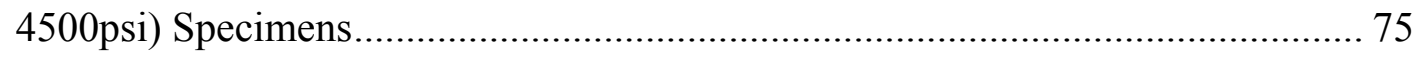

Table 5-9 Axial Stress Values at 0.0008, 0.002 and 0.003 Axial Strain for Batch $2\left(f_{c}{ }^{\prime}=\right.$

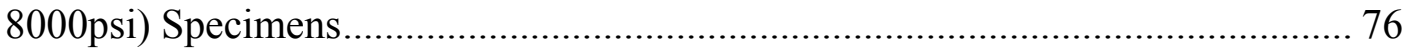

Table 5-10 Axial and Hoop Strain Values of Batch I ( $\left.f_{c}{ }^{\prime}=4500 \mathrm{psi}\right)$ Specimens .................... 77

Table 5-11 Axial and Hoop Strain Values of Batch 2( $\left.f_{c}{ }^{\prime}=8000 \mathrm{psi}\right)$ Specimens..................... 78

Table 5-12 Comparison of Axial and Hoop Strain of Batch 1 Specimens ................................ 79

Table 5-13 Comparison of Axial and Hoop Strain of Batch 2 Specimens ............................... 80

Table 5-14 Comparison of energy for wrapped PCC Specimens with fibers running in $0^{\circ}$ and $45^{\circ}$

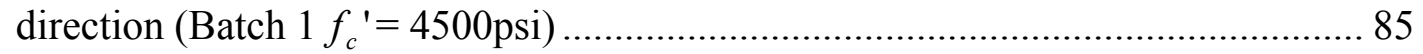

Table 5-15 Comparison of energy for wrapped RCC Specimens with fibers running in $0^{\circ}$ and $45^{\circ}$

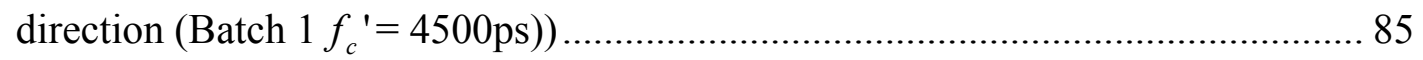

Table 5-16 Comparison of Energy Values for PCC Specimens wrapped with fibers in $0^{\circ}$ and $45^{\circ}$

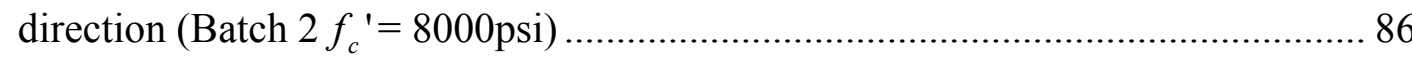


Table 5-17 Comparison of Energy Values for RCC Specimens wrapped with fibers in $0^{\circ}$ and $45^{\circ}$

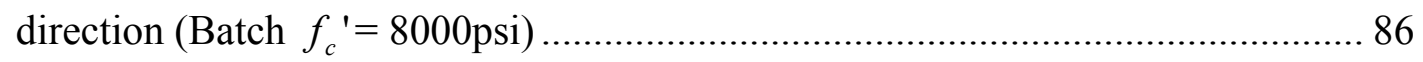

Table 5-18 Deformability in Axial Direction of Plain Concrete Specimens ............................ 87

Table 5-19 Deformability in Hoop Direction of Plain Concrete Specimens ............................. 87

Table 5-20 Deformability in Axial Direction of Reinforced Concrete Specimens ................... 87

Table 5-21 Deformability in Hoop Direction of Reinforced Concrete Specimens .................... 87

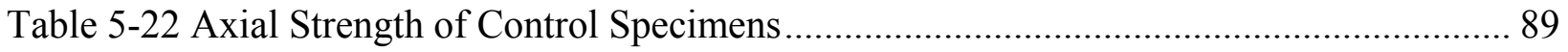

Table 5-23 Axial Strength of Wrapped Cylinders ........................................................... 90

Table 5-24 Failure Stress and Strain of Non Wrapped Specimens........................................ 93

Table 5-25 Stress and Strain of Wrapped Specimens ..................................................... 93

Table 5-26 Strength of Wrapped and Non Wrapped Specimens ......................................... 95

Table 5-27 Stress and Strain of Specimens-Number of Layers ........................................... 97

Table 5-28 Strength of Partially Wrapped Specimens (Batch 5 and Batch 6)......................... 101

Table 5-29 Comparison of Average Strength Increase of Partially Wrapped Cylinders........... 101

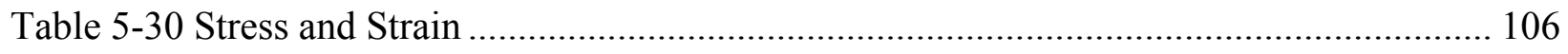

Table 5-31 Strength of Specimens of Batch 1 with Different Fiber Wetting ......................... 111

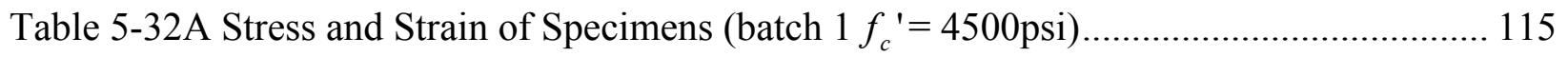

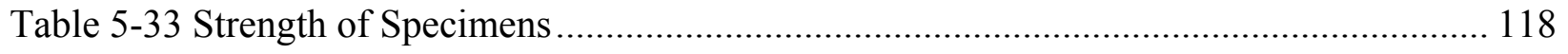

Table 5-34 Strength of Unaged and Aged Plain Concrete Cylinder Specimens ..................... 121

Table 5-35 Strength of Unaged and Aged Reinforced Concrete Cylinder Specimens.............. 122

Table 5-36 Strength of Unaged and Aged Tension Strip Specimens ................................... 123

Table 5-37 Stiffness of Unaged and Aged Tension Strip Specimens..................................... 124

Table 5-38 Hoop Strain of Aged and Unaged Plain Concrete Specimens ............................. 131 
Table 5-39 Hoop Strain of Aged and Unaged Reinforced Concrete Specimens .......

Table 6-1 Constant K Values from Different Researchers

Table 6-2 Experimental Results and Analytical Calculations of Batch 1 (4500 psi) concrete... 153

Table 6-3 Experimental Results and Analytical Calculations of batch 2 (8000 psi) Concrete... 154

Table 6-4 Comparisons of Experimental Results and Analytical Calculations for (batch1) 4500 psi Concrete 155

Table 6-5 Comparisons of Experimental Results and Analytical Calculations of (batch2) 8000 psi Concrete 156

Table B-1 Comparison of energy for wrapped PCC Specimens with fibers running in $0^{\circ}$ direction (Batch 1- $\left.f_{c}^{\prime}=4500 \mathrm{psi}\right)$ 187

Table B-2 Comparison of energy for wrapped PCC Specimens with fibers running in $45^{\circ}$ direction (Batch 1- $\left.f_{c}^{\prime}=4500 \mathrm{psi}\right)$ 187

Table B-3 Comparison of energy for wrapped RCC Specimens with fibers running in zero direction (Batch 1- $\left.f_{c}^{\prime}=4500 \mathrm{psi}\right)$ 188

Table B-4 Comparison of energy for wrapped RCC Specimens with fibers running in $45^{\circ}$ direction (Batch 1- $\left.f_{c}^{\prime}=4500 \mathrm{psi}\right)$. 188

Table B-5 Comparison of Energy Values for PCC Specimens wrapped with fibers in Hoop direction (Batch 2- $\left.f_{c}^{\prime}=8000 \mathrm{psi}\right)$ 189

Table B-6 Comparison of Energy Values for PCC Specimens wrapped with fibers in $45^{\circ}$ direction (Batch $2-f_{c}^{\prime}=8000 \mathrm{psi}$ ). 189

Table B-7 Comparison of Energy Values for RCC Specimens wrapped with fibers in Hoop direction (Batch 2- $\left.f_{c}^{\prime}=8000 \mathrm{psi}\right)$ 190 
Table B-8 Comparison of Energy Values for RCC Specimens wrapped with fibers in $45^{\circ}$

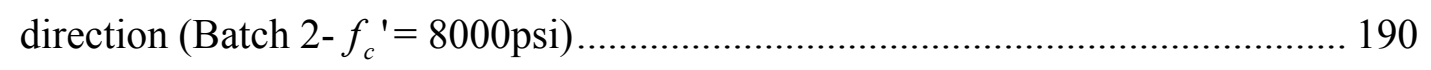

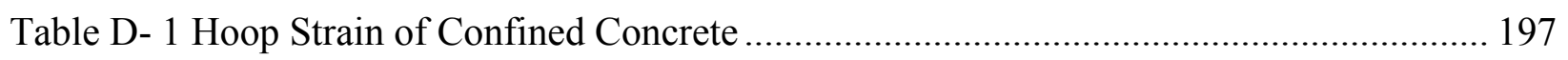

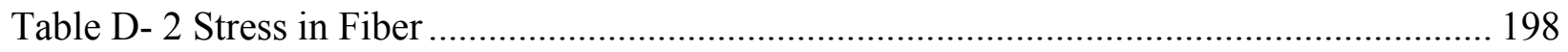

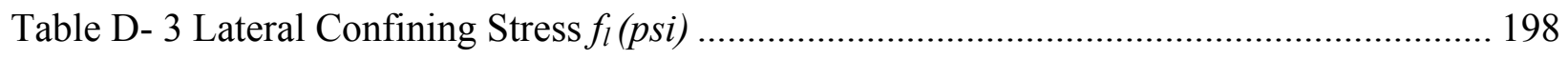

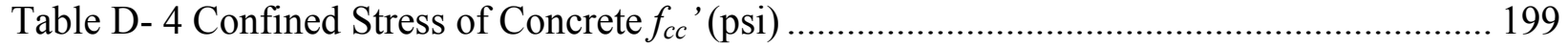

Table D- 5 Comparison of Confined to Unconfined Stiffness …………………………............ 199 


\section{LIST OF FIGURES}

Figure 2.1 Free body diagram of section of confined concrete ............................................. 12

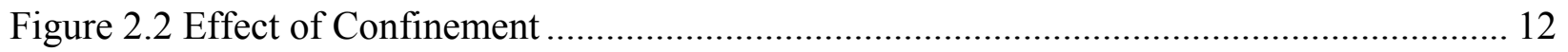

Figure 3.1 Type I Cement, \# 8 Aggregate and Sand................................................................... 23

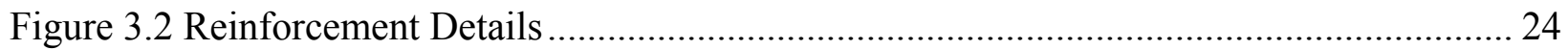

Figure 3.3 Clear Spacing for Steel Reinforcement using $1 / 2$ “ Rods to fix Spacing ..................... 25

Figure 3.4 Clear Spacing for Steel Reinforcement using 4" length rods across the diameter...... 25

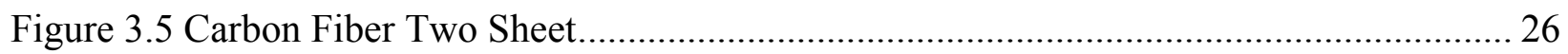

Figure 3.6 Typo S Saturant Epoxy Part A and Part B ........................................................... 27

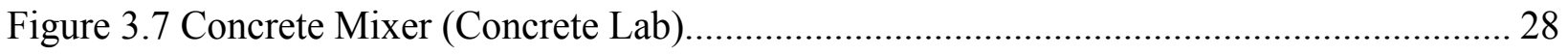

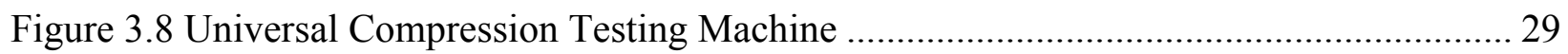

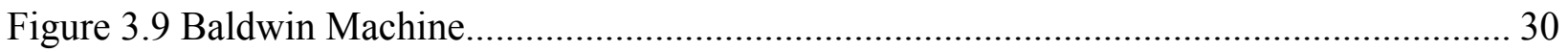

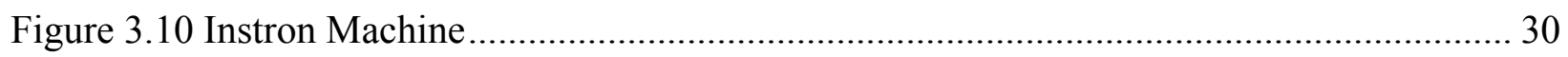

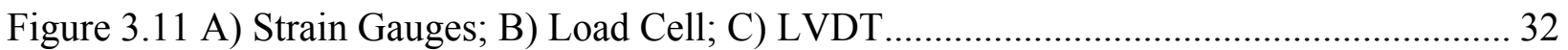

Figure 3.12 ThermaCAMTM S60 infrared camera from FLIR Systems (Refernce, Vasudevan).. 34

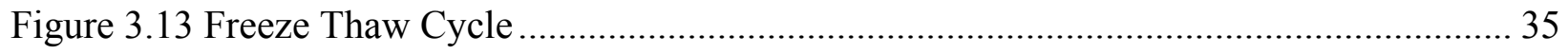

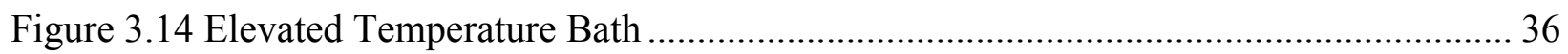

Figure 4-1 Orientation of Gauges Effect of Confinement and aging.......................................... 38

Figure 4-2 Wrapped Test Specimen - 4500 psi Concrete ........................................................... 39

Figure 4-3 Wrapped Test Specimen - 8000 psi Concrete Confinement and Aging Test.............. 39

Figure 4-4 Non Wrapped Concrete Specimens - Gauge Orientation ........................................... 40

Figure 4-5 Wrapped Specimens - Size Effect and Increase in Number of Wrap Effect Tests .... 41

Figure 4-6 Wrapped Specimens - Partial Wrapping and Partial Impregnation Tests ................... 41

Figure 4-7 Non Wrapped Concrete Specimens ............................................................................ 43 


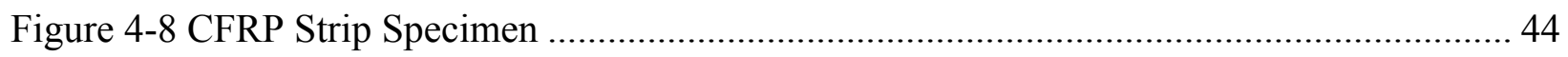

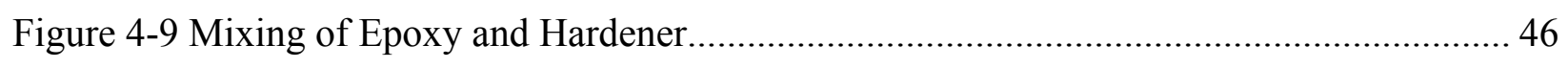

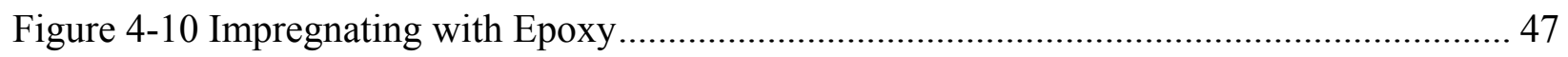

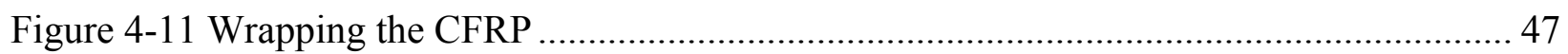

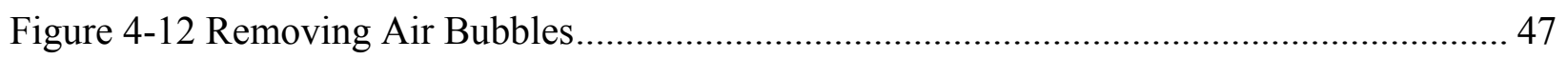

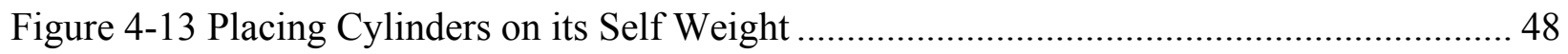

Figure 4-14 1" Slits cut on the Parchment Paper...................................................................... 48

Figure 4-15 Wrapping of Parchment Paper on the Resin Coated Specimen ................................ 49

Figure 4-16 Wrapping the Resin Coated Fiber on the Parchment Paper Wrapped Specimen ..... 49

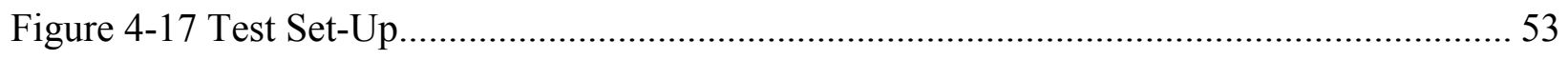

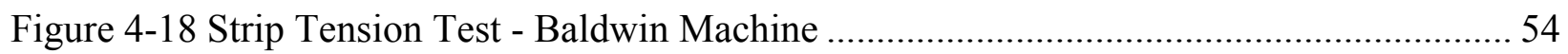

Figure 4-19 Infrared Thermography Tests: Along the Circumference of the Wrapped Cylinder 55

Figure 5-1 Load Strain Plots of Control Specimen: Batch 1 - Plain and Reinforced Non Wrapped

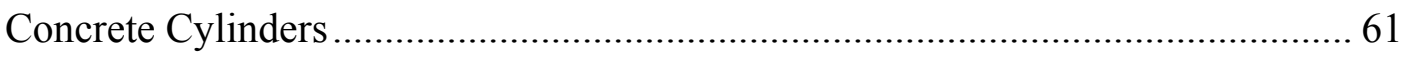

Figure 5-2 Load Strain plots of Control Specimen: Batch 2 - Plain and Reinforced Non Wrapped

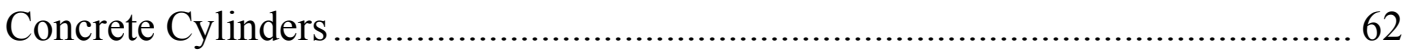

Figure 5-3 Load-Strain Comparison of 1 layer $-0^{\circ}$ Wrapped PCC Specimen with Control

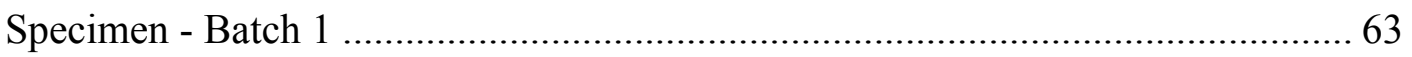

Figure 5-4 Load-Strain Comparison of 3 Layer - $0^{\circ}$ wrapped PCC Specimen with Control

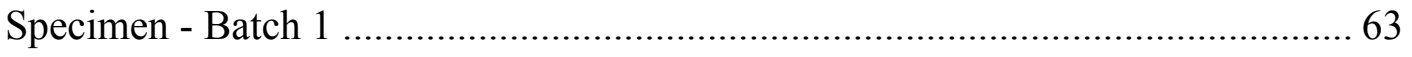

Figure 5-5 Load-Strain Comparison of 1 Layer $-45^{\circ}$ Wrapped PCC Specimen with Control

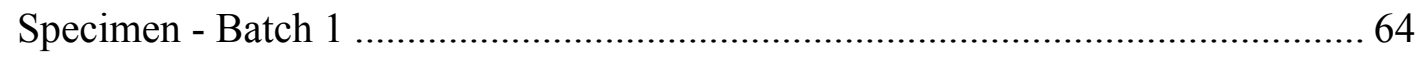

Figure 5-6 Load Strain Comparison of 2 Layer $\pm 45^{\circ}$ Wrapped PCC Specimen with Control Specimen - Batch 1 64 
Figure 5-7 Load Strain Comparison of 1 Layer- $0^{\circ}$ Wrapped RCC Specimen with Control Specimen - Batch 1

Figure 5-8 Load -Strain Comparison of 3 Layer - $0^{\circ}$ Wrapped RCC Specimen with Control Specimen - Batch 1 65

Figure 5-9 Load Strain Comparison of 1 Layer - $45^{\circ}$ Wrapped RCC Specimen with Control Specimen - Batch 1 66

Figure 5-10 Load Strain Comparison of 2 Layer $\pm 45^{\circ}$ Wrapped RCC Specimen with Control Specimen- Batch 1 66

Figure 5-11 Load Strain Comparison of 1 layer - $0^{\circ}$ Wrapped PCC Specimen with Control Specimen - Batch 2

Figure 5-12 Load Strain Comparison of 3 layers - $0^{\circ}$ Wrapped PCC Specimen with Control Specimen - Batch 2 67

Figure 5-13 Load Strain Comparison of 1 layer $45^{\circ}$ Wrapped PCC Specimen with Control Specimen - Batch 2 68

Figure 5-14 Load Strain Comparison of 2 Layer $\pm 45^{\circ}$ Wrapped PCC Specimen with Control Specimen- Batch 2 68

Figure 5-15 Load Strain Comparison of 1 layer - $0^{\circ}$ Wrapped RCC Specimen with Control Specimen - Batch 2 69

Figure 5-16 Load Strain Comparison of 3 layer - $0^{\circ}$ Wrapped RCC Specimen with Control Specimen - Batch 2 69

Figure 5-17 Load Strain Comparison of 1 layer $45^{\circ}$ Wrapped RCC Specimen with Control Specimen - Batch 2 70

Figure 5-18 Load Strain Comparison of 2 Layer $\pm 45^{\circ}$ Wrapped PCC Specimen with Control Specimen- Batch 2 70 
Figure 5-19 Plain Concrete Specimens A) Batch 1; B) Batch 2................................................ 81

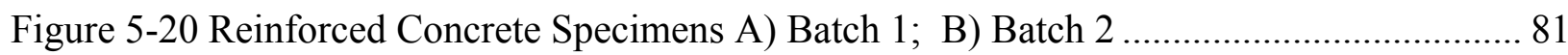

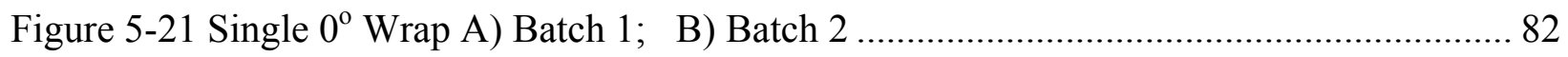

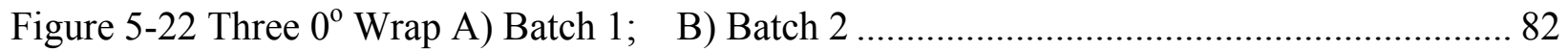

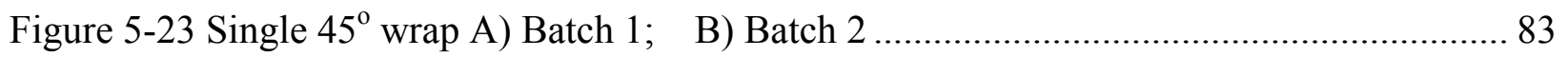

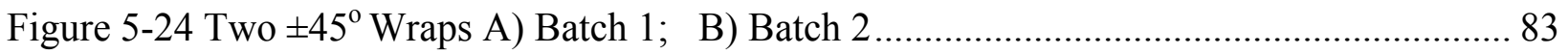

Figure 5-25 Load Strain Comparison of Non Wrapped Specimens - Size Effects ....................... 91

Figure 5-26 Comparison of load Strain to Determine Size Effect in Specimens Wrapped with 1

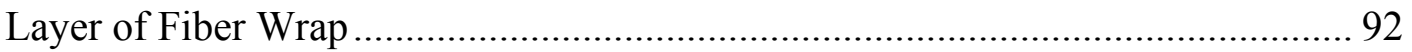

Figure 5-27 Load Strain Comparison of Size Effect in Specimens Wrapped with 3 Layer of Fiber

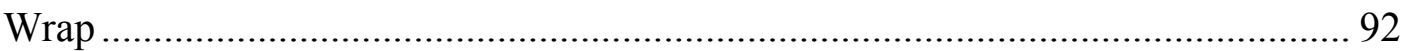

Figure 5-28 Comparison of Effect of Number of Fiber Layers .................................................... 96

Figure 5-29 Failure in Non Wrapped 3"x 6" Specimen ............................................................ 98

Figure 5-30 Failure in One layer FRP Wrapped 3"x 6" Specimen.............................................. 98

Figure 5-31 Failure in Three layer FRP Wrapped 3"x 6" Specimen ............................................. 99

Figure 5-32 Failure in Six Layer FRP Wrapped 3"x 6" Specimen................................................. 99

Figure 5-33 Load Strain Comparison of Partially Wrapped 3"x 6" Cylinders in Table 5-28 … 103

Figure 5-34 Comparison of Maximum Load of Partially Wrapped Concrete Cylinders in Table 528 103

Figure 5-35 Comparison of Maximum Axial Strain of Partially Wrapped Concrete Cylinders in Table 5-28 104

Figure 5-36 Comparison of Maximum Hoop Strain of Partially Wrapped Concrete Cylinders in Table 5-28 104

Figure 5-37 Comparison of Load Strain Plots of B6-P-3S6 and B6-P-S10 Specimens 105 
Figure 5-38 Failure in Completely Wrapped Specimen ............................................................ 107

Figure 5-39 Failure in Specimen with 1/2" Height Gap (Top and Bottom) ……………............. 107

Figure 5-40 Failure in Specimen with 1" Height Gap (Top and Bottom) ................................... 108

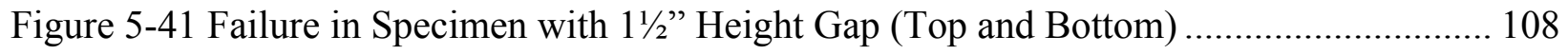

Figure 5-42 Failure in Specimen with 1늘 Height Wrap only at Top and Bottom.................... 109

Figure 5-43 Failure in Specimen with 1" Height Wrap only at Top and Bottom....................... 109

Figure 5-44 Comparison of Load Strain Plots of Partially Wetted Specimens .......................... 112

Figure 5-45 Comparison of Maximum Load of specimens in Table 5-24 (partially wet and bond Fabric) 113

Figure 5-46 Comparison of Maximum Axial Strain $\times 10^{-6}$ of Specimens in Table 5-24 (partially wet and bonded fabric) 113

Figure 5-47 Comparison of Maximum Hoop Strain $\times 10^{-6}$ of Specimens in Table 5-24 (partially wet and bond fabric). 114

Figure 5-48 A) Non Wrapped Specimen B) Fully Wrapped Specimen (Batch 1-Table 5-31)... 116

Figure 5-49 A) Resin Impregnated at 3 points along the Circumference (Batch 1-Table 5-31) B) Resin Impregnated at 2 Points along the Circumference (Batch 1-Table 5-31) 116

Figure 5-50 Bonded at 2 Points along the Circumference for 1" width in Specimen B6-P-3S16 119

Figure 5-51 A) Specimen bonded at 2 positions (Batch 6 Table 5-33) 120

Figure 5-52 Comparison of Maximum Load of Plain Concrete Cylinders Aged in Elevated Temperature refer to Table 5-28 (Aged Plain Concrete Specimens). 125

Figure 5-53 Comparison of Maximum Hoop Strain of Plain Concrete Cylinders Aged in Elevated Temperature refer to Table 5-28(Aged Plain Concrete Specimens) ...... 125 
Figure 5-54 Comparison of Maximum Load of Reinforced Concrete Cylinders Aged in Elevated Temperature refer to Table 5-29 (Reinforced Concrete Specimens). 126

Figure 5-55 Comparison of Strain of Reinforced Concrete Specimens Aged in Elevated Temperature refer to Table 5-29(Reinforced Concrete Specimens) 126

Figure 5-56 Comparison of load of Plain Concrete Cylinder Specimens Subjected to Freeze Thaw Condition refer to Table 5-28 (Plain Concrete Specimens). 127

Figure 5-57 Comparison of Strain of Plain Concrete Cylinder Specimens Subjected to Freeze Thaw Condition refer to Table 5-28 (Plain Concrete Specimens). 127

Figure 5-58 Comparison of Load of Reinforced Concrete Cylinder Specimens Subjected to Freeze Thaw Condition refer to Table 5-29 (Reinforced Concrete Specimens)... 128

Figure 5-59 Comparison of Strain of Reinforced Concrete Cylinder Specimens Subjected to Freeze Thaw Condition refer to Table 5-29 (Reinforced Concrete Specimens)... 128

Figure 5-60 Stress Strain Comparison of Unaged Strip Specimen. 129

Figure 5-61 Stress Strain Comparison of 1 and 2 Month Aged Strip Specimen - Elevated Temperature 130

Figure 5-62 Stress Strain Comparison of 1 and 2 Month Aged Strip Specimen - Freeze-Thaw Aging. 130

Figure 5-63 Thermogram after 1 hour of wrapping: Reaction has not started 133

Figure 5-64 Thermogram after 4 hours of wrapping: Exothermic reaction is taking place 133

Figure 5-65 Thermogram after 6 Hours of Wrapping: Exothermic Reaction continues 134

Figure 5-66 Thermogram after 8 hours of wrapping: Cross Linking Continues 134

Figure 5-67 Thermogram after 24 hours of Wrapping: Reaction stops 135

Figure 5-68: Infrared Thermogram of B2-P-4S1 Wrapped Cylinder -Quadrant/Face 1 137

Figure 5-69: Infrared Thermogram of B2-P-4S1 Wrapped Cylinder-Quadrant/Face 2 137 
Figure 5-70: Infrared Thermogram of B2-P-4S1 Wrapped Cylinder -Quadrant/Face 3. 138

Figure 5-71: Infrared Thermogram of B2-P-4S1 Wrapped Cylinder -Quadrant/Face 4 Overlap of 2"of FRP. 138

Fig. A.1 Stress-Strain Curve of Non Wrapped Batch 1 Plain and Reinforced Column Specimens 177

Fig. A.2 Stress-Strain Curve of Non Wrapped Batch 2 Plain and Reinforced Column Specimens 177

Fig. A.3 Stress-Strain Comparison of 1 layer - $0^{\circ}$ Wrapped PCC Specimen with Control Specimen - Batch 1 178

Fig. A.4 Stress-Strain Comparison of 3Layer - $0^{\circ}$ wrapped PCC Specimen with Control Specimen - Batch 1 178

Fig. A.5 Stress-Strain Comparison of 1Layer - $45^{\circ}$ Wrapped PCC Specimen with Control Specimen - Batch 1 179

Fig. A.6 Stress- Strain Comparison of 2 Layer $\pm 45^{\circ}$ Wrapped PCC Specimen with Control Specimen - Batch 1 179

Fig. A.7 Stress Strain Comparison of 1 Layer- $0^{\circ}$ Wrapped RCC Specimen with Control Specimen - Batch 1 180

Fig. A.8 Stress-Strain Comparison of 3 Layer $-0^{\circ}$ Wrapped RCC Specimen with Control Specimen - Batch 1 180

Fig. A.9 Load Strain Comparison of 1 Layer - $45^{\circ}$ Wrapped RCC Specimen with Control Specimen - Batch 1 181

Fig. A.10 Stress Strain Comparison of 2 Layer $\pm 45^{\circ}$ Wrapped RCC Specimen with Control Specimen- Batch 1 181 
Fig. A.11 Stress - Strain Comparison of 1 layer - $0^{\circ}$ Wrapped PCC Specimen with Control Specimen - Batch 2 182

Fig. A.12 Stress -Strain Comparison of 3 layers - $0^{\circ}$ Wrapped PCC Specimen with Control Specimen - Batch 2 182

Fig. A.13 Stress Strain Comparison of 1 layer $45^{\circ}$ Wrapped PCC Specimen with Control Specimen - Batch 2 183

Fig. A.14 Stress Strain Comparison of 2 Layer $\pm 45^{\circ}$ Wrapped PCC Specimen with Control Specimen- Batch 2 183

Fig. A.15 Stress Strain Comparison of 1 layer - $0^{\circ}$ Wrapped RCC Specimen with Control Specimen - Batch 2 184

Fig. A.16 Load Strain Comparison of 3 layer $-0^{\circ}$ Wrapped RCC Specimen with Control Specimen - Batch 2 184

Fig. A.17 Load Strain Comparison of 1 layer $45^{\circ}$ Wrapped RCC Specimen with Control Specimen - Batch 2 185

Fig. A.18 Stress - Strain Comparison of 2 Layer $\pm 45^{\circ}$ Wrapped PCC Specimen with Control Specimen- Batch 2 185

Fig C.1 Comparison of Stress- Strain of Non Wrapped Plain Concrete Specimens Aged in Elevated Temperature Condition 192

Fig C.2 Comparison of Stress- Strain of Wrapped Plain Concrete Specimens Aged in Elevated Temperature Condition 192

Fig C.3 Comparison of Stress- Strain of Non Wrapped Reinforced Concrete Specimens Aged in Elevated Temperature Condition 193

Fig C.4 Comparison of Stress- Strain of Wrapped Reinforced Concrete Specimens Aged in 
Elevated Temperature Condition 193

Fig C.5 Comparison of Stress- Strain of Non Wrapped Plain Concrete Specimens Aged in Freeze-Thaw Condition 194

Fig C.6 Comparison of Stress- Strain of Wrapped Plain Concrete Specimens Aged in FreezeThaw Condition. 194

Fig C.7 Comparison of Stress- Strain of Non Wrapped Reinforced Concrete Specimens Aged in Freeze-Thaw Condition 195

Fig C.8 Comparison of Stress- Strain of Wrapped Reinforced Concrete Specimens Aged in Freeze-Thaw Condition. 195

Figure D-1 Partially Wrapped Specimen - Failure Pattern 200 


\section{INTRODUCTION}

\subsection{General Remarks}

Structures in service are being subjected to increased service loads and severe environmental conditions. The FHWA, 1995 reports that nearly $32 \%$ of the nation's 581,942 bridges need to be repaired/rehabilitated or replaced. Rehabilitation and retrofit of existing structures is traditionally done using steel or reinforced concrete jacketing. To ensure safety of structurally deficient reinforced concrete structures there is a need for better methods and techniques. Reinforced concrete (RC) columns, being the key lateral and vertical load resisting members are particularly vulnerable to failures in earthquakes (Teng et al., 2001) and a need to retrofit them seismically was highlighted after the collapse and damage of several structures during earthquakes. In the case of a seismic event, good energy dissipation is facilitated by wellconfined concrete core resulting in structural safety. External wrapping of concrete structures using FRP composite wraps provides significant amount of lateral confinement leading to increased axial strength and energy absorption (Ref. Kharbari et al., 1998, Tountanji 1999, Pessiki et al. 2001). The use of fiber reinforced composites for strengthening and rehabilitation of structures has gained increasing popularity due to favorable properties such as high strength to weight ratio, tailor ability and corrosion resistance (Lorenzis, 2001).

This research evaluates confinement related strength, stiffness and ductility increases in FRP wrapped concrete cylinders with and without internal steel reinforcement. Strength and stiffness increases of a wrapped cylinder depend on the properties of FRP material and concrete. Constituents and properties of the FRP material like type of resin, fiber orientation, fillers and 
additives, processing techniques and concrete properties like $f_{c}^{\prime}$ (compressive strength of concrete) etc. influence behavior of FRP wrapped concrete members.

\subsection{Objectives}

The main objectives of this research are to:

- Evaluate confinement related strength and stiffness increase in concrete cylinders using FRP wraps with respect to:

Concrete compressive strength $\left(f_{c}^{\prime}\right)$

Fiber orientation of CFRP wrap

$>$ Cylinder size

$>$ Number of CFRP wraps

$>$ Wrapping height and location

Degree of fiber wetting and

Degree of bonding fabric onto concrete.

- Evaluate effect of aging on wrapped cylinders in terms of strength, stiffness, durability and failure modes.

- Conduct infrared thermography tests to identify the debonding/delaminations between FRP and concrete interface before and after aging.

\subsection{Scope}

Wrapped and non-wrapped concrete cylinders were subjected to axial compressive loads to establish the effects of confinement. The wrapped cylinder test results under compression were compared to results of non-wrapped specimens (control specimens). The effect of confinement due to different fiber orientations of the wrap was studied by wrapping specimens 
with $0^{\circ}$ and $\pm 45^{\circ}$ wrap. The effect due to increase in number of fiber wrap layers was studied by wrapping 3" x 6" cylinders with 1, 3 and 6 wrap layers. Size effect tests were done by testing wrapped 3"x 6", 4"x8" and 6"x12" cylinders. The effects due to FRP wrapping for particular heights and positions, i.e., in the middle (3", 4" and 5") or top and bottom (1" and 11/2") of 3"x 6" cylinders were tested and the magnitude of strength increase due to partial confinement was studied. Specimens wrapped with a single layer of FRP with fiber wetting at 2 or 3 positions for a width on 1" along the height of the cylinder were studied for increases in strength and ductility. Specimens were bonded only at these 2 or 3 locations for 1 "circumferential length and tested to determine if confinement related increase in strength was bond or contact critical. Specimens were aged and compared with unaged specimens in accelerated conditions using elevated temperature $\left(175^{\circ} \mathrm{F}\right)$ and freeze thaw $\left(-20^{\circ} \mathrm{F}\right.$ to $\left.120^{\circ} \mathrm{F}\right)$. Bonding area between fiber and wrap was evaluated using non-destructive infrared thermography technique. Details of various parameters used in this research are elaborated in sub-sections 1.3.1 to1.3.6.

\subsubsection{Concrete Cylinders Confinement}

Non-wrapped concrete cylinders with and without internal reinforcement were tested under axial compression and values of strength and strain were recorded and used as control, (base) values to compare with wrapped concrete cylinders.

- Casting was done in two batches of 30 cylinders each, i.e. for $f_{c}^{\prime}$ of $4500 \mathrm{psi}$ and $f_{c}^{\prime}$ of 8000psi.

- Among 30 concrete cylinders of each batch, 15 were plain concrete cylinders and the other 15 were reinforced concrete cylinders 
Table 1-1 Test Matrix for Effect of Confinement

\begin{tabular}{|c|c|c|c|c|c|c|}
\hline & $\begin{array}{c}\text { Number } \\
\text { of Wraps }\end{array}$ & $\begin{array}{c}\text { Wrap } \\
\text { Type }\end{array}$ & Reinforcement & $\mathrm{f}_{\mathrm{c}}{ }^{\prime}$ & Replication & Total \\
\cline { 1 - 6 } Description & One & $0^{\circ}$ & None & $4500 \mathrm{psi}$ & --- & \multirow{2}{*}{--} \\
\cline { 2 - 6 } & Three & $45^{\circ}, \pm 45^{\circ}$ & Provided & $8000 \mathrm{psi}$ & 3 & 48 \\
\hline $\begin{array}{c}\text { Number of } \\
\text { parameters }\end{array}$ & 2 & 2 & 2 & 2 & 3 & 12 \\
\hline $\begin{array}{c}\text { Control } \\
\text { Specimen }\end{array}$ & --- & --- & 2 & 2 & 60 \\
\hline \multicolumn{7}{|c|}{} \\
\hline
\end{tabular}

- The results of the control specimens from each batch (6 for $f_{c}$ ' of 4500 psi and 6 for $f_{c}$ ' of $8500 \mathrm{psi}$ ) were common to all representative specimens in that particular batch.

- Control specimens are plain concrete cylinders and reinforced concrete cylinder without FRP wraps.

Table 1-2 Parameters: Effect of Confinement

\begin{tabular}{|c|c|c|c|c|c|}
\hline $\begin{array}{c}\text { Size of } \\
\text { Cylinder }\end{array}$ & $\begin{array}{c}\text { Type of } \\
\text { Cylinder }\end{array}$ & $\begin{array}{c}\text { Concrete Strength } \\
\left(f_{c}^{\prime}-\text { psi }\right)\end{array}$ & $\begin{array}{c}\text { No. of } \\
\text { wraps }\end{array}$ & $\begin{array}{c}\text { Orientation of } \\
\text { Fibers }\end{array}$ & Replications \\
\hline \multirow{3}{*}{4 "x 8" } & Plain & 4500 & 1 & $0^{\circ}$ & \multirow{2}{*}{3} \\
\cline { 2 - 5 } & Reinforced & 8000 & 2 & $45^{\circ}$ & \multirow{2}{*}{3} \\
\cline { 2 - 6 } & & & 3 & $\pm 45^{\circ}$ & \\
\hline
\end{tabular}

Control specimens (non-wrapped specimens) were initially evaluated and wrapped specimens were compared with those control specimens in terms of strength, strain, stiffness, ductility/deformability and failure modes.

\subsubsection{Tests to Determine Effect of Number of Wraps}

Increase in strength due to number of layers was evaluated by testing 3" x 6" cylinders with 1, 3 and 6 layers of wrap. The cylinders were wrapped in the hoop direction using CFRP 
wrap and epoxy resin. The increase in load carrying capacity of the concrete cylinder due to increase in number of FRP wrap layers was evaluated.

Table 1-3 Test matrix for effect of Increased Number of Carbon Wraps

\begin{tabular}{|c|c|c|c|c|c|}
\hline $\begin{array}{c}\text { Type of } \\
\text { Specimen }\end{array}$ & Non Wrapped & Single Wrap & 3 Wraps & 6 Wraps & Total \\
\hline Replications & 3 & 3 & 3 & 3 & 12 \\
\hline
\end{tabular}

Table 1-4 Parameters: Effect of Number of Wraps

\begin{tabular}{|c|c|c|c|c|c|}
\hline $\begin{array}{c}\text { Size of } \\
\text { Cylinder }\end{array}$ & $\begin{array}{c}\text { Type of } \\
\text { Cylinder }\end{array}$ & $\begin{array}{c}\text { Concrete Strength } \\
\left(f_{c}^{\prime} \text { - } \text { psi }\right)\end{array}$ & $\begin{array}{c}\text { Orientation } \\
\text { of Fibers }\end{array}$ & No. of Wraps & Replications \\
\hline \multirow{2}{*}{ 3"x 6" } & Plain & 8000 & $0^{\circ}$ & 1 & \multirow{2}{*}{3} \\
& & & & 6 & 3 \\
\hline
\end{tabular}

From the test results, increases in strength and strain due to increase in number of FRP layers were evaluated.

\subsubsection{Tests to Determine Effects due to Cross Sectional Area of Concrete}

Plain concrete cylinders were cast with different cross sectional areas and different heights with a diameter to height ratio of 1:2. The increase in strength due to wrapping was compared with different cross sectional areas of the cylinders.

Table 1-5 Test Matrix for Size Effect Tests

\begin{tabular}{|c|c|c|c|}
\hline Type of Specimen & 3 " $\mathrm{x}$ 6" & 4 " $\mathrm{x} 8$ 8" & 6 " 12 12" \\
\hline Non Wrap & 3 & 3 & 3 \\
\hline Single Wrap & 3 & 3 & 2 \\
\hline 3 Wraps & 3 & 3 & --- \\
\hline Total & $\mathbf{9}$ & $\mathbf{9}$ & $\mathbf{5}$ \\
\hline
\end{tabular}


Table 1-6 Parameters: Effect of Concrete Cross Sectional Area

\begin{tabular}{|c|c|c|c|c|c|}
\hline $\begin{array}{c}\text { Size of } \\
\text { Cylinder }\end{array}$ & $\begin{array}{l}\text { Type of } \\
\text { Cylinder }\end{array}$ & $\begin{array}{c}\text { Concrete Strength } \\
\left(f_{c}{ }^{\prime}-\mathrm{psi}\right)\end{array}$ & $\begin{array}{c}\text { Orientation } \\
\text { of Fibers }\end{array}$ & No. of wraps & Replications \\
\hline 3"x 6" & \multirow{3}{*}{ Plain } & \multirow{3}{*}{8000} & \multirow{3}{*}{$0^{\circ}$} & 1 & \multirow{3}{*}{3} \\
\hline $4 " x 8 "$ & & & & 3 & \\
\hline 6"x12" & & & & & \\
\hline
\end{tabular}

Differences in increases of strength and strain due to different cross sectional areas were evaluated.

\subsubsection{Tests Conducted to Determine Effect of Wrap Position and Height}

Effects of confining concrete cylinders with partial and full wrapping were evaluated by testing cylinders that were partially wrapped at middle or only at top and bottom for different heights. Cylinders were wrapped with $1 / 2 ", 1$ " and $1 \frac{1}{2}$ " gap at top and bottom of the cylinders of they were wrapped with 1 " and $1 \frac{1}{2}$ " at top and bottom leaving the center of the cylinders non wrapped. Completely wrapped specimens were also evaluated along with non-wrapped control specimens.

Table 1-7 Test Matrix for Effect of Wrap Position and Height

\begin{tabular}{|c|c|c|c|c|c|c|c|}
\hline $\begin{array}{l}\text { Type of } \\
\text { Specimen }\end{array}$ & $\begin{array}{c}\text { Completely } \\
\text { Wrapped }\end{array}$ & $\begin{array}{c}1 / 2 " \text { height } \\
\text { gap in } \\
\text { wrap at } \\
\text { top and } \\
\text { bottom }\end{array}$ & $\begin{array}{l}\text { 1" height } \\
\text { gap in } \\
\text { wrap at } \\
\text { top and } \\
\text { bottom }\end{array}$ & $\begin{array}{c}11 / 2 " \\
\text { height gap } \\
\text { in wrap at } \\
\text { top and } \\
\text { bottom }\end{array}$ & $\begin{array}{l}\text { 1"height } \\
\text { wrap at } \\
\text { top and } \\
\text { bottom }\end{array}$ & $\begin{array}{c}1 \frac{1}{2} " \\
\text { height } \\
\text { wrap at } \\
\text { top and } \\
\text { bottom }\end{array}$ & Total \\
\hline Test 1 & 3 & 2 & 2 & 2 & 0 & 0 & 9 \\
\hline Test 2 & 2 & 0 & 2 & 2 & 2 & 2 & 10 \\
\hline
\end{tabular}

Table 1-8 Parameters: Effect of Wrap Position and Height

\begin{tabular}{|c|c|c|c|c|c|}
\hline $\begin{array}{c}\text { Size of } \\
\text { Cylinder }\end{array}$ & $\begin{array}{c}\text { Type of } \\
\text { Cylinder }\end{array}$ & $\begin{array}{c}\text { Orientation of } \\
\text { Fibers }\end{array}$ & No. of Wraps & $\begin{array}{c}\text { Concrete Strength } \\
\left(f_{c}^{\prime}-\text { psi }\right)\end{array}$ & Replications \\
\hline 3"x 6" & Plain & $0^{\circ}$ & 1 & 5000 & \multirow{2}{*}{3} \\
\hline
\end{tabular}


The difference in strength and strain due to discrete location confinement and failure pattern of the partially confined specimens was compared with fully wrapped specimens.

\subsubsection{Confinement effects due to Partial Fabric Wetting}

Tests were conducted on 4"x 8 " specimens with $f_{c}^{\prime}=4500$ psi wrapped with partially resin impregnated fabric. The fabric was wetted at 2 or 3 positions along the circumference for a width of 1" and wrapped specimens were subjected to axial compression.

Table 1-9 Test Matrix for Effect of Partial Fabric Wetting

\begin{tabular}{|c|c|c|c|c|c|c|}
\hline $\begin{array}{c}\text { Type of } \\
\text { Specimen }\end{array}$ & Size & $\begin{array}{c}\text { Non } \\
\text { Wrapped }\end{array}$ & $\begin{array}{c}\text { Single } \\
\text { Wrap }\end{array}$ & $\begin{array}{c}\text { Resin } \\
\text { Wetting on } \\
\text { Fabric at 3 } \\
\text { Positions }\end{array}$ & $\begin{array}{c}\text { Resin } \\
\text { Wetting on } \\
\text { Fabric at 2 } \\
\text { Positions }\end{array}$ & Total \\
\hline Replication & 4 " 8 8" & 3 & 3 & 3 & 3 & 12 \\
\hline
\end{tabular}

Table 1-10 Parameters: Effect of Partial Fabric Wetting

\begin{tabular}{|c|c|c|c|c|c|}
\hline $\begin{array}{c}\text { Size of } \\
\text { Cylinder }\end{array}$ & $\begin{array}{c}\text { Type of } \\
\text { Cylinder }\end{array}$ & $\begin{array}{c}\text { Orientation } \\
\text { of Fibers }\end{array}$ & No. of Wraps & $\begin{array}{c}\text { Concrete Strength } \\
\left(f_{c}^{\prime}-\text { psi }\right)\end{array}$ & Replications \\
\hline 4"x 8" & Plain & $0^{\circ}$ & 1 & 4500 & \multirow{2}{*}{3} \\
& & & 1 & 6000 & 3 \\
\hline
\end{tabular}

Increase in strength of cylinders with partially and fully resin impregnated wrap was studied. The failure patterns of these specimens were also compared.

\subsubsection{Confinement effects due to degree of Bonding Fabric on Concrete}

In order to study if increase in strength due to confinement is bond or contact critical, tests were conducted on specimens wrapped with a layer of parchment paper at selected locations in-between the fabric and the concrete to obtain debonding. 
Table 1-11 Test Matrix for Effect of Degree of Bonding Fabric to Concrete

\begin{tabular}{|c|c|c|c|c|c|}
\hline $\begin{array}{c}\text { Type of } \\
\text { Specimen }\end{array}$ & $\begin{array}{c}\text { Non } \\
\text { Wrapped }\end{array}$ & $\begin{array}{c}\text { Completely } \\
\text { Bonded }\end{array}$ & $\begin{array}{c}\text { Specimens Bonded } \\
\text { at 3 Positions }\end{array}$ & $\begin{array}{c}\text { Specimens Bonded } \\
\text { at 2 Positions }\end{array}$ & Total \\
\hline Replication & 3 & 2 & 3 & 3 & 11 \\
\hline
\end{tabular}

Table 1-12 Parameters: Effect of Degree of Bonding

\begin{tabular}{|c|c|c|c|c|c|}
\hline $\begin{array}{c}\text { Size of } \\
\text { Cylinder }\end{array}$ & $\begin{array}{c}\text { Type of } \\
\text { Cylinder }\end{array}$ & $\begin{array}{c}\text { Orientation of } \\
\text { Fibers }\end{array}$ & No. of Wraps & $\begin{array}{c}\text { Concrete Strength } \\
\left(f_{c}^{\prime}-\text { psi }\right)\end{array}$ & Replications \\
\hline 4 "x 8" & Plain & $0^{\circ}$ & 1 & 5000 & 3 \\
\hline
\end{tabular}

Axial compression tests were done on the specimens completely bonded and specimens with no bond. The differences in strength and strain to failure along with failure patterns were studied.

\subsubsection{Accelerated Aging Tests}

Cylinders wrapped and non-wrapped were subjected to accelerated aging conditions. In the form of elevated temperature $\left(175^{\circ} \mathrm{F}\right)$ and freeze thaw cycles $\left(-20^{\circ} \mathrm{F}\right.$ to $\left.120^{\circ} \mathrm{F}\right)$ and compared with control specimens in terms of stress, strain, ductility, durability, and failure modes.

Table 1-13 Test Matrix for Aging Test

\begin{tabular}{|c|c|c|c|c|c|c|c|c|c|c|c|}
\hline Type of Specimen & \multicolumn{4}{|c|}{ Freeze thaw cycle } & \multicolumn{4}{|c|}{ Elevated Temp } & \multicolumn{2}{|c|}{ Control Specimen } & \multirow[t]{2}{*}{ Total } \\
\hline No of months & \multicolumn{2}{|c|}{1} & \multicolumn{2}{|c|}{2} & \multicolumn{2}{|c|}{1} & \multicolumn{2}{|c|}{2} & \multicolumn{2}{|c|}{--} & \\
\hline & $\mathrm{P} *$ & $\mathrm{R}^{*}$ & $\mathrm{P}$ & $\mathrm{R}$ & $\mathrm{P}$ & $\mathrm{R}$ & $\mathrm{P}$ & $\mathrm{R}$ & $\mathrm{P}$ & $\mathrm{R}$ & \\
\hline Non wrapped & -- & -- & 1 & 1 & -- & -- & 1 & 1 & 1 & 1 & 6 \\
\hline Wrapped & 2 & 2 & 2 & 2 & 2 & 2 & 2 & 2 & 2 & 2 & 24 \\
\hline \multicolumn{11}{|c|}{ Grand Total } & 30 \\
\hline
\end{tabular}


- $\quad \mathrm{P}^{*}$ - Plain Concrete Specimens and R*- Reinforced Concrete Specimens

- The test matrix (Table 1-6) gives the number of specimens subjected to accelerated aging with a total of 15 plain concrete and 15 reinforced concrete specimens

- Results of the control specimens from each batch will be common to all specimens subjected to both one and two months aging.

Table 1-14 Parameters: Aging

\begin{tabular}{|c|c|c|c|c|c|}
\hline $\begin{array}{c}\text { Size of } \\
\text { Cylinder }\end{array}$ & $\begin{array}{l}\text { Type of } \\
\text { Cylinder }\end{array}$ & $\begin{array}{l}\text { Orientation of } \\
\text { Fibers } \\
\end{array}$ & No. of wraps & $\begin{array}{c}\text { Concrete Strength } \\
\left(f_{c}{ }^{\prime}-\mathrm{psi}\right)\end{array}$ & Replications \\
\hline \multirow{2}{*}{$4 " x 8 "$} & Plain & \multirow{2}{*}{$0^{\circ}$} & \multirow{2}{*}{1} & \multirow{2}{*}{8000} & \multirow{2}{*}{3} \\
\hline & Reinforced & & & & \\
\hline
\end{tabular}

Non-aged specimens were the control specimens compared with aged specimens to evaluate strength, strain to failure, durability and failure modes

\subsection{Summary}

This report is organized into 9 chapters. Each of the chapters deals with a particular aspect of the topic, "Behavior of FRP Wrapped Concrete Cylinders." Chapter 1 describes the objectives and scope of this research along with general introduction. Chapter 2 contains literature review on the effect of confinement due to external FRP strengthening and effect of aging on the FRP strengthened structures. Chapter 3 deals with the materials, accessories and test set up used in this research including the equipments used. Chapter 4 gives a description of the test specimens and the test procedures. Tests were conducted both on un-aged and aged specimens. Results of the tests are provided in chapter 5 in the form of tables and figures and analyzed. The results include evaluation of mechanical properties such as strength/stiffness, 
strain, energy absorption and failure modes. Infrared thermography tests and thermograms are also included. Analytical evaluations are carried out in Chapter 6 by calculating the value of $f_{c c}$ ' (confined concrete compressive strength) using 6 different confinement models. In chapter 7, conclusions of the research along with recommendations for future research are provided. Appendices on some of the test results are also provided. 


\section{LITERATURE REVIEW}

\subsection{Introduction}

FRP wrapping of concrete columns is extensively used in repair, retrofit, rehabilitation and strengthening of infrastructure because of its improved strength, ductility and durability when compared to non-wrapped columns (CDCC 1998 and 2002). Piers and columns upgraded by using FRP sheets result in enhanced flexural and shear capacity, and improved ductility as well as increased ultimate load carrying capacity (Parretti, 2002). Composite materials provide several advantages in terms of high strength to weight ratio, electrochemical corrosion resistance, availability in any length or shape, improved fatigue resistance and creep rupture level, chemical and environmental resistance.

The increases in strength, stiffness and ductility of FRP wrapped concrete columns are due to the confinement effect of the wrap around the concrete specimen. Typically concrete columns are wrapped with CFRP (Carbon Fiber Reinforced Polymers) or GFRP (Glass Fiber Reinforced Polymers) in a resin matrix. Compressive load applied on the column causes expansion of the column in the circumferential (hoop) direction and the fibers of the FRP wrap in the hoop and $\pm 45^{\circ}$ direction minimize this expansion and confine the concrete, thus bringing about enhanced strength. Confinement effect of composite FRP on concrete is illustrated in the Figure 2.1. Effect of axial compression on the specimen in terms of lateral expansion of the specimen in the hoop direction and wrapping a specimen to achieve confinement is shown in Figure 2.2. 


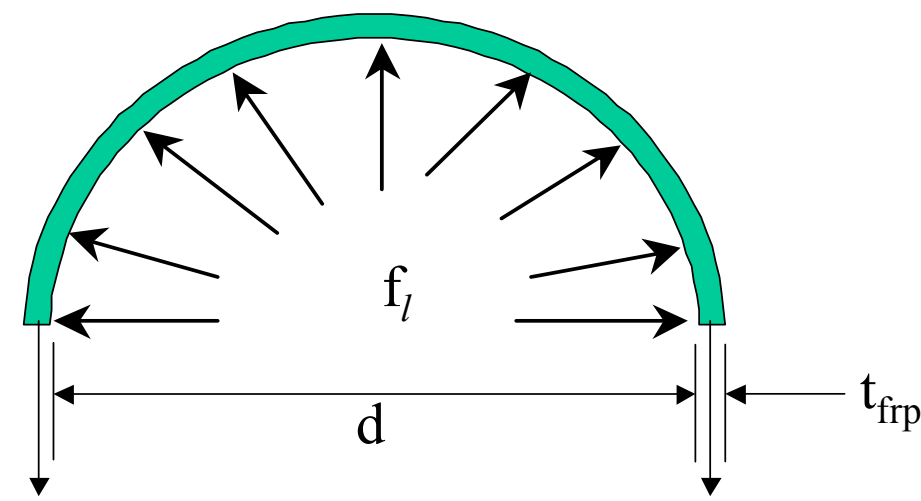

$f_{\text {frpu }} \quad f_{\text {frpu }}$

$f_{\text {frpu }}=$ Ultimate Tensile Strength of Circular Confined Concrete (ksi)

$f_{l}=$ Lateral Confining Pressure (ksi)

$t_{\text {frp }}=$ Thickness of FRP (inches); $d=$ Diameter of Cylinder (inches)

Figure 2.1 Free body diagram of section of confined concrete

Force Equilibrium: $f_{l}=\frac{2 f_{f r p u} t_{f r p}}{d}$

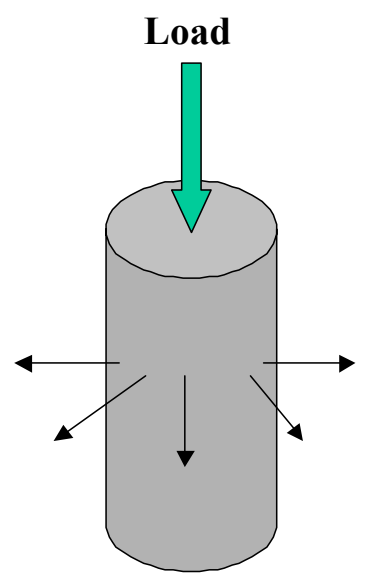

a) Lateral Expansion
Load

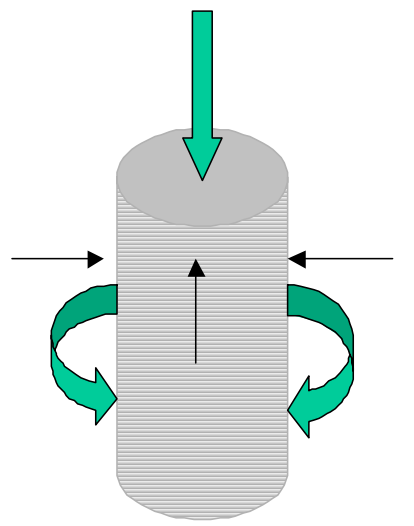

b) Effect of Confinement

Figure 2.2 Effect of Confinement 
Literature survey was done in two parts. One aspect examines the performance of concrete columns wrapped with FRP and the other looks at the effects of aging on wrapped structures. The performance of the wrapped concrete columns includes increase in strength, stiffness, enhanced energy absorption and ductility. Aging effect due to environmental conditions involves concrete, concrete FRP interface, fiber-matrix bond and the FRP. The durability issues of FRP wrapped concrete columns subjected to environmental exposure are still being evaluated and have to be standardized.

\subsection{External FRP Strengthening}

Confinement due to external wrapping of FRP leads to increased strength, stiffness and strain.

Nanni (1993) studied the effects of lateral confinement of concrete members using FRP reinforcement by spirally wrapping the FRP onto the concrete surface. The specimens of size $150 \mathrm{~mm} \times 300 \mathrm{~mm}$ were of three groups and the first group, Group A was conventional concrete columns with diameter to height ratio 1:2 was used for axial compression tests. Twenty such specimens were tested in uniaxial compression. Tape wrapping was done using braided aramid FRP impregnated with epoxy (Dow Chemical Der 330). When the pitch was high about 50mm the wrapped specimen showed no increase in strength and strain. At $25 \mathrm{~mm}$ pitch the pseudoductility of the column was increased with no increase in strength and with $0 \mathrm{~mm}$ pitch the increase in both strength and stiffness was evident.

Picher (1996) studied the effects of confinement of concrete cylinders with CFRP wraps. Fifteen circular cylinders $150 \mathrm{~mm}$ diameter and $300 \mathrm{~mm}$ height (1:2 ratio) wrapped with 
unidirectional carbon composite sheet using epoxy resin were tested. Wrap was applied in hoop direction in continuous manner in one or three layers. An angle ply configuration $[ \pm \theta / 0]$ was applied in helicoidal shape. Stress strain curves were plotted and the results were compared to unconfined concrete specimens. The curves clearly showed a plastic zone in the confined concrete cylinders. Even though the curves indicate an increase in the ductile behavior, failure of confined concrete cylinders occurred without warning. Failure was usually caused by a sudden breakage of the composite wrap due to brittle behavior of CFRP. When the wrap failed the concrete core was unable to withstand the load and triggered immediate fatal failure. Location of initial failure was difficult and the failure was characterized by a combination of fiber breakage and separation between parallel fibers. Confinement stiffness enhanced both the stress at the initiation of the plastic zone and mean slope of the plastic zone in the stress-strain curve.

Matthys (1999) studied columns and cylinders confined by fiber reinforced polymer sheet wrapping by conducting axial loading tests on them. Standardized cylinders (6"x12") were wrapped with one layer of CFRP (carbon). Strength increase of about 1.17 and 1.32 was obtained for wrapped cylinders. Once the cylinder was loaded above the strength of the unconfined concrete, stiffness decreased considerably. A combination of increase in load capacity and increase in ductility was noted. In addition to compression testing of confined cylinders, large scale testing of confined columns was also performed. Three columns were tested and one of these was non-wrapped while the other two were wrapped with CFRP. From the tests it was concluded that both strength and ductility were increased for wrapped columns with higher FRP stiffness, lower ductility. Compared to wrapped cylinders lower ultimate hoop stress were observed. 
Abu Khashaba (2002) studied the effect of number of Carbon Fiber Sheet layers on the behavior of confined RC columns. He tested 4 columns confined with 0, 1, 2 and 3 layers. From the stress strain curves plotted, it was concluded that larger number of layers provided higher confinement and increased strength. From the tests it was inferred that maximum strength for column confined with single layer was 1.3 , for two layers and 3 layers it was 1.55 and 1.65 respectively. A good ductile behavior was noted in all the specimens tested.

Rousakis (2002) studied the behavior of concrete confined by high modulus carbon FRP sheets subjected to monotonic and cyclic loading. Concrete cylinders 6"x 12" were wrapped with 1,2, 3 and 5 layers of carbon FRP sheets and the confining effect was evaluated in terms of concrete strength, ductility and expansion. Increasing the volumetric ratio of the carbon sheet enhanced the axial rigidity of the carbon jacket. The results showed an increase of strength of 1.64 and 2.7 times for 1 and 3 wraps respectively. The increase in ductility increased from 4.48 to 7.85 correspondingly.

Nanni (2002) conducted axial tests on confined concrete columns with different fiber orientations of the carbon FRP. The performance of the $\pm 45^{\circ}$ FRP laminate was compared to the unidirectional $0^{\circ}$ FRP laminates of different materials from different manufacturers. Five circular columns and three rectangular columns were tested under pure axial load. Three circular columns were tested using $\pm 45^{\circ}$ wrap and three columns using $0^{\circ}$ unidirectional CFRP laminates. The columns had internal longitudinal and lateral reinforcement. Specimens strengthened with $0^{\circ}$ unidirectional fibers had explosive failures. A gentler and less sudden 
failure was observed for the specimen wrapped with \pm 45 -degree wrap. The failure was progressively reached and warnings of collapse were noted.

Masia (2004) studied the size effects of axially loaded square concrete prisms (4" $\times 4$ " $\times$ $12 ", 5 " \times 5 " \times 15 ", 6 " \times 6 " \times 18$ ") strengthened using CFRP wrapping. Thirty prisms of three different cross sectional sizes were tested. Ten prisms were cast in each size, where 5 were tested non-wrapped and the rest were wrapped. All specimens were loaded till failure and significant increase in strength and ductility was achieved with wrapping. It was seen the effectiveness of the wrap as by the percentage rate increase in strength and strain reduced with increase in cross sectional area.

\subsection{Aging of FRP Strengthened Structures}

For the practical acceptance of FRP confined columns, it is essential to consider the effects of aggressive environment on the long-term performance of the member. Any environmental or external factors that could damage the fibers or cause the matrix to deteriorate would reduce the ability of the system to transfer stress between the fibers.

Homan (2000) studied the durability of fiber reinforced polymer composites. Five different aging conditions were used to understand and evaluate the durability of the FRP composite. FRP coupons and FRP-FRP single lap bond specimens were subjected to freeze thaw cycles, $\mathrm{UV}$ radiation, temperature variation, $\mathrm{NaOH}$ solutions with different values of $\mathrm{pH}$ and moisture conditions for chosen number of days. From the results, it appeared that the tensile property of coupons subjected to freeze thaw cycles in the controlled laboratory environments 
were not significantly affected for CFRP and GFRP specimens. Temperature variation between $\left(20^{\circ} \mathrm{C}\right.$ and $\left.+40^{\circ} \mathrm{C}\right)$ also presented no degradation to the properties of the composite material. The strength of GFRP coupons decreased by a maximum of $7 \%$ after 84 days of exposure to $\mathrm{NaOH}$ solutions with a $\mathrm{pH}$ of 10 and 12 at $22^{\circ} \mathrm{C}$.

Toutanji (1998) studied the performance of concrete columns strengthened with composites by subjecting those to freeze thaw conditions. The specimens were $76 \mathrm{~mm}$ in diameter and $305 \mathrm{~mm}$ in length and were subjected to two different environments: room temperature $\left(23^{\circ} \mathrm{C}\right)$ and freeze thaw exposure under sea water. Specimens were wrapped with 2 layers of 2 types of carbon fiber and one type of glass fiber. Samples were subjected to 300 cycles of freezing and thawing in salt-water condition. Compression tests were done and the stress strain behavior of the freeze thaw exposed specimens was obtained in order to calculate the strength, stiffness and ductility and compare it with the specimens subjected to room temperature. The wrapped specimens exhibited a significant reduction in strength due to freeze thaw exposure when compared to the control specimens. The glass fiber wrapped specimens exhibited a reduction of $28 \%$ strength while both the carbon fiber wrapped specimens exhibited a reduction of $19 \%$ when compared with the control specimen.

Kshirsagar (1998) studied the durability of fiber-reinforced composite wrap system for the rehabilitation of concrete structures. Standard concrete cylinder specimens wrapped with one layer of GFRP using epoxy as binder were used as test specimens. Specimens were subjected to 6 different accelerated aging conditions. Four of the aging conditions had varied $\mathrm{pH}$ solutions and temperature, whereas the other 2 conditions were dry heat at $150^{\circ} \mathrm{F}$ and extended freeze thaw cycles. Specimens were tested for changes in ultimate strength and strain after exposure periods 
of 1000,3000 and 8000 hours of aging. Specimens subjected to elevated temperature and freeze thaw cycles showed a considerable reduction in strength and ductility. The reduction in strength was attributed both to degradation in FRP and concrete material exposed to freeze thaw cycles. A significant difference in failure mode of the wrap was noted after freeze thaw cycles and it tended to be more brittle/catastrophic.

Debaiky (2000) studied the efficiency of FRP wraps on corrosion damaged concrete cylinders. Fifty-six standard size reinforced cylinders were tested under different combinations of corrosive environment and wrapping schemes. Twenty-four cylinders were corroded electrochemically by applying a constant impressed current producing steel loss of 1.5, 3, 5\% and twenty-three cylinders were subjected to an externally harsh environment of wet dry cycling $(100,200$ and 300 days) in a controlled chamber. Carbon fiber sheet was applied on the cylinders either at the start of testing or in intermediate stages. At the end of each exposure stage the cylinders were tested in axial compression for lateral and axial deformations. From the test results and observations, it was confirmed that the FRP wrap has a potential in slowing down the propagation of corrosion in reinforced concrete elements. The number of FRP layers did not have a significant effect on the corrosion of steel but the extension of wrap over the whole area had a profound effect.

Micelli (2002) performed a study on the durability of FRP confined concrete subjected to accelerated environmental condition. Two different conditioning agents and two different FRP materials were chosen. Unidirectional glass and carbon sheets were used to wrap the cylinders and nonwrapped specimens were used as control specimens. First set of specimens was immersed in a $15 \%$ by weight aqueous solution of $\mathrm{NaCl}$ for a total of 2880 hours. The second set 
was aged in an environmental chamber subjected to freeze-thaw, high-humidity, high temperature cycles, and indirect UV exposure. All specimens were subjected to uni-axial compression tests. GFRP wrapped cylinders showed a moderate decrease in strength and a loss in ductility of more than $30 \%$. CFRP confined specimens did not show a significant decrease in ultimate strength but the cylinders in $\mathrm{NaCl}$ solution showed a loss of $30 \%$ of their axial strain. Thus, environmental factors were found to affect the mechanical properties of the FRP confined concrete.

\subsection{Methods of wrapping and Types of FRP wrap}

Different methods of wrapping are used for strengthening specimens based on the type of force to be resisted. Type of strengthening for beams, slabs, columns and piers to resist the necessary force within a structural system is tabulated in Table 2-1.

Table 2-1 Rehabilitation Techniques

\begin{tabular}{|c|c|c|}
\hline $\begin{array}{c}\text { Type of } \\
\text { Specimen }\end{array}$ & $\begin{array}{c}\text { Force } \\
\text { Resisted }\end{array}$ & Rehabilitation/Strengthening Technique \\
\hline \multirow{2}{*}{ Beams } & Flexure & $\begin{array}{l}\text { Bonding of FRP Plates, Wet Lay-up of Fiber Sheets or Strips, } \\
\text { Prepreg Winding }\end{array}$ \\
\hline & Shear & U jacketing plates, FRP Sheet Wrapping \\
\hline Slabs & Flexure & FRP Sheet or Strip bonding \\
\hline \multirow{2}{*}{ Columns } & Axial & $\begin{array}{l}\text { FRP sheet or strip wrapping, Filament Winding, Bonding } \\
\text { Prefabricated Shells }\end{array}$ \\
\hline & Eccentric & FRP Sheet Wrapping, Prefabricated Shells \\
\hline \multirow{2}{*}{ Piers } & Flexure & Jacketing using FRP Plates, FRP Rods \\
\hline & Shear & FRP Sheet Wrapping \\
\hline
\end{tabular}

Among various techniques used to repair and rehabilitate the existing structures, usage of FRP sheet wrapping is the most common technique. The advantages of using FRP sheets are 
flexibility in coping with different shapes of structures, ease in site handling and cost effectiveness while the disadvantages are least quality control and demand on labor.

Different types of fibers used in FRP composites are glass, carbon and aramid. The qualitative comparison between glass, carbon and aramid fibers is given in Table 2-2. Carbon wraps show high tensile and compressive strength and also shows good long-term behavior in terms of creep and fatigue.

Table 2-2 Qualitative Comparison between Fibers (Ref. Meier and Winistorfer, 1995)

\begin{tabular}{|c|c|c|c|}
\hline \multirow{2}{*}{ Criterion } & \multicolumn{3}{|c|}{ FRP Composites } \\
\cline { 2 - 4 } & E- Glass & Carbon & Aramid \\
\hline Tensile Strength & Very Good & Very Good & Very Good \\
\hline Compressive Strength & Good & Very Good & Inadequate \\
\hline Young's Modulus & Adequate & Very Good & Good \\
\hline Ductiltiy & Very Good & Adequate & Good \\
\hline Long Term Behavior & Adequate & Very Good & Good \\
\hline Fatigue Behavior & Adequate & Excellent & Good \\
\hline Bulk Density & Adequate & Good & Excellent \\
\hline Alkaline Resistance & Inadequate & Very Good & Good \\
\hline Price & Very Good & Adequate & Adequate \\
\hline
\end{tabular}

\subsection{Summary}

Based on the literature review, effects of the concrete cross section in increasing strength and ductility of FRP confined concrete and the edge effects due to FRP confinement should be 
studied. Significance of a proper bond between concrete and FRP with respect to degree of bonding need to be established with respect to increase in strength due to FRP wrapping. Also, increase in strength and durability with respect to different values of $f_{c}^{\prime}$ (compressive strength of concrete) need to be studied. The effects of various environmental factors over a period of time could deteriorate the materials in a FRP confined concrete system. Research on effects of FRP wrapped concrete elements under environmental factors is not comprehensive regarding their serviceability, mechanical and physical properties of the wrapped system. Hence there is a need to study the effects of aging on the composite material. 


\section{MATERIALS AND TEST SET-UP}

\subsection{Introduction}

Mechanical properties of the materials used in this research and equipments used to conduct tests are explained in this chapter. Environmental chamber used for aging of specimens and infrared camera used for conducting non-destructive evaluation (NDE) of wrapped cylinders is discussed.

\subsection{Materials}

Materials used in preparation of test specimens like concrete, steel, carbon fiber tow sheet and resin are described in detail. Mechanical properties of the materials used in preparing the specimens affect the properties of the wrapped concrete specimens.

\subsubsection{Concrete}

The concrete used in this study was made in six batches. Concrete used in the preparation of specimens was mixed in WVU concrete lab and HOY REDI-MIx, Morgantown, WV, also supplied a batch of 4500 psi concrete mix (batch 1). The concrete made in the WVU laboratory in civil engineering department was made using a concrete mixer (fig 3-7). Three batches (batch 2, batch 3 and batch 4) were made in the laboratory with compressive strengths of 8000, 9000 and 8000psi respectively. Batch 1 and 2 was used to test wrapped cylinders for confinement and batch 3 was used for aging tests. Batch 4 concrete was used to test size effects and effect of number of layers. Batch 5 specimens with $f^{\prime}{ }_{c}=6000$ psi and batch 6 with $f^{\prime}{ }_{c}=$ 5000 psi was also prepared in the laboratory. Batch 5 specimens were used in the tests to 
determine effects of confinement by partially wrapping of cylinders. Part of the Batch 1 specimens was used to test specimens wrapped with partial fiber wetting. Batch 6 specimens were used to determine if confinement is contact on bond critical. Type I cement and \#8 aggregates (small stone) (Figure 3-1) were used to prepare concrete mix in the laboratory. Cement, sand and aggregate were obtained from Hoy Redi-Mix.
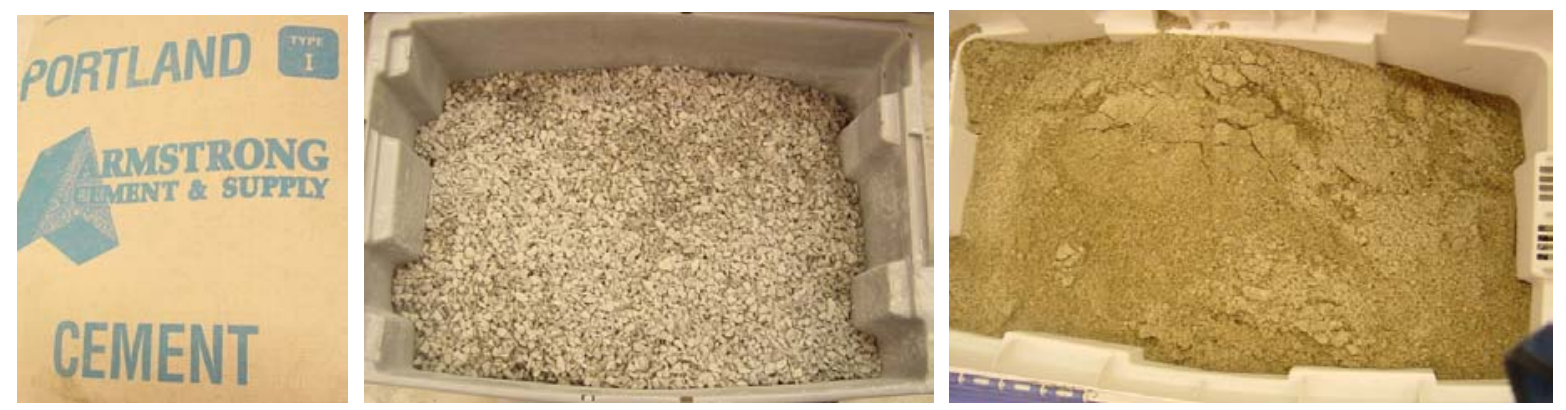

Figure 3.1 Type I Cement, \# 8 Aggregate and Sand

After mixing, concrete was allowed to set in the mold for 24 hours. Concrete was poured in six batches; first 3 batches had 30 cylinders each. Half of the cylinders (15 cylinders) in each batch had steel reinforcement in them. The fourth batch of concrete was used to cast 30 plain concrete cylinders of varying sizes of 3 "x 6 ", 4 "x 8 " and 6 "x 12 ". The $5^{\text {th }}$ and the $6^{\text {th }}$ batch consisted of plain concrete cylinders of 3" x 6" size. The plain concrete columns were numbered first from 1 to 15 and the reinforced concrete columns were numbered from 16 to 30 in batch 1, 2 and 3.

\subsubsection{Steel}

The main steel reinforcement provided in the cylinder was in the form of threaded steel rods of $1 / 4$ " diameter with a corrosion resistant coating. Threaded steel bars were used to provide 
good bond between steel and concrete. These steel rods were tested in the Instron machine under tension and compression, indicating yield strength of $40 \mathrm{ksi}$ in tension and compression. Hoop reinforcement was provided in the form of a chicken mesh with $1 / 2$ " mesh squares (Figure 3.2).

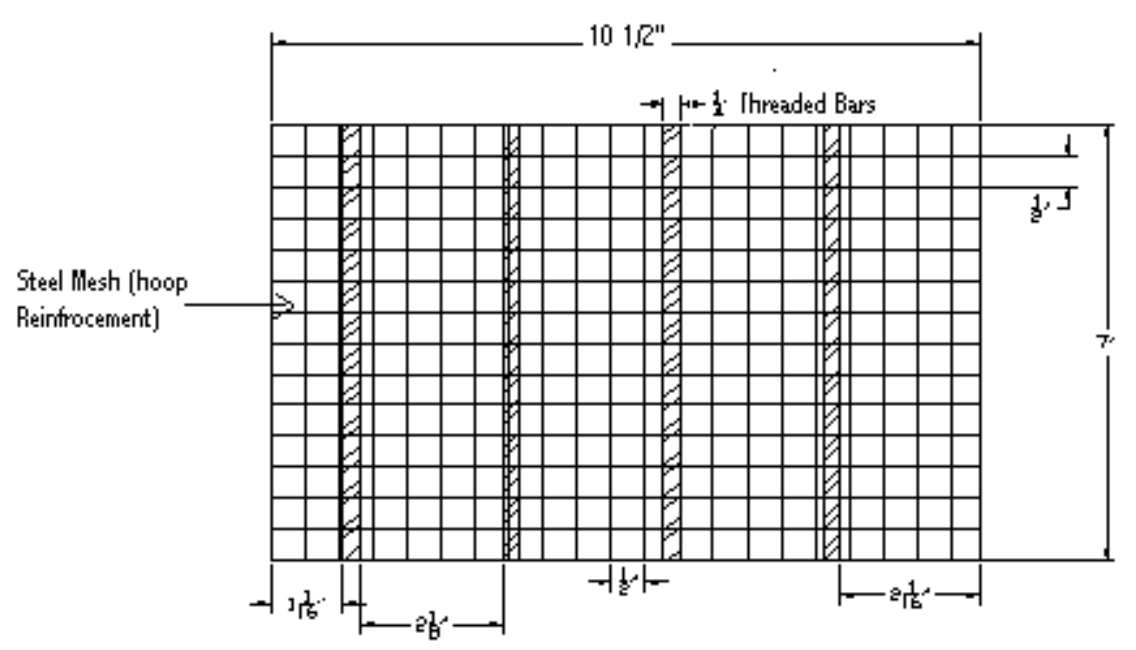

Figure 3.2 Reinforcement Details

The main reinforcement was tied onto the steel chicken mesh using steel wire ties and the whole system of reinforcement was then rolled into a cylinder with at least an inch of overlap.

Initially $1 / 2 "$ clear spacing was maintained between the mold and the internal reinforcement using $1 / 2$ " rebars (Figure 3.3). This method of maintaining the clear spacing was not very accurate. Hence two rods with a length equal to the cylinder diameter were tied and placed horizontally with $1 / 2$ " spacing on either side of the mesh to help maintain the clear spacing more accurately (Figure 3.4). 


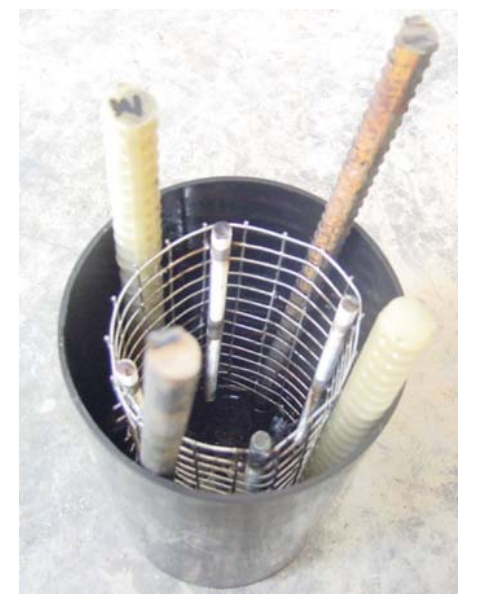

Figure 3.3 Clear Spacing for Steel Reinforcement using $1 \frac{1}{2}$ " Rods to fix Spacing
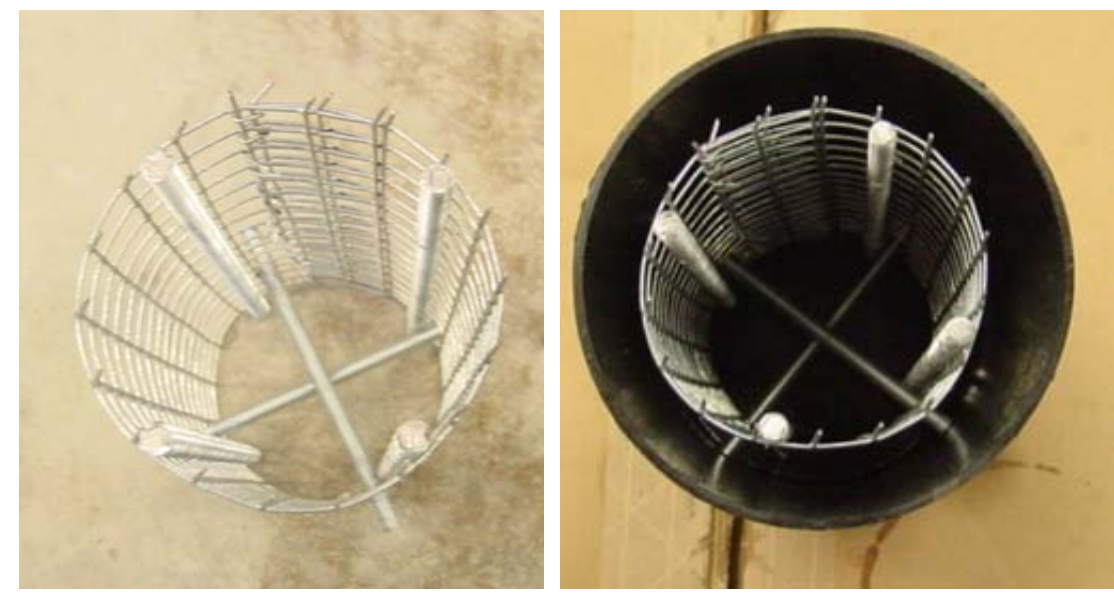

Figure 3.4 Clear Spacing for Steel Reinforcement using 4" length rods across the diameter

\subsubsection{Carbon Fiber Tow Sheet}

The Carbon Fiber Tow Sheet manufactured by Tonen Corporation, Japan was used in this research. Tow sheet was made of unidirectional fibers $\left(0^{\circ}\right)$ and the fibers were supported on a glass fiber scrim. The stress strain behavior of carbon fibers is linearly elastic to failure (Ref. Prachasaree, 2002). Carbon fibers are resistant to moisture, some solvents, bases and weak acids. 
Table 3-1 Properties of Carbon Fiber Tow Sheet reported by Manufacturer (Tonen Co., Manufacturer)

\begin{tabular}{|c|c|}
\hline Design Thickness based on single uncoated fabric & 0.004 " $(0.1 \mathrm{~mm})$ \\
\hline Tensile Strength & $22 \mathrm{kip} / \mathrm{inch}(382 \mathrm{~N} / \mathrm{mm})$ \\
\hline Tensile Modulus & $33 \mathrm{Msi}\left(23.03 \times 10^{4} \mathrm{~N} / \mathrm{mm}^{2}\right)$ \\
\hline Ultimate Strain & $1.5 \%$ or .015 \\
\hline Density & $0.056 \mathrm{bs} / \mathrm{in}^{3}$ \\
\hline Shear Modulus & $7687 \mathrm{Ksi}$ \\
\hline Poisson Ratio & 0.28 \\
\hline
\end{tabular}
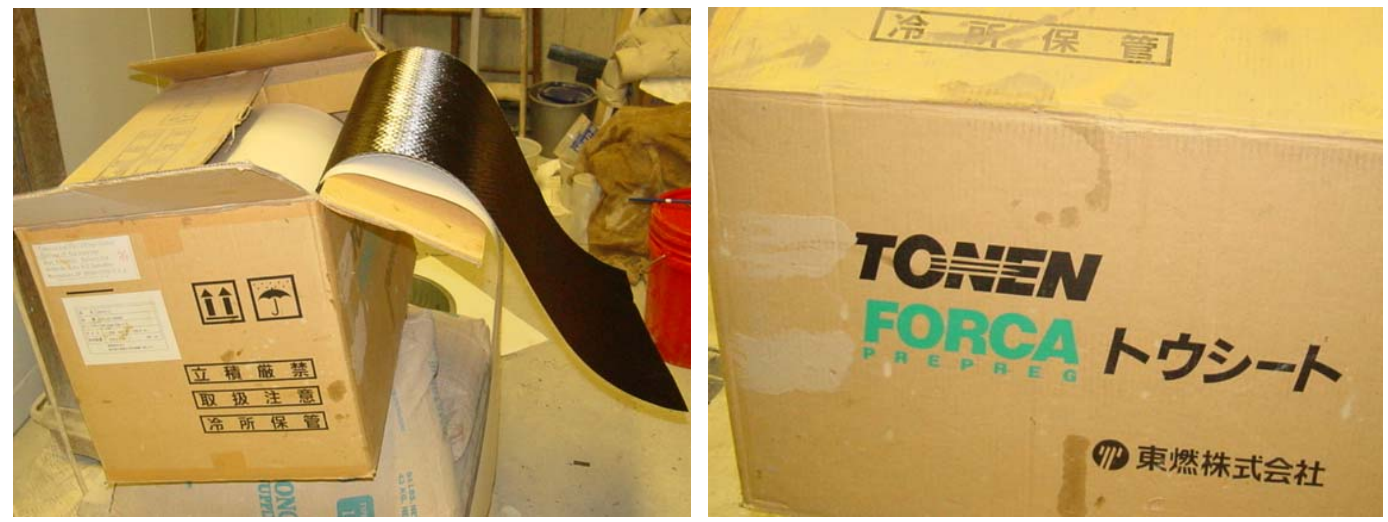

Figure 3.5 Carbon Fiber Two Sheet

\subsubsection{Adhesive and primer}

During initial trails, vinyl ester resin, rated to be carbon compatible was used as adhesive to bond the wrap. The workability with this resin was not good and hence an epoxy resin known as the Typo S Saturant Epoxy manufactured by FYFE Co. was used to bond carbon tow sheets to the concrete surface.

The adhesive consisted of two parts: part A and part B. Part A was epoxy resin and Part B was hardener. Suggested mix ratio was 100 parts of part A to 42 parts of part B by volume. The resin served as the primer also. Carbon wrap was wrapped around the cylinder in few minutes after the adhesive was applied, making sure that there were no air gaps between the wrap and the cylinder. The advantages of the Tyfo S Saturant Epoxy are 
- Good high temperature properties

- Good low temperature properties

- Long working time

- Ambient temperature

- $100 \%$ solvent free

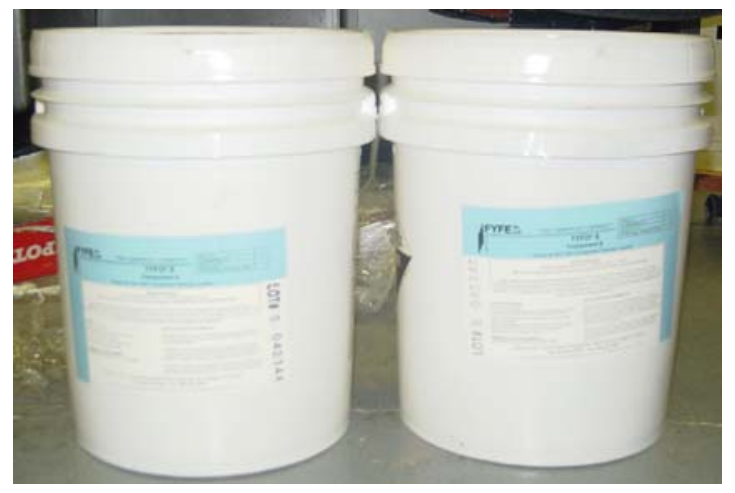

Figure 3.6 Typo S Saturant Epoxy Part A and Part B

Manufacturer (FYFE Co) supplied properties of the epoxy Type S Saturant Epoxy are given below in the Table 3-2.

Table 3-2 Properties of Epoxy Resin reported by Manufacturer

\begin{tabular}{|c|c|}
\hline Tensile Strength & $10500 \mathrm{psi}$ \\
\hline Tensile Modulus & $461000 \mathrm{psi}$ \\
\hline Flexural Strength & $17900 \mathrm{psi}$ \\
\hline Flexural Modulus & $452000 \mathrm{psi}$ \\
\hline Density of Mixed Resin & $9.17 \mathrm{lb} /$ gallon \\
\hline Percentage Elongation & $5 \%$ \\
\hline
\end{tabular}

\subsection{Equipment and Accessories}

Data acquisition system and other accessories were used to test concrete cylinders in compression and carbon strip specimens in tension to establish mechanical properties of wrapped cylinders. A brief description of equipment and accessories was provided in this chapter. 


\subsubsection{Concrete Mixer}

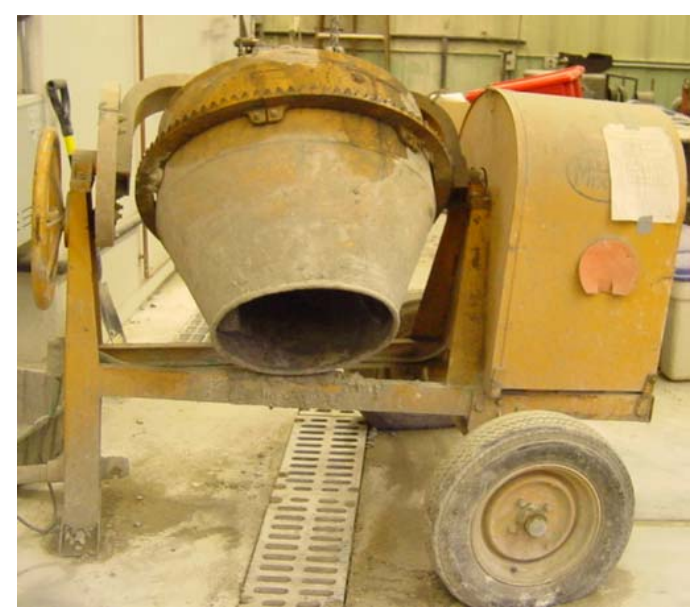

Figure 3.7 Concrete Mixer (Concrete Lab)

The concrete mixer used to prepare concrete in the laboratory had $3 \mathrm{ft}^{3}$ capacity and is operated by a motor for the rotary action and a manual wheel for tilting the mixer.

\subsubsection{Universal Compression-Testing Machine}

The universal compression-testing machine is a 300 kips capacity testing machine fitted with low (50 kips) and high (350 kips) load indicator dials for reading applied loads. The higher scale was used in all the compression tests of the specimens conducted in the machine. The machine consisted of stationary top plate and a hydraulic jack was used to move the lower loading plate in the upward direction. Speed of loading can be adjusted using a gear handle. To automatically read the applied load into data acquisition system, a load cell was used. 


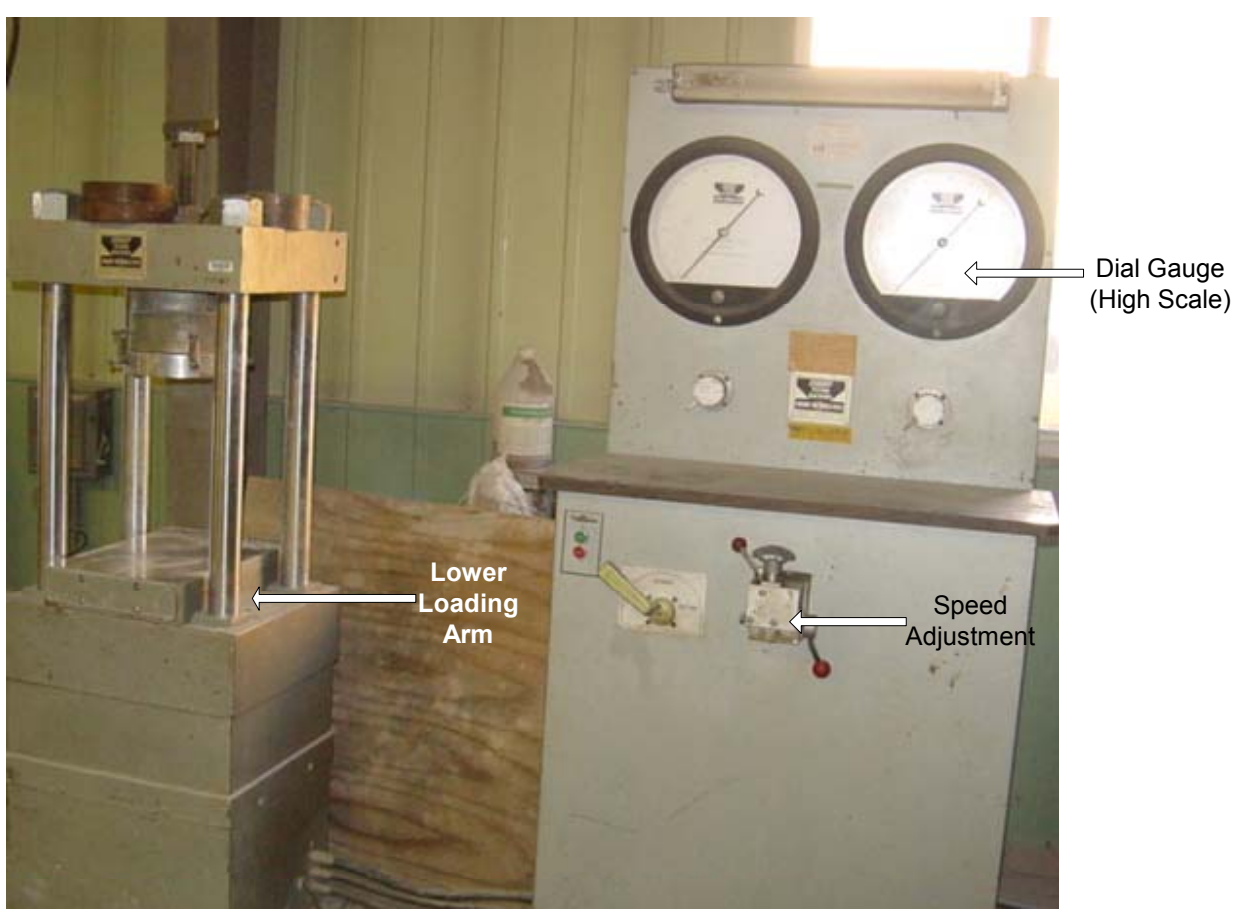

Figure 3.8 Universal Compression Testing Machine

\subsubsection{Baldwin Machine}

The Baldwin machine was used to test the carbon strip specimens in tension. The machine has three loading scales and the lower scale of capacity $10000 \mathrm{lbs}$ was used in testing. The Baldwin machine has electrical signal outlet to record load directly form the machine to automatic data acquisition system. Using a manual-loading wheel, speed of loading was controlled. 


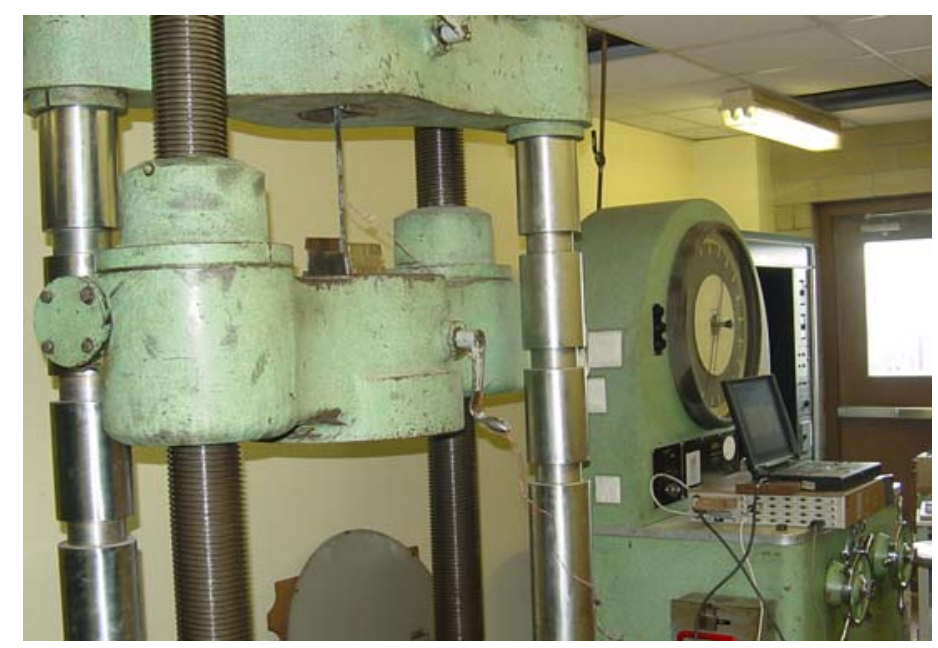

Figure 3.9 Baldwin Machine

\subsubsection{Instron Machine}

Instron machine was used to test steel rods used as internal reinforcement for concrete cylinders. The machine can read both load and position and can be used to test specimens in tension, compression, bending, shear etc., by changing the grips. The Instron machine has a capacity of 22kips $(100 \mathrm{KN})$ and is operated by a hydraulic system with a frequency range of 1$10 \mathrm{~Hz}$.

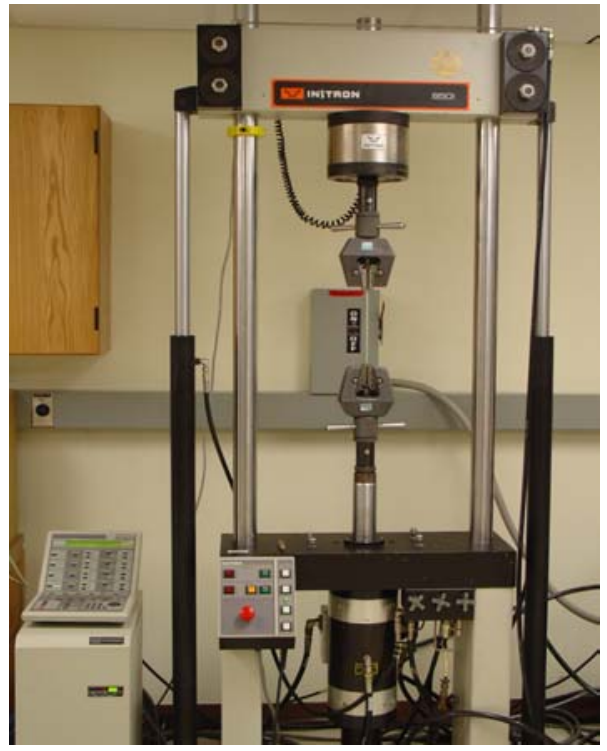

Figure 3.10 Instron Machine 


\subsubsection{Data Acquisition, Strain Gauges, Load cell and LVDT}

In order to collect the test data, of system 5000 - scanner 5100 data acquisition manufactured by Vishay Micromeasurements was used. The data acquisition system had strain gauge cards and high-level cards. Depending on the data to be collected, appropriate cards were used. The data was interpreted using the strain smart software. The recorded readings could be reduced into excel files by the software. The data acquisition system is capable of being connected to 20 channels. Usually three strain gauge cards and one high-level card was used in the tests conducted for this research. The channels were used to detect strain gauges, load cells and LVDT's during testing. Some of the features of the data acquisition systems are:

- Inputs accepted from strain gauges, strain gauge based transducers, LVDT's, thermocouples and sensors with high-level outputs

- Stable, accurate, low-noise signal conditioning

- Scanning and recording intervals as short as 0.1 second for up to 1,200 inputs

- Built-in bridge completion for 120,350 and 1,000 Ohm strain gauges

- Available with ISA (Windows 3.1 or 95) and/or PCMCIA (Windows 95) hardware interfaces

Strain gauges used were ordered from Vishay Micromeasurements with $350 \mathrm{ohm}$ resistance. For carbon strip tests, gauges from Omegas Inc. Company with similar specifications were used. These gauges were attached to the surface prepared using M-bond. The universal compression-testing machine did not have an outlet for continuous measurement of load. In order to record continuous and accurate measurement of load, a load cell with a maximum capacity of 200 Kips was used. It was calibrated and attached to the strain gauge card of the data acquisition. LVDTs (Linear Variable Displacement Transducers) were used to record global 
displacements after calibrating them; they were attached to the high level card of the data acquisition system.

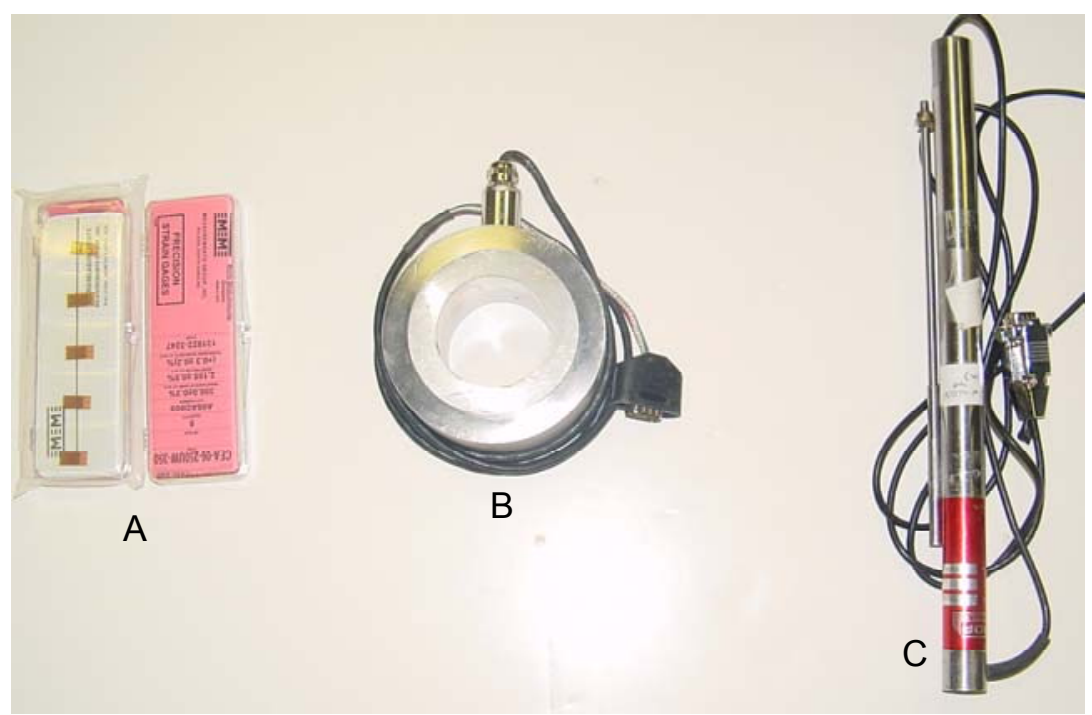

Figure 3.11 A) Strain Gauges; B) Load Cell; C) LVDT

\subsubsection{Infrared Camera}

The infrared thermography is one of the non-destructive methods used for material and specimen evaluation. Infrared thermography utilizes the heat energy emitted by an object to characterize its subsurface conditions. The method is based on the principle that subsurface voids will affect the rate of heat flow through a structure, thereby resulting in surface temperature differentials. By measuring the surface temperatures under known heat flow conditions, the subsurface defects can be located (Weil 1991 and Halabe et al.1995).

ThermaCAM ${ }^{\mathrm{TM}}$ S60 (FLIR Systems) (Figure 3.13) camera was used to detect debonding of wrap and concrete interface and to visualize the increase in growth of debonding due to aging. The infrared monitoring system consisted of an advanced digital infrared camera and associated image-processing software. Features of the ThermaCAM ${ }^{\mathrm{TM}}$ camera are: 
- Handheld, lightweight and a truly portable camera with a built-in $24^{\circ}$ lens.

- Detect radiation in the spectral range of 7.5 to 13 microns.

- Temperature ranges for the measurement available are 0 to $+500^{\circ} \mathrm{C}\left(+32\right.$ to $\left.+932{ }^{\circ} \mathrm{F}\right),-40$ to $+120^{\circ} \mathrm{C}\left(-40\right.$ to $\left.+248{ }^{\circ} \mathrm{F}\right)$ and +350 to $1500{ }^{\circ} \mathrm{C}\left(+662\right.$ to $\left.+2732{ }^{\circ} \mathrm{F}\right)$.

- Measurements can be detected up to an accuracy of $\pm 2{ }^{\circ} \mathrm{C}$ or $\pm 2 \%$ of reading in ${ }^{\circ} \mathrm{C}$.

- Imaging performance has a spatial resolution of $1.3 \mathrm{mrad}$ and can record images at a frequency of $50 / 60 \mathrm{~Hz}$, non-interlaced.

- Also features burst recording functionality that allows the user to record sequence of events into the internal RAM memory.

- Images can be analyzed either in the field by using the real-time measurement markers built into the camera software, or in a PC using FLIR Systems software (FLIR Systems 2002a).

The software ThermaCAM ${ }^{\mathrm{TM}}$ Researcher 2002 was used with the IR camera. It deals with the live IR images arriving through the camera interface and can also receive IR images from other media, such as PC card hard disk from the camera. The software can be used to display the IR images, record them on the disk, or analyze them later during the replay. 


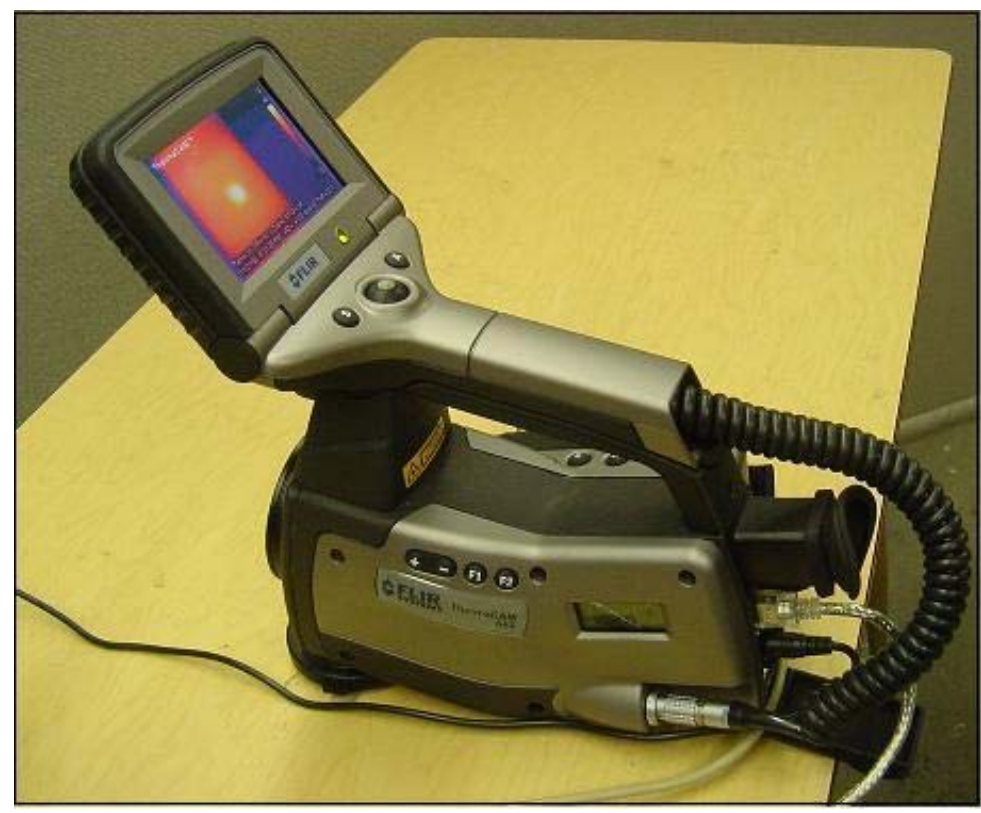

Figure 3.12 ThermaCAMTM S60 infrared camera from FLIR Systems (Refernce, Vasudevan)

\subsubsection{Environmental Chamber for Freeze Thaw Cyclic Aging}

CFC-WVU environmental chamber in the Engineering research building was used to age the specimens under freeze thaw cycle condition. The chamber was set to run the cycles shown in Figure 3.14. The specimens were aged for a period of 1 and 2 months. Both wrapped and non-wrapped specimens were aged and compared with control specimens (unaged specimens). Specimens were tested in axial compression using the universal testing machine. Carbon strip specimens were also aged in the chamber along with the cylinders. 


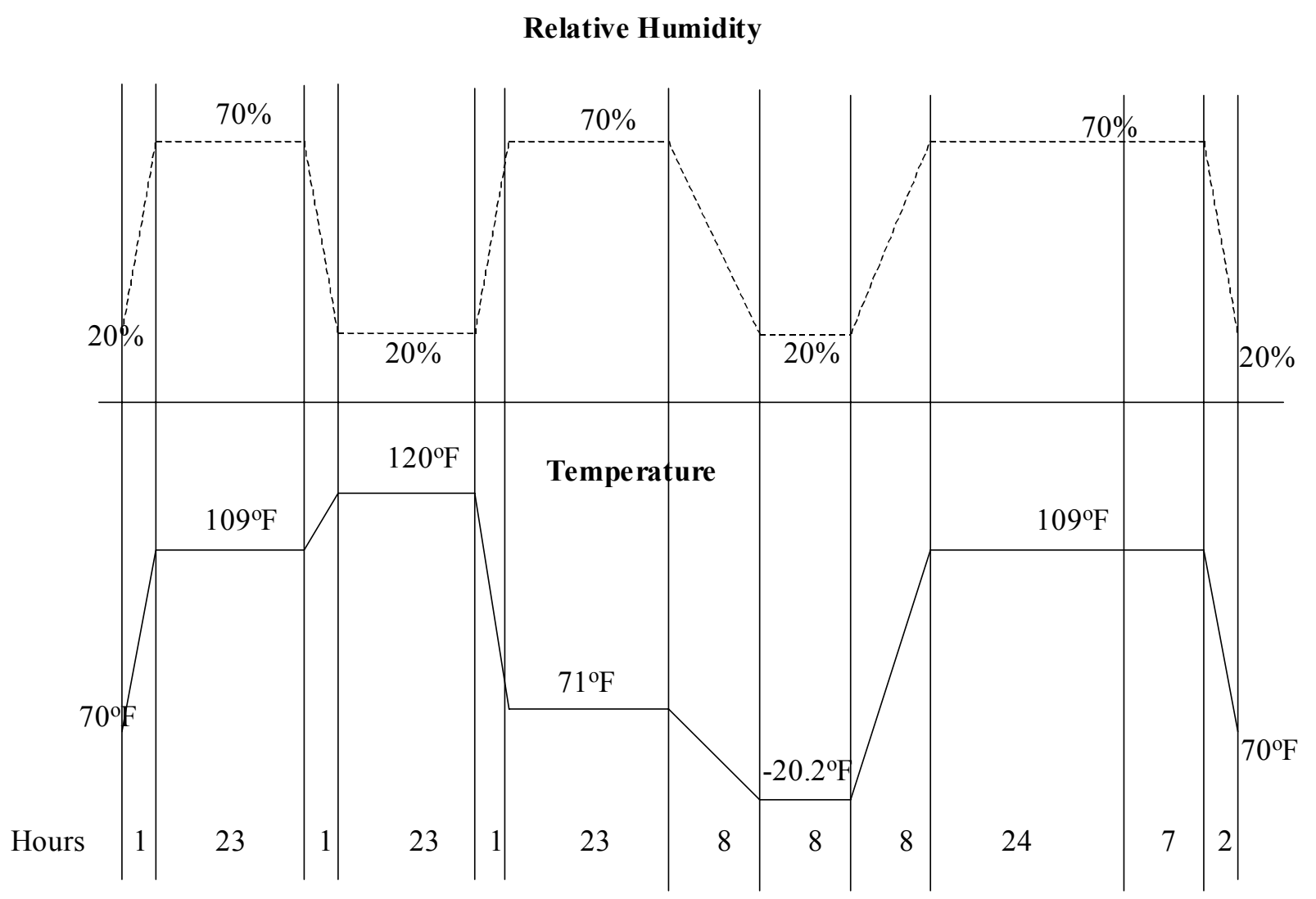

Figure 3.13 Freeze Thaw Cycle

(Relative humidity of the specimen is $100 \%$ as they are immersed in water)

\subsubsection{Elevated Temperature Bath for Aging}

Accelerated aging of specimens at elevated temperature was achieved by immersing the specimens in a bath of water maintained at a temperature of $175^{\circ} \mathrm{F}$. Both wrapped and nonwrapped specimens were immersed for a period of 1 and 2 months and tested. The bath was heated using thermostats and the temperature was maintained by covering the bath with a heat resistance cover. Carbon strip specimens were also aged for a period of 1 and 2 months along with the cylinders. 


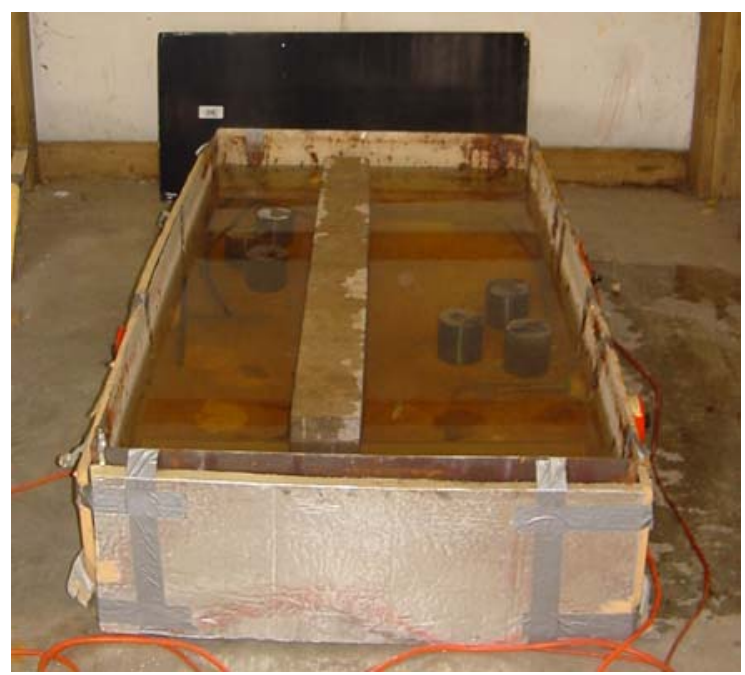

Figure 3.14 Elevated Temperature Bath

\subsection{Summary}

The materials used to prepare concrete cylinders such as the small stone aggregate was chosen to ensure good compaction while making small size cylinders. Carbon fiber was chosen due to its high tensile and compressive strength and good long-term behavior. The cylinders were made to a specific size to make sure that failure of the specimen takes place within the maximum capacity of the testing machines. Different testing equipments were used depending on the type of tests conducted. The elevated temperature bath and the freeze thaw cycles were chosen as long term aging techniques for a period of 1 and 2 months and the aging is being continued. 


\section{TEST SPECIMEN AND TEST PROCEDURE}

\subsection{Introduction}

This chapter discusses the test set up and specimen preparation used in testing carbon fiber wrapped cylinders. Smaller specimens were chosen to make sure the failure was within the $200-300$ kip capacity of the testing machines. Dimensions were also decided based on the type of results to be evaluated from conducting the tests. Specimens with high and low compressive strength of concrete with and without internal steel reinforcement, having dimensions of 3"x6" 4"x8" and 6"x 8" was prepared to evaluate the effect of confinement. Carbon strip specimens were also prepared with a dimension of $1 / 2 " \times 15 "$.

\subsection{Specimen Description}

\subsubsection{Specimens}

Non-wrapped specimens with and without internal steel reinforcement were used as control specimens. The increase in strength of the wrapped specimens was evaluated by comparing them to the non-wrapped control specimens.

\subsubsection{Axial Compression Test Specimens to determine Confinement Effects and Effects due to Aging}

Control specimens used in these tests were non-wrapped cylinders (4"x 8 ") from batch 1 , 2 and 3. The specimen dimensions were 4" diameter and 8" height with compressive strengths varying from 4500 psi to 8000 psi. Specimens with compressive strength of 8000 psi (batch 3) 
were used to determine effects due to aging. Reinforced concrete specimens were prepared using $1 / 2 "$ diameter ribbed steel rods and chicken mesh with $1 / 2 "$ mesh squares. Non-wrapped plain or reinforced concrete cylinders were used as control specimen. The cylinders were wrapped with 1 and 3 layers of CFRP sheets with fibers in $0^{\circ}$ orientation in the hoop direction and one layer $45^{\circ}$ and two layers $\pm 45^{\circ}$ fiber orientation.

Table 4-1 Test Specimens -Confinement Effects and Aging

\begin{tabular}{|c|c|c|}
\hline Test & $f_{c}{ }^{\prime}$ psi & Gauge Position \\
\hline $\begin{array}{c}\text { Confinement } \\
\text { Effect Test } 1\end{array}$ & 4500 & $\begin{array}{c}\text { Axial, Hoop and } \\
\text { 45 degree }\end{array}$ \\
\hline $\begin{array}{l}\text { Confinement } \\
\text { Effect Test 2 }\end{array}$ & 8000 & Axial, Hoop \\
\hline Aging & 8000 & Hoop \\
\hline
\end{tabular}

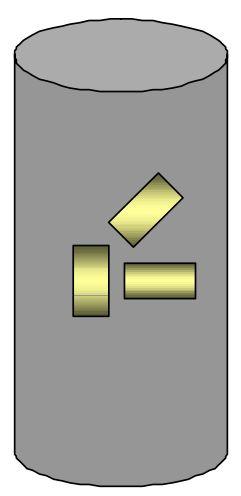

Confinement Test ISpecimens

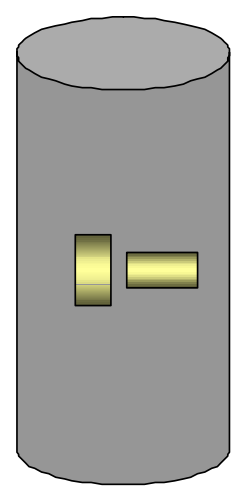

Confinement Test IISpecimens

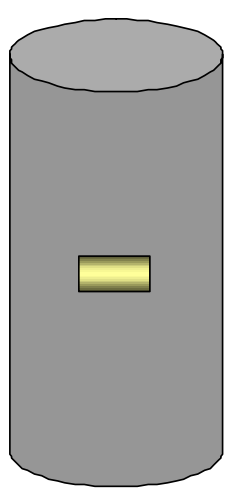

Aging TestSpecimens

Figure 4-1 Orientation of Gauges Effect of Confinement and aging 


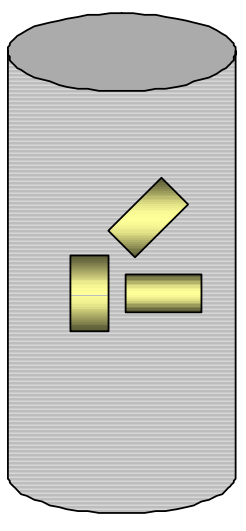

Single wrap $0^{\circ}-\mathrm{fc}$ $4500 \mathrm{psi}$

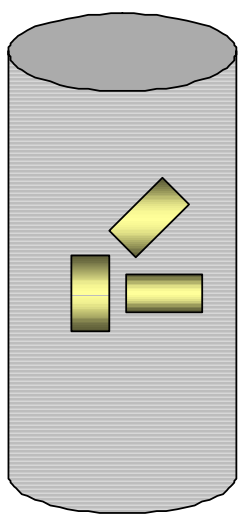

3 wraps $0^{\circ}-\mathrm{fc}^{\prime}$ $4500 \mathrm{psi}$

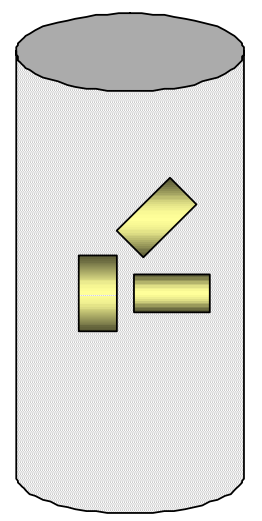

$45^{\circ}$ wrap - fc' 4500 psi

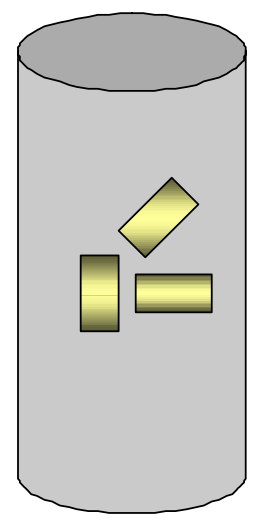

$\pm 45^{\circ}$ wrap $-\mathrm{fc}^{\prime}$ $4500 \mathrm{psi}$

Figure 4-2 Wrapped Test Specimen - 4500 psi Concrete

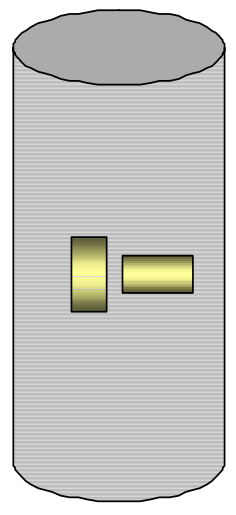

Single wrap - fc' 8000 psi

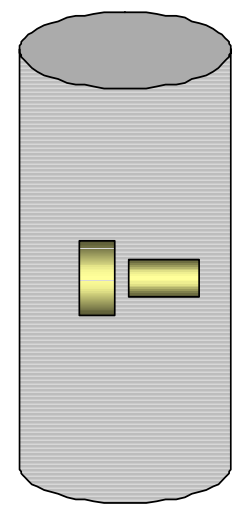

3 wraps $-\mathrm{fc}^{\prime}$ 8000 psi

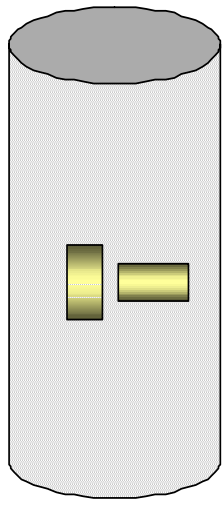

$45^{\circ}$ wrap - fc' 8000 psi

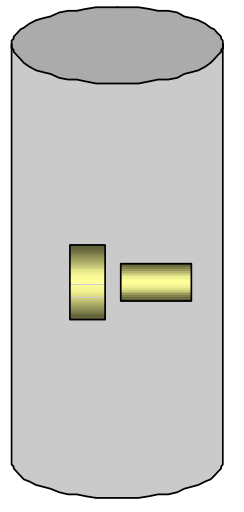

$\pm 45^{\circ}$ wrap - fc' $8000 \mathrm{psi}$

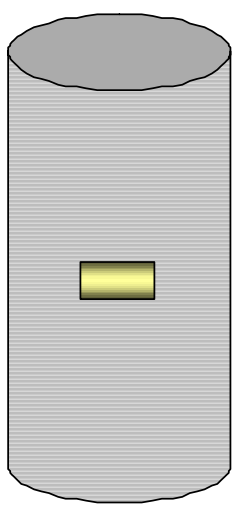

Aging TestSpecimens

Figure 4-3 Wrapped Test Specimen - 8000 psi Concrete Confinement and Aging Test

\subsubsection{Axial Compression Test Specimens to determine Effects of Size, \\ Number of Wraps and Wrapping Height and Location}

Specimens used in these tests were plain concrete cylinders of compressive strength $f_{c}$ ' of 8000 psi (batch 4) and $f_{c}^{\prime} 6000$ psi (batch 5). Circular cylinders were of dimensions 3"x6", 4"x8" and 6"x12" were tested. Non-wrapped cylinders were used as control specimens to evaluate the increase in strength and ductility of the wrapped specimens. One specimen from each size was attached with two gauges: one in the axial direction and one in the hoop direction 
as shown in Figure 4-4. To investigate effect of increase in number of FRP layers on cylinder properties 3"x 6" cylinders were used with 1, 3 and 6 layers of wrap (Figure 4-6). Two specimens of batches 5 and 6 were completely wrapped with fibers in the zero degree direction. Two specimens each from batch 5 were wrapped with $1 / 2$ ", 1 " and $1 \frac{1 / 2}{2}$ gap at top and bottom i.e. for example the fiber was cut to a height of $5 "$ and $1 / 2 "$ cover was given at the top and bottom while wrapping. One cylinder from each batch was attached with two strain gauges in axial and hoop direction. Some of the specimens from batch 6 were partially wrapped for a height of 3" and 4" in the center and some other specimens from the same batch were wrapped for a height of 1" and 11/2" FRP at the top and the bottom only. The test specimens are shown in Figure 4-6.

Table 4-2 Test Specimens - Effect of Size, Number of Wraps and Partial Wrapping

\begin{tabular}{|c|c|c|c|}
\hline Test & Specimen Size & $f_{c}^{\prime}(\mathrm{psi})$ & Gauge Position \\
\hline Size Effect & $\begin{array}{c}\text { 3"x 6", 4"x 8", } \\
\text { 6"x 12" }\end{array}$ & 8000 & Axial and Hoop \\
\hline Number of Layers & 3"x 6" & 8000 & Axial and Hoop \\
\hline $\begin{array}{c}\text { Wrapping Heights } \\
\text { and Location }\end{array}$ & 3"x 6" & 6000 & Axial and Hoop \\
\hline
\end{tabular}

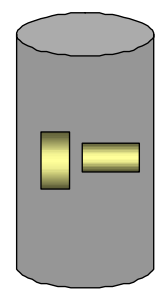

3" $\times 6 "$

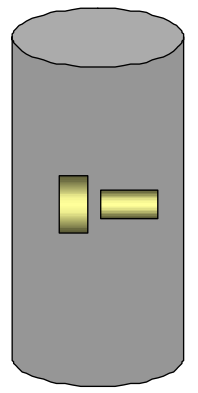

$4 " \times 8 "$

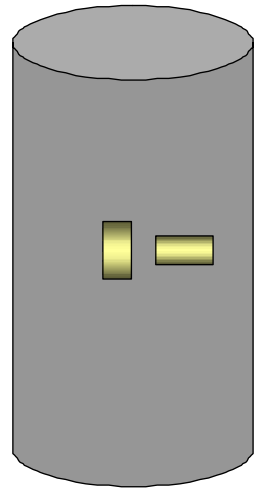

$6 " \times 12 "$

Figure 4-4 Non Wrapped Concrete Specimens - Gauge Orientation 

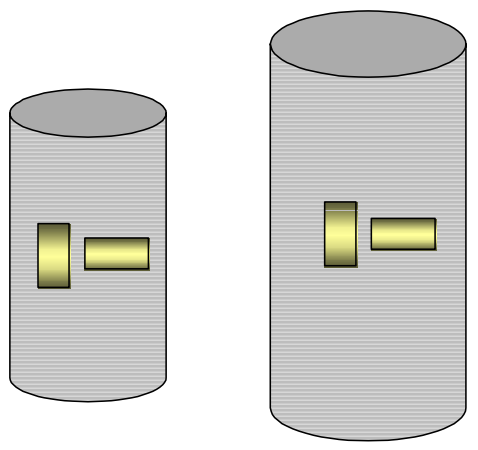

3" $\times 6 "$

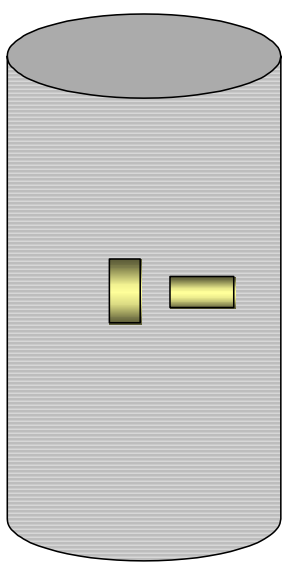

$6 " X 12 "$

Figure 4-5 Wrapped Specimens - Size Effect and Increase in Number of Wrap Effect Tests

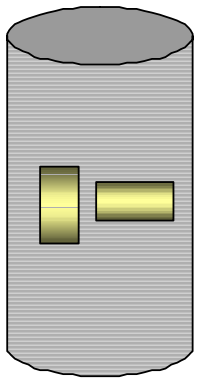

Fully Wrapped

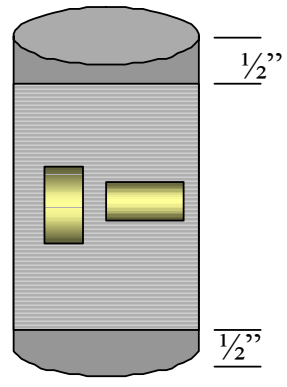

$1 / 2$ "Non Wrapped (a) top \& Bottom

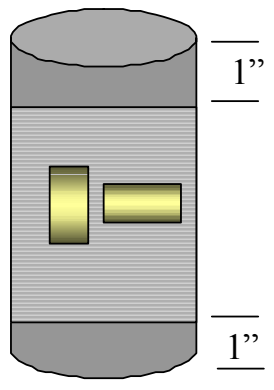

1"Non Wrapped (a) Top and Bottom

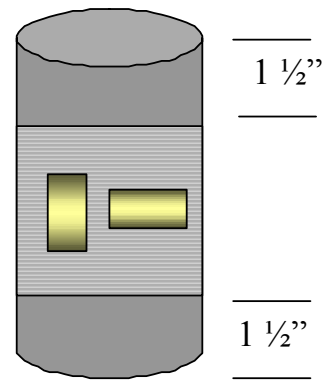

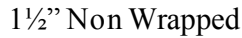
(a) Top and Bottom
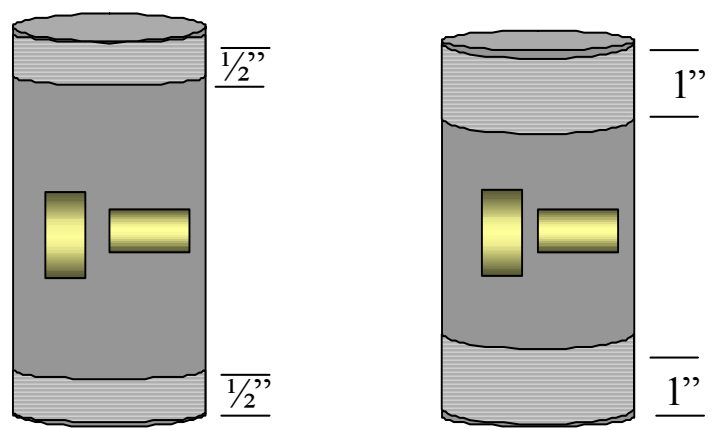

1/2”Wrap@ @ top \& Bottom

1”Wrap @ Top and Bottom

Figure 4-6 Wrapped Specimens - Partial Wrapping and Partial Impregnation Tests 


\subsubsection{Axial Compression Test Specimens to Determine Effects of Partial Wetting of Resin onto Fabric and Partial Bond}

Batch 1 ( $f_{c}{ }^{\prime}$ of $\left.4500 \mathrm{psi}\right)$ specimens were used to test the effects of partial wetting and batch $6\left(f_{c}{ }^{\prime}\right.$ of $\left.5000 \mathrm{psi}\right)$ specimens were used to evaluate bonding including contact critical nature between wrap and concrete. One specimen in each type of test was attached with 2 gauges one in the hoop direction and one in the axial direction.

To determine effects of partial impregnation, cylinders wrapped with one layer of CFRP with fibers in the $0^{\circ}$ direction were used. The carbon wrap was coated with resin along the height at 3 distinct positions in 3 specimens and at 2 distinct points in 3 specimens along the height of the fiber wrap for a width of 1". Positions were chosen to be equidistant from each other with the overlap being coated with resin.

Batch 6 concrete cylinders were also wrapped with a layer of parchment paper with slits of 1 " size at two or three locations along the length of the paper (Figure 4-14), and then coated with resin and wrapped with fiber completely impregnated in resin. The fiber and the concrete would have a bond at the 1" slits, however while around the circumference of the cylinder, the parchment paper would prevent the bonding and the wrap would just be in contact with the specimen. Gauges were attached to one single specimen bonded at two locations and the other specimens were tested for increase in axial strength alone. Gauges were attached at two locations, one where there is bond and one where there is no bond and the difference in strength to strain at these two locations was plotted. The procedure to prepare these specimens is given in section 4.3.2.1. 
Table 4-3 Test Specimens - Partial Wetting and Bond

\begin{tabular}{|c|c|c|c|}
\hline Test & Specimen Size & $f_{c}{ }^{\prime}(\mathrm{psi})$ & Gauge Position \\
\hline Partial Wetting & 4"x 8" & 4500 & Axial and Hoop \\
\hline Partial Bond & 3"x 6" & 5000 & Axial and Hoop \\
\hline
\end{tabular}

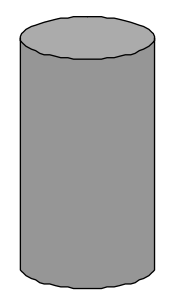

$3 " \times 6 "$

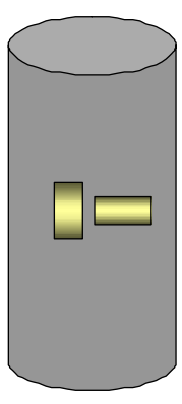

$4 " \times 8 "$

Figure 4-7 Non Wrapped Concrete Specimens

\subsubsection{FRP Strip Specimens}

CFRP strip specimens were prepared in order to test the fiber in tension. The strip specimen $1 / 2$ " in width and 15 " in length were prepared to be tested in the Baldwin machine in tension. The specimens were cut along their length and they measured 15" along the length of the fibers. The specimens were attached with one strain gauge in the axial direction. The thickness of the CFRP was 0.004". The preparation of the FRP strip specimens is given in section 4.3.3. 


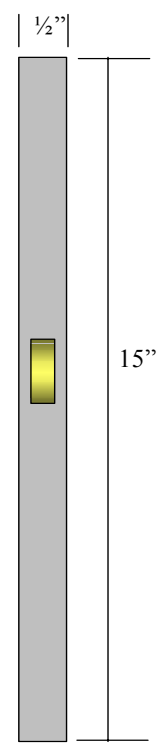

Figure 4-8 CFRP Strip Specimen

\subsection{Specimen Preparation}

Concrete cylinders were prepared in the concrete laboratory for the specified strengths. The cylinders were cast and cured and then wrapped with FRP. Depending on the tests to be conducted, size of the specimen and number of wraps were decided. The cylinders to be aged were prepared and then placed in the chamber and elevated temperature bath for accelerated aging.

\subsubsection{Casting and Curing of Concrete Cylinders}

Plastic molds of size 3"x6", 4"x8" and 6"x12" were ordered from Hogentogler and were used as mold for concrete cylinders. Inside surface was applied with oil to help in the demolding process. 
Concrete mixes of different compressive strengths were cast in separate batches. Depending on the strength of concrete required the mix ratios were varied. The steel reinforcement in the form of a mesh and $1 / 2$ " steel rods was placed in the cylinder mold and checked for accuracy, alignment and necessary concrete cover. Concrete was prepared by using the concrete mixer in the laboratory Figure 3.7. Prepared concrete was filled into the plastic molds and compacted.

The cylinders were compacted with adequate number of tamping in three layers followed by tapping on the sides of the mold with a hammer to make sure that air voids escaped through the surface. Once the tamping and tapping were done, the upper surface of the cylinder was smoothened. Vibration table compaction was also used for some cylinders.

The concrete was allowed to set in the mold for 24 hours by covering it with plastic sheet (Fig 3-12) and then removed the next day with the help of compressed air. The concrete cylinders were placed in the curing chamber and cured at ambient temperature for 28 days in a water tank.

\subsubsection{Wrapping of Cylinders}

The cured concrete cylinders were cleaned with wire brush around the circumference of the cylinders and wiped clean. In general, surface of the concrete cylinder should be clean, dry and free of protrusions or cavities, to avoid voids and stress concentrations between the wrap and concrete. 
The carbon fiber wraps were cut from a big roll of carbon fiber sheet. The sheets were cut as per the required fiber direction in $0^{\circ}$ and $45^{\circ}$ direction. They were cut long enough to cover the circumference of the cylinder with an extra overlap length of 2". The epoxy was prepared by mixing the Resin (Part A) and Hardener (Part B) in a 100 parts of part A to 42 parts of part B ratio by volume. The epoxy and hardener were mixed thoroughly for five minutes with a low speed mixer at 400-600 rpm until uniformly blended. The epoxy was applied to both the concrete cylinder surface and to the surface of the fiber wraps. The carbon fiber sheet was then wrapped along the circumference of the cylinder. To remove any possible air bubbles, a plastic plate was used to smoothen and gently press the surface of the wrapped cylinder. The epoxy was re-applied on the surface of the wrapped cylinder. The wrapped cylinders were left to cure at room temperature for about five days before the testing of the cylinders was done in the Universal Testing Machine. Suggested curing time of epoxy resin is 72 hours at $140^{\circ} \mathrm{F}$ (FYFE Co. Data Sheets) and curing time depends on the curing temperature.

\subsubsection{Wrapping Procedure}

Wrapping Procedure used is shown in Figures 4-9 to 4-13

- Mixing epoxy in the given mix ratio (resin and hardener) using a low speed mixer
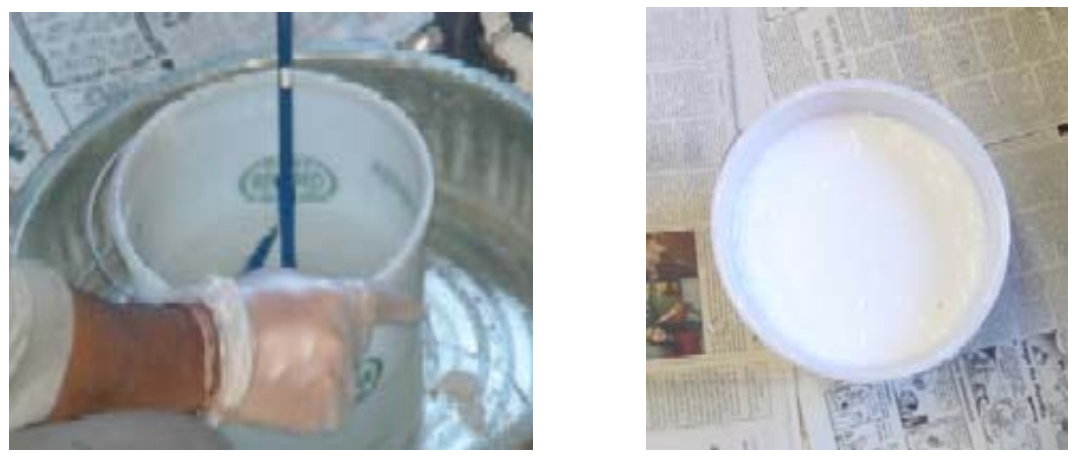

Figure 4-9 Mixing of Epoxy and Hardener

- Applying epoxy to the cylinder surface and the CFRP Sheet 

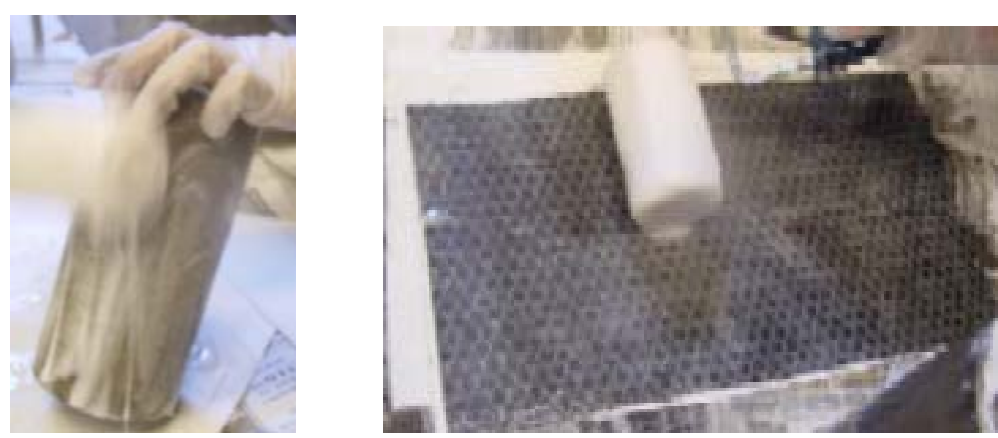

Figure 4-10 Impregnating with Epoxy

- Wrapping the prepared carbon fiber sheet on to the surface of the cylinder

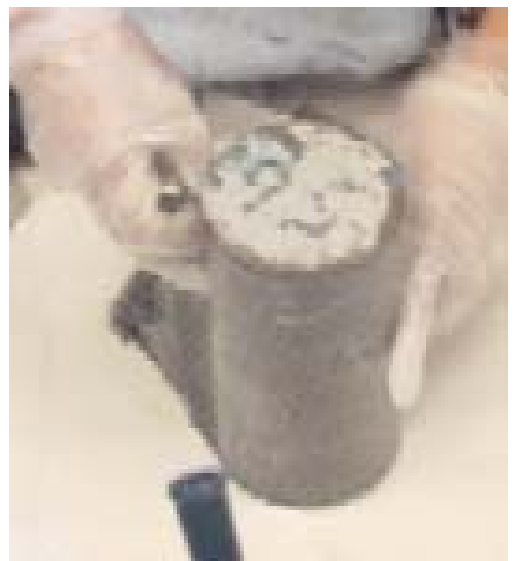

Figure 4-11 Wrapping the CFRP

- Using a thin plastic plate to remove air bubbles, excess resin and smoothening the surface
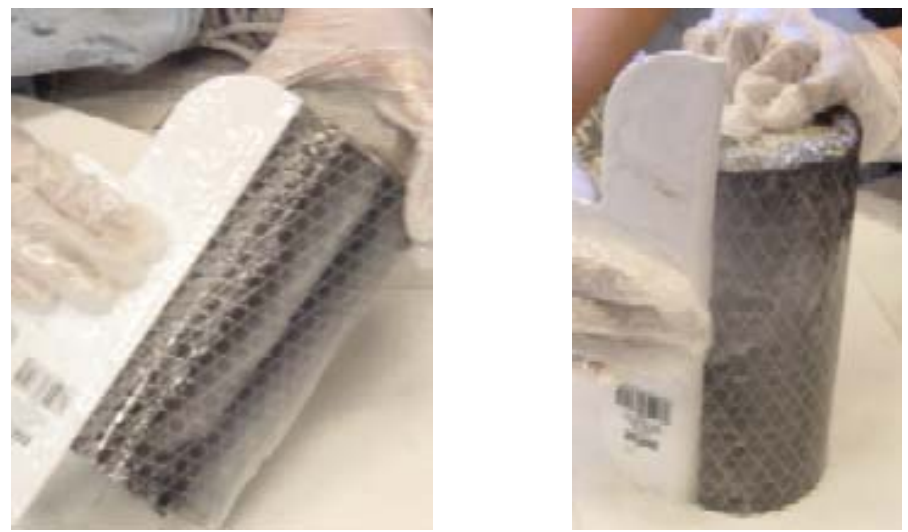

Figure 4-12 Removing Air Bubbles

- Reapplying epoxy to the wrapped cylinder specimen

- Placing the cylinders on its own self weight at the overlap position for few minutes and then moving to the vertical position 


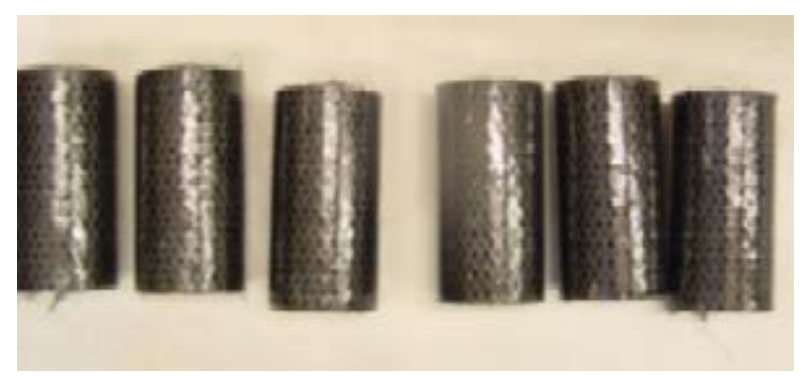

Figure 4-13 Placing Cylinders on its Self Weight

Fabric was cut and wrapped according to the requirement of each test. In case of testing for confinement effects the wraps were cut in the 0 degree and 45 degree fiber direction and wrapped with one, two and three layers. In case of testing for edge effects the CFRP wraps were cut $1 / 2 ", 1$ " and $1 \frac{1}{2}$ " smaller than the concrete cylinder height from both top and bottom. Fabric of size 1 " and $1 \frac{1 / 2}{2}$ was also cut to wrap only the top and bottom of the specimens. For test specimens to determine effect of partial wetting, resin was coated for a 1" width strip at 2 or 3 equidistant locations along the circumference of wrap.

While wrapping cylinders, used for determining if confinement is bond or contact critical some additional steps were followed during wrapping.

- A parchment paper with length equal to the circumference of cylinder was cut

- 3 or 2 slits of size 1 " was made in the paper
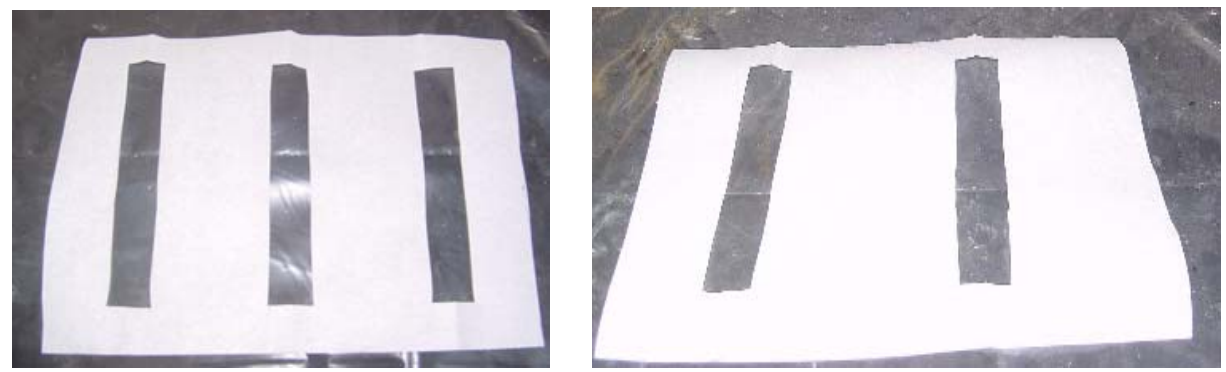

Figure 4-14 1" Slits cut on the Parchment Paper

- Paper with openings was first wrapped around the specimen 


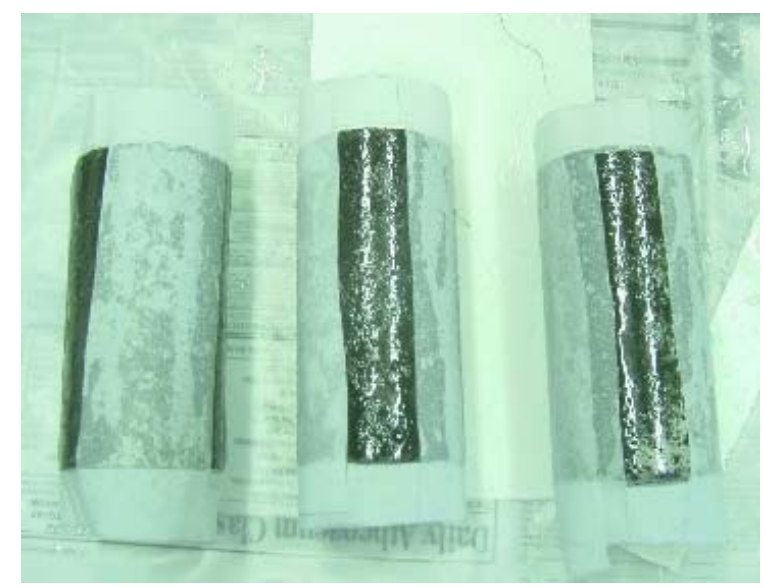

Figure 4-15 Wrapping of Parchment Paper on the Resin Coated Specimen

- Carbon fiber sheet was wrapped on top of the parchment paper

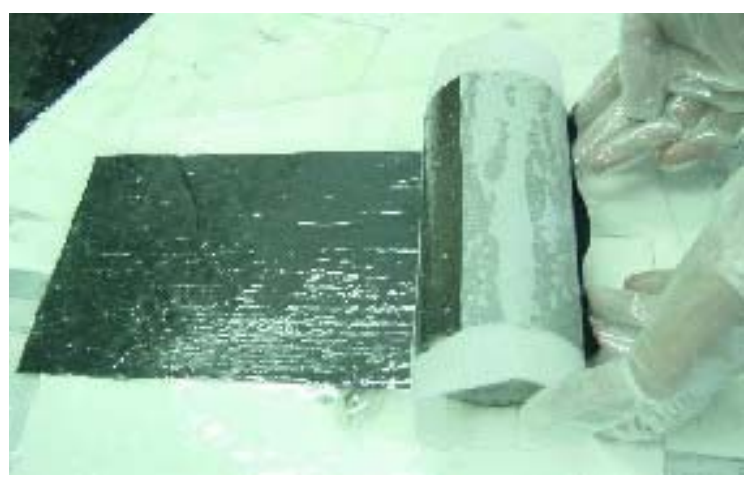

Figure 4-16 Wrapping the Resin Coated Fiber on the Parchment Paper Wrapped Specimen

\subsubsection{Preparation of FRP Strip Specimens}

FRP Strip Specimens were prepared by applying resin on the CFRP sheet. The procedure for preparation of FRP strip specimens is as follows.

- CFRP sheet of size 16"x 20" was cut

- Epoxy resin was prepared by mixing hardener and resin in the mix ratio of 100 parts of A to 42 parts of $B$ by volume

- Resin was impregnated into fiber sheet on both sides

- Non stick paper was applied on both sides of the impregnated fiber sheet 
- Sheet was allowed to cure for about 6 hours

- Test specimens of size $1 / 2$ " $\times 15$ " were cut. (15" length was cut along the fiber direction)

- The cut specimens were allowed to cure for 5 days

- Specimens were attached with a gauge in the middle and tested in tension

FRP Strip specimens were also subjected to aging under freeze thaw cyclic conditions and elevated temperature conditions.

\subsubsection{Aging of Cylinders}

30 specimens from batch 3 concrete were tested to study the effects of accelerated aging in elevated temperature and freeze thaw conditions for a period of 1 and 2 months.

\subsubsection{Freeze Thaw Conditioning}

In order to study the effect of freeze thaw conditions on wrapped concrete cylinders, 12 cylinders were placed in the environmental chamber. The cylinders were placed inside the chamber when the temperature was $70^{\circ} \mathrm{F} .6$ reinforced concrete specimens and 6 plain concrete specimens were placed in the chamber. The specimens were wrapped with 1 layer of CFRP with the fibers in the zero degree direction. Unaged specimens were common to both types of accelerated aging conditions. The freeze thaw cyclic aging follows the temperature and humidity cycle shown in Figure 3.14. The test samples were immersed in water within the environmental chamber and hence the humidity is $100 \%$. The aging scheme was as follows:

\section{Unaged specimens}

- Non-wrapped 
Plain concrete specimens: 1

Reinforced concrete specimens: 1

- Wrapped

Plain concrete specimens: 2

Reinforced concrete specimens: 2

\section{Aged Specimens}

- Non-wrapped

Plain Concrete Specimens: 1

Reinforced Concrete specimens: 1

- Wrapped

Plain Concrete specimens: 5 (2-1 month; 2- 2 months; 1 - 9 months)

Reinforced concrete specimens: 5 (2-1 month; 2- 2 months; 1 - 9 months)

\subsubsection{Elevated Temperature Conditioning}

The elevated temperature bath was an insulated tank of size 80 " x 50 ". The tank was

filled with water and heated to a temperature of $175^{\circ} \mathrm{F}$ using thermostats and the tank was covered with an insulating Teflon sheet.

\section{Unaged specimens}

- Non-wrapped

Plain concrete specimens: 1

Reinforced concrete specimens: 1

- Wrapped

Plain concrete specimens: 2

Reinforced concrete specimens: 2

\section{Aged Specimens}

- Non-wrapped

Plain Concrete Specimens: 1 


\section{Reinforced Concrete specimens: 1}

- Wrapped

Plain Concrete specimens: 5 (2 - 1 month; 2- 2 months; 1 - 9 months)

Reinforced concrete specimens: 5 (2-1 month; 2- 2 months; 1 - 9 months)

\subsubsection{Instrumentation}

Test instrumentation consisted of data acquisition, laptop with strain smart software, strain gauges, load cell and LVDT's. The Data acquisition with twenty channels (fifteen for strain gauge and five for high-level cards) was calibrated to read both strain gauge and high-level

cards. Strain gauges were used to evaluate the strain in hoop, axial and 45-degree direction depending on its position. Load was measured using the load cell and initially the load cell was calibrated and the calibration data was fed to the strain smart software. LVDT's were calibrated and the strain smart software was set to the calibration value. LVDT's were used at the top and bottom of the specimen as shown in Figure 4-17. The difference in readings between both the LVDT's gave the actual deflection of the specimen. The strain smart software recorded the readings from the load cell, strain gauge and LVDT'S and the recorded readings were reduced to excel format.

\subsection{Test Procedure}

Axial Compression tests were conducted on the specimens to evaluate effects of confinement, size, number of wraps, wrap location and height, partial wetting, partial bond and effects due to aging. The test specimens were all prepared in accordance to specifications and tests were conducted. The tests also include tension test on strip specimens and infrared thermography on cylinders. 


\subsubsection{Axial Compression Tests}

Axial compression test was done as per ASTM standards. The cylindrical specimens were placed at the lower mounting table of the test apparatus (Figure. 4-17). Lower platen of the testing machine moves in the upward direction and the upper platen is stationary. The specimens were capped at the top and bottom with steel capping plates having internal elastomeric (neoprene) pads on the inside. Capping was done to make sure the specimens were loaded equally throughout the cylinder and to maintain concentric loading.

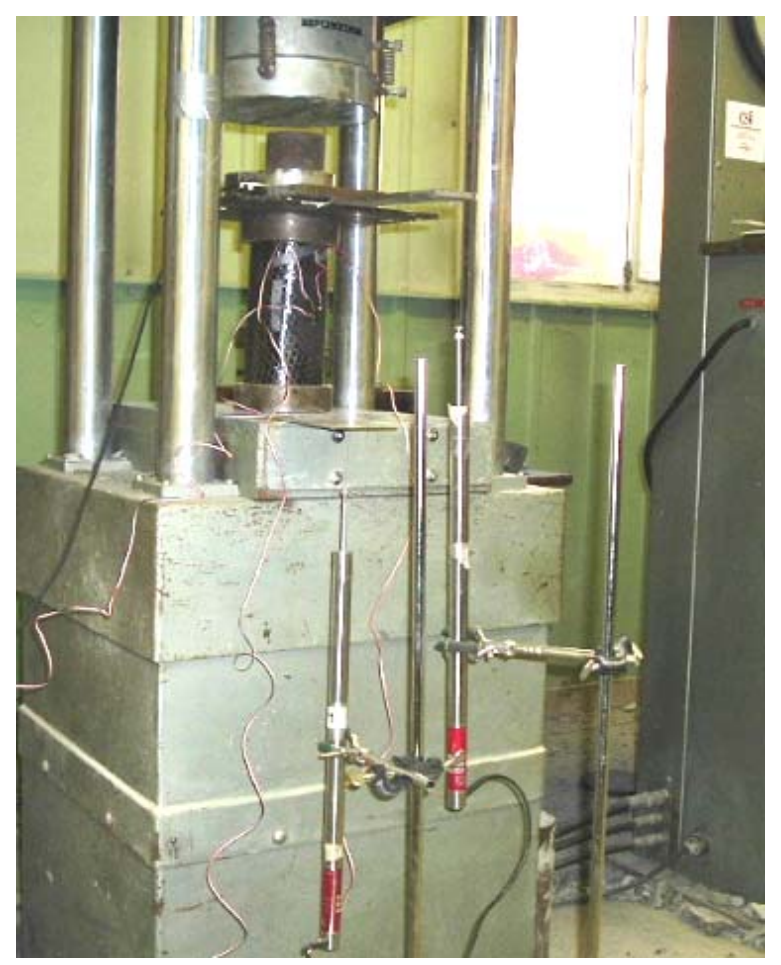

Figure 4-17 Test Set-Up

The test specimens were placed and centered in the lower platen. A steel plate was placed above the specimen and the load cell was placed on it. On top of the load cell another metal cylinder was placed. This was done to increase the height of the testing specimen. LVDTs were suitably attached to the top metal plate and bottom lower platen. The loading of the testing apparatus was set to ASTM standards and the specimen was loaded. 


\subsubsection{FRP Strip Tension Test}

FRP strip specimens were tested in tension using the Baldwin machine. The specimen was bonded with a strain gauge at the mid-height and the low load scale was chosen for testing. Additional plates were used with the grips for holding and testing the thin specimen. Strain gauge and load cell were attached to the data acquisition system and specimen was loaded at required rate by using the loading wheel.

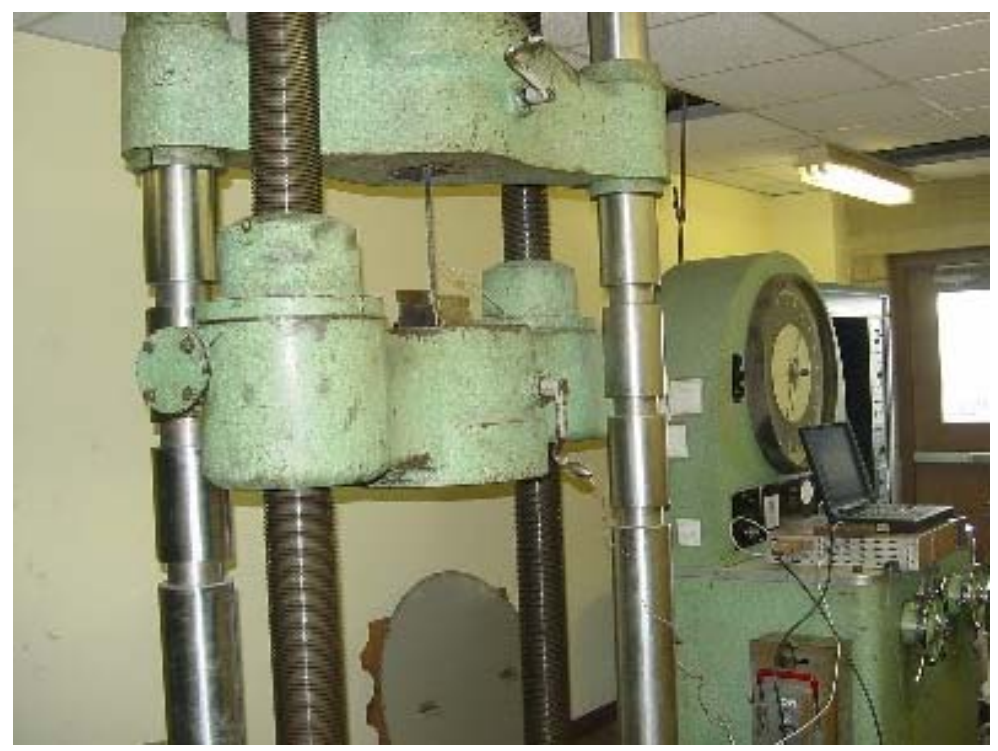

Figure 4-18 Strip Tension Test - Baldwin Machine

\subsubsection{Infrared Thermography Test}

Infrared thermography tests were conducted to determine delamination/debonding between FRP wrap and concrete surface interface. The tests were conducted by placing the specimen on a table and moving the camera around four quadrant surfaces of the specimen. The camera was set to record the images at a distance of 2' and the specimens were set accordingly. The first set of tests was done to determine the rate of exothermic reaction and the images were recorded every hour. The captured images showed a temperature profile, which was used to observe the exothermic reaction of the cross linking epoxy. Debonding between the fiber wrap 
and concrete surface was examined by using an external source (quartz heater) of heating followed by infrared imaging. Brighter regions of higher temperature seen in the infrared camera were characterized as debonds/delaminations.

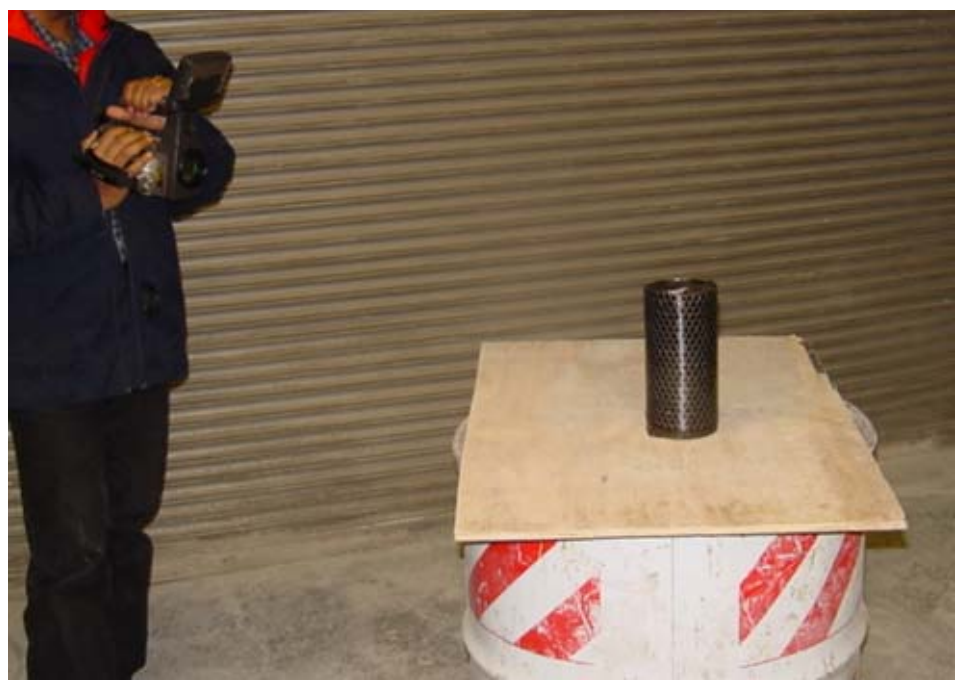

Figure 4-19 Infrared Thermography Tests: Along the Circumference of the Wrapped Cylinder

\subsection{Summary}

Specimen preparations for different tests were discussed in this chapter. Specimen dimensions and test instrumentation and procedures of conducting compression, tension, aging and infrared thermography were also discussed. Results from the tests and analysis and discussions of those results are provided in chapter 5. 


\section{TEST RESULTS AND ANALYSIS}

\subsection{Introduction}

Results of the compression tests conducted on the wrapped and non-wrapped cylinder specimens are given in this chapter in the form of tables and graphs. All specimens were hand wrapped and there was no pretension in the wrap. Results are discussed by comparing load, strain, stiffness etc. of wrapped and non-wrapped specimens, prepared with and without internal reinforcement. Axial compression tests of cylinders are tabulated in terms of: 1) concrete compressive strength $\left.\left(f_{c}^{\prime}\right), 2\right)$ fiber orientation of CFRP wrap, 3) cylinder size, 4) number of CFRP wraps, 5) height of wrapping by providing gaps at top and bottom or in the middle of specimen, 6) degree of fiber wetting and, 7) degree of bonding of wrap to concrete surface. The results from freeze thaw condition and elevated temperature $\left(175^{\circ} \mathrm{F}\right)$ aging have also been

tabulated. Infrared thermography tests were done to determine the delaminated areas between concrete and FRP wrap, either during wrapping of due to aging. The results of different tests conducted to verify various parameters of confinement and aging are discussed and analyzed.

\subsection{Axial Compression Tests to Determine Effect of Confinement}

Axial compression tests were conducted on the wrapped and non-wrapped specimens and the effect of confinement due to internal hoop reinforcement and external CFRP sheet was determined in terms of maximum strength, strain and stiffness. 


\subsubsection{Ultimate Load}

Ultimate load carrying capacity of the cylinder specimens was noted from the dial gauge when the specimen failed under compressive force. Values of load were also recorded continuously from the load cell attached to the data acquisition system, as shown in Figure 4-17.

\subsubsection{Strength of Control Specimens}

Ultimate strength of the control specimens without wrapping is shown in Table 5-1. The average of 3 compression tests conducted on the specimens is given below. The tested specimens were 4" in diameter and 8" in height and two batches with compressive strength of 4500 and 8000 psi were tested. As example, specimen designation B1-P-4C1 stands for batch $1\left(f_{c}^{\prime}=\right.$ $4500 \mathrm{psi})$ diameter and specimens number 1 . Similarly B1-R-4C2 $\left(f_{c}{ }^{\prime}=8000 \mathrm{psi}\right)$ represents the reinforcement in the cylinder with the letter R. Similarly all specimens were given notations.

Table 5-1 Strength of Control Specimens (Effect of Confinement)

\begin{tabular}{|c|c|c|c|c|c|}
\hline No & Designation & Axial Strength (lbs) & Axial Stress $f_{c}^{\prime}(\mathrm{psi})$ & $\begin{array}{l}\text { Average Axial } \\
\text { Strength (lbs) }\end{array}$ & $\begin{array}{l}\text { Average Axial } \\
\text { Stress (psi) }\end{array}$ \\
\hline 1 & B1-P-4C1 & 56900 & 4528 & \multirow{3}{*}{56895} & \multirow{3}{*}{4527} \\
\hline 2 & B1-P-4C2 & 56885 & 4527 & & \\
\hline 3 & B1-P-4C3 & 56895 & 4527 & & \\
\hline 4 & B1-R-4C1 & 66800 & 5316 & \multirow{3}{*}{66834} & \multirow{3}{*}{5318} \\
\hline 5 & B1-R-4C2 & 66700 & 5308 & & \\
\hline 6 & B1-R-4C3 & 67000 & 5332 & & \\
\hline 7 & B2-P-4C1 & 97650 & 7771 & \multirow{3}{*}{97600} & \multirow{3}{*}{7767} \\
\hline 8 & B2-P-4C2 & 98760 & 7860 & & \\
\hline 9 & B2-P-4C3 & 96390 & 7670 & & \\
\hline 10 & $\mathrm{~B} 2-\mathrm{R}-4 \mathrm{C} 1$ & 109400 & 8706 & \multirow{3}{*}{108350} & \multirow{3}{*}{8622} \\
\hline 11 & B2-R-4C2 & 104350 & 8304 & & \\
\hline 12 & B2-R-4C3 & 111300 & 8857 & & \\
\hline
\end{tabular}




\subsubsection{Strength of Control Specimens}

The plain concrete specimens from batch $1\left(f_{c}{ }^{\prime}=4527 \mathrm{psi}\right)$ and batch $2\left(f_{c}{ }^{\prime}=7766 \mathrm{psi}\right)$ were tested in compression and the following trends are drawn after analysis of the results.

- Reinforced concrete of higher compressive strength (batch $2, f_{c}{ }^{\prime}=7766 \mathrm{psi}$ ) showed an average increase in strength by about $11 \%$ when compared with the plain concrete specimens while the specimens of lower compressive strength (batch $1, f_{c}{ }^{\prime}=4527 \mathrm{psi}$ ) showed an increase of $17 \%$ in strength when compared to the plain concrete specimens

- However, Both the batches of concrete cylinders show an increase in strength due to internal confinement by the steel mesh in an average of about 10 kips.

\subsubsection{Strength of Wrapped Specimens}

The specimens with wrapped in $0^{\circ}$ direction ( 1 and 3 wraps) and wraps in $45^{\circ}$ ( 1 wrap) and $\pm 45^{\circ}$ ( 2 wraps) direction were tested in axial compression and the ultimate strengths of the specimens are shown in Table 5-2 and 5-3. Specimen designation B1-P-4S1 stands for batch1 $\left(f_{c}^{\prime}=4500 \mathrm{psi}\right)$ diameter and specimen number 1 . Similarly B2-R-4S2 represents the reinforcement in the cylinder with the letter $\mathrm{R}\left(f_{c}{ }^{\prime}=8000 \mathrm{psi}\right)$. The wrapped specimens are compared to the control specimens of each particular batch. The control specimens (without wrap) are designated with a $\mathrm{C}$ while the wrapped specimens are designated with an $\mathrm{S}$. 
Table 5-2 Comparison of Axial Strength of Plain and Reinforced Cylinders with Control Specimens of Batch 1(Effect of Confinement)

\begin{tabular}{|c|c|c|c|c|c|c|c|c|}
\hline No & Designation & $\begin{array}{l}\text { No of } \\
\text { Fiber } \\
\text { Layers }\end{array}$ & $\begin{array}{c}\text { Orientation of } \\
\text { Fiber } \\
\text { Direction }\end{array}$ & $\begin{array}{c}\text { Axial } \\
\text { Strength (lbs) }\end{array}$ & $\begin{array}{l}\text { Percent } \\
\text { Strength } \\
\text { Increase }\end{array}$ & $\begin{array}{l}\text { Average \% } \\
\text { Strength } \\
\text { Increase }\end{array}$ & $\begin{array}{c}\text { Average } \\
\% \\
\text { Strength } \\
\text { increase } \\
\text { per } \\
\text { Layer } \\
\end{array}$ & $\begin{array}{l}\text { Increase } \\
\text { in } \\
\text { strength }\end{array}$ \\
\hline 1 & B1-P-4S1 & \multirow{4}{*}{1} & \multirow{2}{*}{0 Degree } & 90050 & 58.3 & \multirow{2}{*}{52.85} & \multirow{2}{*}{52.85} & \multirow{2}{*}{1.53} \\
\hline 2 & B1-P-4S2 & & & 83875 & 47.4 & & & \\
\hline 3 & B1-P-4S3 & & & 57800 & 1.6 & & & \\
\hline 4 & B1-P-4S4 & & 45 Degree & 56600 & -0.48 & 0.56 & 0.56 & 1.005 \\
\hline 5 & B1-P-4S5 & \multirow{2}{*}{3} & \multirow{2}{*}{0 Degree } & 160875 & 182.8 & \multirow{2}{*}{187.02} & \multirow{2}{*}{62.3} & \multirow{2}{*}{2.86} \\
\hline 6 & B1-P-4S6 & & & 165650 & 191.25 & & & \\
\hline 7 & B1-P-4S7 & \multirow{2}{*}{2} & \multirow{2}{*}{ \pm 45 Degree } & 61200 & 7.6 & \multirow{2}{*}{10.5} & \multirow{2}{*}{5.25} & \multirow{2}{*}{1.1} \\
\hline 8 & B1-P-4S8 & & & 64550 & 13.47 & & & \\
\hline 9 & B1-R-4S1 & \multirow{4}{*}{1} & \multirow{2}{*}{0 Degree } & 109524.96 & 63 & \multirow{2}{*}{55.35} & \multirow{2}{*}{53.35} & \multirow{2}{*}{1.56} \\
\hline 10 & B1-R-4S2 & & & 98769.091 & 47.7 & & & \\
\hline 11 & B1-R-4S3 & & \multirow{2}{*}{45 Degree } & 70199.89 & 5 & \multirow{2}{*}{0} & \multirow{2}{*}{0} & \multirow{2}{*}{1.00} \\
\hline 12 & B1-R-4S4 & & & 62973.35 & $-5^{*}$ & & & \\
\hline 13 & B1-R-4S5 & \multirow{2}{*}{3} & \multirow{2}{*}{0 Degree } & 163999.9 & 145 & \multirow{2}{*}{129.5} & \multirow{2}{*}{43.16} & \multirow{2}{*}{2.3} \\
\hline 14 & B1-R-4S6 & & & 143174.9 & 114 & & & \\
\hline 15 & B1-R-4S7 & \multirow{2}{*}{2} & \multirow{2}{*}{ \pm 45 Degree } & 80440.16 & 20 & \multirow{2}{*}{17} & \multirow{2}{*}{8.5} & \multirow{2}{*}{1.17} \\
\hline 16 & B1-R-4S8 & & & 76731.14 & 14 & & & \\
\hline
\end{tabular}

* Stress reduction is within statistical limit of the result for a single specimen

$>$ Plain cylinders wrapped with 1 layer of CFRP with fibers in $0^{\circ}$ direction show an average percent increase in strength of $44 \%$ and with 3 layers average percent increase was $161 \%$. The increase in strength per layer is $53 \%$

Plain concrete cylinders wrapped with $+45^{\circ}$ fiber direction fabric shows no significant increase in the strength. While plain concrete cylinders wrapped with $\pm 45^{\circ}$ fiber directions show an increase of $13.6 \%$.

Reinforced concrete cylinders wrapped with 1 layer of CFRP with fibers in $0^{\circ}$ direction show an increase in strength of $44.7 \%$ while cylinders with 3 layers show an increase of $150.25 \%$. Each layer shows an increase of $50.08 \%$.

Reinforced concrete cylinders wrapped with $+45^{\circ}$ fiber direction fabric shows no increase in strength while reinforced concrete cylinders wrapped with $\pm 45^{\circ}$ fiber directions show an average increase of $11.6 \%$. 
The cylinders of lower compressive strength show a higher increase in the effect of confinement due to wrapping in both plain and reinforced concrete cylinders

Cylinders with 3 layers of $0^{\circ}$ wrap have maximum increase in strength. Increase in strength of $45^{\circ}$ wraps when compared to $0^{\circ}$ wraps are much lesser (Table 5-2 and 5-3) indicating better confinement with $0^{\circ}$ wraps leading to increased axial load capacity as compared to $45^{\circ}$ wraps.

Table 5-3 Comparison of Axial Strength of Plain and Reinforced Cylinders with Control Specimens of Batch 2 (Effect of Confinement)

\begin{tabular}{|c|c|c|c|c|c|c|c|c|}
\hline No & Designation & $\begin{array}{l}\text { No of } \\
\text { Fiber } \\
\text { Layers }\end{array}$ & $\begin{array}{l}\text { Orientation of } \\
\text { Fiber } \\
\text { Direction }\end{array}$ & $\begin{array}{l}\text { Axial Strength } \\
\text { (lbs) }\end{array}$ & $\begin{array}{l}\text { Percent } \\
\text { Strength } \\
\text { Increase }\end{array}$ & $\begin{array}{l}\text { Average } \\
\quad \% \\
\text { Increase }\end{array}$ & $\begin{array}{c}\text { Increase } \\
\text { in } \% \\
\text { Strength } \\
\text { per } \\
\text { layer }\end{array}$ & $\begin{array}{l}\text { Increase } \\
\quad \text { in } \\
\text { Strength }\end{array}$ \\
\hline 1 & B2-P-4S1 & \multirow{6}{*}{1} & \multirow{3}{*}{0 Degree } & 130625 & 33.83 & \multirow{3}{*}{36.17} & \multirow{3}{*}{36.17} & \multirow{3}{*}{1.36} \\
\hline 2 & B2-P-4S2 & & & 132875 & 36.14 & & & \\
\hline 3 & B2-P-4S3 & & & 135225 & 38.55 & & & \\
\hline 4 & B2-P-4S4 & & \multirow{3}{*}{45 Degree } & 99300 & 3.6 & \multirow{3}{*}{3.6} & \multirow{3}{*}{3.6} & \multirow{3}{*}{1.01} \\
\hline 5 & B2-P-4S5 & & & 99225 & 3.4 & & & \\
\hline 6 & B2-P-4S6 & & & 99725 & 3.8 & & & \\
\hline 7 & B2-P-4S7 & \multirow{2}{*}{3} & \multirow{2}{*}{0 Degree } & 231900 & 137.6 & \multirow{2}{*}{134.8} & \multirow{2}{*}{44.9} & \multirow{2}{*}{2.35} \\
\hline 8 & B2-P-4S8 & & & 226500 & 132.07 & & & \\
\hline 9 & B2-P-4S9 & \multirow{3}{*}{2} & \multirow{3}{*}{ \pm 45 Degree } & 113025 & 15.8 & \multirow{3}{*}{16.8} & \multirow{3}{*}{8.4} & \multirow{3}{*}{1.16} \\
\hline 10 & B2-P-4S10 & & & 111275 & 14.01 & & & \\
\hline 11 & B2-P-4S11 & & & 117800 & 20.69 & & & \\
\hline 12 & B2-R-4S1 & \multirow{6}{*}{1} & \multirow{3}{*}{0 Degree } & 161600 & 49.14 & \multirow{3}{*}{42} & \multirow{3}{*}{42} & \multirow{3}{*}{1.42} \\
\hline 13 & B2-R-4S2 & & & 161150 & 48.73 & & & \\
\hline 14 & B2-R-4S3 & & & 140325 & 29.51 & & & \\
\hline 15 & B2-R-4S4 & & \multirow{3}{*}{45 Degree } & 107300 & -0.97 & \multirow{3}{*}{2.8} & \multirow{3}{*}{2.8} & \multirow{3}{*}{1.04} \\
\hline 16 & B2-R-4S5 & & & 118500 & 9.36 & & & \\
\hline 17 & B2-R-4S6 & & & 111800 & 8.36 & & & \\
\hline 18 & B2-R-4S7 & \multirow{2}{*}{3} & \multirow{2}{*}{0 Degree } & 226825 & 109.34 & \multirow{2}{*}{108} & \multirow{2}{*}{36} & \multirow{2}{*}{2.08} \\
\hline 19 & B2-R-4S8 & & & 224625 & 107.31 & & & \\
\hline 20 & B2-R-4S9 & & & 116525 & 7.5 & & & \\
\hline 21 & B2-R-4S10 & 2 & \pm 45 Degree & 113400 & 4.6 & 6.2 & 3.1 & 1.06 \\
\hline 22 & B2-R-4S11 & & & 115600 & 6.6 & & & \\
\hline
\end{tabular}




\subsubsection{Load/Strain Curves}

The compressive tests were conducted on the specimens and the test results of load and strain are plotted and plots of stress and strain are provided in appendix A.

\subsubsection{Load Strain Plots of Control Specimen}

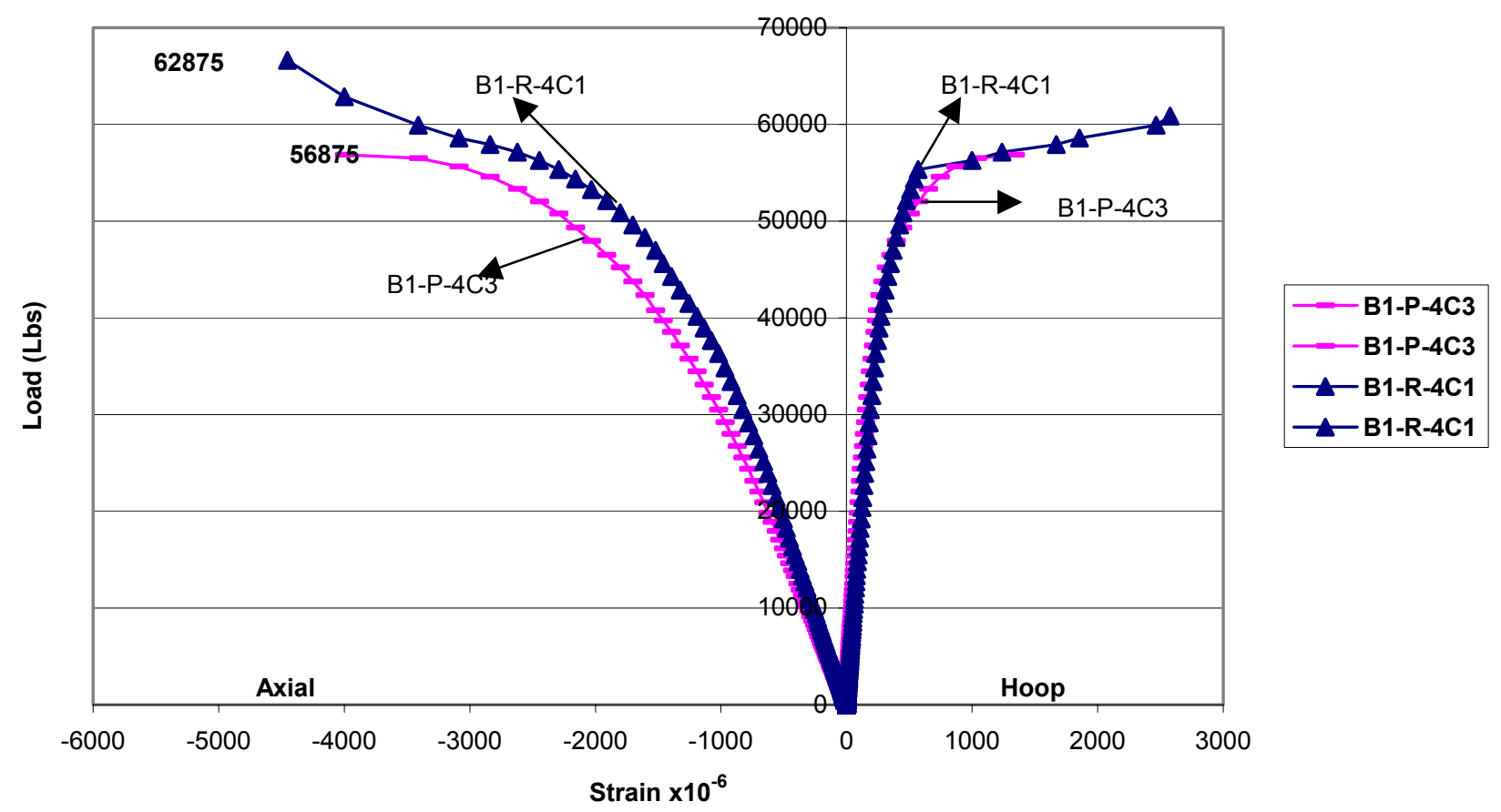

Figure 5-1 Load Strain Plots of Control Specimen: Batch 1 - Plain and Reinforced Non Wrapped Concrete Cylinders 


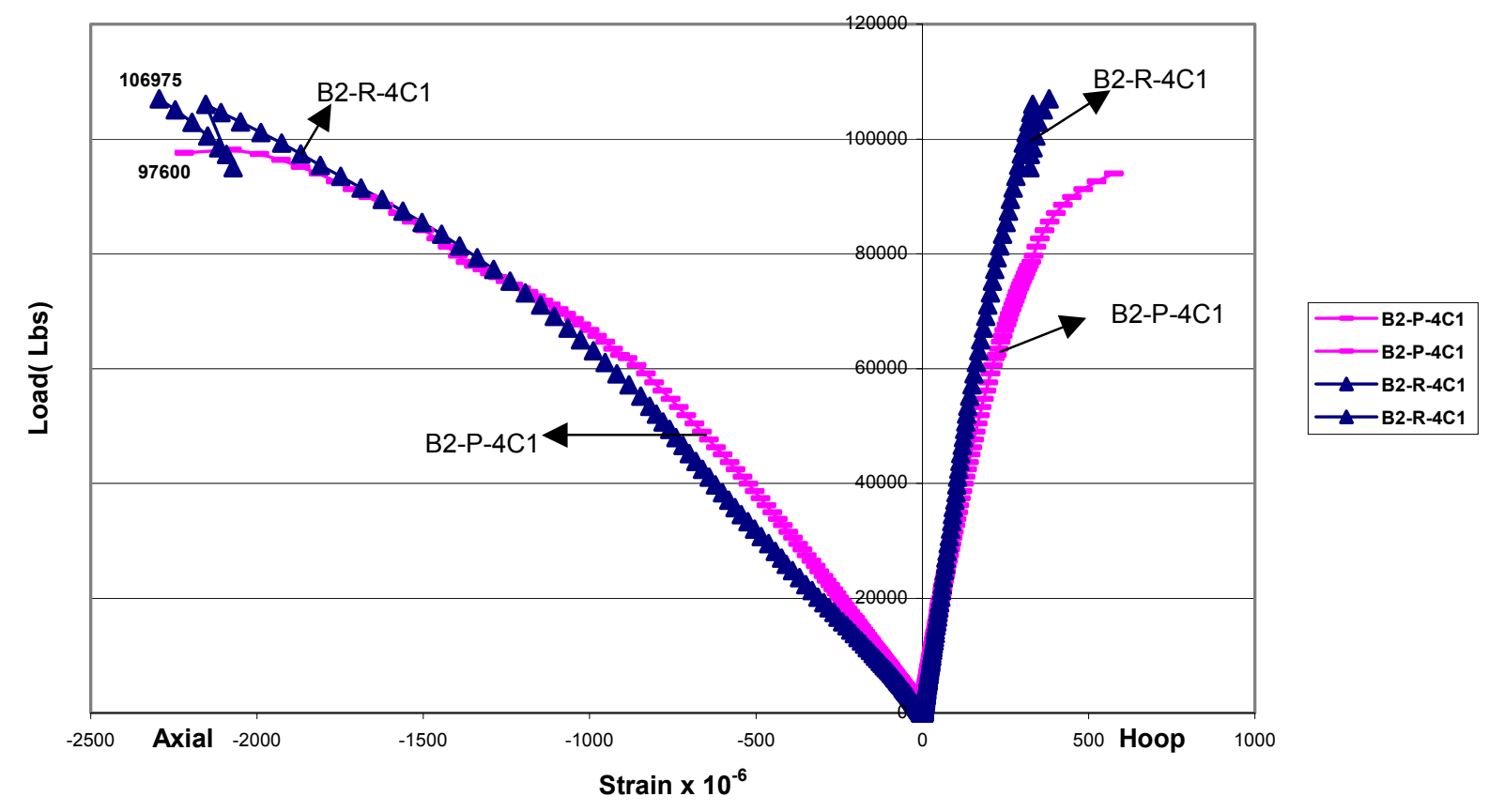

Figure 5-2 Load Strain plots of Control Specimen: Batch 2 - Plain and Reinforced Non Wrapped Concrete Cylinders

\subsubsection{Load Strain Plots of Wrapped Specimens}

Load strain plots of the wrapped specimens were compared with non-wrapped specimens and increases in strength and ductility were evaluated. The plots of 0 -degree wraps with 1 and 3 layers and 45-degree wraps with 1 layer and 2 layers are plotted against the non wrapped control specimens and the results of the effects of confinement are evaluated and shown in Figure 5-3 to Figure 5-18. 

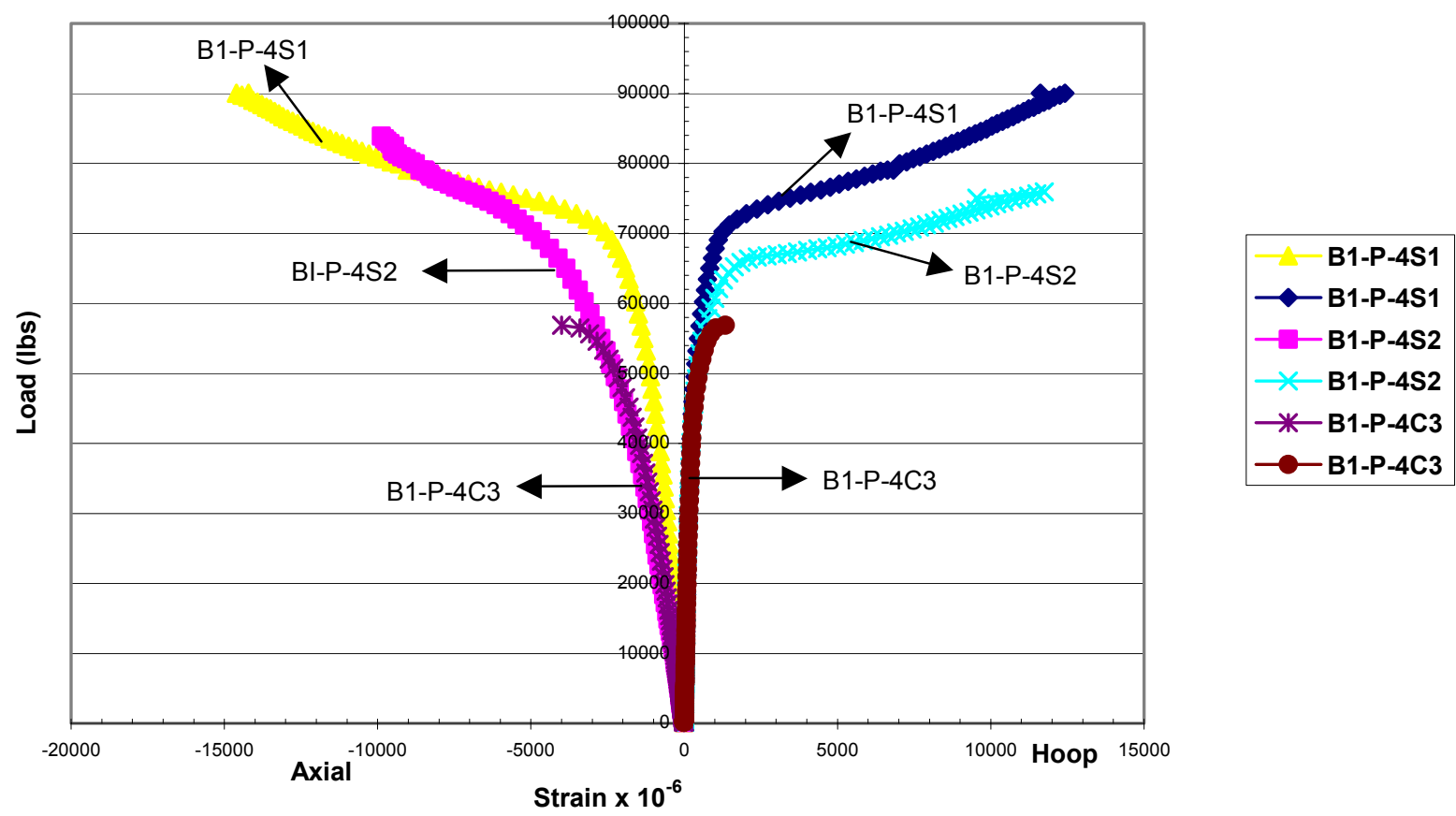

Figure 5-3 Load-Strain Comparison of 1 layer $-0^{\circ}$ Wrapped PCC Specimen with Control Specimen - Batch 1
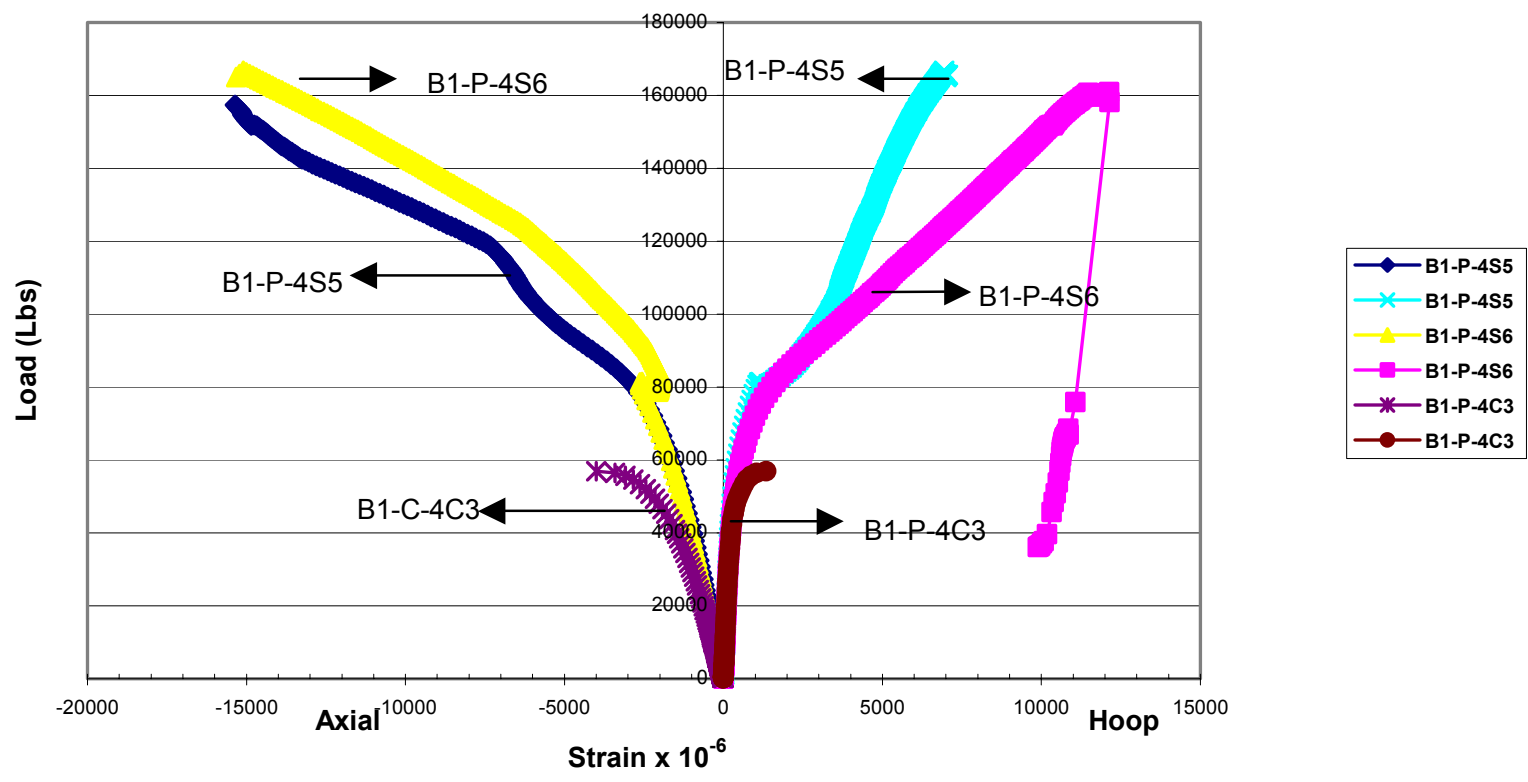

Figure 5-4 Load-Strain Comparison of 3 Layer - $0^{\circ}$ wrapped PCC Specimen with Control Specimen - Batch 1 

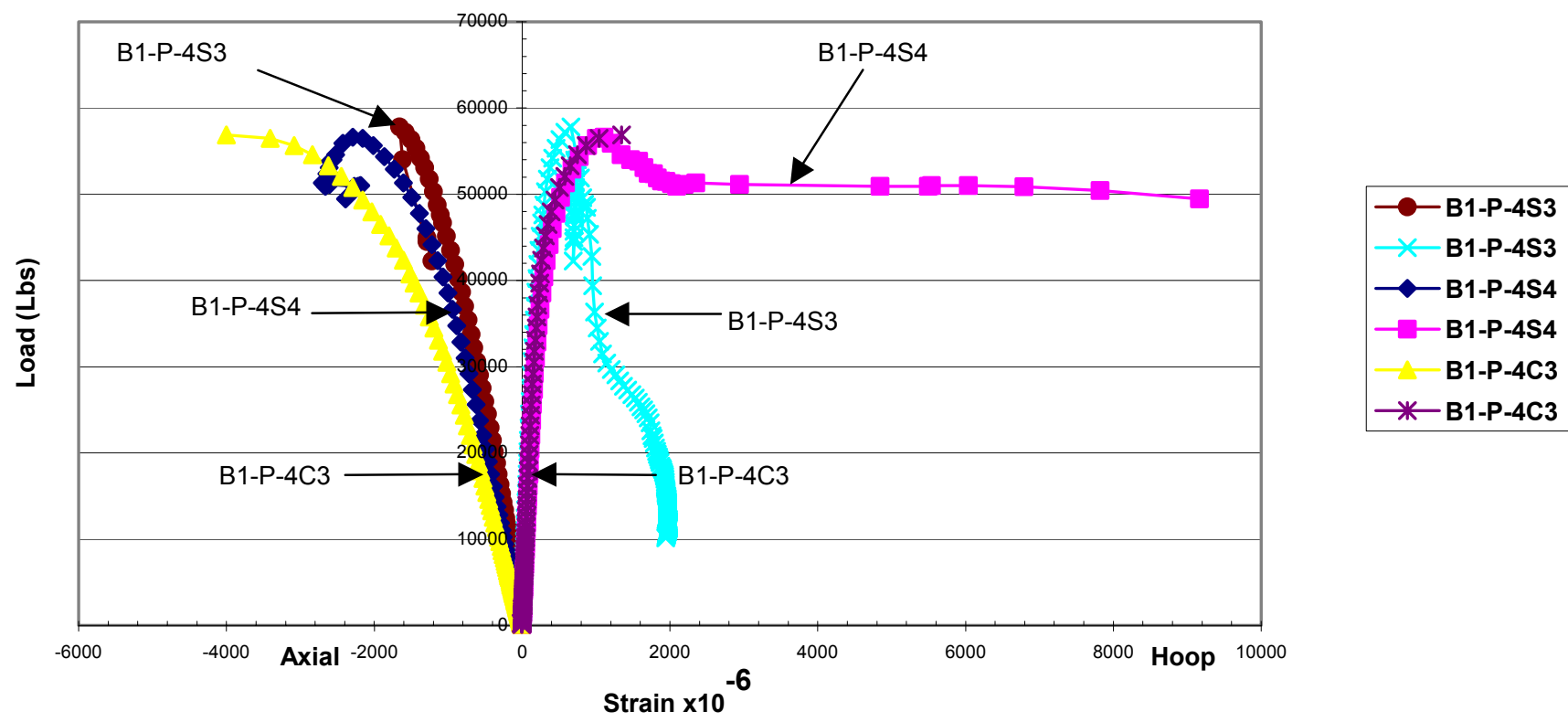

Figure 5-5 Load-Strain Comparison of 1 Layer $-4^{\circ}$ Wrapped PCC Specimen with Control Specimen - Batch 1

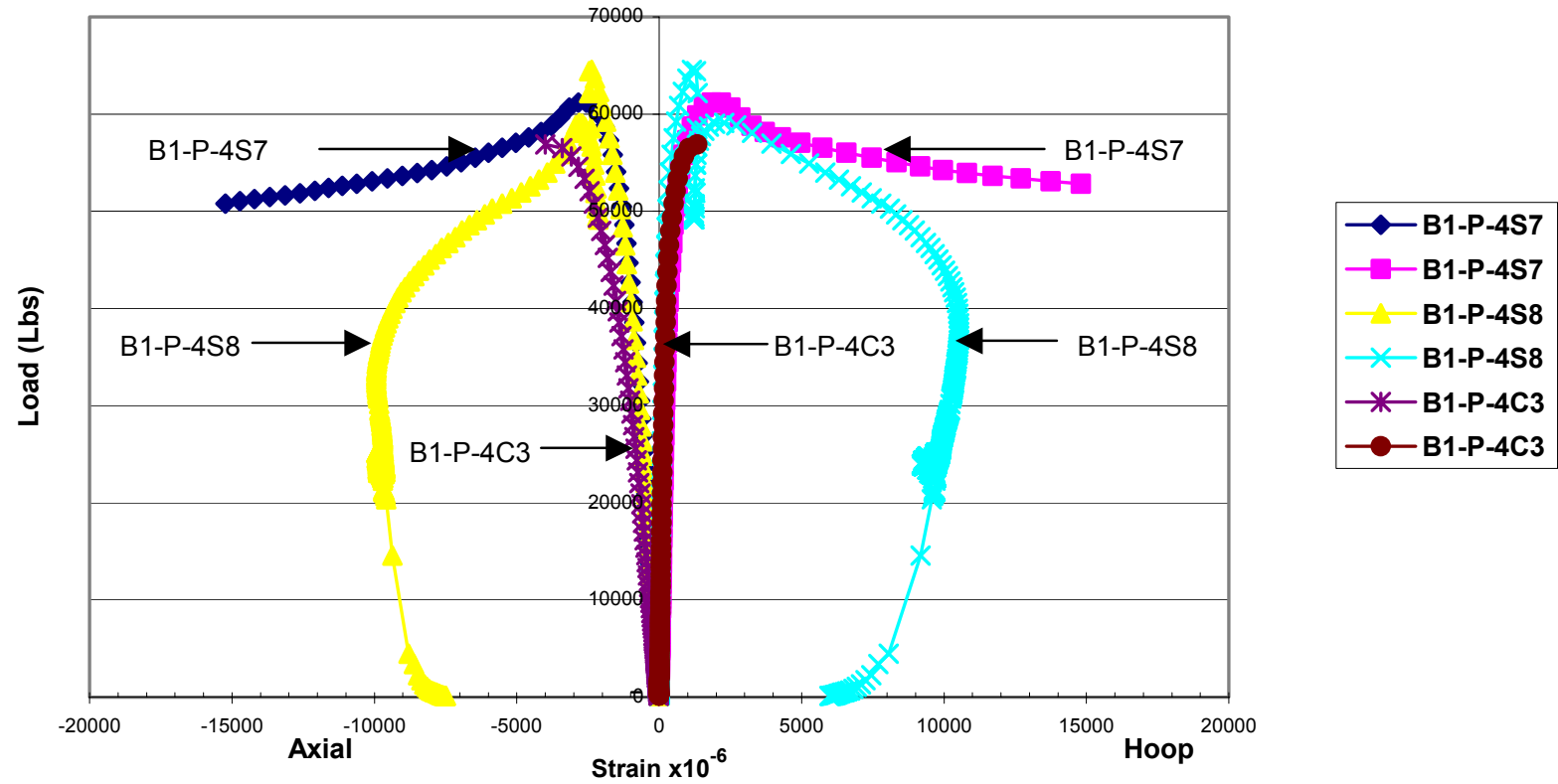

Figure 5-6 Load Strain Comparison of 2 Layer $\pm 45^{\circ}$ Wrapped PCC Specimen with Control Specimen - Batch 1 


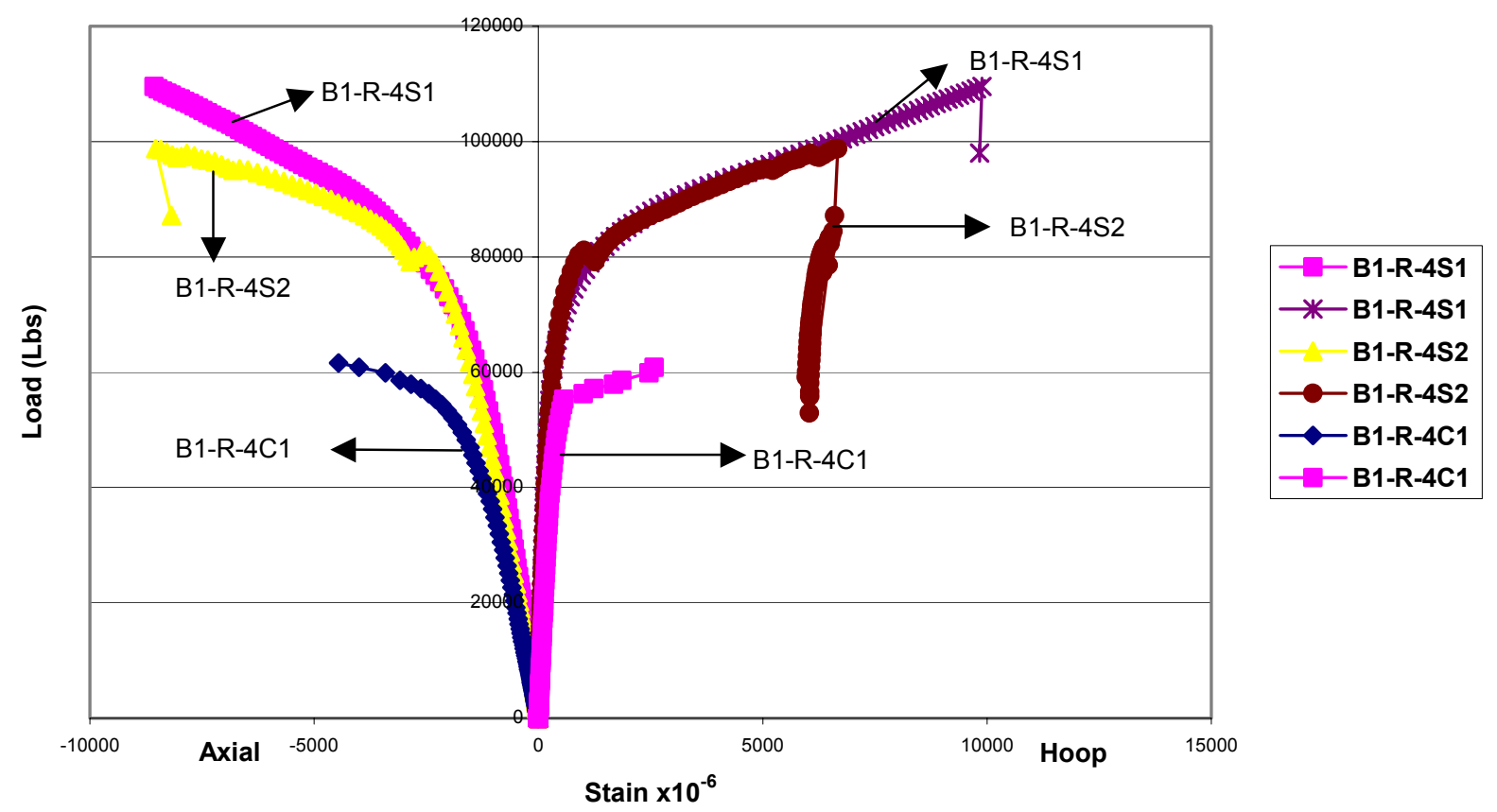

Figure 5-7 Load Strain Comparison of 1 Layer- ${ }^{\circ}$ Wrapped RCC Specimen with Control Specimen - Batch 1

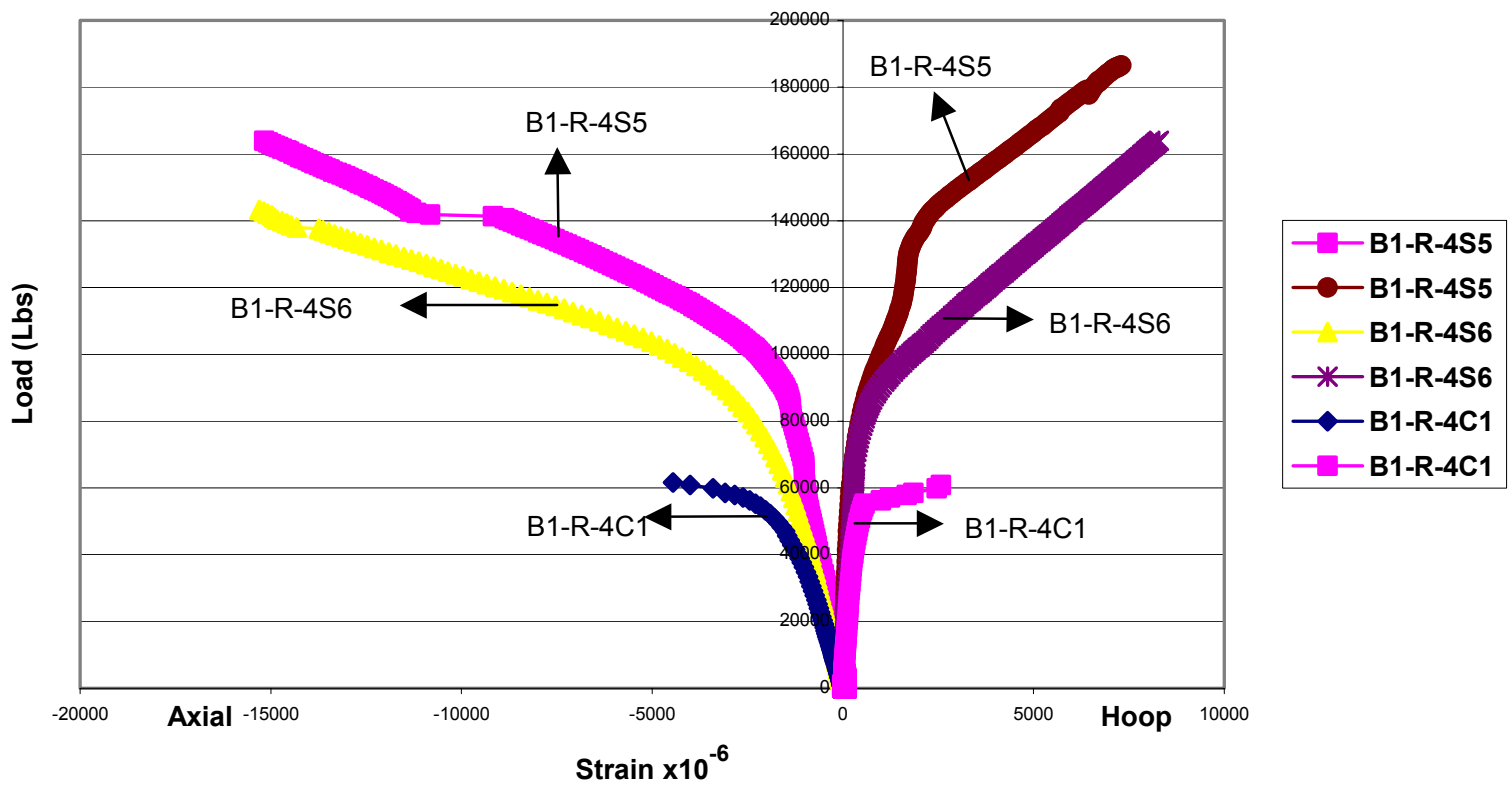

Figure 5-8 Load -Strain Comparison of 3 Layer - $0^{\circ}$ Wrapped RCC Specimen with Control Specimen - Batch 1 


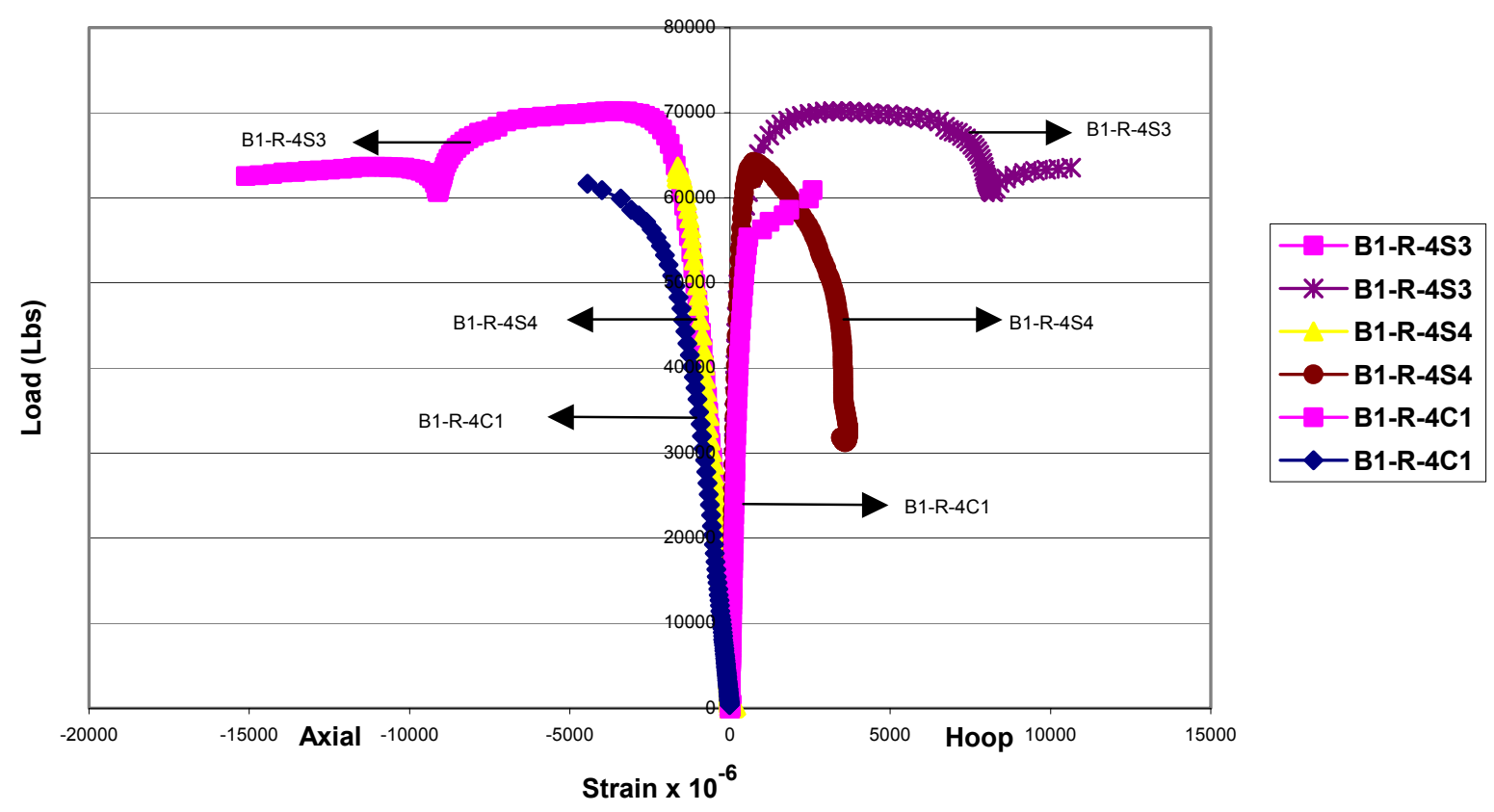

Figure 5-9 Load Strain Comparison of 1 Layer $-45^{\circ}$ Wrapped RCC Specimen with Control Specimen - Batch 1
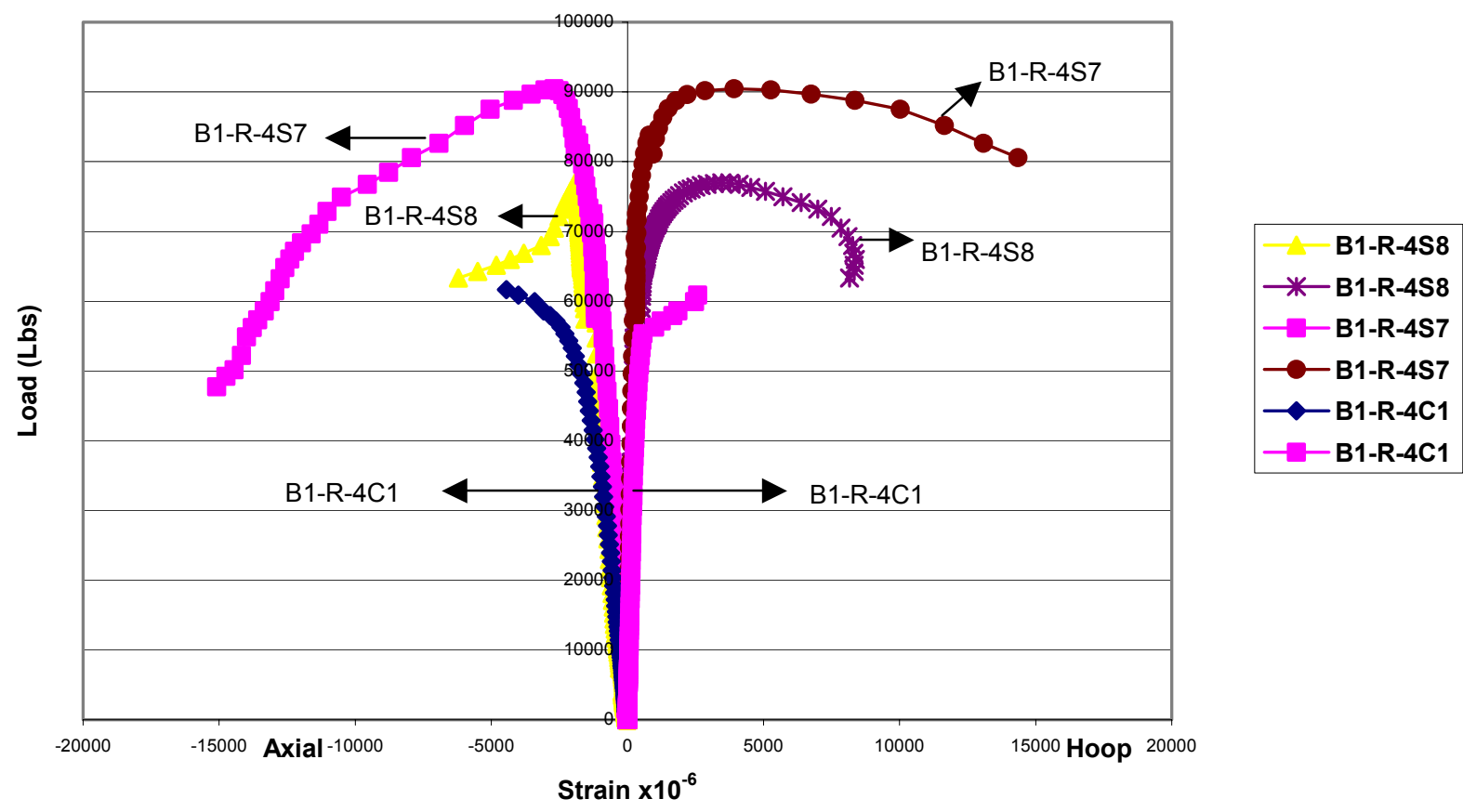

Figure 5-10 Load Strain Comparison of 2 Layer $\pm 45^{\circ}$ Wrapped RCC Specimen with Control Specimen- Batch 1 


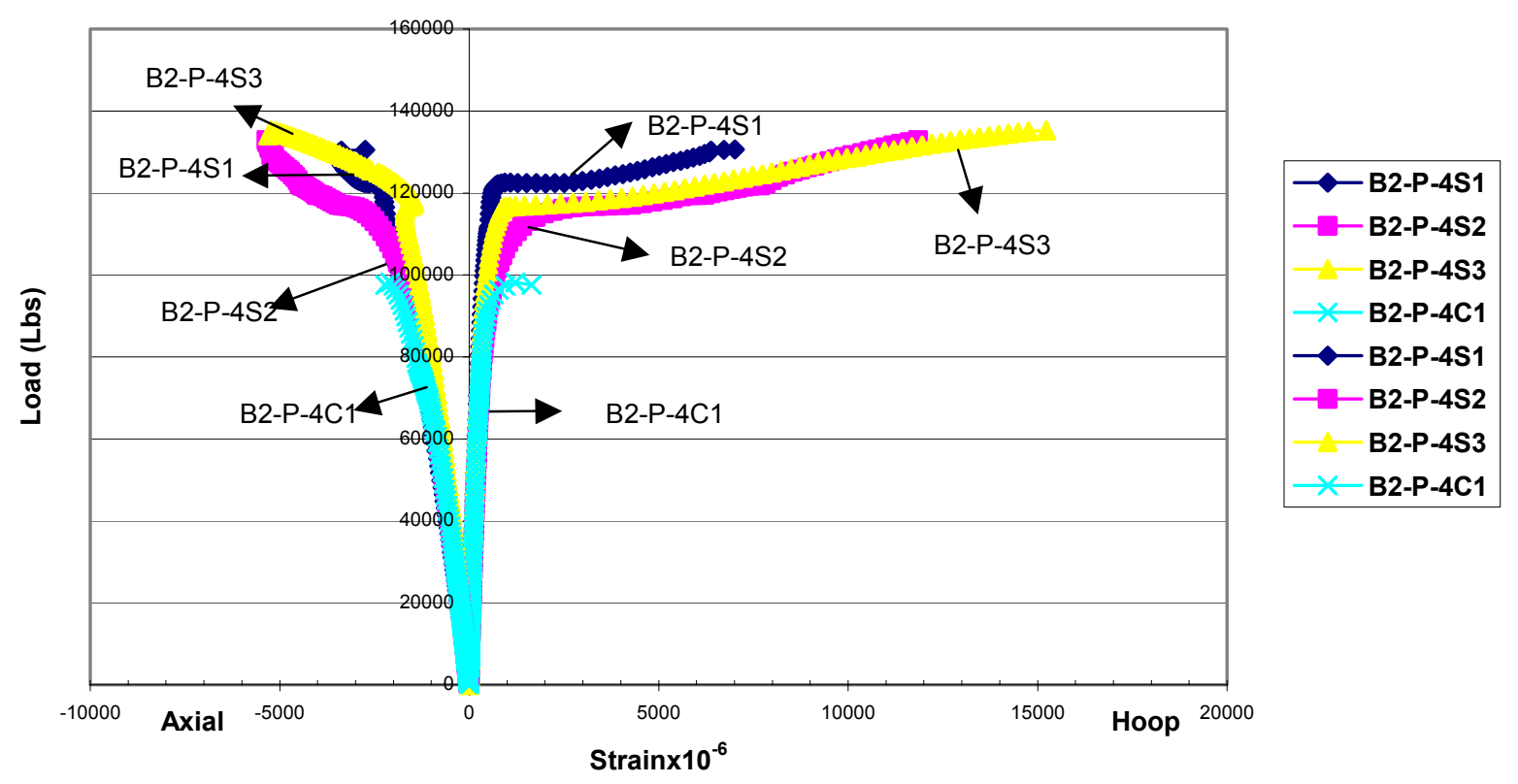

Figure 5-11 Load Strain Comparison of 1 layer - $0^{\circ}$ Wrapped PCC Specimen with Control Specimen - Batch 2

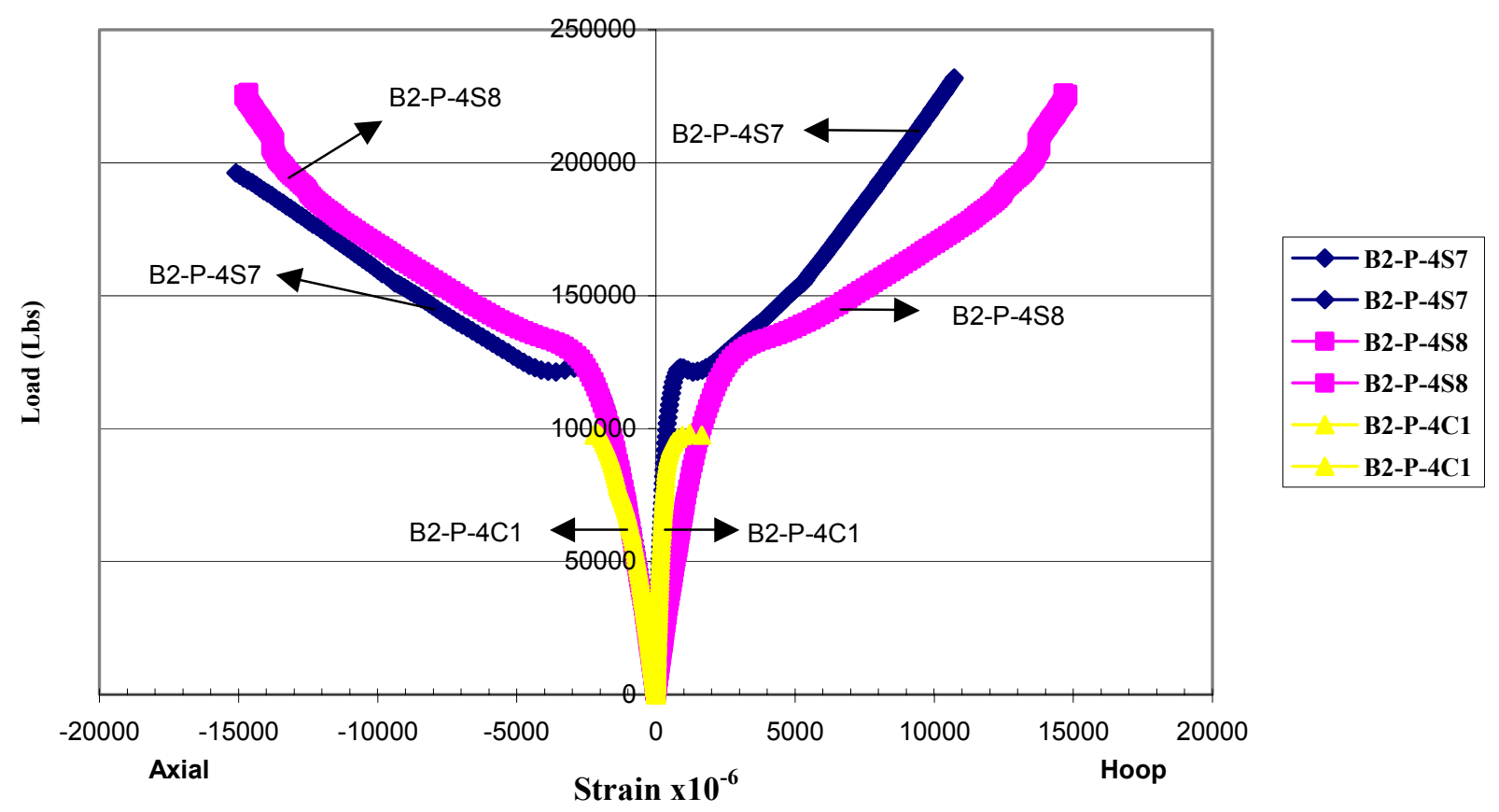

Figure 5-12 Load Strain Comparison of 3 layers - $0^{\circ}$ Wrapped PCC Specimen with Control Specimen - Batch 2 


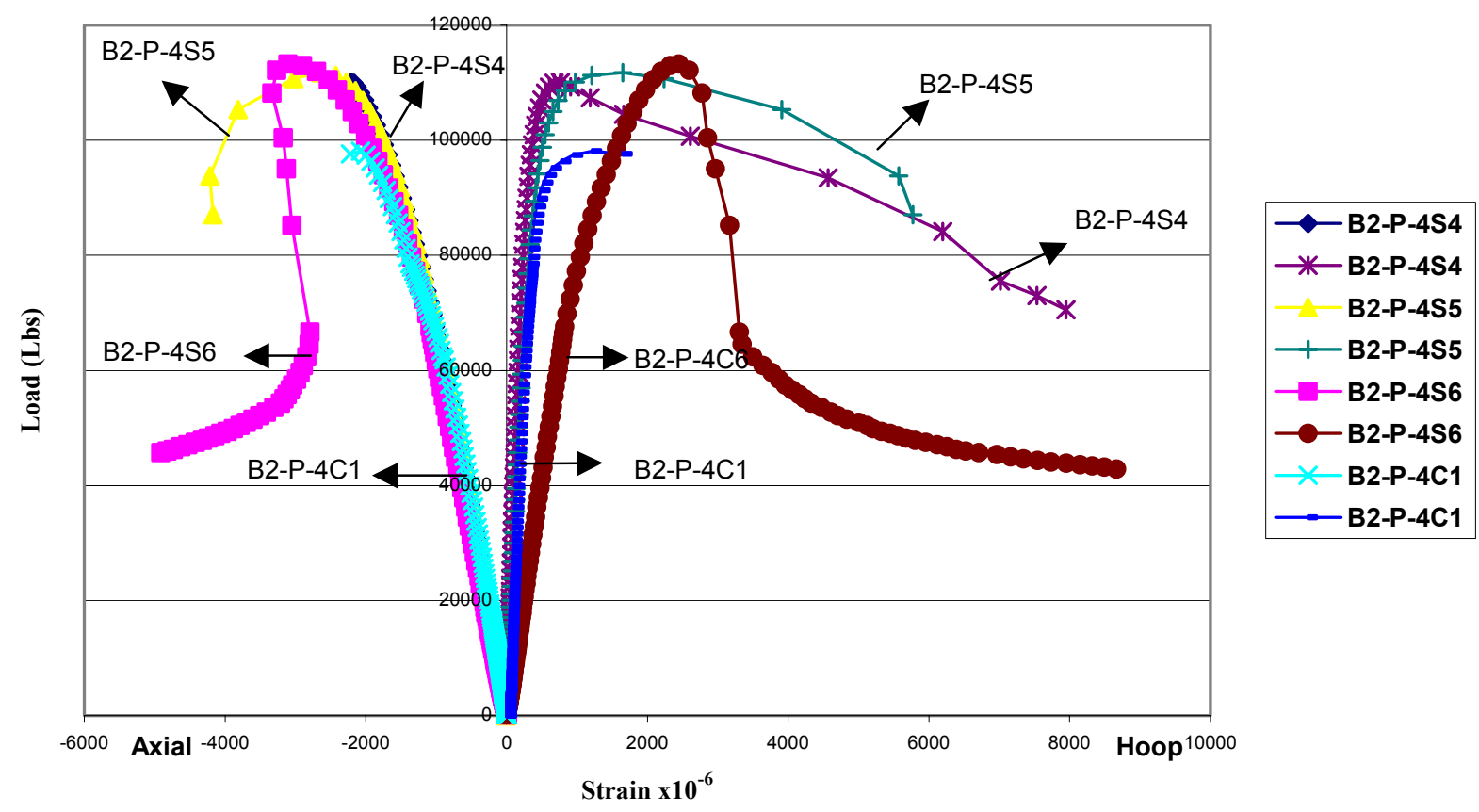

Figure 5-13 Load Strain Comparison of 1 layer $45^{\circ}$ Wrapped PCC Specimen with Control Specimen - Batch 2

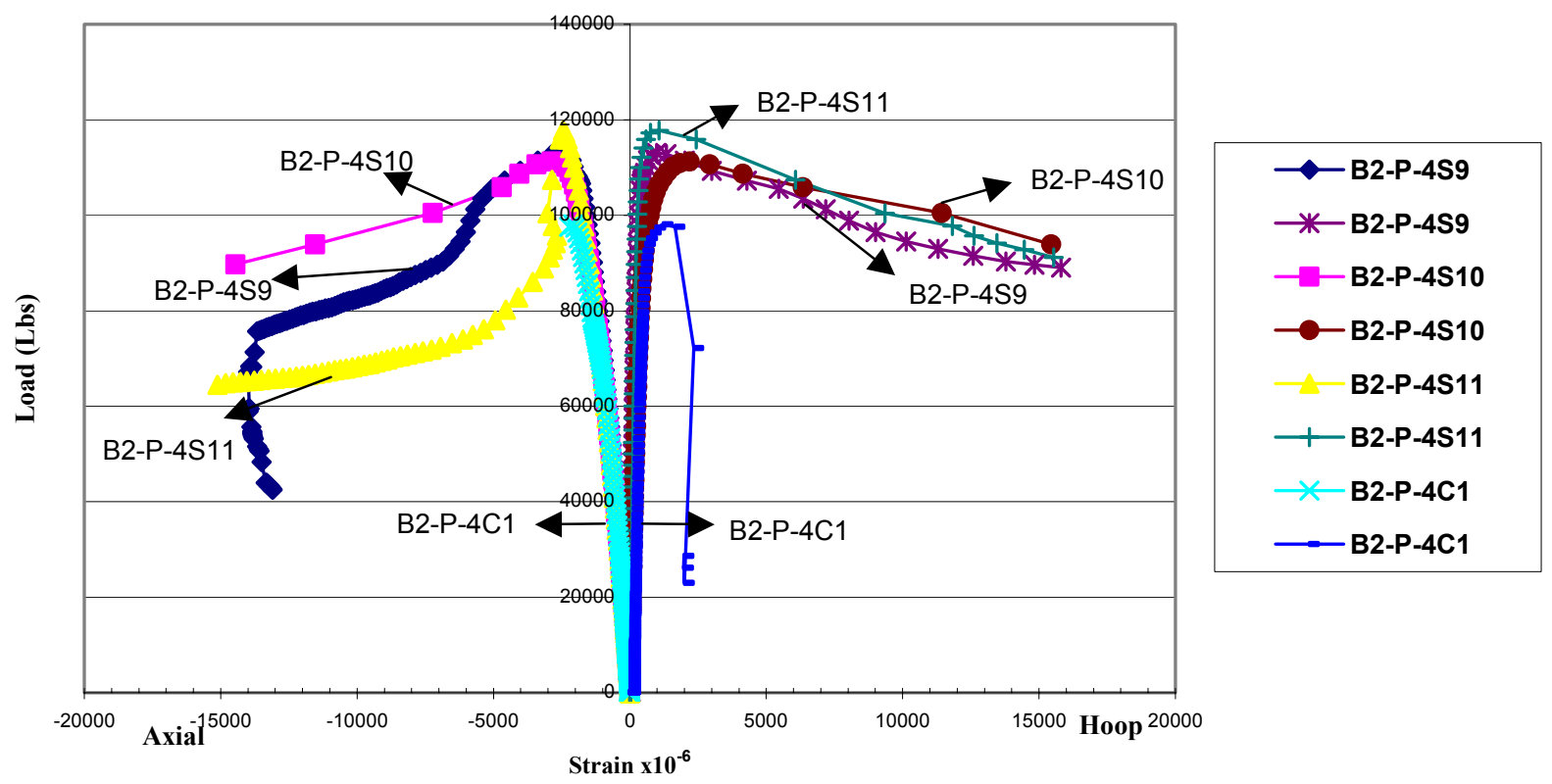

Figure 5-14 Load Strain Comparison of 2 Layer $\pm 45^{\circ}$ Wrapped PCC Specimen with Control Specimen- Batch 2 


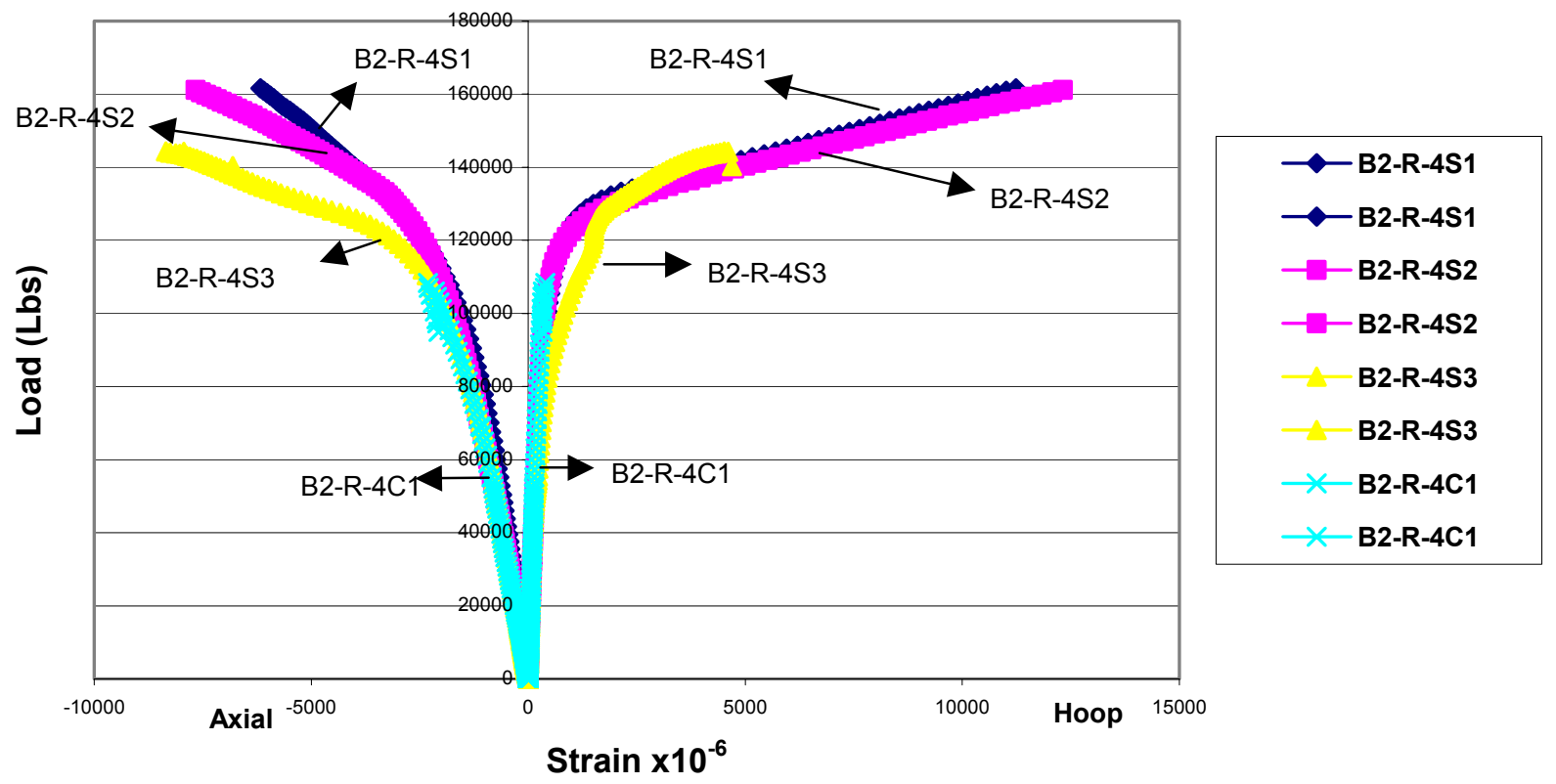

Figure 5-15 Load Strain Comparison of 1 layer - $0^{\circ}$ Wrapped RCC Specimen with Control Specimen - Batch 2

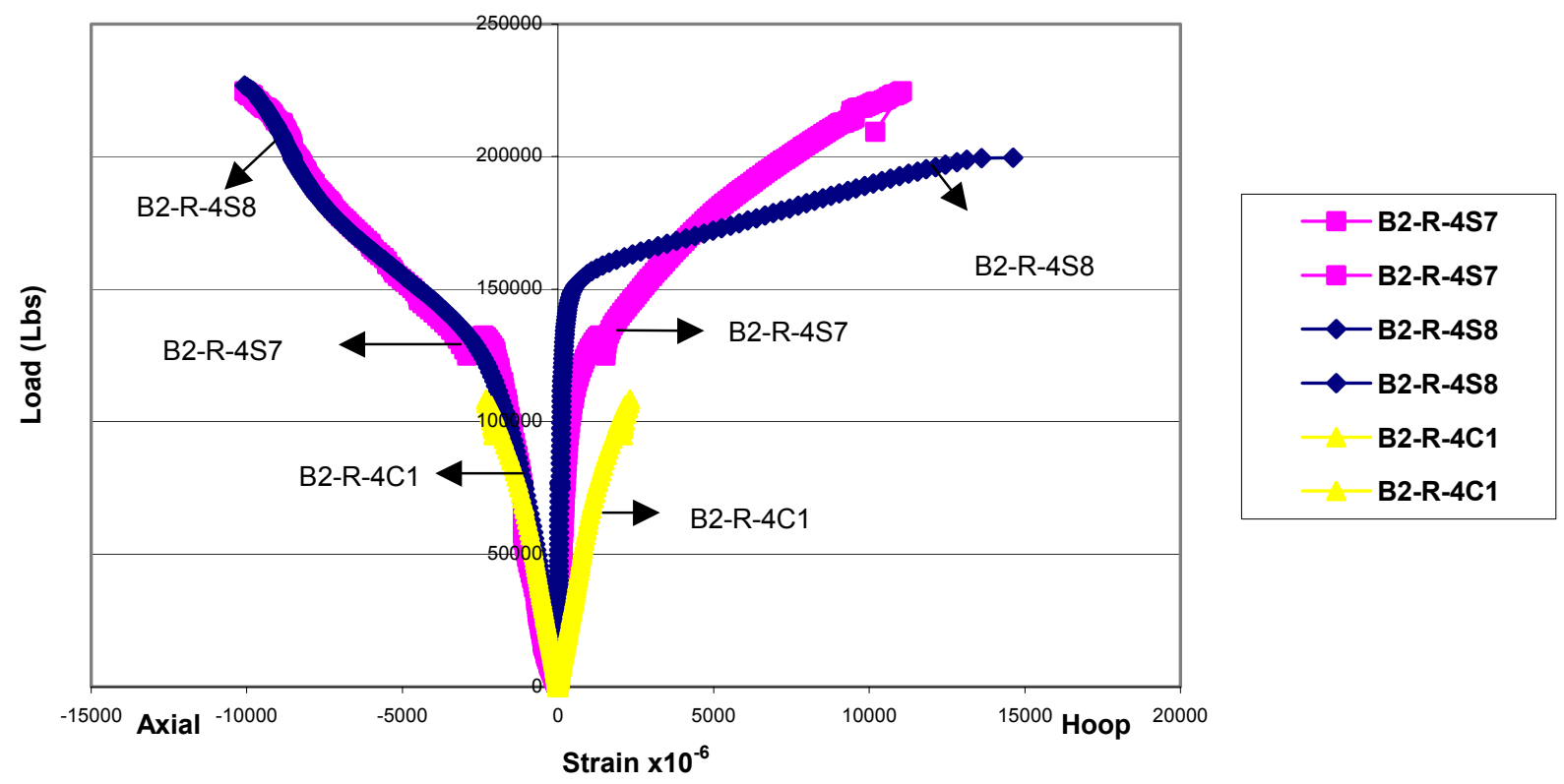

Figure 5-16 Load Strain Comparison of 3 layer - $0^{\circ}$ Wrapped RCC Specimen with Control Specimen - Batch 2 


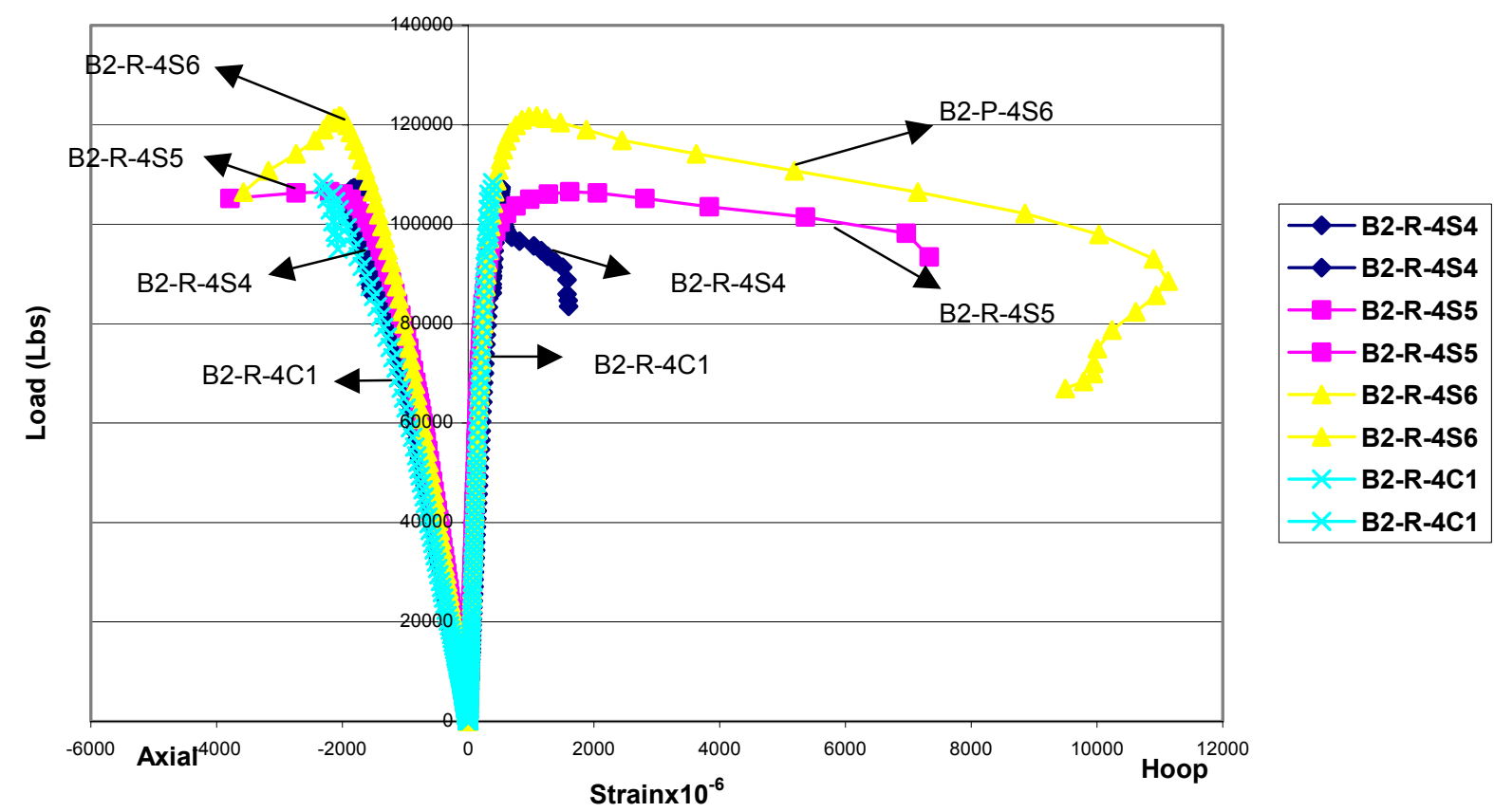

Figure 5-17 Load Strain Comparison of 1 layer $45^{\circ}$ Wrapped RCC Specimen with Control Specimen - Batch 2

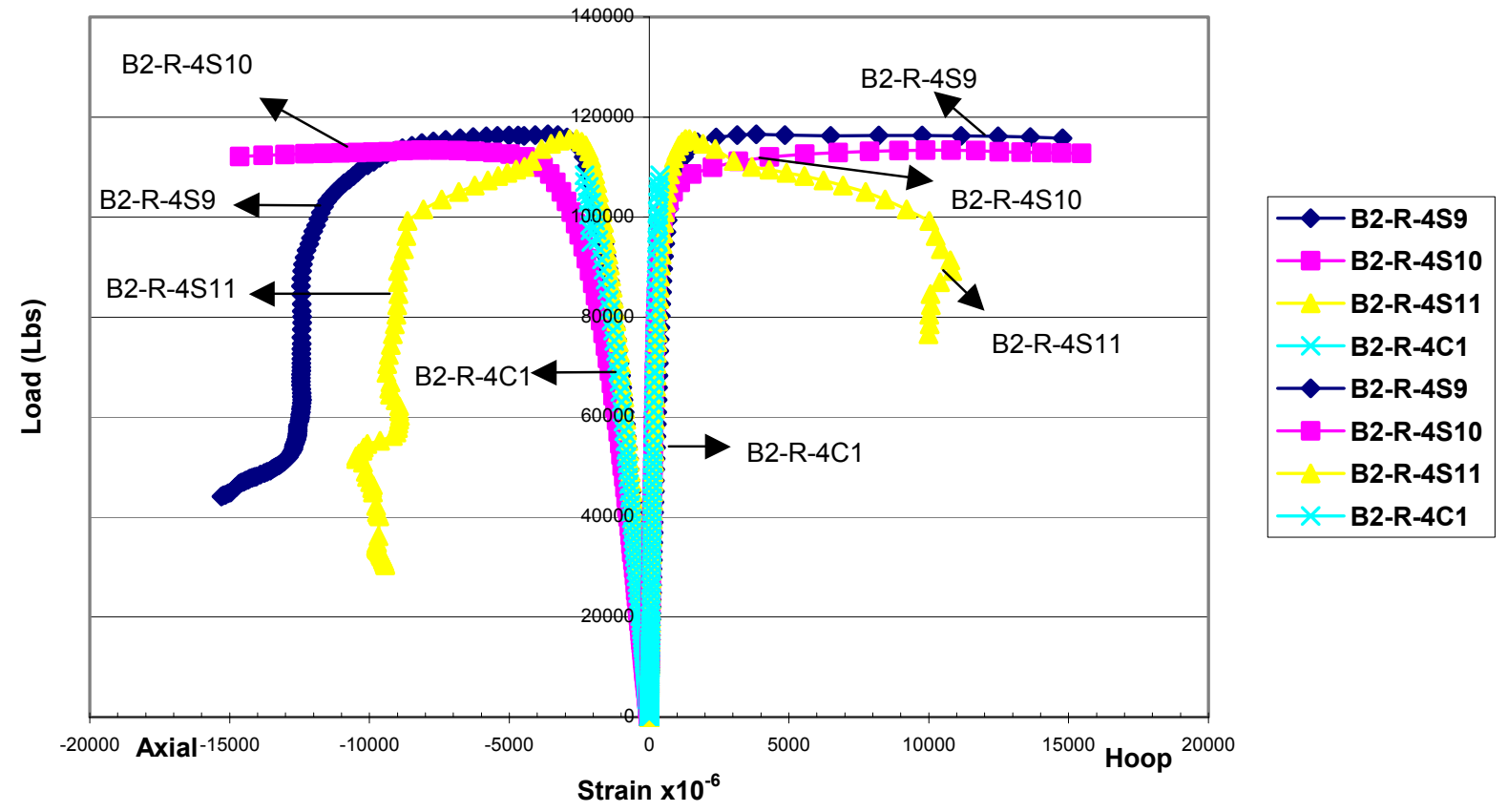

Figure 5-18 Load Strain Comparison of 2 Layer $\pm 45^{\circ}$ Wrapped PCC Specimen with Control Specimen- Batch 2 


\subsubsection{Stress/Stiffness}

The stress in the plain and wrapped concrete cylinder specimens with and without internal steel reinforcement was calculated by dividing applied load with the original concrete cross sectional area. While calculating stress the thickness of the wrap was not taken into account. Stress values were tabulated in the Tables 5-4 and 5-5. Stiffness was evaluated using the charts in Appendix A by calculating the slopes $\mathrm{m}_{1}$, and $\mathrm{m}_{2}$ at the bifurcation points. The initial slope of the curve is $\mathrm{m}_{1}$ and the slope after the bifurcation point is $\mathrm{m}_{2}$.

\subsubsection{Maximum Stress and Failure Stress}

Table 5-4 Maximum Stress of Batch $1\left(f_{c}{ }^{\prime}=4500 \mathrm{psi}\right)$ Specimens

\begin{tabular}{|c|c|c|c|c|c|}
\hline No. & Designation & No of Layers & Fiber Orientation & $\begin{array}{l}\text { Maximum Stress } \\
\text { (psi) }\end{array}$ & $\begin{array}{c}\text { Average Stress } \\
\text { (psi) }\end{array}$ \\
\hline 1 & B1-P-4C3 & - & - & 4526 & 4526 \\
\hline 2 & B1-P-4S1 & \multirow{4}{*}{1} & \multirow{2}{*}{0 Degree } & 7166 & \multirow{2}{*}{6604} \\
\hline 3 & B1-P-4S2 & & & 6042 & \\
\hline 4 & B1-P-4S3 & & \multirow{2}{*}{45 Degree } & 4599 & \multirow{2}{*}{4552} \\
\hline 5 & B1-P-4S4 & & & 4504 & \\
\hline 6 & B1-P-4S5 & \multirow{2}{*}{3} & \multirow{2}{*}{0 Degree } & 12802 & \multirow{2}{*}{12992} \\
\hline 7 & B1-P-4S6 & & & 13182 & \\
\hline 8 & B1-P-4S7 & \multirow{2}{*}{2} & \multirow{2}{*}{ \pm 45 Degree } & 4870 & \multirow{2}{*}{5003} \\
\hline 9 & B1-P-4S8 & & & 5136 & \\
\hline 10 & B1-R-4C1 & - & - & 5402 & 5402 \\
\hline 11 & B1-R-4S1 & \multirow{4}{*}{1} & \multirow{2}{*}{0 Degree } & 8716 & \multirow{2}{*}{8288} \\
\hline 12 & B1-R-4S2 & & & 7860 & \\
\hline 13 & B1-R-4S3 & & \multirow{2}{*}{45 Degree } & 5586 & \multirow{2}{*}{5299} \\
\hline 14 & B1-R-4S4 & & & 5011 & \\
\hline 15 & B1-R-4S5 & \multirow{2}{*}{3} & \multirow{2}{*}{0 Degree } & 13051 & \multirow{2}{*}{12222} \\
\hline 16 & B1-R-4S6 & & & 11393 & \\
\hline 17 & B1-R-4S7 & \multirow{2}{*}{2} & \multirow{2}{*}{ \pm 45 Degree } & 6401 & \multirow{2}{*}{6254} \\
\hline 18 & B1-R-4S8 & & & 6106 & \\
\hline
\end{tabular}


Table 5-5 Maximum Stress of Batch $2\left(f_{c}{ }^{\prime}=8000 \mathrm{psi}\right)$ Specimens

\begin{tabular}{|c|c|c|c|c|c|}
\hline No. & Designation & No of Layers & Fiber Orientation & Ultimate stress (psi) & Average Stress (psi) \\
\hline 1 & B2-P-4C1 & -- & -- & 7767 & 7767 \\
\hline 2 & B2-P-4S1 & \multirow{6}{*}{1} & \multirow{3}{*}{0 degree } & 10395 & \multirow{3}{*}{10577} \\
\hline 3 & B2-P-4S2 & & & 10574 & \\
\hline 4 & B2-P-4S3 & & & 10761 & \\
\hline 5 & B2-P-4S4 & & \multirow{3}{*}{45 degree } & 8698 & \multirow{3}{*}{8866} \\
\hline 6 & B2-P-4S5 & & & 9010 & \\
\hline 7 & B2-P-4S6 & & & 8891 & \\
\hline 8 & B2-P-4S7 & \multirow{2}{*}{3} & \multirow{2}{*}{0 degree } & 18454 & \multirow{2}{*}{18239} \\
\hline 9 & B2-P-4S8 & & & 18024 & \\
\hline 10 & B2-P-4S9 & \multirow{3}{*}{2} & \multirow{3}{*}{ \pm 45 Degree } & 8994 & \multirow{3}{*}{9074} \\
\hline 11 & B2-P-4S10 & & & 8855 & \\
\hline 12 & B2-P-4S11 & & & 9374 & \\
\hline 13 & B2-R-4C1 & --- & --- & 8622 & 8622 \\
\hline 14 & B2-R-4S1 & \multirow{6}{*}{1} & \multirow{3}{*}{0 degree } & 12860 & \multirow{3}{*}{12283} \\
\hline 15 & B2-R-4S2 & & & 12824 & \\
\hline 16 & B2-R-4S3 & & & 11167 & \\
\hline 17 & B2-R-4S4 & & \multirow{3}{*}{45 degree } & 8539 & \multirow{3}{*}{8868} \\
\hline 18 & B2-R-4S5 & & & 8372 & \\
\hline 19 & B2-R-4S6 & & & 9692 & \\
\hline 20 & B2-R-4S7 & \multirow{2}{*}{3} & \multirow{2}{*}{0 degree } & 18050 & \multirow{2}{*}{17962} \\
\hline 21 & B2-R-4S8 & & & 17875 & \\
\hline 22 & B2-R-4S9 & \multirow{3}{*}{2} & \multirow{3}{*}{ \pm 45 Degree } & 9273 & \multirow{3}{*}{9165} \\
\hline 23 & B2-R-4S10 & & & 9024 & \\
\hline 24 & B2-R-4S11 & & & 9199 & \\
\hline
\end{tabular}




\subsubsection{Stiffness}

Table 5-6 Stiffness of Batch $1\left(f_{c}{ }^{\prime}=4500\right.$ psi) Specimens

\begin{tabular}{|c|c|c|c|c|c|c|c|c|c|c|c|}
\hline \multirow[t]{2}{*}{ No. } & \multirow[t]{2}{*}{ Designation } & \multirow[t]{2}{*}{$\begin{array}{l}\text { No of } \\
\text { Layers }\end{array}$} & \multirow[t]{2}{*}{$\begin{array}{c}\text { Fiber } \\
\text { Direction }\end{array}$} & \multicolumn{2}{|c|}{$\begin{array}{l}\text { Stiffness Slope } \\
\quad\left(\mathrm{m}_{1}\right) \mathrm{Msi}\end{array}$} & \multicolumn{2}{|c|}{$\begin{array}{l}\text { Stiffness Slope } \\
\qquad\left(\mathrm{m}_{2}\right) \mathrm{Msi}\end{array}$} & \multicolumn{2}{|c|}{$\begin{array}{l}\text { Comparison } \\
\text { of } \mathrm{m}_{1} \text { to Non } \\
\text { wrapped } \mathrm{m}_{1}\end{array}$} & \multicolumn{2}{|c|}{$\begin{array}{l}\text { Comparison } \\
\text { of } \mathrm{m}_{2} \text { to } \mathrm{m}_{1} \\
\text { (wrapped) }\end{array}$} \\
\hline & & & & Axial & Hoop & Axial & Hoop & Axial & Hoop & Axial & Hoop \\
\hline 1 & B1-P-4C3 & -- & -- & 2.46 & 11.08 & --- & --- & --- & -- & --- & --- \\
\hline 2 & B1-P-4S1 & & \multirow{2}{*}{0 Degree } & \multirow{2}{*}{2.6} & \multirow{2}{*}{13.08} & \multirow{2}{*}{0.16} & \multirow{2}{*}{0.98} & \multirow{2}{*}{1.06} & \multirow{2}{*}{1.18} & \multirow{2}{*}{0.06} & \multirow{2}{*}{0.07} \\
\hline 3 & B1-P-4S2 & & & & & & & & & & \\
\hline 4 & B1-P-4S3 & & 45 & & & & & & & & \\
\hline 5 & B1-P-4S4 & & Degree & 2.55 & 12.89 & -- & --- & 1.03 & 1.16 & -- & --- \\
\hline 6 & B1-P-4S5 & & \multirow{2}{*}{0 Degree } & \multirow{2}{*}{2.99} & \multirow{2}{*}{13.865} & \multirow{2}{*}{0.635} & \multirow{2}{*}{2.965} & \multirow{2}{*}{1.2} & \multirow{2}{*}{1.25} & \multirow{2}{*}{0.17} & \multirow{2}{*}{0.15} \\
\hline 7 & B1-P-4S6 & & & & & & & & & & \\
\hline 8 & B1-P-4S7 & & \multirow{2}{*}{$\begin{array}{c} \pm 45 \\
\text { Degree }\end{array}$} & \multirow{2}{*}{2.75} & \multirow{2}{*}{13.585} & \multirow{2}{*}{0.23} & 025 & 117 & 122 & 000 & 0018 \\
\hline 9 & B1-P-4S8 & & & & & & 0.25 & 1.17 & 1.23 & 0.08 & 0.018 \\
\hline 10 & B1-R-4C1 & -- & -- & 2.94 & 12.01 & --- & --- & -- & --- & --- & -- \\
\hline 11 & B1-R-4S1 & & 0 Deoree & 3125 & 146 & 0315 & 0335 & 108 & 121 & 009 & 0023 \\
\hline 12 & B1-R-4S2 & 1 & 0 Degree & 3.125 & 14.6 & 0.315 & 0.335 & 1.08 & 1.21 & 0.09 & 0.023 \\
\hline 13 & B1-R-4S3 & 1 & 45 & 329 & 1105 & 022 & 0365 & 111 & 092 & 007 & 003 \\
\hline 14 & B1-R-4S4 & & Degree & 3.29 & 11.02 & 0.22 & 0.365 & 1.11 & 0.92 & 0.07 & 0.03 \\
\hline 15 & B1-R-4S5 & 3 & 0 & 205 & 1474 & 025 & 0255 & 128 & 12 & 01 & 0015 \\
\hline 16 & B1-R-4S6 & 3 & 0 Degree & 3.85 & $14 . / 4$ & 0.35 & 0.255 & 1.28 & 1.2 & 0.1 & 0.015 \\
\hline 17 & B1-R-4S7 & $?$ & \pm 45 & 265 & 142 & 02 & 0.17 & 124 & 110 & 000 & 002 \\
\hline 18 & B1-R-4S8 & 2 & Degree & 3.65 & 14.3 & 0.3 & $0.4 /$ & 1.24 & 1.19 & 0.08 & 0.05 \\
\hline
\end{tabular}

- Stiffness of three layer $0^{\circ}$ fiber is wrapped specimen increases 1.2 to 1.28 times while single layer $0^{\circ}$ wrapped specimens stiffness increases by 1.06 to 1.1 times the non wrapped specimens

- Specimens wrapped with single layer $45^{\circ}$ specimens showed the least increase in stiffness while specimens with $\pm 45^{\circ}$ wrap showed increased stiffness in the hoop direction

- The stiffness reduces considerably from slope $\mathrm{m}_{1}$ to $\mathrm{m}_{2}$ in all the cases 
Table 5-7 Stiffness of Batch $2\left(f_{c}{ }^{\prime}=8000\right.$ psi) Specimens

\begin{tabular}{|c|c|c|c|c|c|c|c|c|c|c|c|}
\hline \multirow[t]{2}{*}{ No. } & \multirow[t]{2}{*}{ Designation } & \multirow[t]{2}{*}{$\begin{array}{l}\text { No of } \\
\text { Layers }\end{array}$} & \multirow[t]{2}{*}{$\begin{array}{c}\text { Fiber } \\
\text { Orientation }\end{array}$} & \multicolumn{2}{|c|}{$\begin{array}{l}\text { Stiffness } \\
\text { Slope }\left(\mathrm{m}_{1}\right)\end{array}$} & \multicolumn{2}{|c|}{$\begin{array}{l}\text { Stiffness Slope } \\
\qquad\left(\mathrm{m}_{2}\right)\end{array}$} & \multicolumn{2}{|c|}{$\begin{array}{c}\text { Comparison of } \\
\mathrm{m}_{1} \text { to Non } \\
\text { wrapped } \mathrm{m}_{1} \\
\end{array}$} & \multicolumn{2}{|c|}{$\begin{array}{c}\text { Comparison of } \\
\mathrm{m}_{2} \text { to } \mathrm{m}_{1}\end{array}$} \\
\hline & & & & Axial & Hoop & Axial & Hoop & Axial & Hoop & Axial & Hoop \\
\hline 1 & B2-P-4C1 & --- & --- & 5.1 & 15.3 & --- & --- & --- & --- & --- & --- \\
\hline 2 & B2-P-4S1 & & \multirow{3}{*}{0 Degree } & \multirow{3}{*}{5.4} & \multirow{3}{*}{21.1} & \multirow{3}{*}{0.43} & \multirow{3}{*}{0.13} & \multirow{3}{*}{1.06} & \multirow{3}{*}{1.37} & \multirow{3}{*}{0.07} & \multirow{3}{*}{0.006} \\
\hline 3 & B2-P-4S2 & & & & & & & & & & \\
\hline 4 & B2-P-4S3 & & & & & & & & & & \\
\hline 5 & B2-P-4S4 & & \multirow{3}{*}{45 Degree } & \multirow{3}{*}{5.38} & \multirow{3}{*}{21.63} & \multirow{3}{*}{---} & \multirow{3}{*}{---} & \multirow{3}{*}{1.05} & \multirow{3}{*}{1.4} & \multirow{3}{*}{---} & \multirow{3}{*}{---} \\
\hline 6 & B2-P-4S5 & & & & & & & & & & \\
\hline 7 & B2-P-4S6 & & & & & & & & & & \\
\hline 8 & B2-P-4S7 & \multirow{2}{*}{3} & \multirow{2}{*}{0 Degree } & \multirow{2}{*}{5.85} & & & & & & & \\
\hline 9 & B2-P-4S8 & & & & 25.5 & 1.26 & 1.71 & 1.14 & 1.67 & 0.215 & 0.07 \\
\hline 10 & B2-P-4S9 & & & & & & & & & & \\
\hline 11 & B2-P-4S10 & 2 & & 5.56 & 23.6 & 0.15 & 0.103 & 1.09 & 1.54 & 0.027 & 0.004 \\
\hline 12 & B2-P-4S11 & & & & & & & & & & \\
\hline 13 & B2-R-4C1 & --- & ---- & 5.2 & 23.6 & --- & --- & --- & --- & --- & --- \\
\hline 14 & B2-R-4S1 & & & & & & & & & & \\
\hline 15 & B2-R-4S2 & & 0 Degree & 5.63 & 25.24 & 0.46 & 0.33 & 1.08 & 1.07 & 0.08 & 0.01 \\
\hline 16 & B2-R-4S3 & 1 & & & & & & & & & \\
\hline 17 & B2-R-4S4 & 1 & & & & & & & & & \\
\hline 18 & B2-R-4S5 & & 45 Degree & 5.4 & 23.3 & --- & --- & 1.03 & 0.98 & -- & --- \\
\hline 19 & B2-R-4S6 & & & & & & & & & & \\
\hline 20 & B2-R-4S7 & 3 & 0 Deoree & 505 & 279 & 10 & 075 & 114 & 118 & 017 & 002 \\
\hline 21 & B2-R-4S8 & 3 & 0 Degree & 0.95 & 21.9 & 1.0 & 0.15 & 1.14 & 1.18 & 0.17 & 0.02 \\
\hline 22 & B2-R-4S9 & & & & & & & & & & \\
\hline 23 & B2-R-4S10 & 2 & $\begin{array}{c} \pm 45 \\
\text { Deoreo }\end{array}$ & 5.8 & 28.3 & 0.53 & 0.84 & 1.11 & 1.29 & 0.09 & 0.03 \\
\hline 24 & B2-R-4S11 & & & & & & & & & & \\
\hline
\end{tabular}

\subsubsection{Axial Stress}

Values of stress corresponding to axial strain limits of $0.0008,0.002$ and 0.003 are tabulated below in table 5-8 to 5-9. Table 5-8 gives the stress values of the first batch of tests with $f_{c}$ ' of 4500-psi and Table 5-9 gives the results of the $2^{\text {nd }}$ batch of concrete tests with $f_{c}$ ' of 8000 psi.

The stress of the wrapped and non wrapped specimens seem in Table 5-8 and 5-9 show values of stress which are similar at an axial strain of 0.0008 strain. Initially the slope is linear up to 0.008 value of strain. At strains of 0.002 and 0.003 the wrapped specimens show an increased 
value of stress when compared to the non-wrapped specimens. Thus the 0.0008 strain limit was chosen as the limiting curvature to calculate the deformability factor.

Table 5-8 Axial Stress Values at 0.0008, 0.002 and 0.003 Axial Strain for Batch $1\left(f_{c}{ }^{\prime}=4500 \mathrm{psi}\right)$ Specimens

\begin{tabular}{|c|c|c|c|c|c|c|}
\hline No. & Designation & No of layers & $\begin{array}{c}\text { Fiber } \\
\text { Orientation }\end{array}$ & $\begin{array}{l}\text { Axial Stress } \\
\text { at } 0.0008 \\
\text { Axial Strain }\end{array}$ & $\begin{array}{c}\text { Axial Stress } \\
\text { at } 0.002 \\
\text { Axial Strain }\end{array}$ & $\begin{array}{l}\text { Axial Stress } \\
\text { at } 0.003 \\
\text { Axial Strain }\end{array}$ \\
\hline 1 & B1-P-4C3 & -- & -- & 2939.7 & 3817.729 & 4342.94 \\
\hline 2 & B1-P-4S1 & \multirow{4}{*}{1} & \multirow{2}{*}{0 Degree } & 3091.58 & 5174.525 & 5665.9159 \\
\hline 3 & B1-P-4S2 & & & 2994.87 & 4203.679 & 4516.02 \\
\hline 4 & B1-P-4S3 & & \multirow{2}{*}{45 Degree } & 3073.67 & --- & -- \\
\hline 5 & B1-P-4S4 & & & 2616.11 & 4426.496 & -- \\
\hline 6 & B1-P-4S5 & \multirow{2}{*}{3} & \multirow{2}{*}{0 Degree } & 3224.87 & 5218.29 & 6579.06 \\
\hline 7 & B1-P-4S6 & & & 3079.42 & 6344.31 & 7657.34 \\
\hline 8 & B1-P-4S7 & \multirow{2}{*}{2} & \multirow{2}{*}{ \pm 45 Degree } & 1977.42 & 4762.71 & 4870.14 \\
\hline 9 & B1-P-4S8 & & & 2009.29 & 4710.98 & 4681.14 \\
\hline 10 & B1-R-4C1 & -- & -- & 2429.1 & 4237 & 4661.25 \\
\hline 11 & B1-R-4S1 & \multirow{4}{*}{1} & \multirow{2}{*}{0 Degree } & 3347.82 & 5735.2 & 6581.85 \\
\hline 12 & B1-R-4S2 & & & 2910.14 & 5885.8 & 6461.69 \\
\hline 13 & B1-R-4S3 & & \multirow{2}{*}{45 Degree } & 2212.3 & 5357.78 & 5566.44 \\
\hline 14 & B1-R-4S4 & & & 2166.5 & -- & -- \\
\hline 15 & B1-R-4S5 & \multirow{2}{*}{3} & \multirow{2}{*}{0 Degree } & 4022.64 & 7766.66 & 8588.39 \\
\hline 16 & B1-R-4S6 & & & 3155.24 & 5831.03 & 7106.26 \\
\hline 17 & B1-R-4S7 & \multirow{2}{*}{2} & \multirow{2}{*}{ \pm 45 Degree } & 4148.2 & 6749.66 & 7183.85 \\
\hline 18 & B1-R-4S8 & & & 3005.6 & 6106.07 & 5509.24 \\
\hline
\end{tabular}

- Plain and reinforced concrete specimens have a similar pattern in load strain curves as shown in Figures 5-1 and 5-2. The load to failure is higher in the case of reinforced concrete specimens but the curves are similar. The internal reinforcement increased the axial capacity of the column in terms of axial load and strain to failure.

- Wrapped concrete specimens with $0^{\circ}$ show a bilinear load strain curve. The slope of the load strain curve is linear to a strain value of about -2000 micro stains. After the bifurcation point the concrete and the wrap start acting together and the specimen takes up a different slope, which is lower than the initial slope as shown in Figure 5-3 and 5-11. 
Table 5-9 Axial Stress Values at 0.0008, 0.002 and 0.003 Axial Strain for Batch $2\left(f_{c}{ }^{\prime}=8000 \mathrm{psi}\right)$ Specimens

\begin{tabular}{|c|c|c|c|c|c|c|}
\hline No. & Designation & $\begin{array}{l}\text { No of } \\
\text { Layers }\end{array}$ & $\begin{array}{c}\text { Fiber } \\
\text { Orientation }\end{array}$ & $\begin{array}{c}\text { Axial Stress at } \\
0.0008 \text { Axial } \\
\text { Strain }\end{array}$ & $\begin{array}{c}\text { Axial Stress at } \\
0.002 \text { Axial } \\
\text { Strain }\end{array}$ & $\begin{array}{c}\text { Axial Stress at } \\
0.003 \text { Axial } \\
\text { Strain }\end{array}$ \\
\hline 1 & B2-P-4C1 & --- & ---- & 4708.97 & 7750.84 & ---- \\
\hline 2 & B2-P-4S1 & \multirow{6}{*}{1} & \multirow{3}{*}{0 Degree } & 4392.676 & 8347.67 & 9803.944 \\
\hline 3 & B2-P-4S2 & & & 4814.43 & 8469.03 & 9270.775 \\
\hline 4 & B2-P-4S3 & & & 5325.72 & 9774.13 & 10128.22 \\
\hline 5 & B2-P-4S4 & & \multirow{3}{*}{45 Degree } & 4442.41 & 8403.38 & ---- \\
\hline 6 & B2-P-4S5 & & & 3994.79 & 8017.43 & 4653.29 \\
\hline 7 & B2-P-4S6 & & & 4533.92 & 8357.62 & 8811.21 \\
\hline 8 & B2-P-4S7 & \multirow{2}{*}{3} & \multirow{2}{*}{0 Degree } & 4788.57 & 9026.07 & 9770.12 \\
\hline 9 & B2-P-4S8 & & & 4376.76 & 8880.846 & 10249.58 \\
\hline 10 & B2-P-4S9 & \multirow{3}{*}{2} & \multirow{3}{*}{$\begin{array}{c} \pm 45 \\
\text { Degree }\end{array}$} & 4734.86 & 8663.99 & 8976.339 \\
\hline 11 & B2-P-4S10 & & & 4607.54 & 8749.55 & 8854.98 \\
\hline 12 & B2-P-4S11 & & & 4372.78 & 8463.06 & 7255.47 \\
\hline 13 & B2-R-4C1 & --- & --- & 4143.9 & 8049.26 & --- \\
\hline 14 & B2-R-4S1 & \multirow{6}{*}{1} & \multirow{3}{*}{0 Degree } & 5176.51 & 8940.5 & 10343.08 \\
\hline 15 & B2-R-4S2 & & & 4243.46 & 8747.5 & 10309.08 \\
\hline 16 & B2-R-4S3 & & & 4406.6 & 8232.28 & 9473.69 \\
\hline 17 & B2-R-4S4 & & \multirow{3}{*}{45 Degree } & 4354.88 & 4557.8 & 2454.96 \\
\hline 18 & B2-R-4S5 & & & 5293.89 & 8437.2 & 2812.07 \\
\hline 19 & B2-R-4S6 & & & 5210.33 & 9682.58 & 5188.2 \\
\hline 20 & B2-R-4S7 & \multirow{2}{*}{3} & \multirow{2}{*}{0 Degree } & 4637.37 & 9026.07 & 10689.24 \\
\hline 21 & B2-R-4S8 & & & 3111.47 & 10066.55 & 10126.23 \\
\hline 22 & B2-R-4S9 & \multirow{3}{*}{2} & \multirow{3}{*}{$\begin{array}{c} \pm 45 \\
\text { Degree }\end{array}$} & 4468.27 & 8449.13 & 9221.04 \\
\hline 23 & B2-R-4S10 & & & 3489.47 & 6901.35 & 8202.44 \\
\hline 24 & B2-R-4S11 & & & 2047.64 & 8769.43 & 9175.28 \\
\hline
\end{tabular}

- The load strain curves of specimens with single layer of $45^{\circ}$ wrap are similar to the curves of plain non-wrapped specimens and are shown in Figure 5-5 and 5-13. Specimens fail once the wrap starts shearing in the direction of the fiber.

- Specimens wrapped with 2 layers of $\pm 45^{\circ}$ fibers show a bilinear load strain curve. The specimens have the same slope up to maximum stress and then stress decreases with increase in strain with a different slope as shown in Figure 5-6 and 5-14. 


\subsubsection{Strain}

The strain to failure of the specimens was recorded using the strain gauge. Gauges were attached both in the vertical and horizontal direction and hence both the values of axial and hoop strain were recorded.

\subsubsection{Axial/Hoop Strain to Failure}

The maximum value of strain is recorded and the values are tabulated in the Table 5-10 and 5-11

Table 5-10 Axial and Hoop Strain Values of Batch $I\left(f_{c}{ }^{\prime}=4500 \mathrm{psi}\right)$ Specimens

\begin{tabular}{|c|c|c|c|c|c|c|c|}
\hline No. & Designation & $\begin{array}{l}\text { No of } \\
\text { layers }\end{array}$ & $\begin{array}{c}\text { Fiber } \\
\text { Orientation }\end{array}$ & $\begin{array}{l}\text { Strain to failure } \\
\text { (Axial) } \times 10^{-6}\end{array}$ & $\begin{array}{l}\text { Strain to failure } \\
\text { (Hoop) } \times 10^{-6}\end{array}$ & $\begin{array}{r}\text { Percent ir } \\
\text { Compar } \\
\end{array}$ & $\begin{array}{l}\text { in strain - } \\
\text { Control } \\
\text { en }\end{array}$ \\
\hline 1 & B1-P-4C3 & - & - & -4000.387 & 1343.628 & Axial & Hoop \\
\hline 2 & B1-P-4S1 & \multirow{4}{*}{1} & \multirow{2}{*}{0 Degree } & -14603.1896 & 12417.713 & 265.04 & 824.19 \\
\hline 3 & B1-P-4S2 & & & -9874.893 & 11738.854 & 146.84 & 773.67 \\
\hline 4 & B1-P-4S3 & & \multirow{2}{*}{45 Degree } & -1657.5416 & 685.8334 & --- & --- \\
\hline 5 & B1-P-4S4 & & & -2293.1585 & 1108.5813 & --- & ---- \\
\hline 6 & B1-P-4S5 & \multirow{2}{*}{3} & \multirow{2}{*}{0 Degree } & -15357.2 & 12125.27 & 383.86 & 801.42 \\
\hline 7 & B1-P-4S6 & & & -15318.7 & 7061.7 & 282.9 & 425.64 \\
\hline 8 & B1-P-4S7 & \multirow{2}{*}{2} & \multirow{2}{*}{ \pm 45 Degree } & -15227.5 & 14804.91 & 280.65 & 1001 \\
\hline 9 & B1-P-4S8 & & & -9938.08 & 10535.42 & 148.43 & 684.1 \\
\hline 10 & B1-R-4C1 & - & - & -4452.85 & 2566.18 & ---- & --- \\
\hline 11 & B1-R-4S1 & \multirow{4}{*}{1} & \multirow{2}{*}{0 Degree } & -8750.02 & 9886.15 & 96.5 & 285.2 \\
\hline 12 & B1-R-4S2 & & & -8529.54 & 8773.1 & 91.55 & 241.8 \\
\hline 13 & B1-R-4S3 & & \multirow{2}{*}{45 Degree } & -12457.73 & 13759.4 & 179.76 & 436.18 \\
\hline 14 & B1-R-4S4 & & & -- & -- & & \\
\hline 15 & B1-R-4S5 & \multirow{2}{*}{3} & \multirow{2}{*}{0 Degree } & -15168.33 & 15087.94 & 240.6 & 487.9 \\
\hline 16 & B1-R-4S6 & & & -15300.25 & 15636.66 & 243.6 & 509.33 \\
\hline 17 & B1-R-4S7 & \multirow{2}{*}{2} & \multirow{2}{*}{ \pm 45 Degree } & 9836.9 & 16847.16 & 120.9 & 578.5 \\
\hline 18 & B1-R-4S8 & & & 15037.4 & 15050.7 & 237.7 & 478.56 \\
\hline
\end{tabular}

Specimens wrapped with 3 layers of $0^{\circ}$ fiber and specimens wrapped with $\pm 45^{\circ}$ fibers show a high increase in axial and hoop strain. Specimens wrapped with $45^{\circ}$ fibers do not show much increase in strain as failure occurs very soon when he specimen fails in the direction of fibers in the wrap and concrete starts spalling. 
Table 5-11 Axial and Hoop Strain Values of Batch $2\left(f_{c}{ }^{\prime}=8000 \mathrm{psi}\right)$ Specimens

\begin{tabular}{|c|c|c|c|c|c|c|c|}
\hline No. & Designation & No of Layers & $\begin{array}{c}\text { Fiber } \\
\text { Orientation }\end{array}$ & $\begin{array}{l}\text { Strain to failure } \\
\text { (Axial) } \times 10^{-6}\end{array}$ & $\begin{array}{l}\text { Strain to failure } \\
\text { (Hoop) } \times 10^{-6}\end{array}$ & $\begin{array}{r}\text { Percent } \\
\text { Compa }\end{array}$ & $\begin{array}{l}\text { ncrease - } \\
\text { Control }\end{array}$ \\
\hline 1 & B2-P-4C1 & --- & ---- & -2219.26 & 648.85 & Axial & Hoop \\
\hline 2 & B2-P-4S1 & \multirow{6}{*}{1} & \multirow{3}{*}{0 Degree } & -3373.63 & 7007.18 & 55.01 & 324.97 \\
\hline 3 & B2-P-4S2 & & & -5350.28 & 11846.32 & 141.08 & 618.46 \\
\hline 4 & B2-P-4S3 & & & -5304.61 & 15232.58 & 139.03 & 823.83 \\
\hline 5 & B2-P-4S4 & & \multirow{3}{*}{45 Degree } & -2395.08 & 9033.08 & 79.22 & 447.84 \\
\hline 6 & B2-P-4S5 & & & -4913.37 & 5773.34 & 121.39 & 250.14 \\
\hline 7 & B2-P-4S6 & & & -4171.24 & 8666.71 & 87.95 & 425.62 \\
\hline 8 & B2-P-4S7 & \multirow{2}{*}{3} & \multirow{2}{*}{0 Degree } & -15094.78 & 10719.85 & 580.17 & 550.14 \\
\hline 9 & B2-P-4S8 & & & -14649.85 & 14657.71 & 560.12 & 788.96 \\
\hline 10 & B2-P-4S9 & \multirow{3}{*}{2} & \multirow{3}{*}{ \pm 45 Degree } & -13662.14 & 15809.89 & 515.61 & 858.84 \\
\hline 11 & B2-P-4S10 & & & -14465.07 & 15450.56 & 551.79 & 837.05 \\
\hline 12 & B2-P-4S11 & & & -15113.67 & 15533.77 & 581.02 & 842.09 \\
\hline 13 & B2-R-4C1 & --- & ---- & -2311.09 & 792.37 & & \\
\hline 14 & B2-R-4S1 & \multirow{6}{*}{1} & \multirow{3}{*}{0 Degree } & -6173.19 & 11232.33 & 167.11 & 1317.56 \\
\hline 15 & B2-R-4S2 & & & -7660.57 & 12312.11 & 231.47 & 1453.83 \\
\hline 16 & B2-R-4S3 & & & -8348.75 & 4604.10 & 261.24 & 481.05 \\
\hline 17 & B2-R-4S4 & & \multirow{3}{*}{45 Degree } & -1877.82 & 1596.64 & -18.75 & 101.5 \\
\hline 18 & B2-R-4S5 & & & -3783.28 & 7332.3 & 63.68 & 825.36 \\
\hline 19 & B2-R-4S6 & & & -3571.61 & 9498.58 & 54.51 & 1098.75 \\
\hline 20 & B2-R-4S7 & \multirow{2}{*}{3} & \multirow{2}{*}{0 Degree } & -10068.75 & 14624.84 & 335.67 & 1745.7 \\
\hline 21 & B2-R-4S8 & & & -10094.68 & 11051.07 & 336.79 & 1294.68 \\
\hline 22 & B2-R-4S9 & \multirow{3}{*}{2} & \multirow{3}{*}{ \pm 45 Degree } & -15299.38 & 14779.18 & 561.99 & 1765.18 \\
\hline 23 & B2-R-4S10 & & & -14644.08 & 15464.64 & 533.64 & 1851.6 \\
\hline 24 & B2-R-4S11 & & & -10472.48 & 10844.90 & 353.14 & 1268.67 \\
\hline
\end{tabular}

\section{Axial Strain}

- The axial strains of the specimens wrapped with 3 layers of fiber showed 8 times increase in strain compared to non-wrapped specimens.

- Specimens with $\pm 45^{\circ}$ fiber orientation show high hoop increase in strain. The strain capacity of the specimen is enhanced with $\pm 45^{\circ}$ wrapping

- Specimens wrapped with a single layer of $45^{\circ}$ fiber show least increase in strain as the specimens start failing in the $45^{\circ}$ direction along the fibers. 
Table 5-12 Comparison of Axial and Hoop Strain of Batch 1 Specimens

\begin{tabular}{|c|c|c|c|c|c|c|c|}
\hline No. & Specification & $\begin{array}{l}\text { No of } \\
\text { layers }\end{array}$ & $\begin{array}{c}\text { Fiber } \\
\text { Orientation }\end{array}$ & \multicolumn{2}{|c|}{ Average Increase in Strain } & \multicolumn{2}{|c|}{$\begin{array}{c}\text { Average Percent increase in } \\
\text { strain-Comparison to Contro } \\
\text { Specimen }\end{array}$} \\
\hline 1 & B1-P-4C3 & - & - & Axial & Ноор & Axial & Ноор \\
\hline 2 & B1-P-4S1 & \multirow{4}{*}{1} & 0 Dromer & \multirow{2}{*}{3.06} & \multirow{2}{*}{8.9} & \multirow{2}{*}{205.94} & \multirow{2}{*}{798.93} \\
\hline 3 & B1-P-4S2 & & 0 Degree & & & & \\
\hline 4 & B1-P-4S3 & & 45. Deoree & 040 & 0.66 & 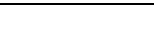 & --- \\
\hline 5 & B1-P-4S4 & & 45 Degree & 0.49 & 0.00 & $\cdots-$ & --- \\
\hline 6 & B1-P-4S5 & \multirow{2}{*}{3} & \multirow{2}{*}{0 Degree } & \multirow{2}{*}{3.83} & \multirow{2}{*}{7.13} & \multirow{2}{*}{333.38} & \multirow{2}{*}{613.53} \\
\hline 7 & B1-P-4S6 & & & & & & \\
\hline 8 & B1-P-4S7 & \multirow{2}{*}{2} & \multirow{2}{*}{ \pm 45 Degree } & \multirow{2}{*}{3.15} & \multirow{2}{*}{9.42} & \multirow{2}{*}{214.54} & \multirow{2}{*}{842.55} \\
\hline 9 & B1-P-4S8 & & & & & & \\
\hline 10 & B1-R-4C1 & - & - & & & $\begin{array}{ll}--- \\
--1\end{array}$ & --- \\
\hline 11 & B1-R-4S1 & \multirow{4}{*}{1} & \multirow{2}{*}{0 Degree } & \multirow{2}{*}{1.94} & \multirow{2}{*}{3.63} & \multirow{2}{*}{94.02} & \multirow{2}{*}{263.5} \\
\hline 12 & B1-R-4S2 & & & & & & \\
\hline 13 & B1-R-4S3 & & \multirow{2}{*}{45 Degree } & \multirow{2}{*}{2.79} & \multirow{2}{*}{5.36} & \multirow{2}{*}{179.76} & \multirow{2}{*}{436.18} \\
\hline 14 & B1-R-4S4 & & & & & & \\
\hline 15 & B1-R-4S5 & \multirow{2}{*}{3} & \multirow{2}{*}{0 Degree } & \multirow{2}{*}{3.42} & \multirow{2}{*}{5.98} & \multirow{2}{*}{242.1} & \multirow{2}{*}{498.6} \\
\hline 16 & B1-R-4S6 & & & & & & \\
\hline 17 & B1-R-4S7 & 2 & \pm 45 Degree & 2.79 & 8.43 & 179.3 & 44353 \\
\hline 18 & B1-R-4S8 & 2 & & & & & 443.53 \\
\hline
\end{tabular}

\section{Hoop Strain}

- In non-wrapped plain concrete specimens the hoop strain value was lower than the axial strain values. The ratio between the lateral and longitudinal strains varied from 0.15 to 0.20

- Reinforced concrete specimens had a Poisson's ratio of about 0.3 . The increase in the Poisson's ratio i.e. the increase in strain in the lateral direction is due to the confinement of the internal core of reinforcement present in the reinforced concrete cylinder specimens. The presence of internal reinforcement increased the capacity of the column and makes it more ductile

- The increase in hoop strains of the wrapped specimens was noted to be much higher than the axial strain increase as shown in Table 5-12 and 5-13. The specimens showed an increase of 20 times the strain of the non-wrapped specimen. The ductility of the column is increased. 
Table 5-13 Comparison of Axial and Hoop Strain of Batch 2 Specimens

\begin{tabular}{|c|c|c|c|c|c|c|c|}
\hline \multirow{2}{*}{$\begin{array}{c}\text { No. } \\
\mathbf{1}\end{array}$} & \multirow{2}{*}{$\begin{array}{c}\text { Tyре } \\
\text { B2-P-4C1 }\end{array}$} & \multirow{2}{*}{$\begin{array}{c}\begin{array}{c}\text { No of } \\
\text { Layers }\end{array} \\
---\end{array}$} & \multirow{2}{*}{$\begin{array}{c}\begin{array}{c}\text { Fiber } \\
\text { Orientation }\end{array} \\
----\end{array}$} & \multicolumn{2}{|c|}{$\begin{array}{l}\text { Average Increase in } \\
\text { Strain }\end{array}$} & \multicolumn{2}{|c|}{$\begin{array}{l}\text { Percent Strain Increase } \\
\text { Comparison to Control }\end{array}$} \\
\hline & & & & Axial & Hoop & Axial & Hoop \\
\hline 2 & B2-P-4S1 & \multirow{6}{*}{1} & \multirow{3}{*}{0 Degree } & \multirow{3}{*}{2.1} & \multirow{3}{*}{17.5} & \multirow{3}{*}{140} & \multirow{3}{*}{589.08} \\
\hline 3 & B2-P-4S2 & & & & & & \\
\hline 4 & B2-P-4S3 & & & & & & \\
\hline 5 & B2-P-4S4 & & \multirow{3}{*}{45 Degree } & \multirow{3}{*}{1.72} & \multirow{3}{*}{12.05} & \multirow{3}{*}{96.19} & \multirow{3}{*}{374.5} \\
\hline 6 & B2-P-4S5 & & & & & & \\
\hline 7 & B2-P-4S6 & & & & & & \\
\hline 8 & B2-P-4S7 & \multirow{2}{*}{3} & \multirow{2}{*}{0 Degree } & \multirow{2}{*}{6.7} & \multirow{2}{*}{19.55} & \multirow{2}{*}{570.15} & \multirow{2}{*}{669.5} \\
\hline 9 & B2-P-4S8 & & & & & & \\
\hline 10 & B2-P-4S9 & \multirow{3}{*}{2} & \multirow{3}{*}{ \pm 45 Degree } & \multirow{3}{*}{6.5} & \multirow{3}{*}{24.04} & \multirow{3}{*}{549.47} & \multirow{3}{*}{845.99} \\
\hline 11 & B2-P-4S10 & & & & & & \\
\hline 12 & B2-P-4S11 & & & & & & \\
\hline 13 & B2-R-4C1 & --- & --- & & & --- & --- \\
\hline 14 & B2-R-4S1 & \multirow{6}{*}{1} & \multirow{3}{*}{0 Degree } & \multirow{3}{*}{3.19} & \multirow{3}{*}{14.85} & & \\
\hline 15 & B2-R-4S2 & & & & & 219.94 & 1385.69 \\
\hline 16 & B2-R-4S3 & & & & & & \\
\hline 17 & B2-R-4S4 & & & & & & \\
\hline 18 & B2-R-4S5 & & 45 Degree & 1.33 & 7.75 & 58.5 & 675.2 \\
\hline 19 & B2-R-4S6 & & & & & & \\
\hline 20 & B2-R-4S7 & 3 & 0 Derreo & 436 & 162 & 33623 & 1520 \\
\hline 21 & B2-R-4S8 & 3 & 0 Degree & 4.36 & 16.2 & 336.23 & 1520 \\
\hline 22 & B2-R-4S9 & & & & & & \\
\hline 23 & B2-R-4S10 & 2 & \pm 45 Degree & 5.4 & 16.9 & 482.9 & 1628.4 \\
\hline 24 & B2-R-4S11 & & & & & & \\
\hline
\end{tabular}

\subsubsection{Failure Modes}

Figures 5.19 to 5.24 show failure modes of concrete cylinder specimens with or without wrapping tested in compression.

\subsubsection{Non Wrapped Cylinder}

Plain cylinders and reinforced cylinders without wraps were tested and the failure patterns were noted for batch 1 and batch 2 specimens. 


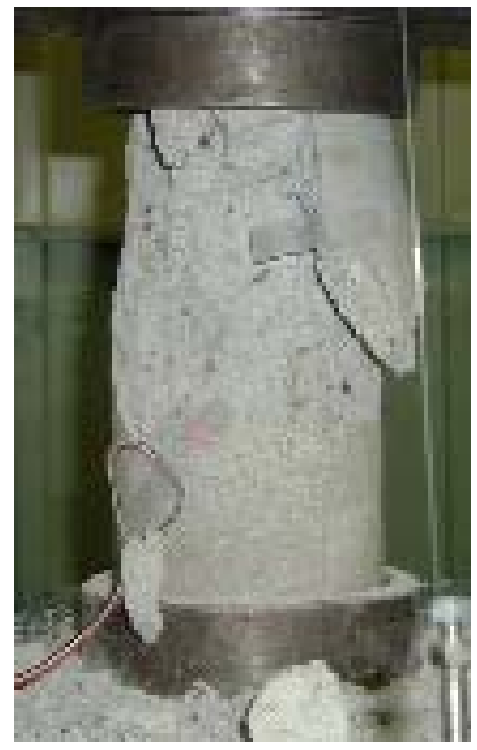

A

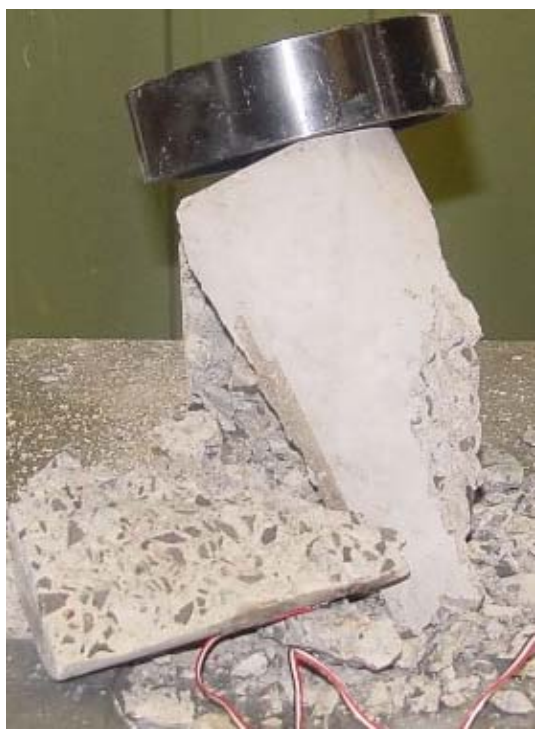

B

Figure 5-19 Plain Concrete Specimens A) Batch 1; B) Batch 2
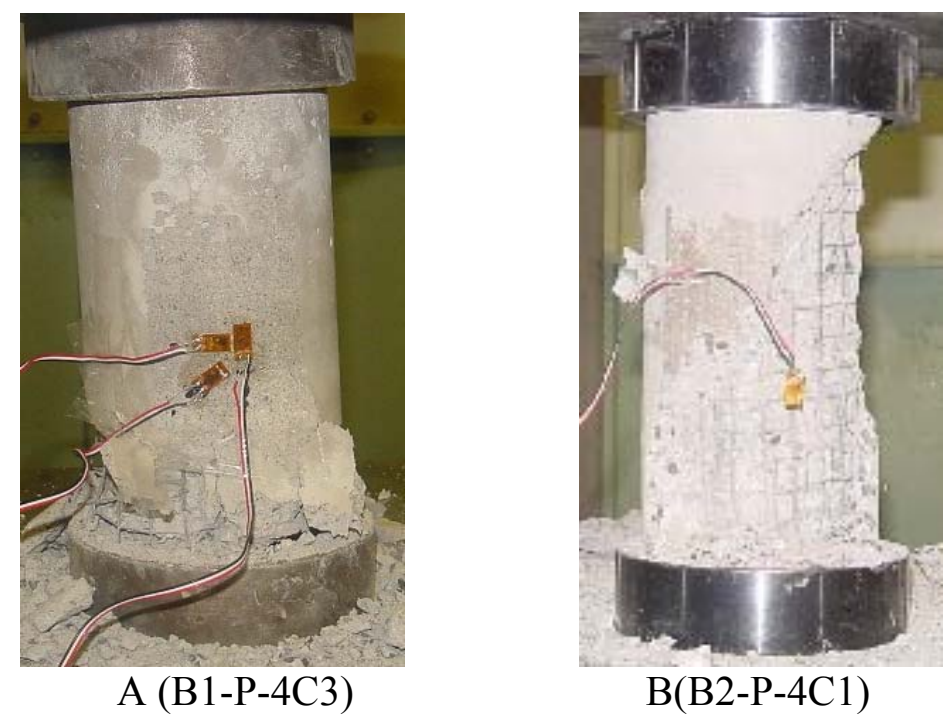

Figure 5-20 Reinforced Concrete Specimens A) Batch 1; B) Batch 2

\subsubsection{Wrapped Cylinders}

Cylinders wrapped with fibers in $0^{\circ}$ direction with 1 layer and 3 layers were tested and the failure modes are shown below in figure 5-21 to 5-24. Failure modes of cylinders with $45^{\circ}$ and $\pm 45^{\circ}$ fiber orientation are also shown 


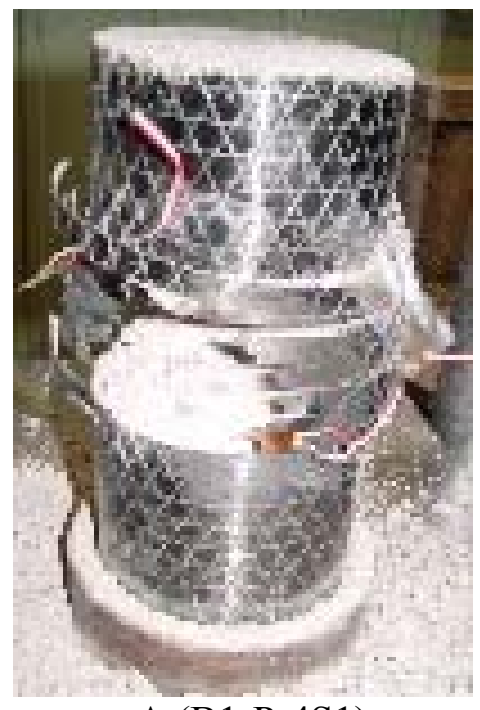

A (B1-P-4S1)

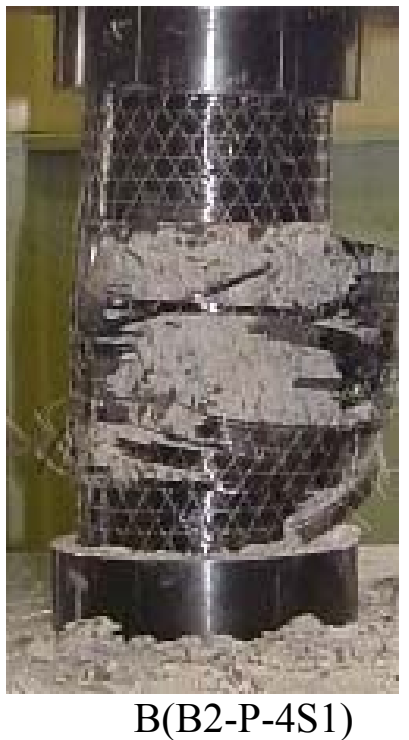

B(B2-P-4S1)

Figure 5-21 Single $0^{\circ}$ Wrap A) Batch 1; B) Batch 2

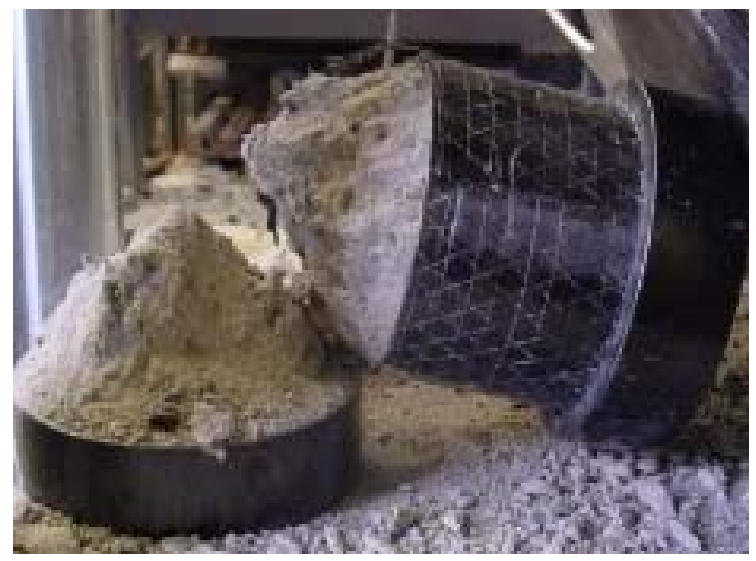

A (B1-P-4S5)

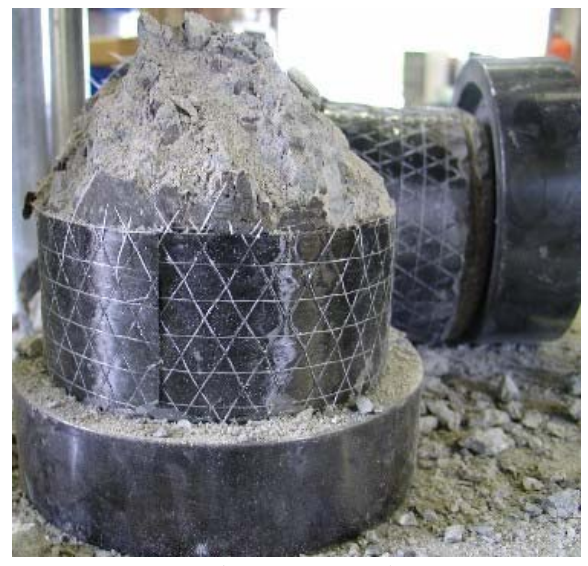

$\mathrm{B}(\mathrm{B} 2-\mathrm{P}-4 \mathrm{~S} 7)$

Figure 5-22 Three $^{\circ}$ Wrap A) Batch 1; B) Batch 2 


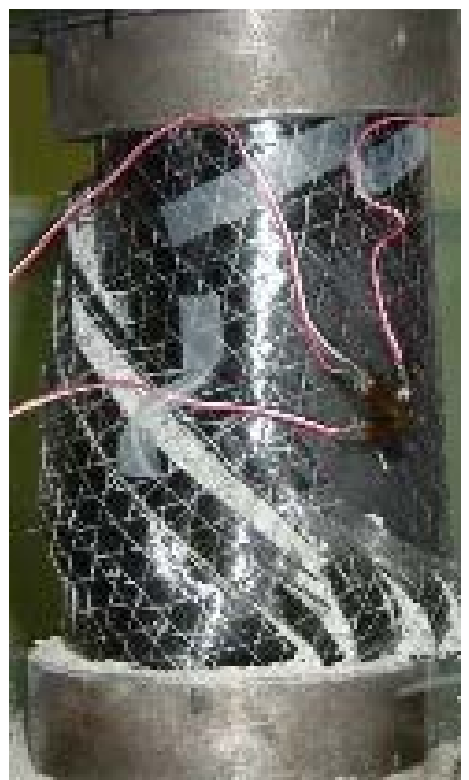

A (B1-P-4S3)

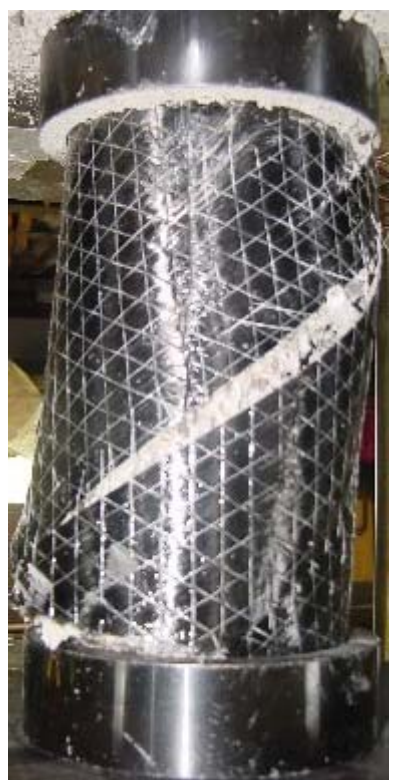

B (B2-P-4S4)

Figure 5-23 Single $4^{\circ}$ wrap A) Batch 1; B) Batch 2

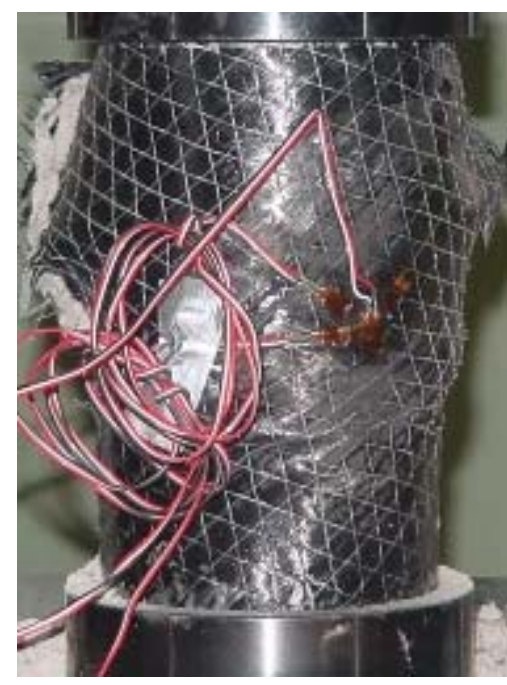

A(B1-P-4S7)

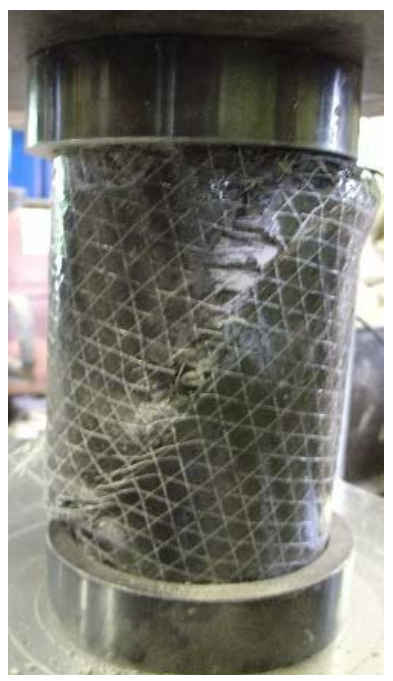

B (B1-P-4S10)

Figure 5-24 Two $\pm 45^{\circ}$ Wraps A) Batch 1; B) Batch 2

- Plain concrete cylinders of higher $f_{c}$ ' had a more brittle failure and the specimen broke into pieces forming a cone shape Figure (5-19).

- Reinforced concrete failed with the internal core of the concrete within the mesh being intact and the outer concrete cover failing (figure 5-20). 
- Specimens with a single wrap with $0^{\circ}$ fiber orientation had a failure when the wrap failed usually at specimen mid height (Figure 21) i.e. at the position of maximum hoop strain with spalling of concrete.

- Specimens with 3 layers of wrap with fibers running in the $0^{\circ}$ direction showed high increase in strength and the failure was accompanied by a huge sound and splitting of the specimen (Figure 5-22).

- Specimens wrapped with a $45^{\circ}$ wrap failed along the lines of the fiber in the wrap. The concrete started spalling from these positions (Figure 5-23).

- Specimens with $\pm 45^{\circ}$ wrap failed by developing small dilations due to aggregate displacement at several locations. The dilations grew in size and then burst locally. The failure was gradual (Figure 5-24).

\subsubsection{Ductility}

Ductility of a material is its capacity to absorb energy. Ductile materials allow better stress distribution and warning to impending failure. In the case of concrete wrapped specimens, ductility of the specimen is given in terms of deformability which is defined as the ratio of energy absorption (or area under load-deflection curve) at ultimate to energy absorption at limiting curvature (Vijay and GangaRao, 1995). In these tests deformability was calculated by finding the total energy under the curve up to failure and calculating the ratio between total energy and energy at a limiting strain of $0.0008,0.002$, and 0.003 . In this section, energy absorption of reinforced and non reinforced concrete cylinders with and without wrapping is discussed. 


\subsubsection{Energy Absorption}

The stress strain curves in Appendix A were used to calculate the area under the curve that represents the energy absorbed by the wrapped concrete cylinders compared to the nonwrapped concrete cylinders. The area under the curve at a limiting strain of $0.0008,0.002$ and 0.003 is used to calculate the deformability factor. Limiting strains of 0.0008 was chosen as it is the linear region of concrete stress-strain curve and $0.002,0.003$ were chosen as it the yield value of steel and concrete, respectively.

Table 5-14 Comparison of energy for wrapped PCC Specimens with fibers running in $0^{\circ}$ and $45^{\circ}$ direction (Batch $\left.1 f_{c}{ }^{\prime}=4500 p s i\right)$

\begin{tabular}{|c|c|c|c|c|c|c|c|c|}
\hline \multirow{2}{*}{ Designation } & \multirow{2}{*}{$\begin{array}{c}\text { Fiber } \\
\text { Orientation }\end{array}$} & \multirow{2}{*}{$\begin{array}{l}\text { No. of } \\
\text { Layers }\end{array}$} & \multicolumn{3}{|c|}{ Ratio of Areas (Axial) } & \multicolumn{3}{|c|}{ Ratio of Areas (Hoop) } \\
\hline & & & 0.0008 & 0.002 & 0.003 & 0.0008 & 0.002 & 0.003 \\
\hline B1-P-4C3 & --- & --- & 15.36 & 2.87 & 1.66 & 39.29 & 6.15 & 2.1 \\
\hline B1-P-4S1 & \multirow{3}{*}{0} & \multirow{2}{*}{1} & \multirow{2}{*}{56.42} & \multirow{2}{*}{11.9} & \multirow{2}{*}{6.76} & \multirow{2}{*}{388.55} & \multirow{2}{*}{47.2} & \multirow{2}{*}{17.31} \\
\hline B1-P-4S2 & & & & & & & & \\
\hline $\begin{array}{l}\text { B1-P-4S5 } \\
\text { B1-P-4S6 }\end{array}$ & & 3 & 56.08 & 23.5 & 11.15 & 483.4 & 31.45 & 14.1 \\
\hline $\begin{array}{l}\text { B1-P-4S3 } \\
\text { B1-P-4S4 }\end{array}$ & 45 & 1 & 5.49 & 1.55 & --- & 53.59 & 12.64 & --- \\
\hline B1-P-4S7 & \multirow{2}{*}{ \pm 45} & \multirow{2}{*}{2} & \multirow{2}{*}{54.46} & \multirow{2}{*}{8.08} & \multirow{2}{*}{4.48} & \multirow{2}{*}{218.45} & \multirow{2}{*}{16.8} & \multirow{2}{*}{6.5} \\
\hline B1-P-4S8 & & & & & & & & \\
\hline
\end{tabular}

Table 5-15 Comparison of energy for wrapped RCC Specimens with fibers running in $0^{\circ}$ and $45^{\circ}$ direction (Batch $\left.1 f_{c}{ }^{\prime}=4500 p s\right)$ )

\begin{tabular}{|c|c|c|c|c|c|c|c|c|}
\hline \multirow{2}{*}{ Designation } & \multirow{2}{*}{$\begin{array}{c}\text { Fiber } \\
\text { Orientation }\end{array}$} & \multirow{2}{*}{$\begin{array}{l}\text { No. of } \\
\text { Layers }\end{array}$} & \multicolumn{3}{|c|}{ Ratio of Areas (Axial) } & \multicolumn{3}{|c|}{ Ratio of Areas (Hoop) } \\
\hline & & & .0008 & .002 & .003 & .0008 & .002 & .003 \\
\hline B1-R-4C1 & --- & --- & 4.08 & ---- & --- & 8.96 & --- & --- \\
\hline B1-R-4S1 & \multirow{3}{*}{0} & \multirow{2}{*}{1} & \multirow{2}{*}{46.18} & \multirow{2}{*}{8.25} & \multirow{2}{*}{4.22} & \multirow{2}{*}{135.18} & \multirow{2}{*}{24.19} & \multirow{2}{*}{7.88} \\
\hline B1-R-4S2 & & & & & & & & \\
\hline $\begin{array}{l}\text { B1-R-4S5 } \\
\text { B1-R-4S6 }\end{array}$ & & 3 & 102.48 & 16.8 & 9.39 & 326.08 & 26.615 & 7.57 \\
\hline $\begin{array}{l}\text { B1-R-4S3 } \\
\text { B1-R-4S4 }\end{array}$ & 45 & 1 & 50.75 & 9.37 & 5.18 & 94.96 & 12.76 & 5.76 \\
\hline B1-R-4S7 & \multirow{2}{*}{ \pm 45} & \multirow{2}{*}{2} & \multirow{2}{*}{43.75} & \multirow{2}{*}{9.06} & \multirow{2}{*}{4.8} & \multirow{2}{*}{280.6} & \multirow{2}{*}{12.92} & \multirow{2}{*}{2.15} \\
\hline B1-R-4S8 & & & & & & & & \\
\hline
\end{tabular}

---- Strain of non-wrapped specimen did not go up to 0.002 
Table 5-16 Comparison of Energy Values for PCC Specimens wrapped with fibers in $0^{\circ}$ and $45^{\circ}$ direction (Batch $2 f_{c}{ }^{\prime}=\mathbf{8 0 0 0 p s i )}$

\begin{tabular}{|c|c|c|c|c|c|c|c|c|}
\hline \multirow{2}{*}{ Designation } & \multirow{2}{*}{$\begin{array}{c}\text { Fiber } \\
\text { Orientation }\end{array}$} & \multirow{2}{*}{$\begin{array}{l}\text { No. of } \\
\text { fiber } \\
\text { Layers }\end{array}$} & \multicolumn{3}{|c|}{ Ratio of Areas (Axial) } & \multicolumn{3}{|c|}{ Ratio of Areas (Hoop) } \\
\hline & & & 0.0008 & 0.002 & 0.003 & 0.0008 & 0.002 & 0.003 \\
\hline B2-P-4C1 & --- & --- & 5.4 & 1.18 & --- & 21.24 & 1.93 & --- \\
\hline B2-P-4S1 & \multirow{5}{*}{0} & \multirow{3}{*}{1} & \multirow{3}{*}{17.51} & \multirow{3}{*}{5.08} & \multirow{3}{*}{2.715} & \multirow{3}{*}{195.29} & \multirow{3}{*}{24.72} & \multirow{3}{*}{4.12} \\
\hline B2-P-4S2 & & & & & & & & \\
\hline B2-P-4S3 & & & & & & & & \\
\hline B2-P-4S7 & & \multirow{2}{*}{3} & \multirow{2}{*}{88.58} & \multirow{2}{*}{16.5} & \multirow{2}{*}{8.67} & \multirow{2}{*}{483.2} & \multirow{2}{*}{70.79} & \multirow{2}{*}{27.28} \\
\hline B2-P-4S8 & & & & & & & & \\
\hline B2-P-4S4 & \multirow{3}{*}{45} & \multirow{3}{*}{1} & \multirow{3}{*}{12.47} & \multirow{3}{*}{2.32} & \multirow{3}{*}{1.46} & \multirow{3}{*}{102.57} & \multirow{3}{*}{20.3} & \multirow{3}{*}{2.18} \\
\hline B2-P-4S5 & & & & & & & & \\
\hline B2-P-4S6 & & & & & & & & \\
\hline B2-P-4S9 & \multirow{3}{*}{ \pm 45} & \multirow{3}{*}{2} & \multirow{3}{*}{49.85} & \multirow{3}{*}{9.38} & \multirow{3}{*}{5.39} & \multirow{3}{*}{342.2} & \multirow{3}{*}{38.14} & \multirow{3}{*}{10.65} \\
\hline B2-P-4S10 & & & & & & & & \\
\hline B2-P-4S11 & & & & & & & & \\
\hline
\end{tabular}

Table 5-17 Comparison of Energy Values for RCC Specimens wrapped with fibers in $0^{\circ}$ and $4^{\circ}$ direction (Batch $f_{c}{ }^{\prime}=8000 \mathrm{psi}$ )

\begin{tabular}{|c|c|c|c|c|c|c|c|c|}
\hline \multirow{2}{*}{ Designation } & \multirow{2}{*}{$\begin{array}{c}\text { Fiber } \\
\text { Orientation }\end{array}$} & \multirow{2}{*}{$\begin{array}{l}\text { No. of } \\
\text { fiber } \\
\text { Layers }\end{array}$} & \multicolumn{3}{|c|}{ Ratio of Areas (Axial) } & \multicolumn{3}{|c|}{ Ratio of Areas (Hoop) } \\
\hline & & & 0.0008 & 0.002 & 0.003 & 0.0008 & 0.002 & 0.003 \\
\hline B2-R-4C1 & ---- & --- & 7.2 & 1.28 & --- & 7.51 & 1.48 & --- \\
\hline B2-R-4S1 & \multirow{5}{*}{0} & \multirow{3}{*}{1} & \multirow{3}{*}{33.71} & \multirow{3}{*}{6.12} & \multirow{3}{*}{3.19} & \multirow{3}{*}{253.57} & \multirow{3}{*}{33.2} & \multirow{3}{*}{7.93} \\
\hline B2-R-4S2 & & & & & & & & \\
\hline B2-R-4S3 & & & & & & & & \\
\hline B2-R-4S7 & & \multirow{2}{*}{3} & \multirow{2}{*}{91.27} & \multirow{2}{*}{12.03} & \multirow{2}{*}{5.88} & \multirow{2}{*}{273.05} & \multirow{2}{*}{28.5} & \multirow{2}{*}{11.9} \\
\hline B2-R-4S8 & & & & & & & & \\
\hline B2-R-4S4 & \multirow{3}{*}{45} & \multirow{3}{*}{1} & \multirow{3}{*}{11.6} & \multirow{3}{*}{2.28} & \multirow{3}{*}{1.1} & \multirow{3}{*}{102.5} & \multirow{3}{*}{10.23} & \multirow{3}{*}{2.23} \\
\hline B2-R-4S5 & & & & & & & & \\
\hline B2-R-4S6 & & & & & & & & \\
\hline B2-R-4S9 & \multirow{3}{*}{ \pm 45} & \multirow{3}{*}{2} & \multirow{3}{*}{71.61} & \multirow{3}{*}{11.17} & \multirow{3}{*}{5.85} & \multirow{3}{*}{339.94} & \multirow{3}{*}{25.04} & \multirow{3}{*}{4.96} \\
\hline B2-R-4S10 & & & & & & & & \\
\hline B2-R-4S11 & & & & & & & & \\
\hline
\end{tabular}

The deformability factors of the wrapped specimen in comparison to the non-wrapped specimens are noted from Table 5-18 to 5-21. 


\section{Plain Concrete Specimens}

Table 5-18 Deformability in Axial Direction of Plain Concrete Specimens

\begin{tabular}{|c|c|c|}
\hline Wrap Type & \multicolumn{2}{|c|}{ Deformability Factor } \\
\hline & LS $^{*}=0.0008$ & LC $^{*}=0.003$ \\
\hline Non Wrapped & 10.38 & 3.5 \\
\hline Single $0^{\circ}$ & 36.96 & 4.29 \\
\hline Three $0^{\circ}$ & 125.68 & 9.19 \\
\hline Single $45^{\circ}$ & --- & --- \\
\hline $\pm 45^{\circ}$ & 52.1 & 4.9 \\
\hline
\end{tabular}

* - Limiting Strain

Table 5-19 Deformability in Hoop Direction of Plain Concrete Specimens

\begin{tabular}{|c|c|c|}
\hline Wrap Type & \multicolumn{2}{|c|}{ Deformability Factor } \\
\hline & LS $^{*}=0.0008$ & LC $^{*}=0.003$ \\
\hline Non Wrapped & 30.29 & 2.1 \\
\hline Single $0^{\circ}$ & 291.89 & 10.02 \\
\hline Three $0^{\circ}$ & 483 & 15.49 \\
\hline Single $45^{\circ}$ & 78.08 & 2.18 \\
\hline $\pm 45^{\circ}$ & 280.3 & 8.08 \\
\hline
\end{tabular}

* - Limiting Strain

\section{Reinforced Concrete Specimens}

Table 5-20 Deformability in Axial Direction of Reinforced Concrete Specimens

\begin{tabular}{|c|c|c|}
\hline Wrap Type & \multicolumn{2}{|c|}{ Deformability Factor } \\
\hline & LS $^{*}=0.0008$ & LC $^{*}=0.003$ \\
\hline Non Wrapped & 6.25 & --- \\
\hline Single $0^{\circ}$ & 40.26 & 3.69 \\
\hline Three $0^{\circ}$ & 96.87 & 7.63 \\
\hline Single $45^{\circ}$ & 10.07 & 3.1 \\
\hline $\pm 45^{\circ}$ & 51.71 & 5.32 \\
\hline
\end{tabular}

* - Limiting Strain

Table 5-21 Deformability in Hoop Direction of Reinforced Concrete Specimens

\begin{tabular}{|c|c|c|}
\hline Wrap Type & \multicolumn{2}{|c|}{ Deformability Factor } \\
\hline & LS $^{*}=0.0008$ & LS $^{*}=0.003$ \\
\hline Non Wrapped & 8.23 & \\
\hline Single $0^{\circ}$ & 195.04 & 7.9 \\
\hline Three $^{\circ}$ & 269.04 & 7.84 \\
\hline Single $45^{\circ}$ & 76.22 & 3.99 \\
\hline $3.99 \pm 45^{\circ}$ & 310.27 & 3.56 \\
\hline
\end{tabular}

*_Limiting Strain 
- Specimens wrapped with single layers of $0^{\circ}$ fiber show 3-5 times increase in energy in the axial direction and 10-15 times increase in energy in the hoop direction

- Specimens wrapped with three layers of $0^{\circ}$ fiber show 5-10 times increase in energy in the axial direction and 10-20 times increase in energy in the hoop direction

- Specimens wrapped with single layers of $45^{\circ}$ fiber show about 1-2 times increase in energy in the axial direction and 5-10 times increase in energy in the hoop direction

- Specimens wrapped with $\pm 45^{\circ}$ fiber show about 3-5 times increase in energy in the axial direction and 10-20 times increase in energy in the hoop direction

\subsection{Axial Compression Tests to Determine Size Effects}

Compression tests were conducted on 3"x6", 4"x8" and 6"x12" sized cylindrical plain concrete wrapped and non-wrapped specimens of Batch $4\left(f_{c}{ }^{\prime}=6000 \mathrm{psi}\right)$ to determine the size effect on increase in strength due to confinement and the results were plotted and tabulated.

\subsubsection{Ultimate Load}

The ultimate load values from the dial gauge were compared to the automatically recorded values from the load cell. The cylinders tested were plain concrete cylinders and cylinders with 1 and 3 layers of fiber wrap. The 6"x12" cylinder with 3 layers of fiber wrap could not be taken to failure as the cylinder capacity was beyond the 250 kips capacity of the UTM in the laboratory. The specimens are noted as B4-P-4C1 where B4 indicated batch 4, 4" diameter control specimens' number 1. 


\subsubsection{Strength of Control Specimens}

The strength of the non-wrapped control specimens of size 3"x6", 4"x8" and 6"x12" was tabulated and is shown in table 5-22. All specimens tested were plain concrete cylinders without internal reinforcement.

Table 5-22 Axial Strength of Control Specimens

\begin{tabular}{|c|c|c|c|}
\hline No & Designation & Axial Strength (lbs) & Average Strength (lbs) \\
\hline 1 & B4-P-3C1 & 59751 & \multirow{2}{*}{58559} \\
\hline 2 & B4-P-3C2 & 593767 & \\
\hline 3 & B4-P-3C3 & 56549 & \multirow{2}{*}{101650} \\
\hline 3 & B4-P-4C1 & 107475 & \\
\hline 4 & B4-P-4C2 & 103250 & \multirow{2}{*}{208500} \\
\hline 5 & B4-P-4C3 & 94225 & \\
\hline 6 & B4-P-6C1 & 219000 & \\
\hline 7 & B4-P-6C2 & 198000 & \\
\hline
\end{tabular}

\subsubsection{Strength of Wrapped Cylinders}

Strength of the wrapped cylinders was noted by using the load cell and the strength was noted from the dial gauge when the load exceeded 200 kips. The increase in strength with reference to the control specimen, of particular dimension was calculated and the increase in strength is tabulated as a percentage of the original non-wrapped specimen's strength (Table 523). 
Table 5-23 Axial Strength of Wrapped Cylinders

\begin{tabular}{|c|c|c|c|c|c|c|c|c|}
\hline No & Designation & $\begin{array}{c}\text { Number of } \\
\text { Fiber } \\
\text { Layers }\end{array}$ & $\begin{array}{l}\text { Axial } \\
\text { Strength } \\
\text { (lbs) }\end{array}$ & $\begin{array}{c}\text { Average } \\
\text { (lbs) }\end{array}$ & $\begin{array}{l}\text { Increase in } \\
\text { Strength - } \\
\text { Compared } \\
\text { to Control } \\
\text { Specimen } \\
\text { (lbs) }\end{array}$ & $\begin{array}{c}\text { Percent } \\
\text { Increase in } \\
\text { Strength - } \\
\text { Compared to } \\
\text { Control } \\
\text { Specimen }\end{array}$ & $\begin{array}{l}\text { Ratio of } \\
\text { Strength }\end{array}$ & $\begin{array}{c}\text { Average \% } \\
\text { Increase in } \\
\text { Strength }\end{array}$ \\
\hline 1 & B4-P-3S1 & \multirow{3}{*}{1} & 76125 & \multirow{3}{*}{74849} & 17566 & 24 & \multirow{3}{*}{1.29} & \multirow{3}{*}{27.22} \\
\hline 2 & B4-P-3S2 & & 74321 & & 15762 & 26 & & \\
\hline 3 & B4-P-3S3 & & 77100 & & 18540.98 & 31.66 & & \\
\hline 3 & B4-P-3S4 & \multirow{3}{*}{3} & 138950 & \multirow{3}{*}{135340} & 80390.98 & 137.28 & \multirow{3}{*}{2.31} & \multirow{3}{*}{131.33} \\
\hline 4 & B4-P-3S5 & & 127595 & & 69035.98 & 117.89 & & \\
\hline 5 & B4-P-3S6 & & 139475 & & 80915.98 & 138.17 & & \\
\hline 7 & B4-P-4S1 & \multirow{3}{*}{1} & 137170 & \multirow{3}{*}{136865} & 35520 & 34.9 & \multirow{3}{*}{1.35} & \multirow{3}{*}{34.62} \\
\hline 8 & B4-P-4S2 & & 147475 & & 45825 & 45.08 & & \\
\hline 9 & B4-P-4S3 & & 125950 & & 24300 & 23.9 & & \\
\hline 10 & B4-P-4S4 & \multirow{3}{*}{3} & 226500 & \multirow{3}{*}{219495} & 124850 & 122.8 & \multirow{3}{*}{2.15} & \multirow{3}{*}{115.92} \\
\hline 11 & B4-P-4S5 & & 215400 & & 113750 & 111.9 & & \\
\hline 12 & B4-P-4S6 & & 216585 & & 114935 & 113.06 & & \\
\hline 13 & B4-P-6S1 & \multirow[b]{2}{*}{1} & 235000 & \multirow{2}{*}{234000} & 26500 & 12.7 & \multirow{2}{*}{1.12} & \multirow{2}{*}{17} \\
\hline 14 & B4-P-6S2 & & 233000 & & 24500 & 21.3 & & \\
\hline
\end{tabular}

Wrapped 3"x6" plain concrete cylinders show an average increase in strength of about $28 \%$ while the 4 "x 8 " specimens showed an increase in strength of $35 \%$ and the 6 "x 12 " specimens showed $17 \%$ increase

3 "x6" specimens wrapped with 3 layers of fibers show an increase of $131 \%$ while the 4 " $x 8$ " specimens show an average increase of $115 \%$. Other authors report reduction in strength with increasing cross section as well (Masia, 2004).

Increase in strength per layer of CFRP is $43.67 \%$ in 3"x6" specimens and $38.3 \%$ in 4 "x 8 " specimens when wrapped with 3 layers of CFRP.

\subsubsection{Load/Strain Plots}

The load strain plots were made from the results of the specimens of batch 4 listed in Table 5-16 and 5-17, which were tested using strain gauges. One specimen in each type was attached with a gauge. The plots are shown in Figure 5-25 to 5-27. 


\subsubsection{Non Wrapped Specimen}

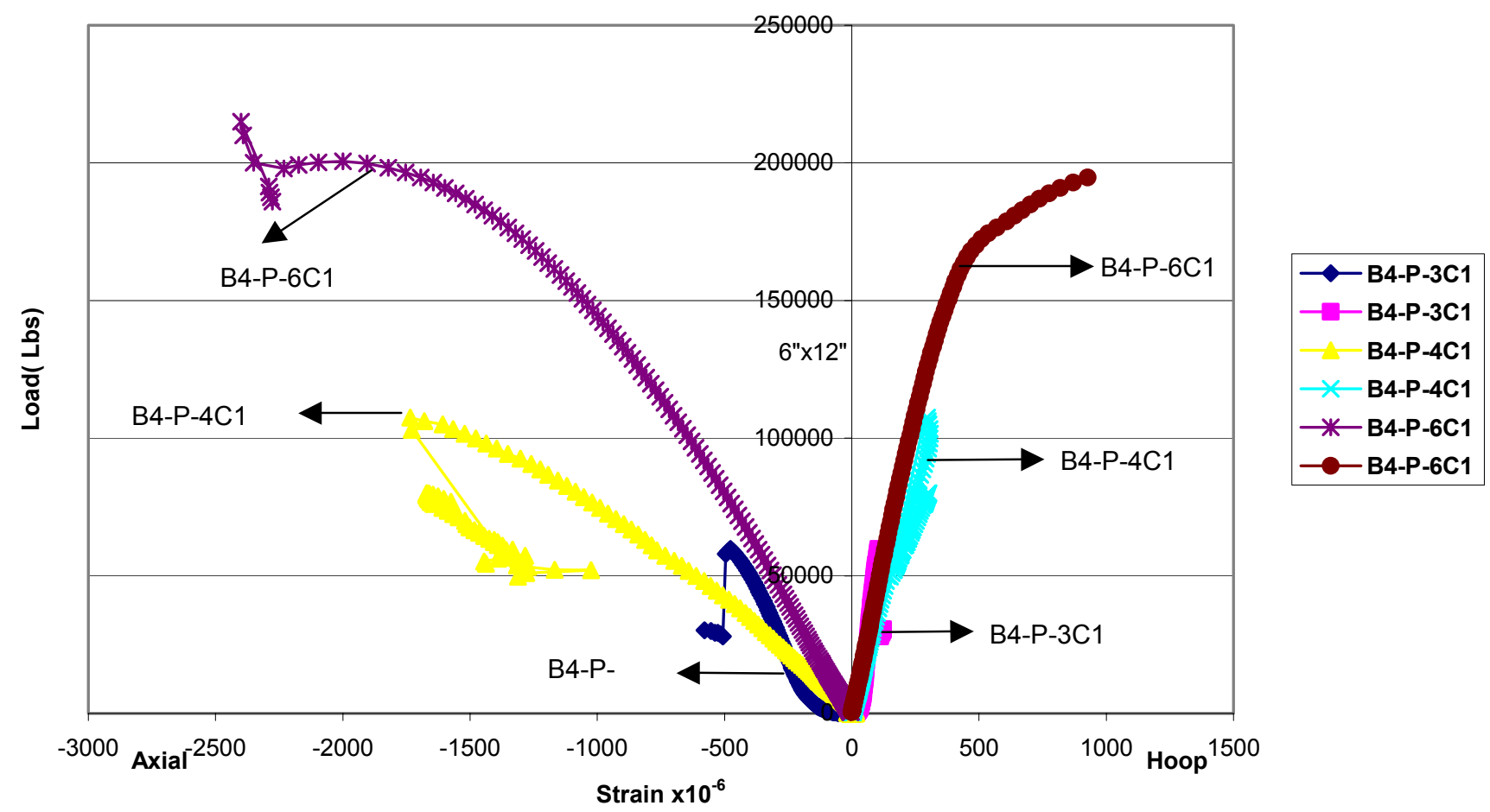

Figure 5-25 Load Strain Comparison of Non Wrapped Specimens - Size Effects

\subsubsection{Wrapped Specimens}

Concrete cylindrical specimens of varying sizes wrapped with 1 or 2 wraps were compared to determine the effect of size or the effect of cross sectional area on the increase in strength due to confinement. 


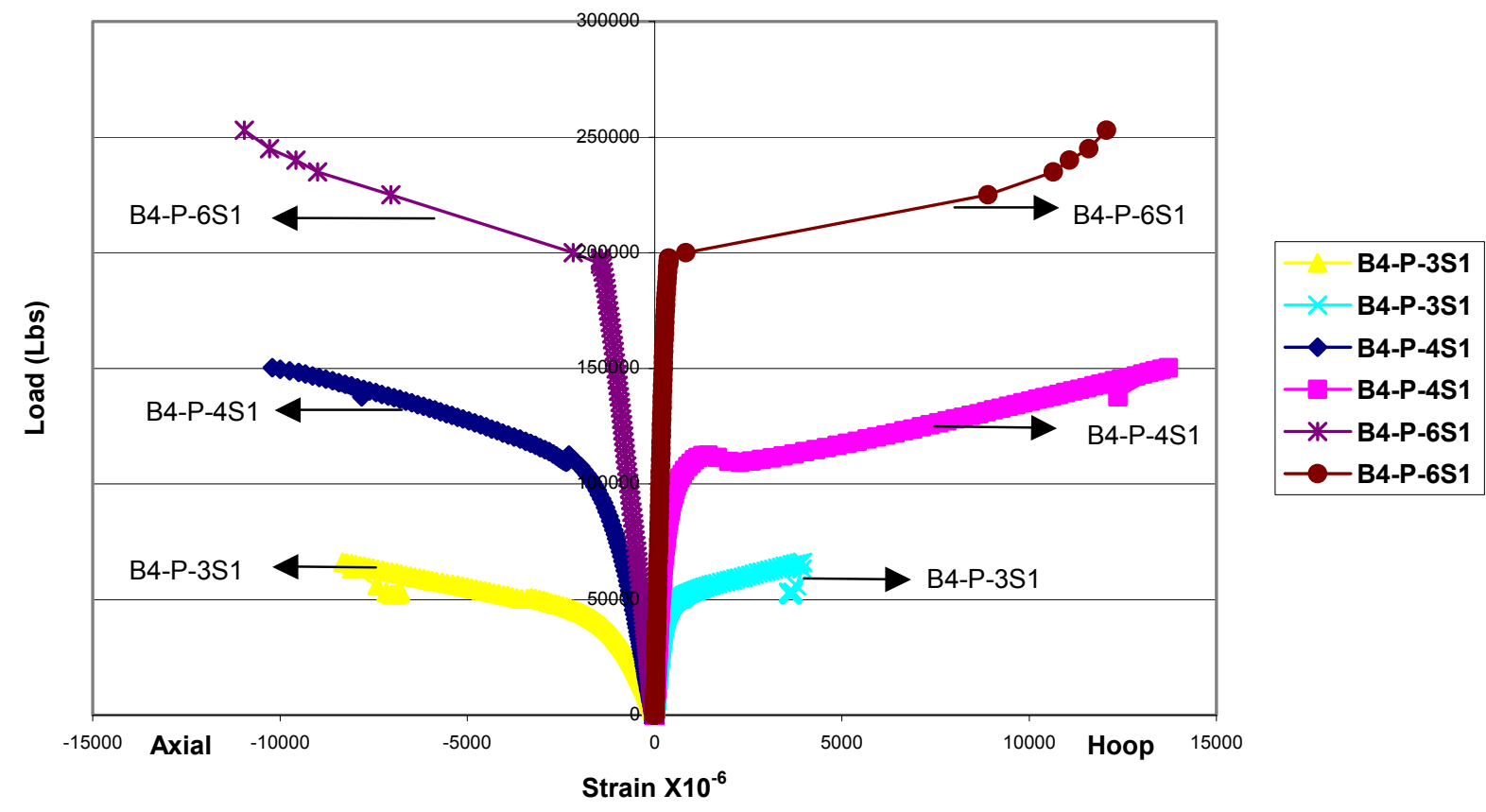

Figure 5-26 Comparison of load Strain to Determine Size Effect in Specimens Wrapped with 1 Layer of Fiber Wrap

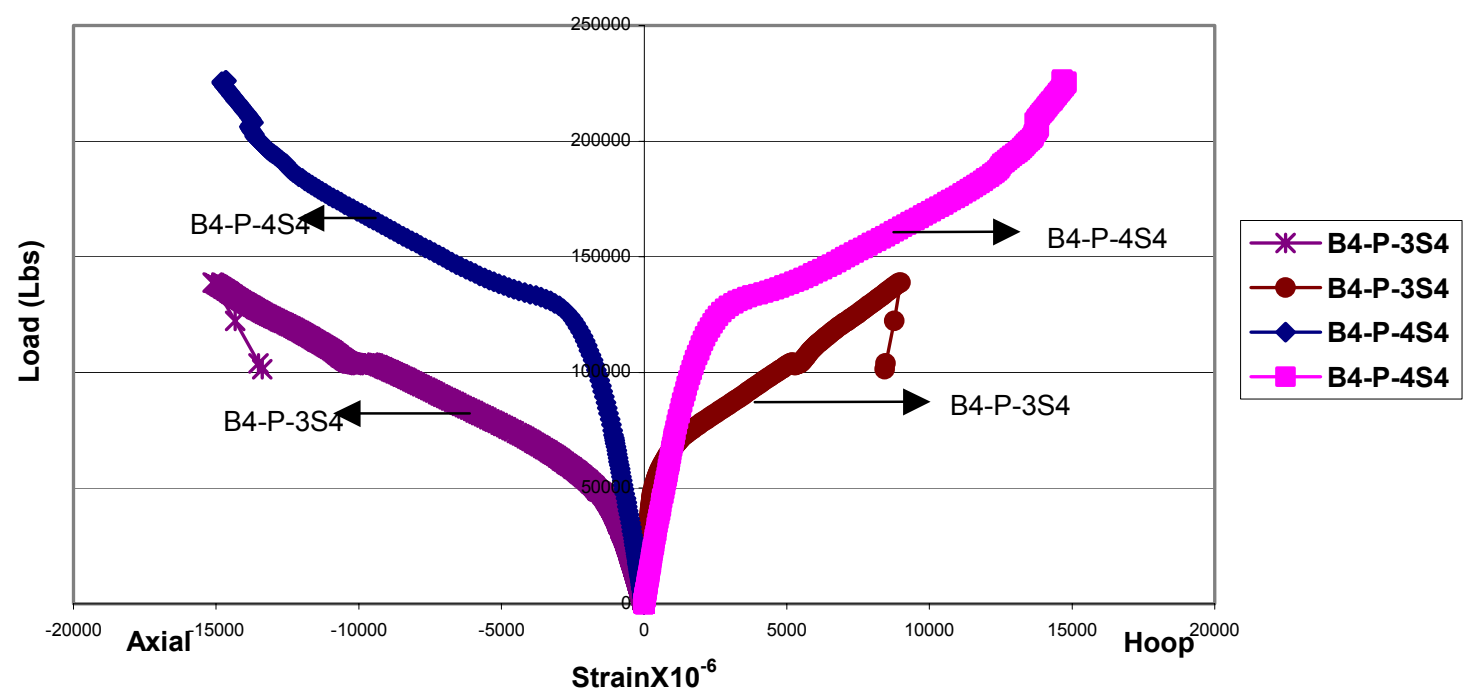

Figure 5-27 Load Strain Comparison of Size Effect in Specimens Wrapped with 3 Layer of Fiber Wrap 


\subsubsection{Failure Stress/Strain}

The specimens were tested to failure and the values of the failure load and strain were noted. The failure stress was calculated by taking a ratio between the applied load and the area of concrete cross section. The effect of wrap thickness was not considered. Gages were attached onto one specimen from each type and hence strain values are tabulated only for those specimens with attached gauges.

Table 5-24 Failure Stress and Strain of Non Wrapped Specimens

\begin{tabular}{|c|c|c|c|c|c|}
\hline No & Designation & Axial Stress (psi) & Average & Axial Strain $\times 10^{-6}$ & Hoop Strain $\times 10^{-6}$ \\
\hline 1 & B4-P-3C1 & 8453.1 & \multirow{3}{*}{8284.4} & $-477^{*}$ & $107.5^{*}$ \\
\hline 2 & B4-P-3C2 & 8400.113 & & --- & --- \\
\hline 3 & B4-P-3C3 & 8000 & & --- & --- \\
\hline 3 & B4-P-4C1 & 8552.589 & \multirow{3}{*}{8089.45} & -1735.24 & 295.16 \\
\hline 4 & B4-P-4C2 & 8216.374 & & --- & --- \\
\hline 5 & B4-P-4C3 & 7498.187 & & --- & --- \\
\hline 6 & B4-P-6C1 & 7745.514 & \multirow{2}{*}{7374.16} & -2350.14 & 926 \\
\hline 7 & B4-P-6C2 & 7002.817 & & --- & --- \\
\hline
\end{tabular}

* Low Values (0.003 (axial) and 0.0006 (hoop) was assumed)

Gauges were not fixed in the specimens in which the strain values are not tabulated

Table 5-25 Stress and Strain of Wrapped Specimens

\begin{tabular}{|c|c|c|c|c|c|c|c|c|}
\hline No & Designation & $\begin{array}{c}\text { Number } \\
\text { of Fiber } \\
\text { Layers }\end{array}$ & $\begin{array}{c}\text { Axial } \\
\text { Stress (psi) }\end{array}$ & $\begin{array}{l}\text { Average } \\
\text { (lbs) }\end{array}$ & $\begin{array}{c}\text { Axial Strain } \\
\times 10^{-6}\end{array}$ & $\begin{array}{c}\text { Increase } \\
\text { in Axial } \\
\text { Strain }\end{array}$ & $\begin{array}{l}\text { Hoop } \\
\text { Strain } \\
\times 10^{-6}\end{array}$ & $\begin{array}{c}\text { Increase } \\
\text { in Axial } \\
\text { Strain }\end{array}$ \\
\hline 1 & B4-P-3S1 & \multirow{3}{*}{1} & 10769 & \multirow{3}{*}{10730} & -8389 & 2.79 & 4707 & 6.78 \\
\hline 2 & B4-P-3S2 & & 10514 & & --- & & --- & \\
\hline 3 & B4-P-3S3 & & 10907.42 & & --- & & --- & \\
\hline 3 & B4-P-3S4 & \multirow{3}{*}{3} & 19657.4 & \multirow{3}{*}{19146} & -15115.56 & 5.03 & 8987.19 & 14.9 \\
\hline 4 & B4-P-3S5 & & 18051 & & --- & & --- & \\
\hline 5 & B4-P-3S6 & & 19731.68 & & --- & & --- & \\
\hline 6 & B4-P-4S1 & \multirow{3}{*}{1} & 10915.64 & \multirow{3}{*}{11462} & -10207.49 & 3.4 & 13717.26 & 22.86 \\
\hline 7 & B4-P-4S2 & & 11735.69 & & --- & & --- & \\
\hline 8 & B4-P-4S3 & & 11735.69 & & --- & & --- & \\
\hline 9 & B4-P-4S4 & \multirow{3}{*}{3} & 18024.3 & \multirow{3}{*}{17467} & -14637.83 & 4.88 & 14669.84 & 24.45 \\
\hline 10 & B4-P-4S5 & & 17140.99 & & --- & & --- & \\
\hline 11 & B4-P-4S6 & & 17235.29 & & --- & & --- & \\
\hline 12 & B4-P-6S1 & \multirow{2}{*}{1} & 8311.425 & \multirow{2}{*}{8276} & -10947.54 & 3.6 & 12065.54 & 20.1 \\
\hline 13 & B4-P-6S2 & & 8240 & & --- & & --- & \\
\hline
\end{tabular}

Gauges were not fixed in the specimens in which the strain values are not tabulated 
- The increase in axial strain of single $0^{\circ}$ wrapped 3" x 6", 4"x 8" and 6"x 12"specimens was 2.79, 3.4 and 3.6respectively (Table 5-18 and 5-19).

- The increase in hoop strain of single $0^{\circ}$ wrapped 3" x 6", 4"x 8" and 6"x 12"specimens was $1.56,22.86$ and 20.1 respectively (Table 5-18 and 5-19).

\subsection{Axial Compression Tests to Determine the Effect of Number of \\ Layers}

Compression tests were conducted on 3"x6" cylindrical specimens of batch 4 to determine the difference in the increase in strength due to varying number of FRP wraps on the plain concrete cylinders. The strength of the concrete specimen was increased by wrapping the cylinders and the increase varied with increasing the number of layers of wrap. The rate of this increase was determined by wrapping cylinders with 1,3 and 6 layers of wrap.

\subsubsection{Ultimate Load}

The ultimate load at which the specimen fails was noted from the load cell readings and dial gage of the compression machine was used to note the load in excess of 200 kips. The strength increase due to increased number of wraps was calculated by comparing the values to the average of the non-wrapped failure strength. 
Table 5-26 Strength of Wrapped and Non Wrapped Specimens

\begin{tabular}{|c|c|c|c|c|c|c|c|c|c|}
\hline No & Designation & $\begin{array}{c}\text { Number } \\
\text { of Fiber } \\
\text { Layers }\end{array}$ & $\begin{array}{l}\text { Axial } \\
\text { Strength } \\
\text { (lbs) }\end{array}$ & $\begin{array}{l}\text { Increase } \\
\text { in } \\
\text { strength } \\
\text { (lbs) }\end{array}$ & $\begin{array}{l}\text { Increase in } \\
\text { Strength } \\
\text { per layer } \\
\text { of Fiber } \\
\text { Wrap (lbs) }\end{array}$ & $\begin{array}{c}\text { Average } \\
\text { Strength } \\
\text { (lbs) }\end{array}$ & $\begin{array}{l}\text { Average } \\
\text { Increase } \\
\text { in } \\
\text { Strength } \\
\text { Per Layer } \\
\text { (lbs) }\end{array}$ & $\begin{array}{l}\text { Ratio of } \\
\text { increase } \\
\text { in } \\
\text { Strength }\end{array}$ & $\begin{array}{l}\text { Average } \\
\text { percent } \\
\text { Increase } \\
\text { in } \\
\text { Strength } \\
\text { per Layer }\end{array}$ \\
\hline 1 & B4-P-3C1 & \multirow{3}{*}{--} & 59751.5 & --- & -- & \multirow{3}{*}{58559.02} & \multirow{3}{*}{---} & \multirow{3}{*}{--} & \multirow{3}{*}{---} \\
\hline 2 & B4-P-3C2 & & 59376.9 & --- & --- & & & & \\
\hline 3 & B4-P-3C3 & & 56548.67 & --- & --- & & & & \\
\hline 1 & B4-P-3S1 & \multirow{3}{*}{1} & 76125 & 17566 & 17566 & \multirow{3}{*}{75848.67} & \multirow{3}{*}{17290} & \multirow{3}{*}{1.29} & \multirow{3}{*}{27.22} \\
\hline 2 & B4-P-3S2 & & 74321 & 15762 & 15762 & & & & \\
\hline 3 & B4-P-3S3 & & 77100 & 18541 & 18541 & & & & \\
\hline 3 & B4-P-3S4 & \multirow{3}{*}{3} & 138950 & 80391 & 26797 & \multirow{3}{*}{135340} & \multirow{3}{*}{25593} & \multirow{3}{*}{2.31} & \multirow{3}{*}{43.7} \\
\hline 4 & B4-P-3S5 & & 127595 & 69036 & 23012 & & & & \\
\hline 5 & B4-P-3S6 & & 139475 & 80916 & 26972 & & & & \\
\hline 6 & B4-P-3S7 & \multirow{3}{*}{6} & 185275 & 126716 & 21119 & \multirow{3}{*}{177783} & \multirow{3}{*}{19870} & \multirow{3}{*}{3.04} & \multirow{3}{*}{33.93} \\
\hline 7 & B4-P-3S8 & & 174860 & 116301 & 19384 & & & & \\
\hline 8 & B4-P-3S9 & & 173215 & 114656 & 19109 & & & & \\
\hline
\end{tabular}

Specimens with a single layer of fiber wrap showed an increase in strength of $28 \%$ while specimens with 3 layers show an increase in strength of $43 \%$ and the cylinders wrapped with 6 layers show an increase in strength of 33\%.

The increase in strength of as shown in Table 5-20 is 17 kip per layer for specimens wrapped with single layer of CFRP and 25 kips per layer for specimens wrapped with 3 layers and 19.8 kips per layer for specimens wrapped with 6 layers of CFRP.

The increase in strength when compared to the non-wrapped specimens is 1.29 for single wrap, 2.31 for 3 wraps and 3.04 for 6 wraps.

Due to increased number of wraps the specimens have an increase in strength but the increase decreases as seen in Table 5-20 for specimens with 6 wraps. This is because of the shear lag between the resin and the fiber once the fiber thickness increases as in 6 layers.

The specimens wrapped with 3 layers show a high increase in strength per layer of fabric. However this increase needs to be evaluated with other core sizes. 


\subsubsection{Load/Strain Plots}

One specimen of each type was fixed with a strain gauge in the axial and hoop direction. Axial and hoop strains were recorded using the gauge and the applied load was directly read from the data acquisition system.

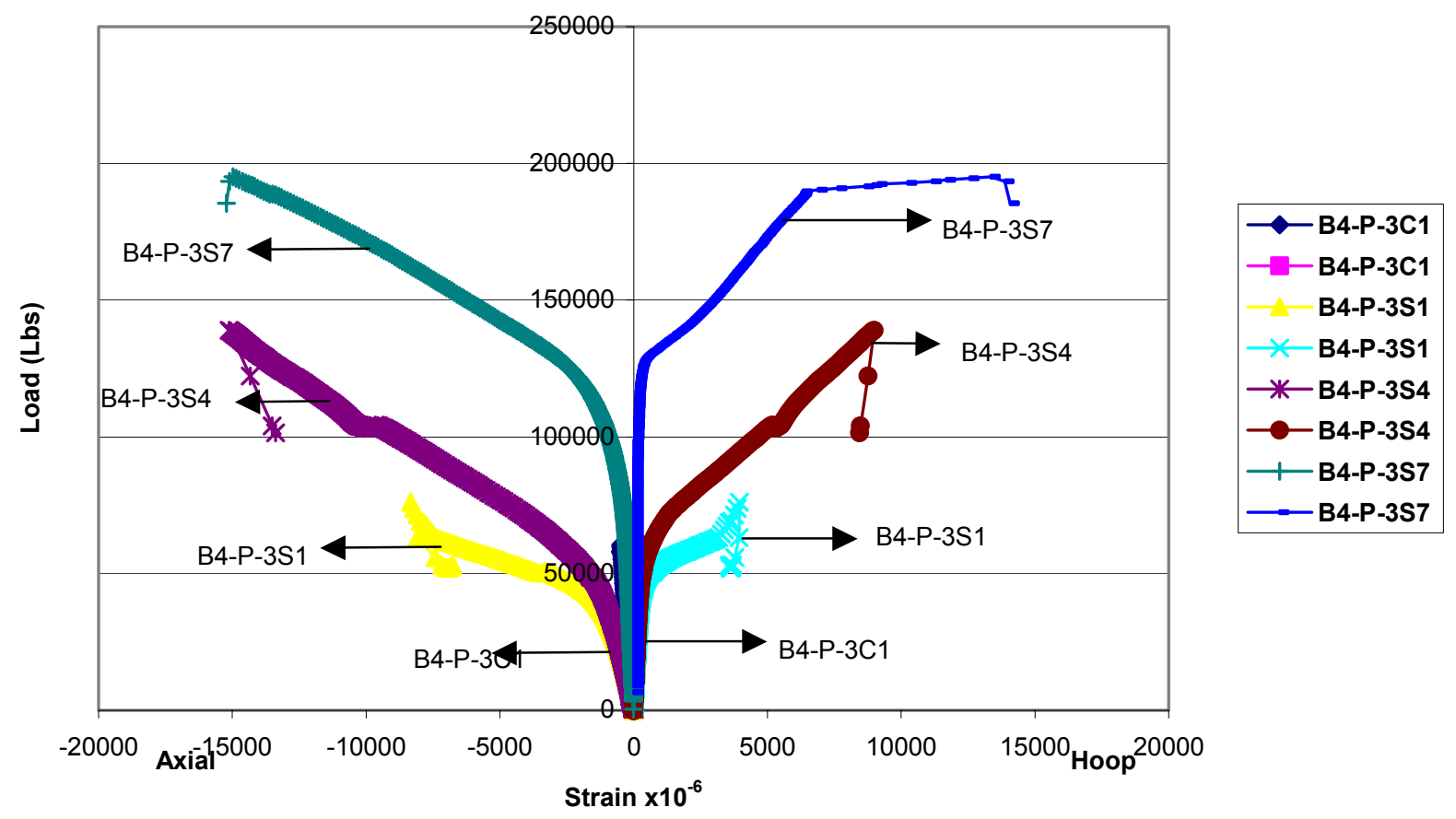

Figure 5-28 Comparison of Effect of Number of Fiber Layers

$>$ The load strain plots of the tested specimens show a bilinear curve in the case of a single wrapped specimen. Up to a strain value of -2000 microstrains the curve is linear and then after the bifurcation point it follows a different slope, which is lower than the initial slope. (Figure 5-26 and 5-27)

The initial stress strain plot slope is the region in which the compressive load is taken by the plain concrete and the second curve is the concrete and the wrap acting together and the specimen taking a different slope. 


\subsubsection{Failure Stress/Strain}

Failure strain values were obtained from the strain gauges that were bonded on one specimen of each type. The stress is calculated as the ratio of applied load to concrete specimen cross sectional area.

Table 5-27 Stress and Strain of Specimens-Number of Layers

\begin{tabular}{|c|c|c|c|c|c|c|c|}
\hline No & Designation & $\begin{array}{c}\text { Number of } \\
\text { Fiber } \\
\text { Layers }\end{array}$ & $\begin{array}{l}\text { Axial } \\
\text { Stress } \\
\text { (psi) }\end{array}$ & $\begin{array}{l}\text { Axial Strain } \\
\times 10^{-6}\end{array}$ & $\begin{array}{l}\text { Increase in } \\
\text { Axial Strain }\end{array}$ & $\begin{array}{l}\text { Hoop Strain } \\
\times 10^{-6}\end{array}$ & $\begin{array}{l}\text { Increase in } \\
\text { Hoop Strain }\end{array}$ \\
\hline 1 & B4-P-3C1 & \multirow{3}{*}{--- } & 8453 & $-477 *$ & & $107.5 *$ & \\
\hline 2 & B4-P-3C2 & & 8400 & --- & & -- & \\
\hline 3 & B4-P-3C3 & & 8000 & --- & & --- & \\
\hline 4 & B4-P-3S1 & \multirow{3}{*}{1} & 10769 & --8389 & 2.79 & 4071 & 6.78 \\
\hline 5 & B4-P-3S2 & & 10514 & --- & & --- & \\
\hline 6 & B4-P-3S3 & & 10907 & --- & & --- & \\
\hline 7 & B4-P-3S4 & \multirow{3}{*}{3} & 19657 & -15116 & 5.03 & 8987 & 14.9 \\
\hline 8 & B4-P-3S5 & & 18051 & --- & & --- & \\
\hline 9 & B4-P-3S6 & & 19732 & --- & & $\begin{array}{l}-- \\
\end{array}$ & \\
\hline 10 & B4-P-3S7 & \multirow{3}{*}{6} & 26211 & -14980 & 5.0 & 14071 & 23.45 \\
\hline 11 & B4-P-3S8 & & 24738 & --- & & --- & \\
\hline 12 & B4-P-3S9 & & 24505 & --- & & --- & \\
\hline
\end{tabular}

* Low Value of Strain (0.003(axial) and 0.0006(hoop) was assumed)

Gauges were not fixed in the specimens in which the strain values are not tabulated

\subsubsection{Failure Modes}

The failure modes of the specimens wrapped with 1,3 and 6 wraps were recorded using a digital camera. The failure modes are shown in the Figures 5-29 to 5-32. 


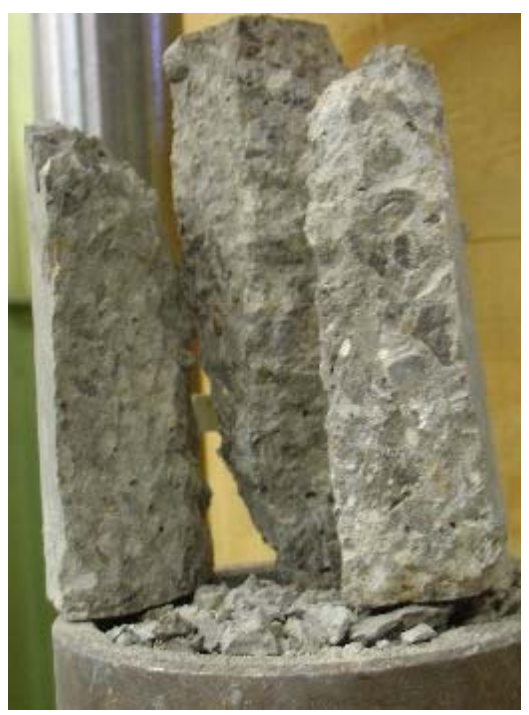

Figure 5-29 Failure in Non Wrapped 3"x 6" Specimen

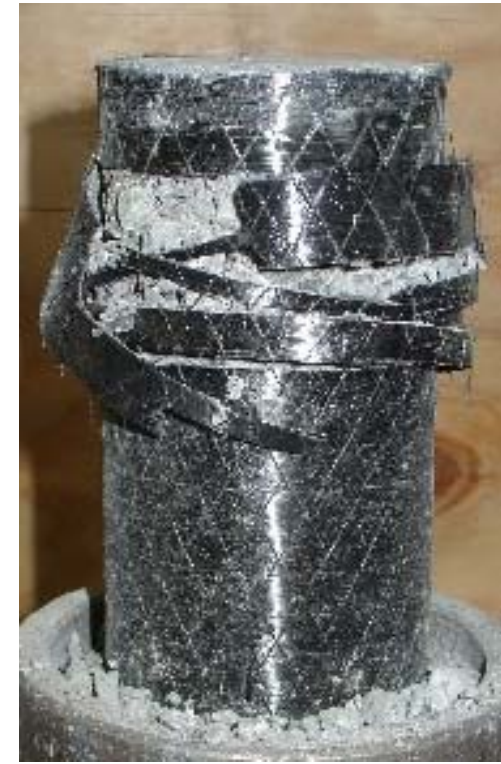

Figure 5-30 Failure in One layer FRP Wrapped 3"x 6" Specimen 


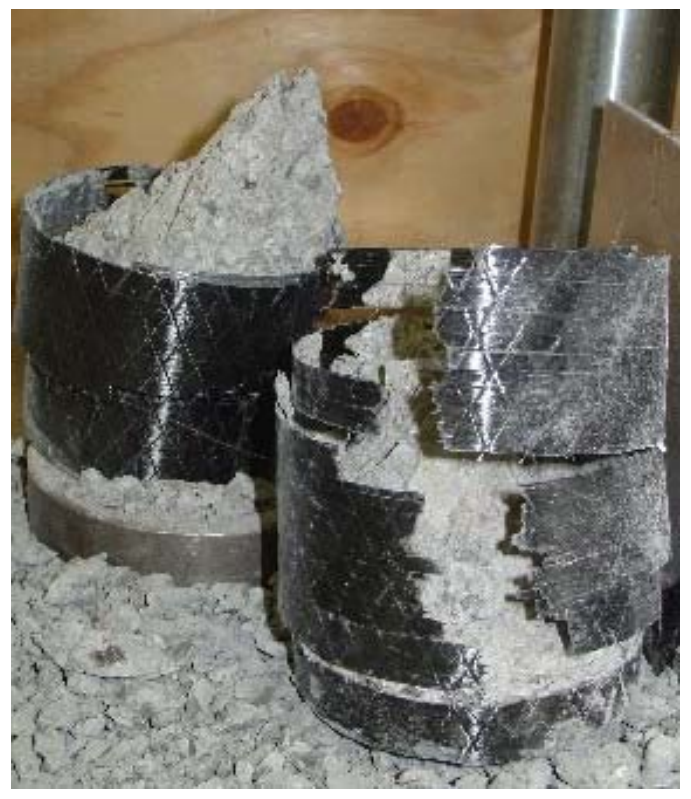

Figure 5-31 Failure in Three layer FRP Wrapped 3"x 6" Specimen

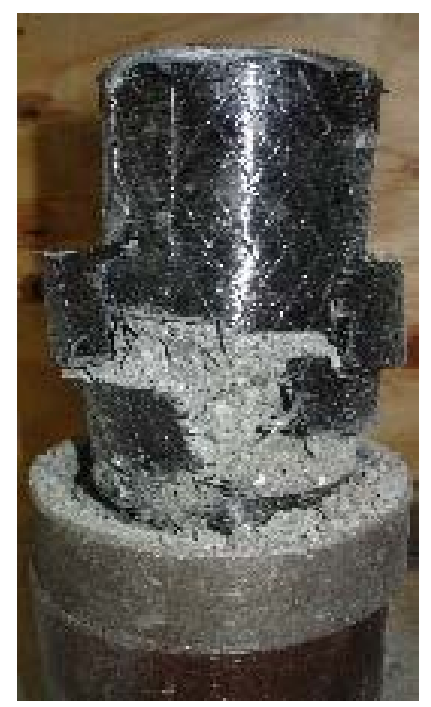

Figure 5-32 Failure in Six Layer FRP Wrapped 3"x 6" Specimen

- Plain Concrete specimens of 3", 4" and 6" diameter fail in the form of complete concrete crushing and break into pieces (Figure 5-29).

- Specimens of 3", 4" and 6" diameter wrapped with a single layer of FRP fail in the form of wrap rapture at cylinder mid height where the recorded hoop strain was maximum (Figure 5-30). 
- Specimens with 3 wraps had a sudden type of failure with wrap rupture followed by specimen splitting (Figure 5-31).

- Specimens with 6 wraps failed at particular locations while the rest of the specimen remained intact (Figure 5-32).

\subsection{Axial Compression Tests to Determine Effects of Height and Position of Wrap}

Tests were conducted on 3"x 6" cylinders of batch 5, completely wrapped with 1 layer of FRP and the results were compared to the specimens wrapped with FRP leaving a gap of $1 / 2 ", 1$ ” and $1 \frac{1}{2}$ " at both top and bottom in terms of maximum strength and the failure modes. The schematics of these cylinders with partial wrapping are shown in Figure 4-7. The cylinders had an $f_{c}$ ' of $6000 \mathrm{psi}$ and the increase in strength due to full and partial wrapping was evaluated.

Tests were conducted on batch 6 specimens of size 3"x 6"with a compressive strength of 5000 psi. Two specimens each were wrapped partially leaving a gap of $1 \frac{1}{2}$ " and 1 " from top and bottom, and two specimens each were wrapped with CFRP only at the top and bottom for a height of 1 " and $1 \frac{1}{2} "$ " Two additional specimens were wrapped completely and tested to failure in compression. The specimens are shown in chapter 4, Figure 4-7.

\subsubsection{Ultimate Load}

The ultimate load capacity recorded using the load cell of the cylinders from batch $5\left(f_{c}{ }^{\prime}=6000 \mathrm{psi}\right)$ and batch $6\left(f_{c}{ }^{\prime}=5000 \mathrm{psi}\right)$ were used to determine the effects of partial wrapping. 
Table 5-28 Strength of Partially Wrapped Specimens (Batch 5 and Batch 6)

\begin{tabular}{|c|c|c|c|c|c|c|}
\hline No & Designation & Wrap Type & $\begin{array}{l}\text { Axial Strength } \\
\text { (lbs) }\end{array}$ & $\begin{array}{c}\text { Average } \\
\text { Increase in } \\
\text { Strength }\end{array}$ & $\begin{array}{c}\text { Percent Change } \\
\text { in Strength - } \\
\text { Compared to } \\
\text { Control } \\
\text { Specimen }\end{array}$ & $\begin{array}{l}\text { Average } \\
\text { Percent } \\
\text { Increase in } \\
\text { Strength }\end{array}$ \\
\hline 1 & B5-P-3C1 & Non Wrapped & 43625 & -- & -- & --- \\
\hline 2 & B5-P-3S1 & \multirow{2}{*}{ Full } & 66125 & \multirow{2}{*}{1.49} & 51.58 & \multirow{2}{*}{49.29} \\
\hline 3 & B5-P-3S2 & & 64317 & & 47 & \\
\hline 4 & B5-P-3S3 & \multirow{2}{*}{0.5 " Height Gap } & 58800 & \multirow{2}{*}{1.38} & 34 & \multirow{2}{*}{38.5} \\
\hline 5 & B5-P-3S4 & & 61298 & & 43 & \\
\hline 6 & B5-P-3S5 & \multirow{2}{*}{ 1" Height Gap } & 45825 & \multirow{2}{*}{1.06} & 5.04 & \multirow{2}{*}{6.02} \\
\hline 7 & B5-P-3S6 & & 46999 & & 7 & \\
\hline 8 & B5-P-3S7 & \multirow{2}{*}{ 1.5" Height Gap } & 35180 & \multirow{2}{*}{$0.77 *$} & $-19 *$ & \multirow{2}{*}{$-22 *$} \\
\hline 9 & B5-P-3S8 & & 32525 & & $-25^{*}$ & \\
\hline 10 & B6-P-3C1 & \multirow{3}{*}{ Non Wrapped } & \multirow{3}{*}{38000} & \multirow{3}{*}{--- } & \multirow{3}{*}{---} & \multirow{3}{*}{--- } \\
\hline 11 & B6-P-3C2 & & & & & \\
\hline 12 & B6-P-3C3 & & & & & \\
\hline 13 & B6-P-3S1 & \multirow{2}{*}{ Fully Wrapped } & 56000 & \multirow{2}{*}{1.52} & 47 & \multirow{2}{*}{52} \\
\hline 14 & B6-P-3S2 & & 60000 & & 57 & \\
\hline 15 & B6-P-3S3 & \multirow{2}{*}{ 1" Height Gap } & 46000 & \multirow{2}{*}{1.26} & 21 & \multirow{2}{*}{26} \\
\hline 16 & B6-P-3S4 & & 50000 & & 31 & \\
\hline 17 & B6-P-3S5 & \multirow{2}{*}{ 1.5" Height Gap } & 33000 & \multirow{2}{*}{$0.89 *$} & $-13 *$ & \multirow{2}{*}{-10.4} \\
\hline 18 & B6-P-3S6 & & 35000 & & $-7.8^{*}$ & \\
\hline 19 & B6-P-3S7 & \multirow{2}{*}{$\begin{array}{l}1 " \text { Height wrap } \\
\text { at top \& Bottom }\end{array}$} & 48000 & \multirow{2}{*}{1.29} & 26 & \multirow{2}{*}{28.75} \\
\hline 20 & B6-P-3S8 & & 50000 & & 31.5 & \\
\hline 21 & B6-P-3S9 & \multirow{2}{*}{$\begin{array}{l}1.5 \text { " Height wrap } \\
\text { at top \& Bottom }\end{array}$} & 53750 & \multirow{2}{*}{1.45} & 41.4 & \multirow{2}{*}{45.05} \\
\hline 22 & B6-P-3S10 & & 56525 & & 48.7 & \\
\hline
\end{tabular}

- Values indicate loss of Strength

Table 5-29 Comparison of Average Strength Increase of Partially Wrapped Cylinders

\begin{tabular}{|c|c|c|}
\hline $\begin{array}{c}\text { Specimens with middle } \\
\text { Wrapping }\end{array}$ & $\begin{array}{c}\text { Batch } 1\left(f_{c}{ }^{\prime}=6000 \mathrm{psi}\right) \text { Increase } \\
\text { in Strength }\end{array}$ & $\begin{array}{c}\text { Batch 2 }\left(f_{c}{ }^{\prime}=3500 \mathrm{psi}\right) \text { Increase } \\
\text { in Strength }\end{array}$ \\
\hline $\begin{array}{c}\text { Fully Wrapped } \\
\begin{array}{c}1 / 2 " \text { height gap at top and } \\
\text { bottom }\end{array}\end{array}$ & $39 \%$ & $52 \%$ \\
\hline $\begin{array}{c}1 \text { " height gap at top and } \\
\text { bottom }\end{array}$ & $7 \%$ & $20 \%$ \\
\hline $\begin{array}{c}1 \frac{1}{2} \text { " height gap at top and } \\
\text { bottom }\end{array}$ & $-21 \%$ & $-10 \%$ \\
\hline 1 "Wrap at top and bottom & $---*$ & $28.75 \%$ \\
\hline $1 \frac{1 / 2 " \text { wrap at top and }}{\text { bottom }}$ & $---*$ & $45 \%$ \\
\hline
\end{tabular}

---* Tests were not conducted

- Specimen with $1 / 2$ " and 1" wrap gap at top and bottom showed slight difference in strength compared to non-wrapped specimen due to wrapping (Table 5-29). The 
specimen with $1 \frac{1}{2}$ " gap in wrap failed even before the center confined portion showed any signs of the wrap failing. Wrapped middle section was stiffer then the non-wrapped top and bottom portions. This resulted in concrete crushing at non-wrapped top and bottom portions of the cylinder. Such crushing failure was also noticed with change in failure plain contributing to reduction in failure stress than regular sized specimens. Stress concentration due to irregular wrapping also resulted in failure at lower stress value.

- Specimens wrapped with fiber at cylinder top and bottom show a higher increase in load than specimens wrapped only in the middle. This is because the load is applied evenly onto the whole concrete cylinder and the wrap at the edges hold the specimen together for a longer period.

\subsubsection{Load/Strain Plots}

The applied load directly measured using the load cell was plotted against the strain readings measured from strain gauges attached to one specimen in each category of partial wrap (Figure 5-33). 


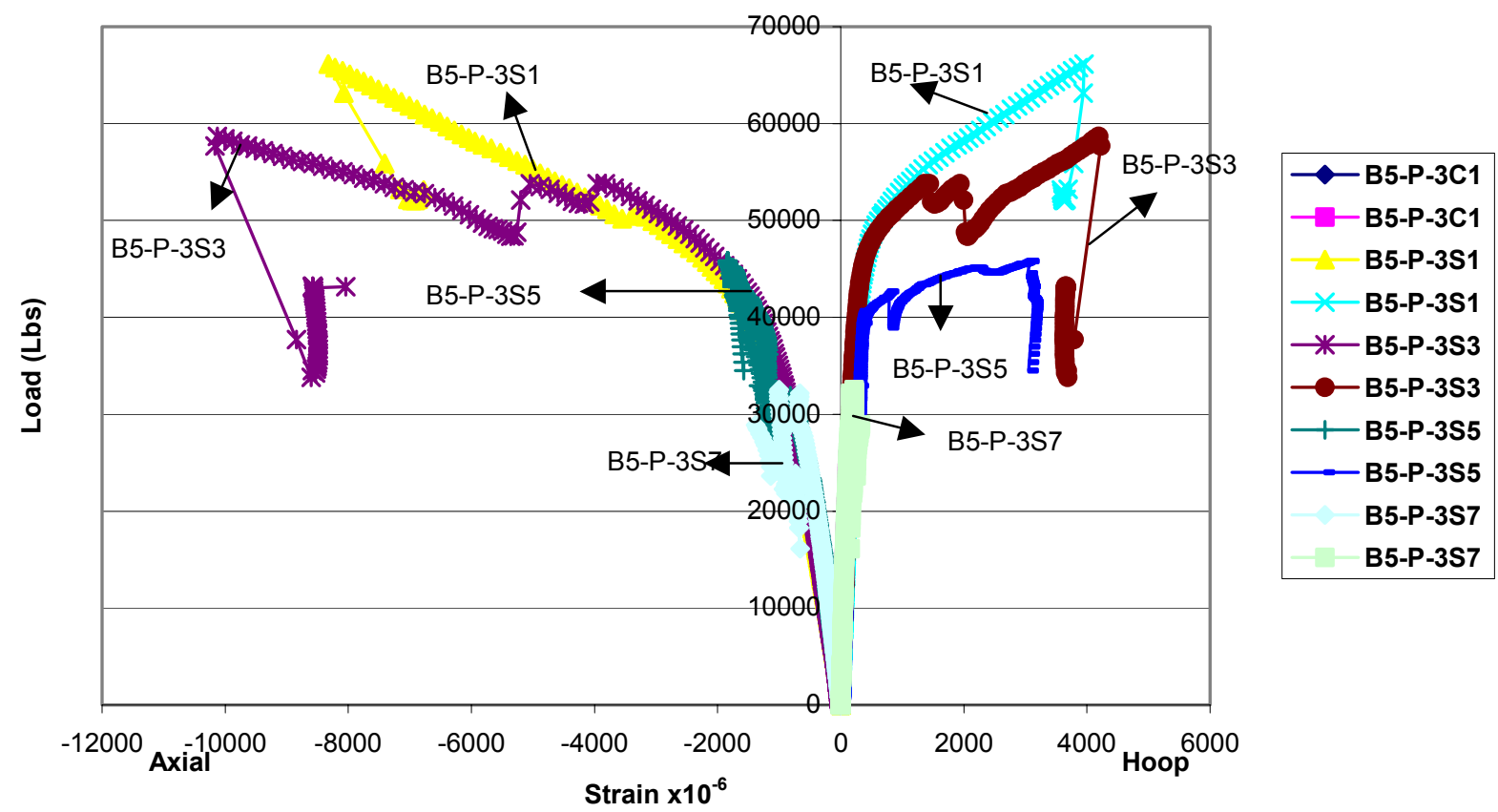

Figure 5-33 Load Strain Comparison of Partially Wrapped 3"x 6" Cylinders in Table 5-28

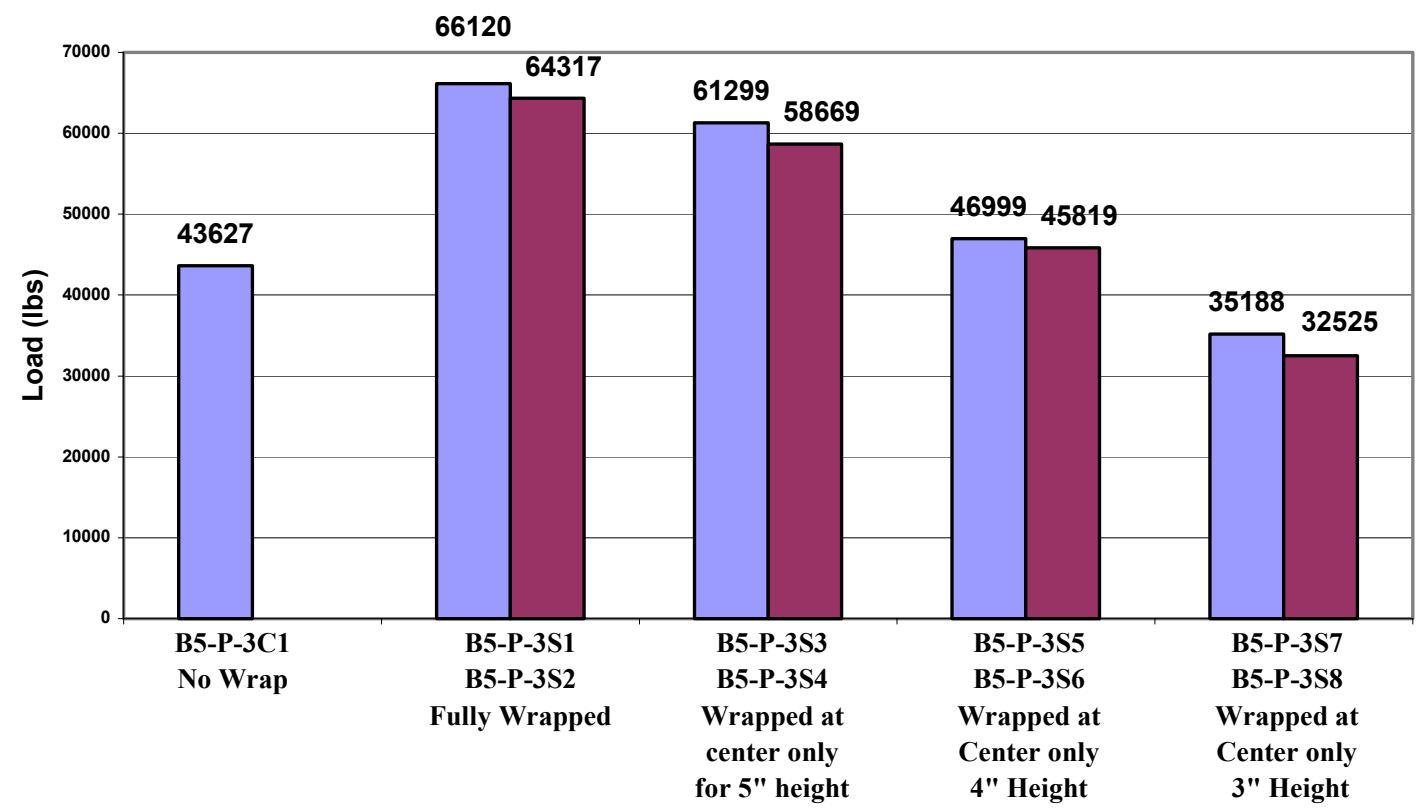

Figure 5-34 Comparison of Maximum Load of Partially Wrapped Concrete Cylinders in Table 5-28 


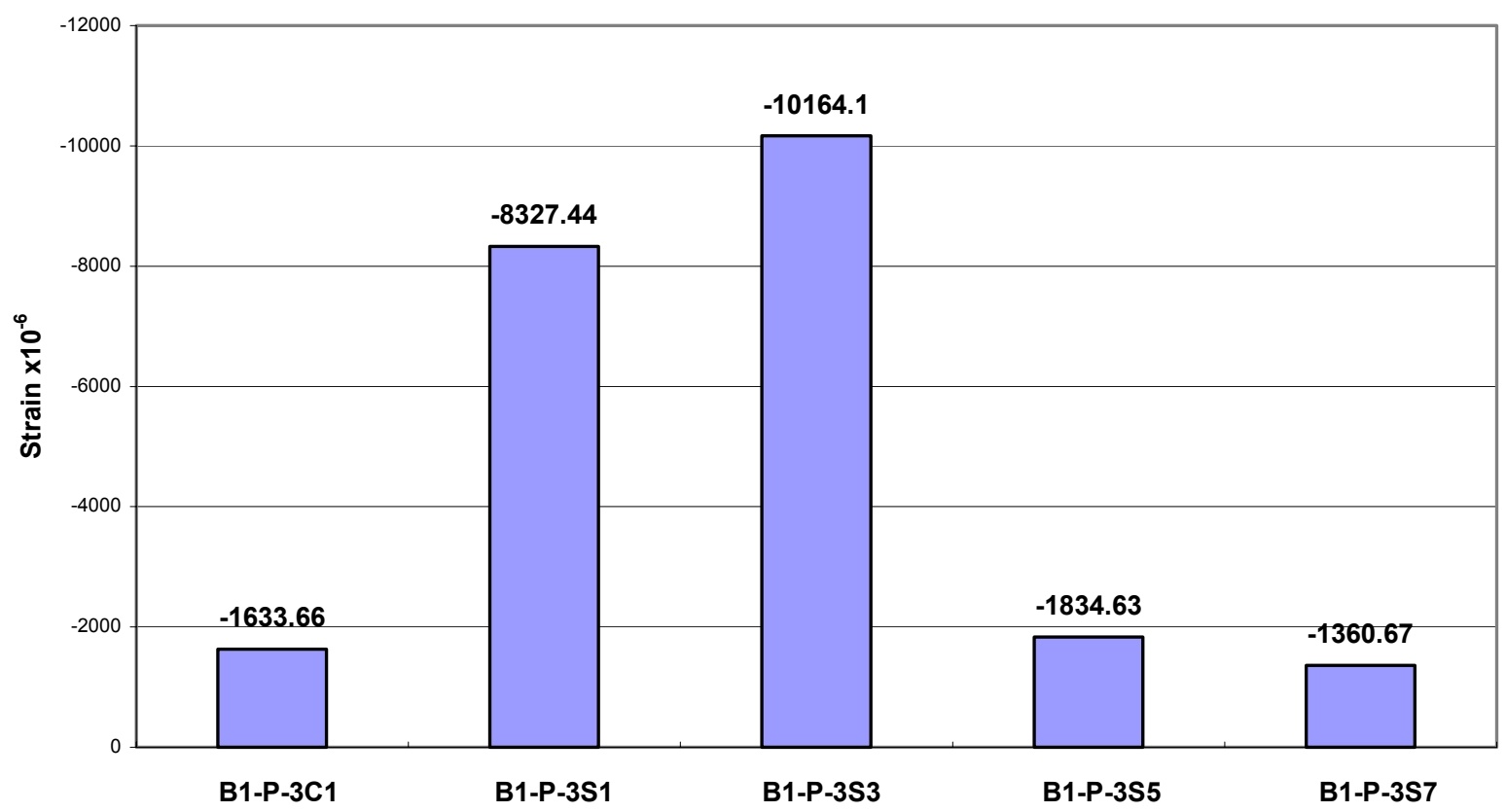

Figure 5-35 Comparison of Maximum Axial Strain of Partially Wrapped Concrete Cylinders in Table 5-28

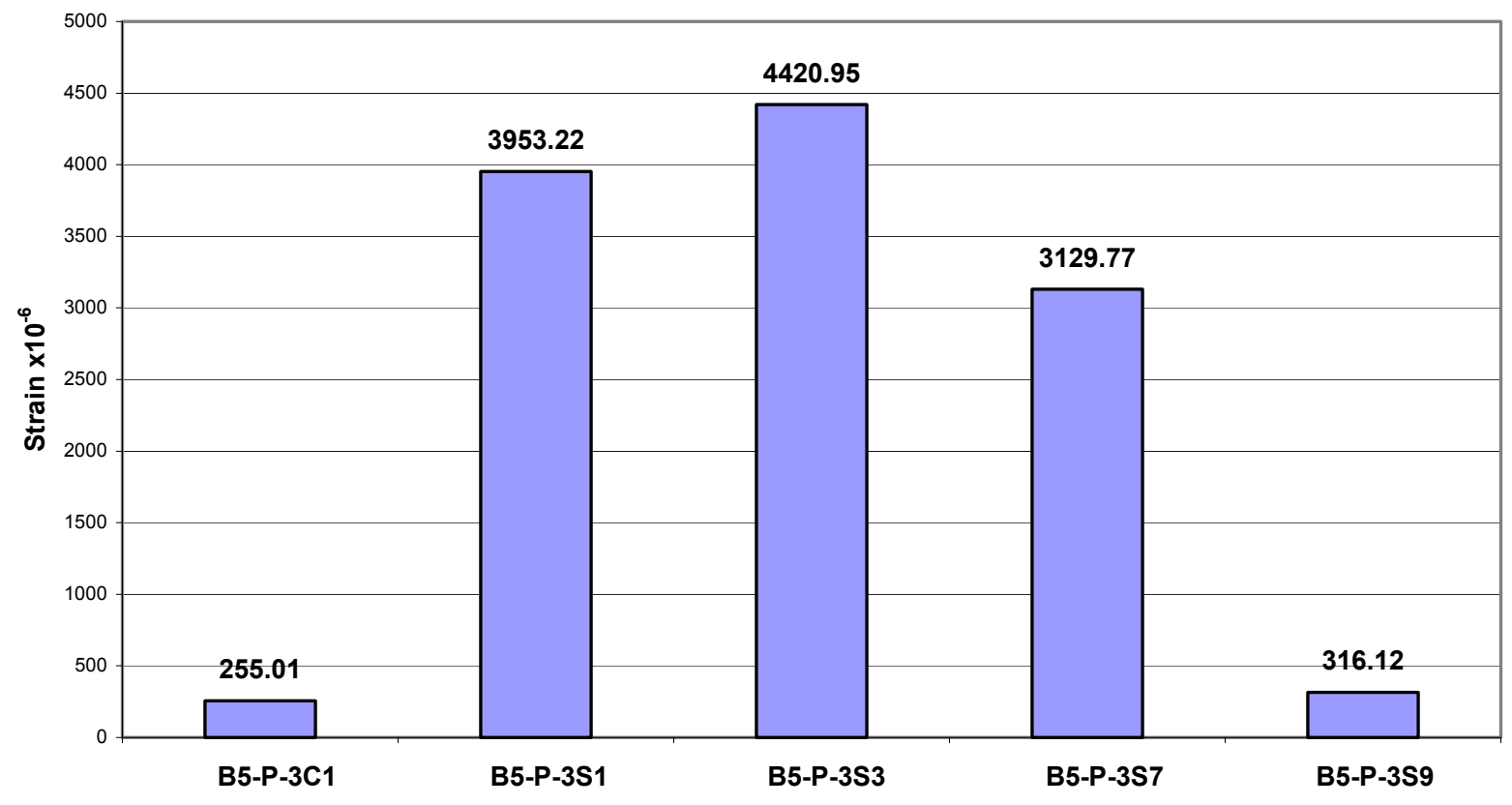

Figure 5-36 Comparison of Maximum Hoop Strain of Partially Wrapped Concrete Cylinders in Table 5-28 


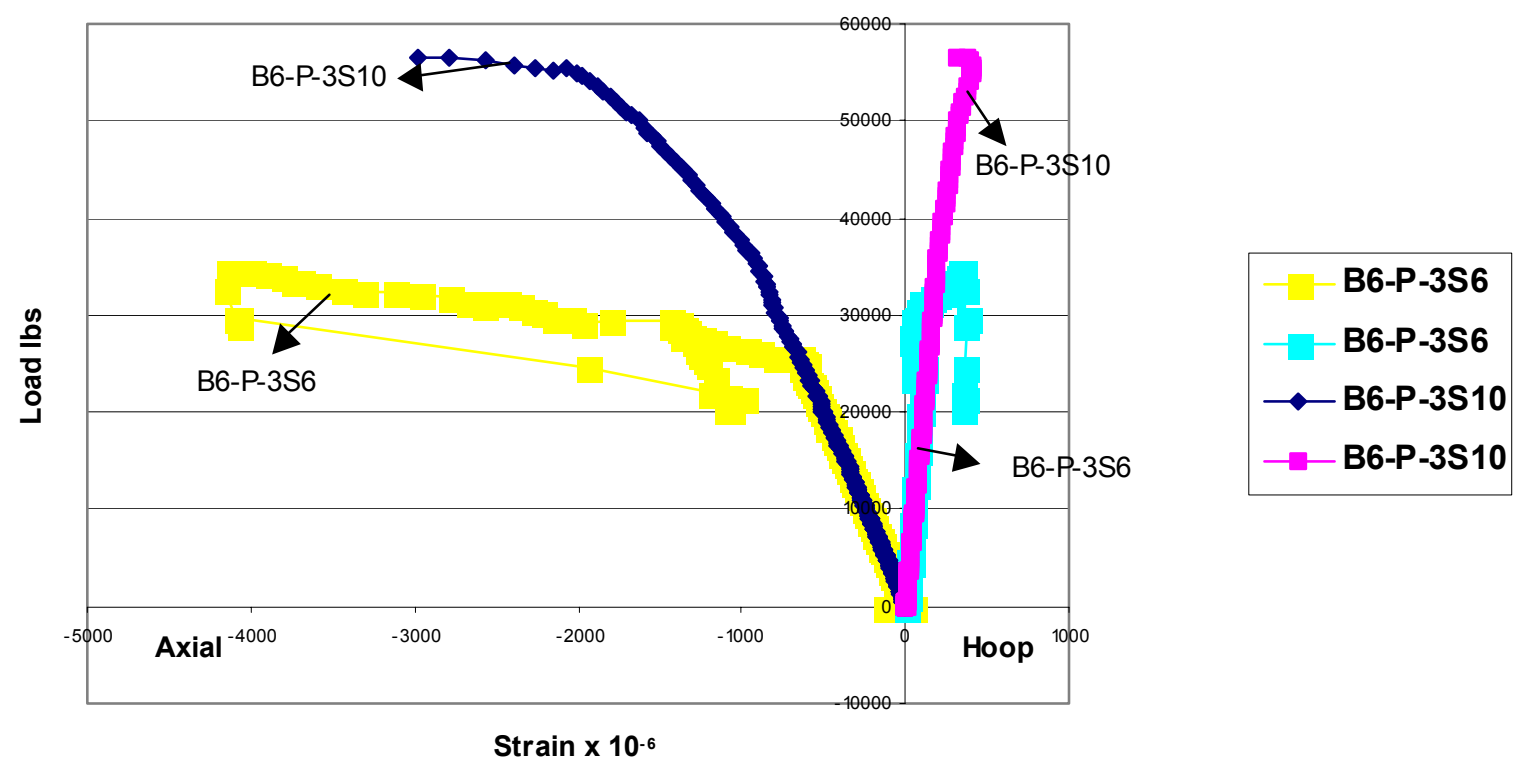

Figure 5-37 Comparison of Load Strain Plots of B6-P-3S6 and B6-P-S10 Specimens

- Specimens with 1" and 11/2" gap at top and bottom have a similar stress strain curve as the non-wrapped specimen (Figure 5-33). This shows crack initiates at the high stress zones at the top and bottom.

- Specimens with 1" and $1 / 2$ " gap showed an increase in strain of about $6 \%$ and $30 \%$ compared to the non wrapped specimens but the specimens with $1 \frac{1}{2} 2$ " failed even before the plain concrete specimen failure strain value. The high stress at the top and bottom leads to failure at the non-wrapped regions.

- The strain of the partially wrapped specimens is lower than the completely wrapped specimens. 


\subsubsection{Failure Stress/ Strain}

The load at failure is recorded and ultimate axial stress was calculated. The strain values at failure were recorded from the strain gauge readings. The strain values were recorded only for a single specimen in each category.

Table 5-30 Stress and Strain

\begin{tabular}{|c|c|c|c|c|c|c|c|}
\hline No & Designation & Wrap Type & $\begin{array}{c}\text { Axial Stress } \\
\quad(\mathrm{psi})\end{array}$ & $\begin{array}{c}\text { Axial Strain } \\
\times 10^{-6}\end{array}$ & $\begin{array}{c}\text { Ratio of } \\
\text { Increase } \\
\text { in Axial } \\
\text { Strain }\end{array}$ & $\begin{array}{l}\text { Hoop } \\
\text { Strain } \\
\text { x10 }\end{array}$ & $\begin{array}{c}\text { Ratio of } \\
\text { Increase } \\
\text { in Hoop } \\
\text { Strain }\end{array}$ \\
\hline 1 & B5-P-3C1 & $\begin{array}{c}\text { Non } \\
\text { Wrapped }\end{array}$ & 6171.67 & -1633.66 & --- & 255.01 & --- \\
\hline 2 & B5-P-3S1 & \multirow{2}{*}{ Full } & 9354.77 & -8327.44 & 5.09 & 3953.22 & 15.5 \\
\hline 3 & B5-P-3S2 & & 9099 & -- & & --- & \\
\hline 4 & B5-P-3S3 & \multirow{2}{*}{$0.5 " \mathrm{Gap}$} & 8672 & -10164.10 & 6.2 & 4420.95 & 17.33 \\
\hline 5 & B5-P-3S4 & & 8300 & --- & & --- & \\
\hline 6 & B5-P-3S5 & \multirow{2}{*}{ 1" Gap } & 6649 & -1834.63 & 1.12 & 3129.77 & 12.2 \\
\hline 7 & B5-P-3S6 & & 6482 & --- & & --- & \\
\hline 8 & B5-P-3S7 & \multirow{2}{*}{ 1.5" Gap } & 4478.77 & -1360.67 & 0.83 & 316.12 & 1.23 \\
\hline 9 & B5-P-3S8 & & 4603 & --- & & --- & \\
\hline
\end{tabular}

Gauges were not fixed in the specimens in which the strain values are not provided

\subsubsection{Failure Pattern}

The cylinders with different wrap height configurations as shown in Table 5-28 were tested in compression and the distinctly different failure modes were noted as shown in Figures 5-38 to Figures 5-43. 


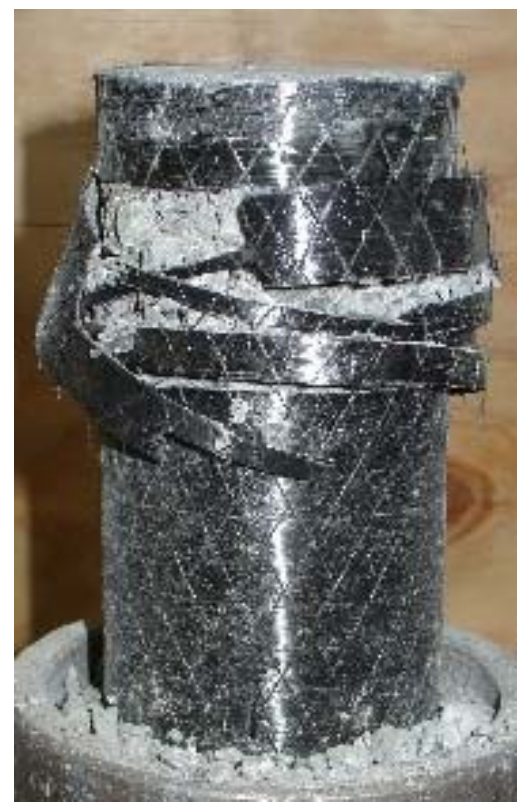

Figure 5-38 Failure in Completely Wrapped Specimen

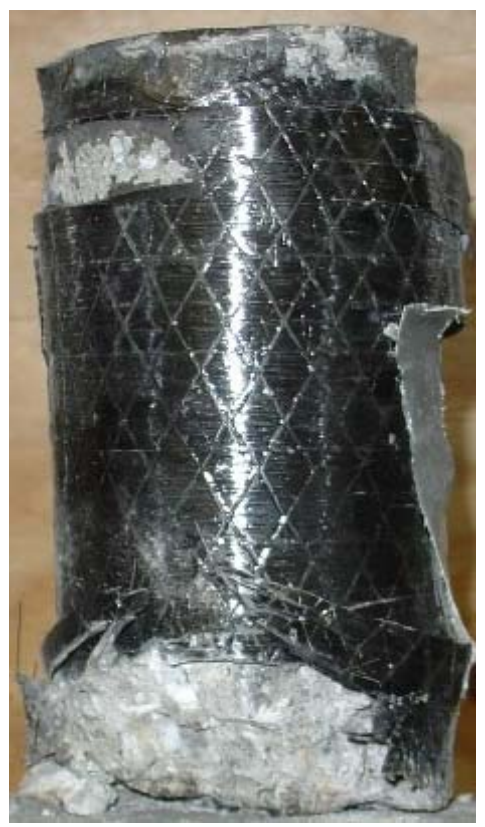

Figure 5-39 Failure in Specimen with 1/2" Height Gap (Top and Bottom) 


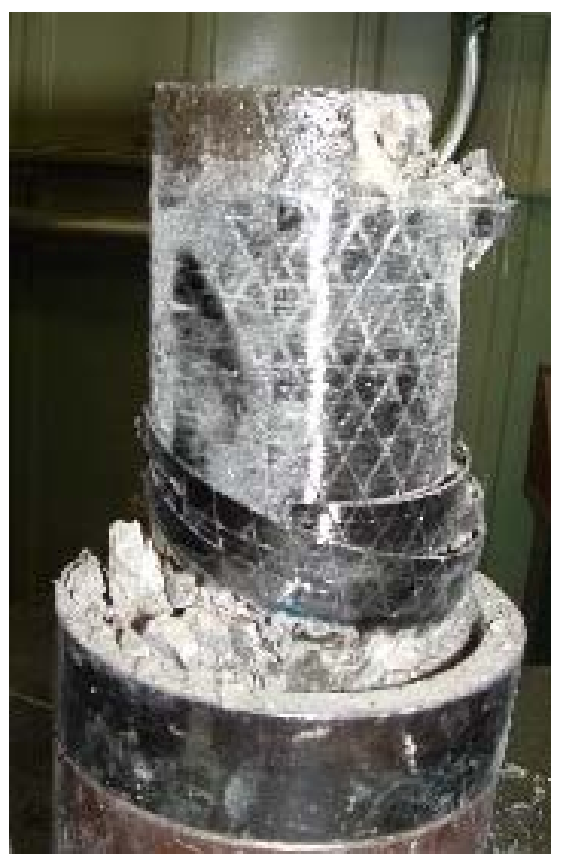

Figure 5-40 Failure in Specimen with 1" Height Gap (Top and Bottom)

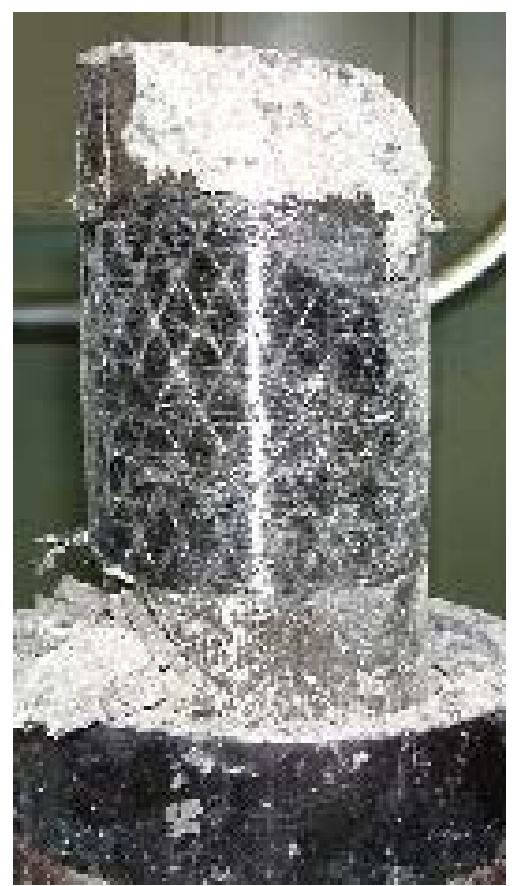

Figure 5-41 Failure in Specimen with 11/2” Height Gap (Top and Bottom) 


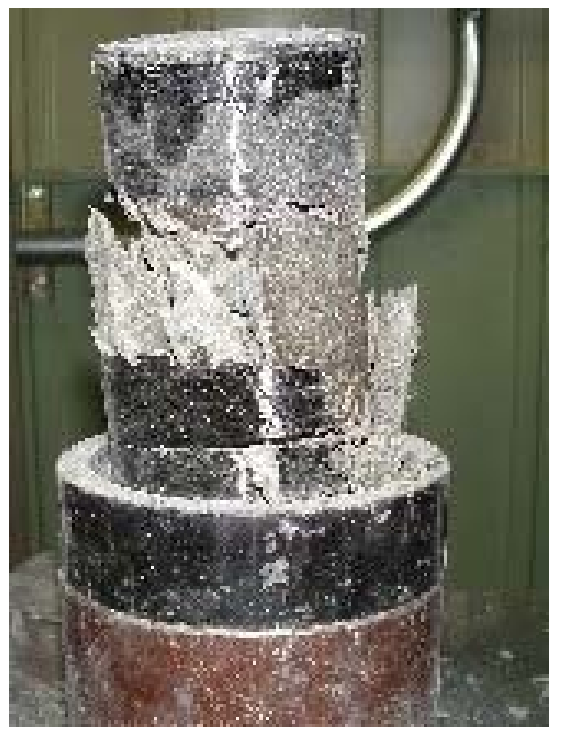

Figure 5-42 Failure in Specimen with 11/2" Height Wrap only at Top and Bottom

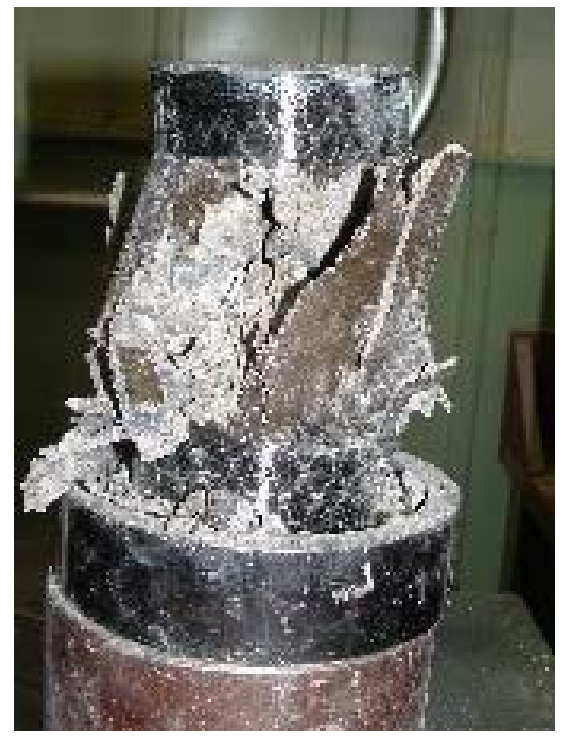

Figure 5-43 Failure in Specimen with 1" Height Wrap only at Top and Bottom

- The completely wrapped specimen failed due to failure of the wrap at the mid section of the specimen where the recorded hoop strain was maximum (Figure 5-38).

- The specimen with $1 / 2$ " gap failed due to failure of wrap and the chipping of the exposed concrete (Figure 5-39). 
- The specimens with 1 " and $1 \frac{1 / 2}{2}$ gap failed due to failure of concrete at the exposed top and bottom regions. The wrapped center layer is intact. (Figure 5-40 and 5-41). It is necessary to wrap the beam column joints, and failure is premature if specimen's edges are not wrapped.

- Batch $6\left(f_{c}^{\prime}=5000\right.$ psi $)$ specimens wrapped with 1 " and $1 \frac{1}{12}$ " fiber at top and bottom failed with the specimen crushing at the center. The upper portions remain intact (Figure 5-41 and 5-42). But the distribution of load is better in this case and hence a higher increase in strength (decreases 0.8 times in the case of $1 \frac{1 / 2}{2}$ gap at top an bottom and increase 1.45 times for specimens with wrap only at top and bottom for $1 \frac{1}{2}$ ", when compared to non-wrapped specimens.

\subsection{Axial Compression Tests to Determine Effect of Fiber Wetting}

Tests were conducted on batch $1\left(f_{c}^{\prime}=4500 \mathrm{psi}\right), 4$ "x 8 " cylinders wrapped with 1 layer of CFRP. The cylinders were wrapped with 1 layer of CFRP by impregnating the fiber with resin. The specimens were tested under three categories: 1) Three specimens were tested with fabric coated with resin at 3 locations along the circumference; 2) three specimens with fabric coated with resin at 3 locations along the circumference; and 3) 3 specimens with fabric coated with resin 2 points along the circumference. Specimens were tested to failure and the failure load strain and failure modes were noted. 


\subsubsection{Ultimate Strength}

The ultimate strength of the specimens was recorded and the results are shown in Table 5-31 for partially resin impregnated and fully wrapped specimens

Table 5-31 Strength of Specimens of Batch 1 with Different Fiber Wetting

\begin{tabular}{|c|c|c|c|c|c|c|}
\hline No & Designation & Wrap Type & $\begin{array}{l}\text { Axial } \\
\text { Strength } \\
\text { (lbs) }\end{array}$ & $\begin{array}{l}\text { Percent Change in } \\
\text { Strength - Compared } \\
\text { to Control Specimen }\end{array}$ & $\begin{array}{l}\text { Average Percent } \\
\text { Increase in } \\
\text { Strength }\end{array}$ & $\begin{array}{l}\text { Average } \\
\text { increase in } \\
\text { Strength }\end{array}$ \\
\hline 1 & B1-P-4C3 & Non Wrapped & 56895 & --- & --- & -- \\
\hline 2 & B1-P-4S9 & \multirow{2}{*}{$\begin{array}{l}\text { Full Resin wetting } \\
\text { and bonding }\end{array}$} & 93950 & 65.18 & \multirow{2}{*}{66.28} & \multirow{2}{*}{1.66} \\
\hline 3 & B1-P-4S10 & & 95200 & 67.38 & & \\
\hline 4 & B1-P-4S11 & \multirow{3}{*}{$\begin{array}{c}\text { Wetting \& } \\
\text { Bonding at } 3 \\
\text { Locations }\end{array}$} & 89250 & 56.92 & \multirow{3}{*}{37.74} & \multirow{3}{*}{1.37} \\
\hline 5 & B1-P-4S12 & & 75975 & 33.58 & & \\
\hline 6 & B1-P-4S13 & & 69800 & 22.72 & & \\
\hline 7 & B1-P-4S14 & \multirow{3}{*}{$\begin{array}{l}\text { Wetting \& } \\
\text { Bonding at } 2 \\
\text { Locations }\end{array}$} & 69400 & 22.02 & \multirow{3}{*}{17.4} & \multirow{3}{*}{1.17} \\
\hline 8 & B1-P-4S15 & & 68975 & 21.27 & & \\
\hline 9 & B1-P-4S16 & & 62000 & 9.01 & & \\
\hline
\end{tabular}

Note: Bonded with 1 " wide fabric wetting at bonded location only

- Fully wrapped specimens showed an average increase of $66 \%$ while the specimens with fiber wetted at 3 locations along the circumference showed an average increase of $38 \%$ and specimens with fiber wetted at 2 locations only showed an average increase of $17 \%$ due to wrapping with a single $0^{\circ}$ fiber wrap. These values are shown in Table 5-24.

- In the case of specimens of batch $1,\left(f_{c}{ }^{\prime}=4500 \mathrm{psi}\right)$, the increase in strength was much lower than the fully resin impregnated specimen as the CFRP fiber was not stiff, due to absence of resin (Table 5-24).

\subsubsection{Load/Strain Plots}

The readings obtained from the strain smart software were reduced to excel format and the values were plotted. The readings of load and strain of the different types of specimens were plotted. 


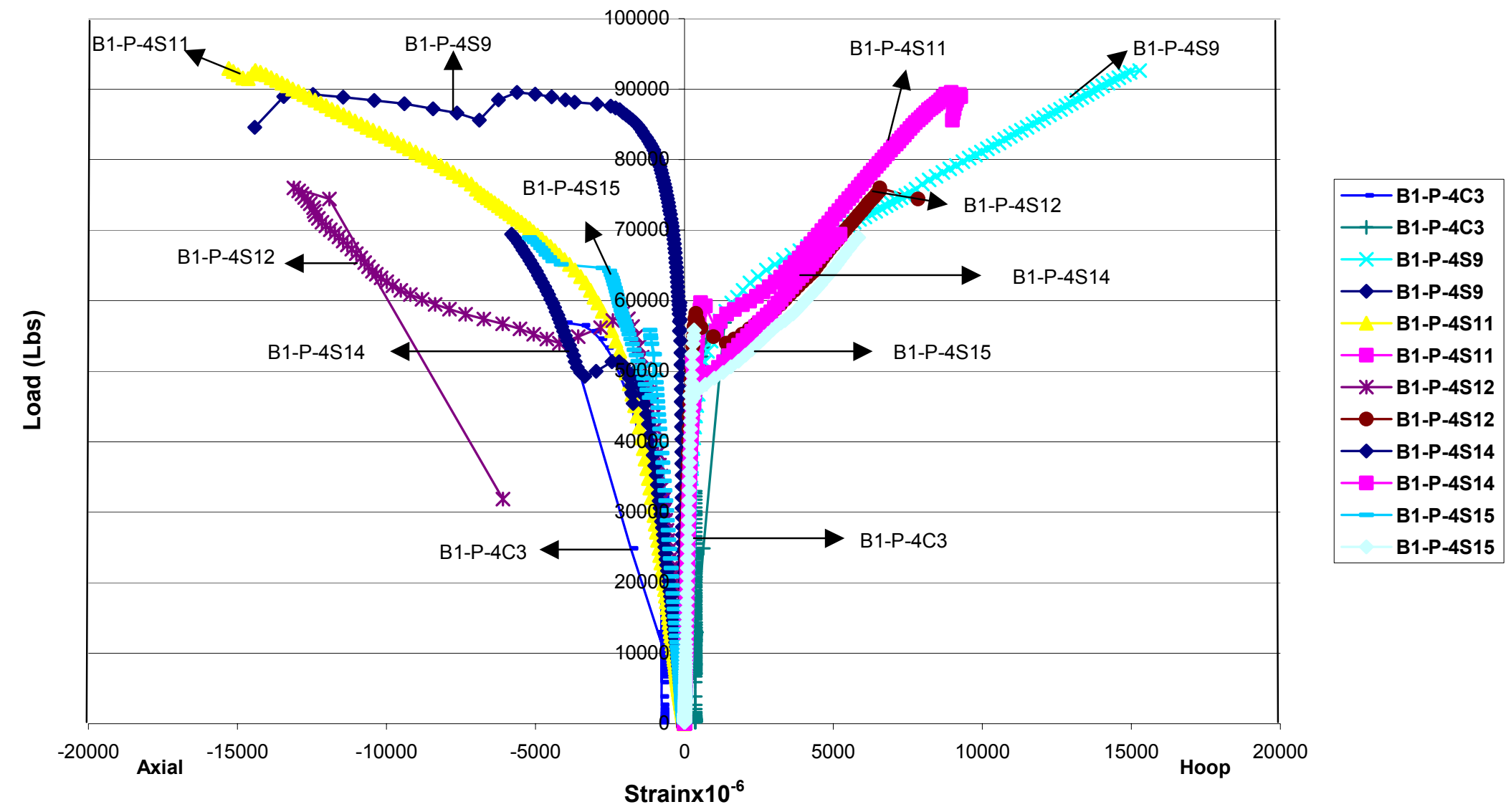

Figure 5-44 Comparison of Load Strain Plots of Partially Wetted Specimens 


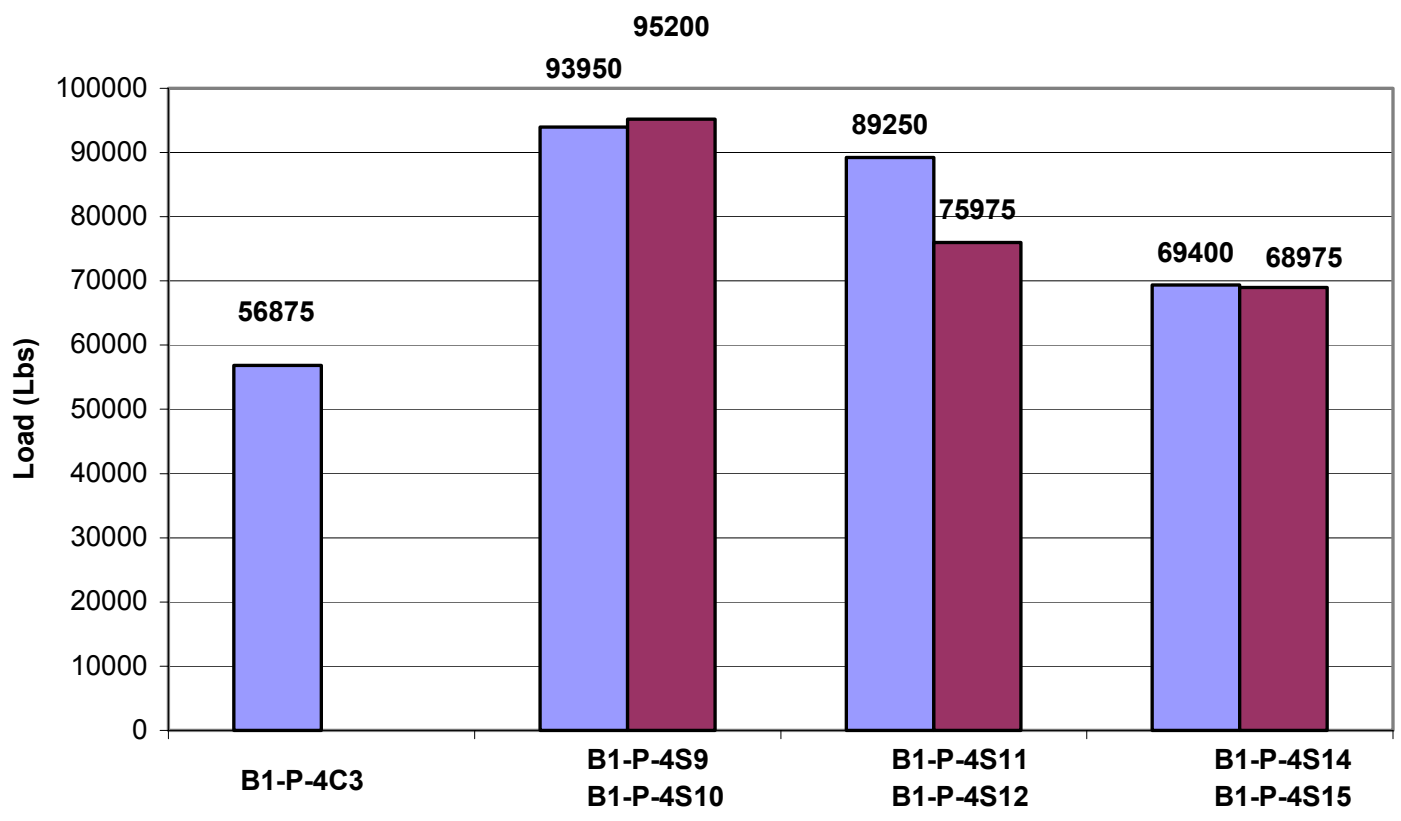

Figure 5-45 Comparison of Maximum Load of specimens in Table 5-24 (partially wet and bonded fabric)

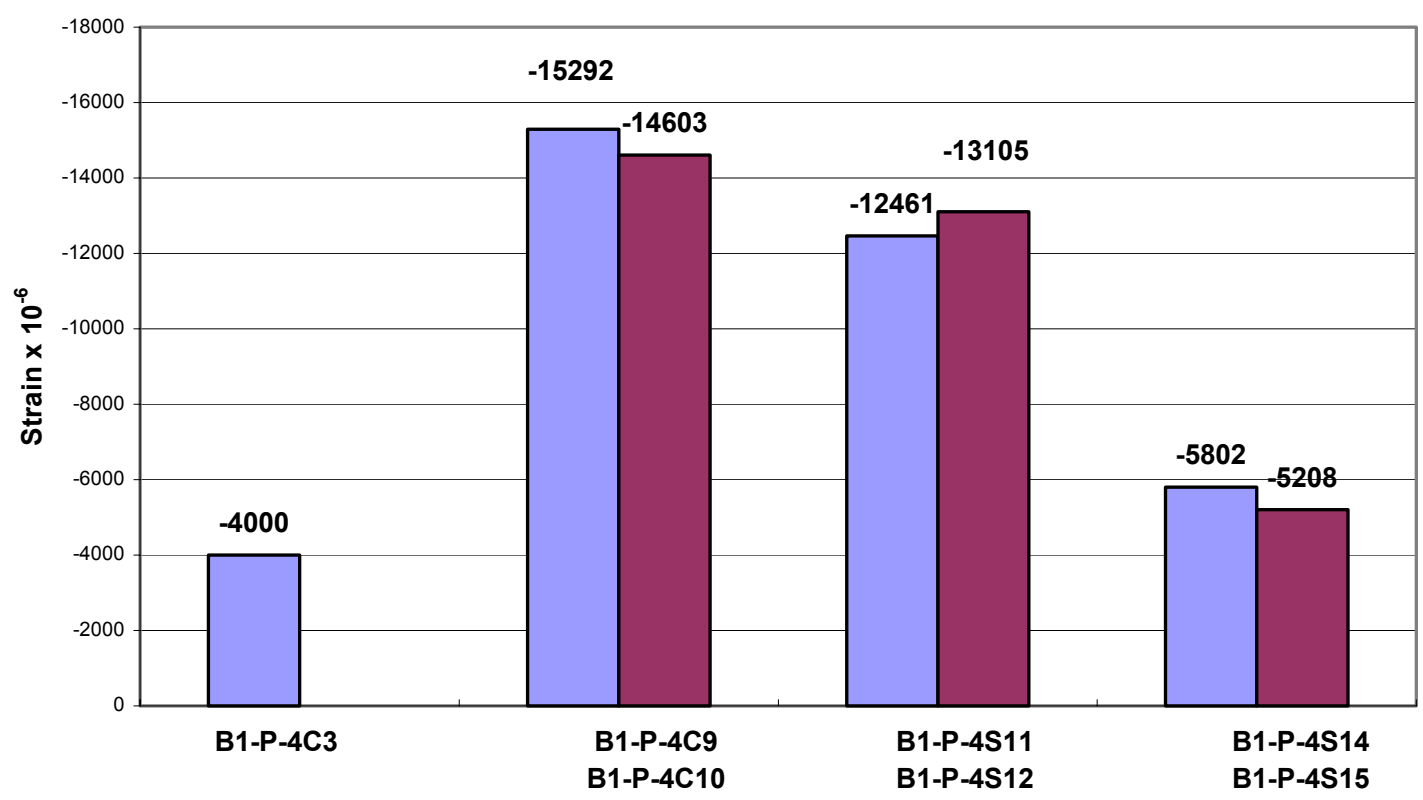

Figure 5-46 Comparison of Maximum Axial Strain $x 10^{-6}$ of Specimens in Table 5-24 (partially wet and bonded fabric) 


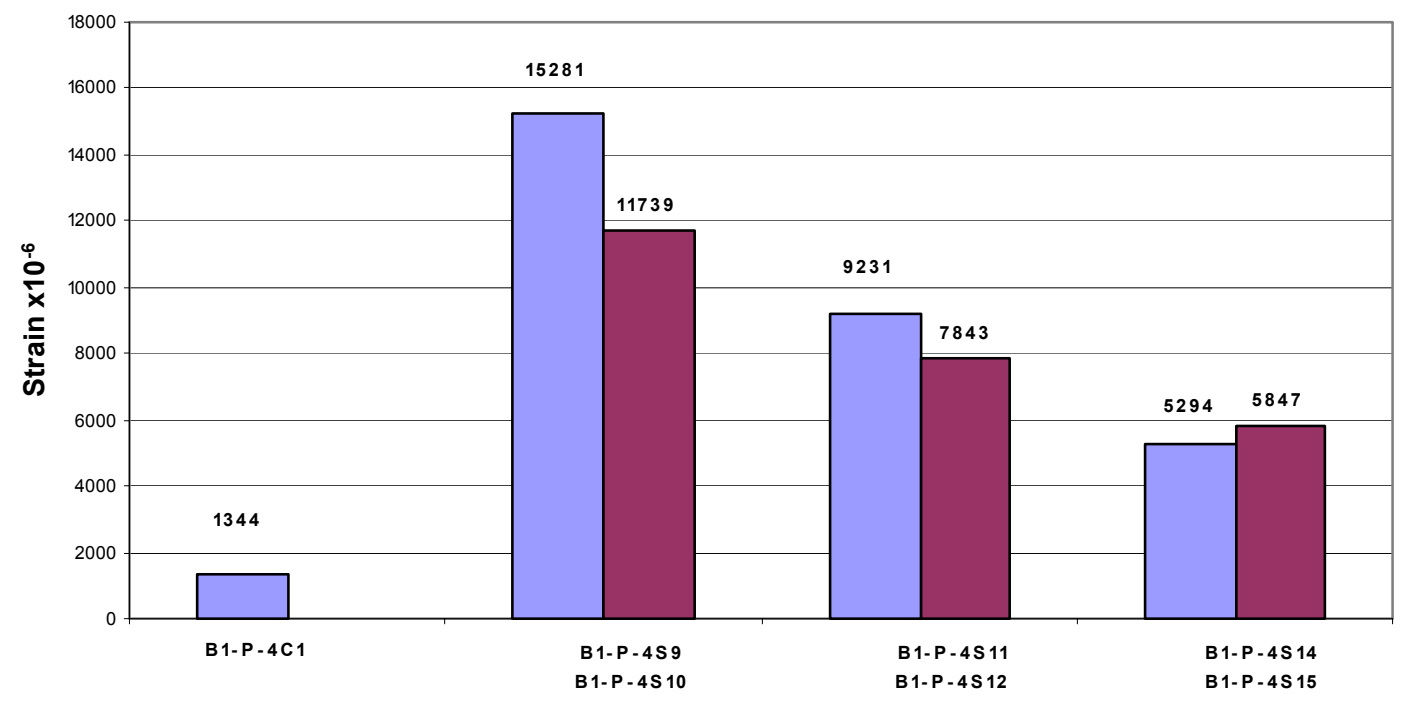

Figure 5-47 Comparison of Maximum Hoop Strain $x^{-6}$ of Specimens in Table 5-24 (partially wet and bond fabric)

The load strain plots of fully wet specimens were compared to the specimens with partial resin impregnation.

- Load strain plots of fully wrapped specimen were similar to the stress strain plots of single wrapped specimens of batch 1 (Figure 5-3). The specimens showed an increase in strength and strain.

- Specimens B1-P-S11 and B1-P-S12 showed an increase in strength and strain but followed a different pattern of load strain curve and had reduced values of hoop strain when compared to the fully wrapped specimens (Figure 5-44)

- Specimens B1-P-S14 and B1-P-S15 show axial load strain curves similar to non-wrapped specimens. The hoop strain values are higher than the non-wrapped specimens. 


\subsubsection{Maximum Stress/Strain and Energy}

The stress in cylinder specimens was calculated as ratio of the applied load to the concrete cross sectional area.

Table 5-32A Stress and Strain of Specimens (batch $\left.1 f_{c}{ }^{\prime}=4500 \mathrm{psi}\right)$

\begin{tabular}{|c|c|c|c|c|c|c|c|c|c|}
\hline No & Designation & Wrap Type & $\begin{array}{c}\text { Axial } \\
\text { Stress } \\
\text { (psi) }\end{array}$ & $\begin{array}{c}\text { Axial } \\
\text { Strain } x \\
10^{-6}\end{array}$ & $\begin{array}{c}\text { Increase } \\
\text { in Axial } \\
\text { Strain }\end{array}$ & $\begin{array}{c}\% \\
\text { Increase } \\
\text { in Axial } \\
\text { Strain } \\
\end{array}$ & $\begin{array}{c}\text { Hoop } \\
\text { Strain } \\
10^{-6}\end{array}$ & $\begin{array}{c}\text { Increase } \\
\text { in Hoop } \\
\text { Strain }\end{array}$ & $\begin{array}{c}\% \\
\text { Increase } \\
\text { in Hoop } \\
\text { Strain } \\
\end{array}$ \\
\hline 1 & B1-P-4C3 & $\begin{array}{c}\text { Non } \\
\text { Wrapped }\end{array}$ & 4525.97 & -4000.39 & --- & --- & 1343.6 & & --- \\
\hline 2 & B1-P-4S9 & \multirow{2}{*}{$\begin{array}{c}\text { Full resin } \\
\text { wetting \& } \\
\text { bonding }\end{array}$} & 7476.3 & -15202.24 & \multirow[b]{2}{*}{3.725} & 280 & 15201.4 & \multirow[b]{2}{*}{10.02} & 1031 \\
\hline 3 & B1-P-4S10 & & 7575.78 & -14603.25 & & 265 & 11738.9 & & 773 \\
\hline 4 & B1-P-4S11 & \multirow{3}{*}{$\begin{array}{c}\text { Resin } \\
\text { wetting and } \\
\text { bonding at } \\
3 \text { points }\end{array}$} & 7102.29 & -12461.00 & \multirow{3}{*}{3.19} & 211 & 9231.0 & \multirow{3}{*}{12.7} & 587 \\
\hline 5 & B1-P-4S12 & & 6045.9 & -13105.42 & & 227 & 7848.8 & & 484 \\
\hline 6 & B1-P-4S13 & & 5554.5 & --- & & --- & --- & & \\
\hline 7 & B1-P-4S14 & \multirow{3}{*}{$\begin{array}{c}\text { Resin } \\
\text { wetting and } \\
\text { bonding at } \\
2 \text { points }\end{array}$} & 5522.6 & -5802.04 & \multirow{3}{*}{1.37} & 45 & 5299.0 & \multirow{3}{*}{4.14} & 294 \\
\hline 8 & B1-P-4S15 & & 5488.86 & -5208.24 & & 30 & 5847.4 & & 335 \\
\hline 9 & B1-P-4S16 & & 4933.8 & --- & & --- & --- & & \\
\hline
\end{tabular}

Gauges were not used in the specimens for which the strain values are not provided

Table 5-32B Energy increase in Partially Wetted Specimens (batch $\left.1 f_{c}{ }^{\prime}=4500 \mathrm{psi}\right)$

\begin{tabular}{|c|c|c|c|c|c|c|}
\hline No & Designation & Wrap Type & $\begin{array}{c}\text { Energy } \\
\text { in Axial } \\
\text { Direction }\end{array}$ & $\begin{array}{l}\text { Energy in } \\
\text { Hoop } \\
\text { direction }\end{array}$ & $\begin{array}{l}\text { Increase } \\
\text { in Axial } \\
\text { Energy }\end{array}$ & $\begin{array}{l}\text { Increase } \\
\text { in Hoop } \\
\text { Energy }\end{array}$ \\
\hline 1 & B1-P-4C3 & $\begin{array}{c}\text { Non } \\
\text { Wrapped }\end{array}$ & 13.06 & 5.108 & --- & --- \\
\hline 2 & B1-P-4S9 & \multirow{2}{*}{$\begin{array}{c}\text { Full resin } \\
\text { wetting \& } \\
\text { bonding }\end{array}$} & 99.1 & 90.3 & \multirow{2}{*}{7.2} & \multirow{2}{*}{16.2} \\
\hline 3 & B1-P-4S10 & & 89.159 & 75.8 & & \\
\hline 4 & B1-P-4S11 & \multirow{3}{*}{$\begin{array}{c}\text { Resin } \\
\text { wetting and } \\
\text { bonding at } \\
3 \text { points }\end{array}$} & 87.47 & 63.03 & \multirow{3}{*}{4.94} & \multirow{3}{*}{11.19} \\
\hline 5 & B1-P-4S12 & & 41.79 & 51.37 & & \\
\hline 6 & B1-P-4S13 & & --- & --- & & \\
\hline 7 & B1-P-4S14 & \multirow{3}{*}{$\begin{array}{c}\text { Resin } \\
\text { wetting and } \\
\text { bonding at } \\
2 \text { points }\end{array}$} & 22.5 & 25.69 & \multirow{3}{*}{1.64} & \multirow{3}{*}{4.8} \\
\hline 8 & B1-P-4S15 & & 20.4 & 24.3 & & \\
\hline 9 & B1-P-4S16 & & --- & --- & & \\
\hline
\end{tabular}

The failure strain of specimen wrapped with resin wetting at 3 positions along the circumference showed a strain increase almost equal to the specimen wrapped with completely 
wetted and bonded fabric. But the specimen with resin at 2 positions showed a decreased value of strain to failure.

\subsubsection{Failure Modes}

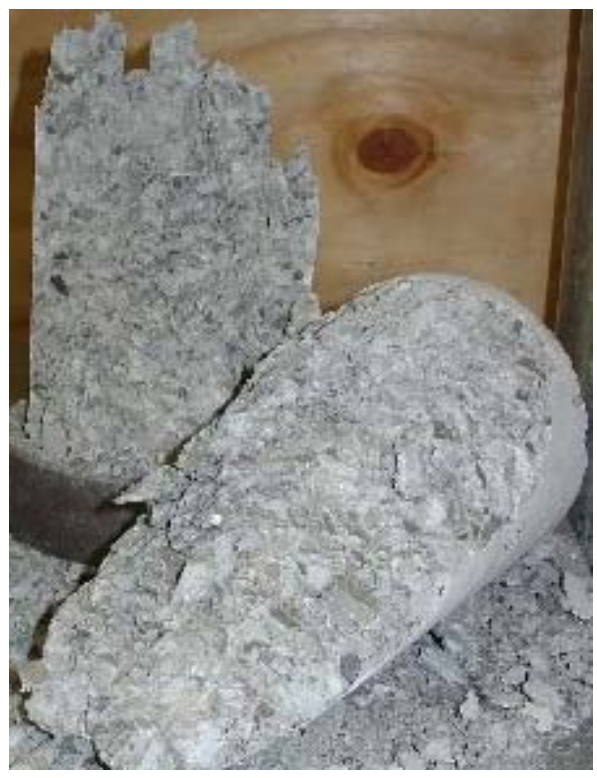

A

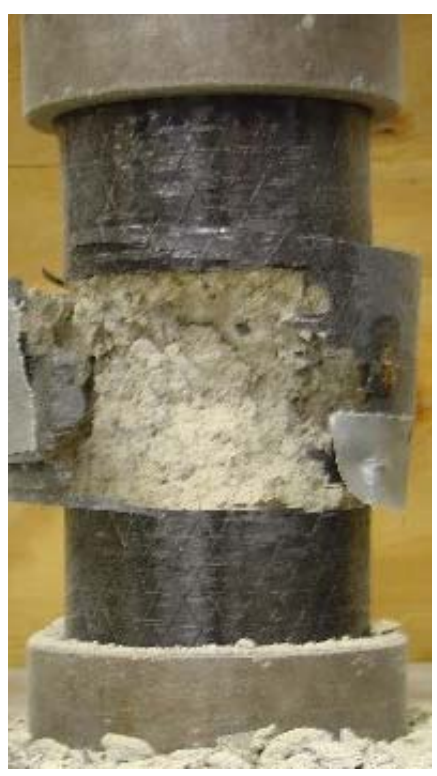

B

Figure 5-48 A) Non Wrapped Specimen B) Fully Wrapped Specimen (Batch 1-Table 5-31)

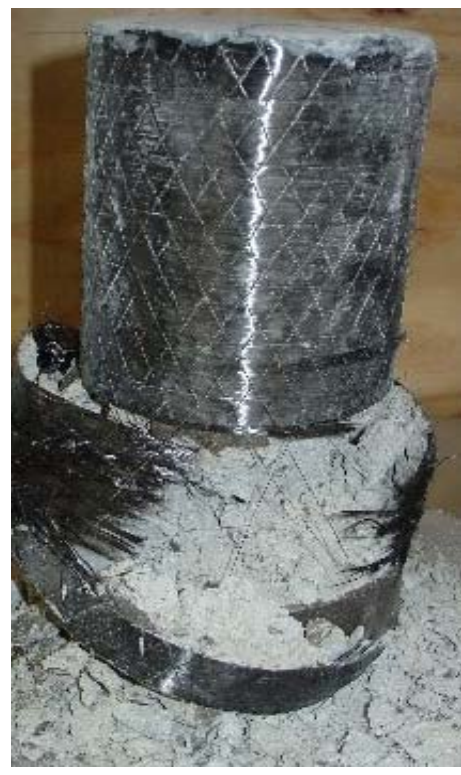

A

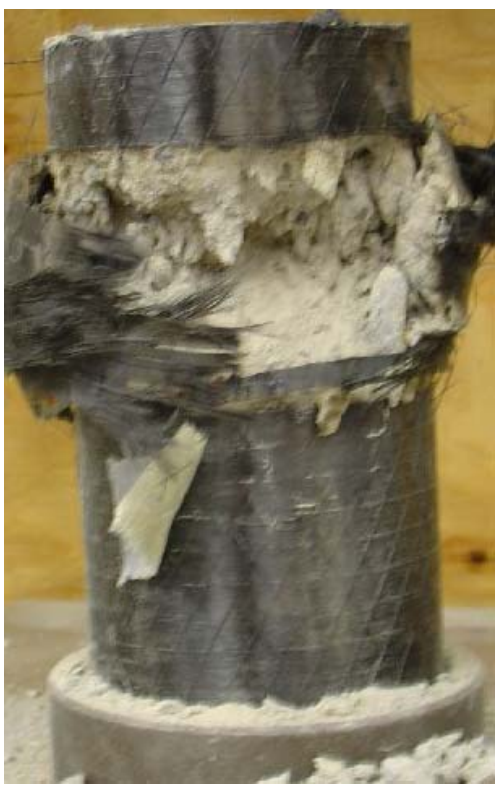

B

Figure 5-49 A) Resin Impregnated at 3 points along the Circumference (Batch 1-Table 5-31) B) Resin Impregnated at 2 Points along the Circumference (Batch 1-Table 5-31) 
- Plain concrete specimen failed with shearing into two halves. The failed specimen is shown in Figure 5-48 A

- Specimen completely impregnated with resin (B1-P-4S9) failed when the wrap failed at the mid section of the specimen due to increase in hoop strains (Figure 5-48 B)

- Specimens with partial resin B1-P-S11 and B1-P-S14 failed either at the top or bottom of the specimen when the fiber, which is not wetted with resin (low stiffness), started to tear off. Failure initiated from that point of fiber tear (Figure 5-49A and 5-49B).

\subsection{Axial Compression Tests to Determine Effect of Degree of Fabric Bonding to Concrete}

Tests were conducted on 3"x 6 " specimens of batch $6\left(f_{c}^{\prime}=5000 \mathrm{psi}\right)$. The method of preparing the specimens is given in Chapter 4 section 4.3.2.1. The specimens were tested for increase in strength. Four gauges were fixed on a single specimen B6-P-3S16 at the bonded location and non-bonded location.

\subsubsection{Ultimate Strength}

The ultimate strength of the specimens was recorded and the results are shown in Table 5-27. The ultimate strength of completely bonded specimens and specimens fully wrapped, but bonded only at 2 and 3 locations for a width of 1 " along the circumference are tabulated.

- Specimens of batch 6 which were fully wrapped showed an increase in strength of $52 \%$, and specimens bonded at 3 positions of 1" strip width showed an increase of $48.5 \%$ and specimens bonded at 2 positions showed an increase of $23 \%$ (Table 5-26). 
- Specimens completely bonded showed an increase of $52 \%$ in strength while specimens with $31.8 \%$ bond showed an increase of 1.52 and specimens with 1.48 bond showed an increase of 1.2

Table 5-33 Strength of Specimens

\begin{tabular}{|c|c|c|c|c|c|c|}
\hline No & Designation & Wrap Type & $\begin{array}{c}\text { Axial } \\
\text { Strength } \\
(\text { lbs }) \\
\end{array}$ & $\begin{array}{l}\text { Percent Change in } \\
\text { Strength - Compared } \\
\text { to Control Specimen }\end{array}$ & $\begin{array}{l}\text { Average Percent } \\
\text { Increase in } \\
\text { Strength } \\
\end{array}$ & $\begin{array}{l}\text { Average } \\
\text { increase in } \\
\text { Strength }\end{array}$ \\
\hline 1 & B6-P-3C1 & Non Wrapped & 38000 & --- & --- & --- \\
\hline 2 & B6-P-3S1 & \multirow{2}{*}{ Full } & 56000 & 47 & \multirow{2}{*}{$52 \%$} & \multirow{2}{*}{1.52} \\
\hline 3 & B6-P-3S2 & & 60000 & 57 & & \\
\hline 4 & B6-P-3S11 & \multirow{3}{*}{$\begin{array}{c}\text { Bonded at3 } \\
\text { positions }\end{array}$} & 55000 & 44.7 & \multirow{3}{*}{$48.2 \%$} & \multirow{3}{*}{1.48} \\
\hline 5 & B6-P-3S12 & & 58000 & 52.6 & & \\
\hline 6 & B6-P-3S13 & & 56000 & 47.3 & & \\
\hline 7 & B6-P-3S14 & \multirow{3}{*}{$\begin{array}{c}\text { Bonded at } 2 \\
\text { positions }\end{array}$} & 49000 & 29 & \multirow{3}{*}{$22.64 \%$} & \multirow{3}{*}{1.2} \\
\hline 8 & B6-P-3S15 & & 43500 & 14.47 & & \\
\hline 9 & B6-P-3S16 & & 47300 & 24.47 & & \\
\hline
\end{tabular}

Note: 2 or 3 point bonded locations consisted of 1 " wide wrap bonding at these locations of the cylinder with full fiber wetting

- The failure load of completely bonded and partially bonded specimens at 3 positions was similar however bonding at only 2 locations considerably reduced the axial strength (Table 5-26). . Bonding at 3 positions with contact throughout was sufficient to get an increase nearly equal to fully bonded specimen. The completely resin impregnated fiber takes the tensile hoop force even though it is not bonded throughout. 


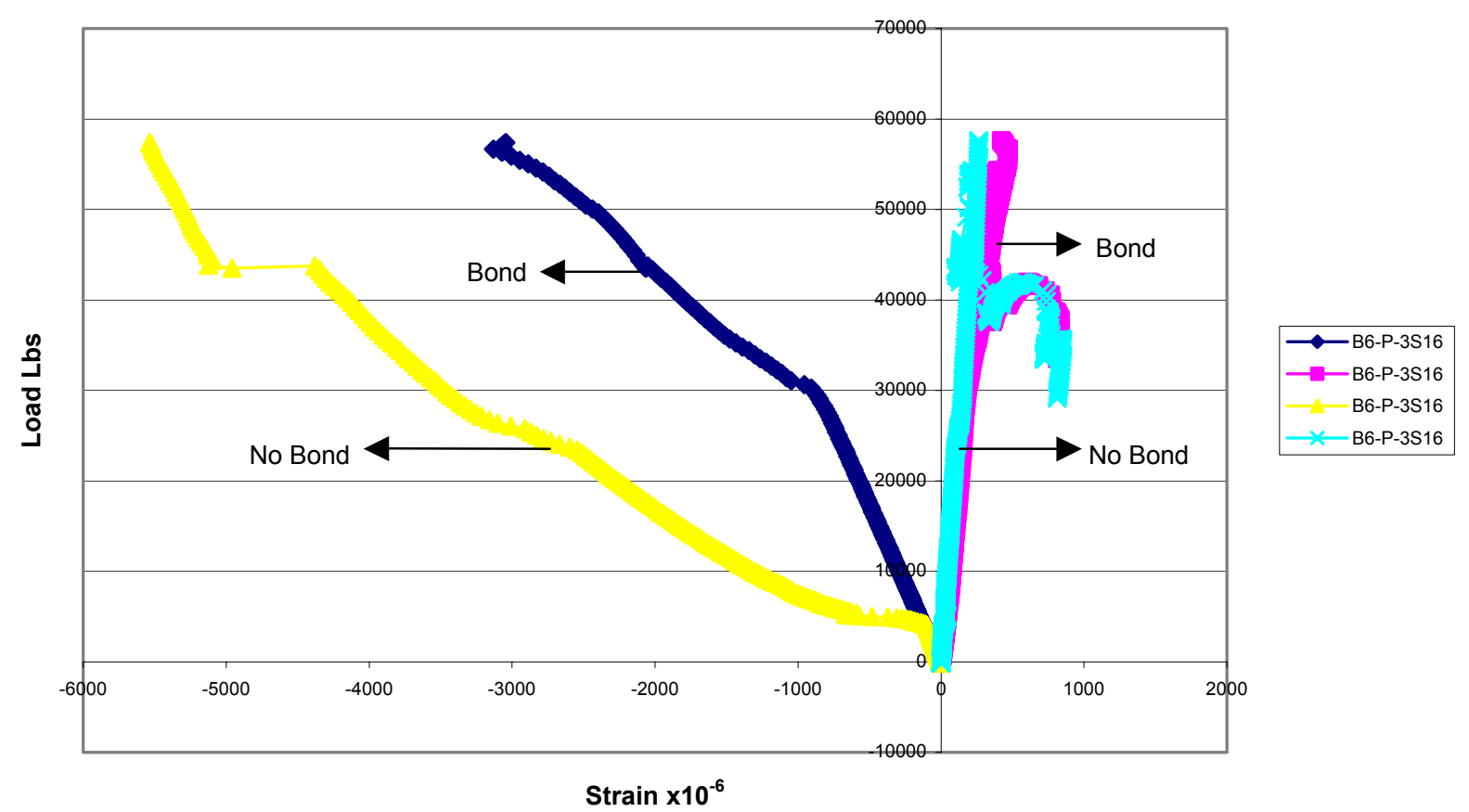

Figure 5-50 Bonded at 2 Points along the Circumference for 1 " width in Specimen B6-P-3S16

- Load/strain plot of batch 6 specimen B6-P-3S16 shown in Figure 5-50 shows an increased value of strain to failure of 5600 microstrains at the non-bonded position while it was only 3000 microstrains at the bonded position.

- Though strength increase is achieved with lesser degree of bonding, increase in axial strains at the unbonded location indicates possible buckling and bending forces that may interfere with the overall efficiency of wrap during long-term loading (Figure 5-50). 


\subsubsection{Failure Modes}

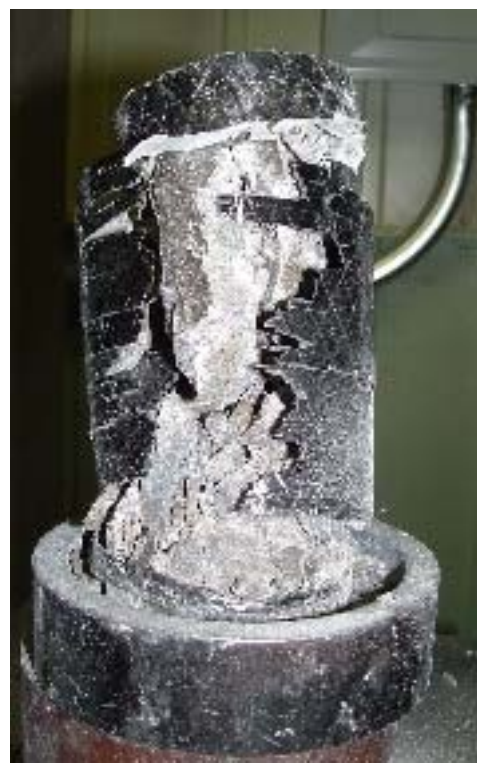

A

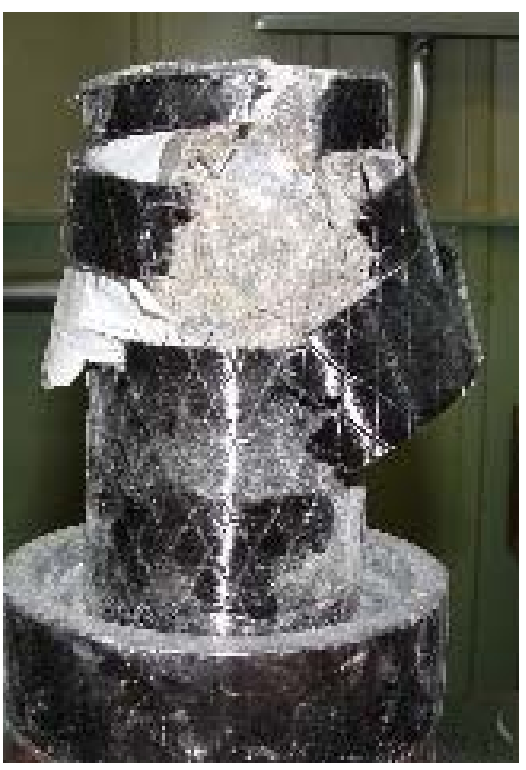

B

Figure 5-51 A) Specimen bonded at 2 positions (Batch 6 Table 5-33)

B) Specimen bonded at 3 positions (Batch 6 Table 5-33)

- Specimens bonded at 3 positions failed like a completely bonded specimen (Figure 5-51 B) except strain to failure is lower than a fully bonded specimen while in specimens bonded at 2 positions the wrap failed completely with concrete crushing (Figure 5-51 A).

\subsection{Aging Study}

\subsubsection{Introduction}

Aging study of wrapped and non-wrapped specimens with and without internal steel reinforcement was done by placing the cylinders from batch $3\left(f_{c}^{\prime}=8000 \mathrm{psi}\right)$ in an elevated temperature bath and in an environmental chamber with freeze thaw capabilities $\left(-20^{\circ} \mathrm{F}\right.$ to $120^{\circ} \mathrm{F}$ ). Cylinders of size 4"x 8 " were tested in compression in the UTM and the values of load 
and hoop strain were recorded. Non-wrapped and wrapped cylinders were tested without aging and after 1 and 2 months of aging. Carbon strip specimens were tested without aging and then after 1 and 2 months of elevated temperature and freeze thaw aging.

\subsubsection{Ultimate Strength/Stiffness}

\subsubsection{Concrete Cylinders}

Ultimate strength of the aged and unaged cylinder specimens tested in the universal compression-testing machine is given in Table 5-27 and 5-30. The difference in strength due to aging of the specimens in these two accelerated conditions was calculated and the results are shown in Table 5-34and Table 5-35.

Table 5-34 Strength of Unaged and Aged Plain Concrete Cylinder Specimens

\begin{tabular}{|c|c|c|c|c|c|c|c|}
\hline No & Designation & $\begin{array}{c}\text { Type of } \\
\text { Aging }\end{array}$ & $\begin{array}{l}\text { Number of } \\
\text { Months of } \\
\text { Aging }\end{array}$ & $\begin{array}{c}\text { Number of } \\
\text { Wraps }\end{array}$ & $\begin{array}{c}\text { Axial Strength } \\
\text { (lbs) }\end{array}$ & $\begin{array}{l}\text { Percent Change in } \\
\text { Strength - Compared } \\
\text { to Unaged Specimen }\end{array}$ & $\begin{array}{l}\text { Average } \\
\text { percent } \\
\text { change in } \\
\text { Strength }\end{array}$ \\
\hline 1 & B3-P-4C1 & \multirow{3}{*}{ Unaged } & \multirow{3}{*}{$\mathbf{0}$} & No Wrap & 106550 & --- & \multirow{3}{*}{--} \\
\hline 2 & B3-P-4C2 & & & \multirow{2}{*}{1} & 130575 & --- & \\
\hline 3 & B3-P-4C3 & & & & 157000 & --- & \\
\hline 4 & B3-P-4S1 & \multirow{5}{*}{$\begin{array}{l}\text { Elevated } \\
\text { Temperature }\end{array}$} & \multirow{2}{*}{1} & \multirow{2}{*}{1} & 128600 & -10 & \multirow{2}{*}{-8.5} \\
\hline 5 & B3-P-4S2 & & & & 132350 & -7 & \\
\hline 6 & B3-P-4S3 & & \multirow{3}{*}{2} & No Wrap & 108500 & 1.2 & 1.2 \\
\hline 7 & B3-P-4S4 & & & \multirow{2}{*}{1} & 117325 & -14 & \multirow{2}{*}{-11.5} \\
\hline 8 & B3-P-4S5 & & & & 130625 & -9.15 & \\
\hline 9 & B3-P-4S6 & \multirow{5}{*}{$\begin{array}{c}\text { Freeze- } \\
\text { Thaw }\end{array}$} & \multirow{2}{*}{1} & \multirow{2}{*}{1} & 153450 & 6 & \multirow{2}{*}{3.15} \\
\hline 10 & B3-P-4S7 & & & & 144300 & 0.3 & \\
\hline 11 & B3-P-4S8 & & \multirow{3}{*}{2} & No Wrap & 107750 & 1.7 & 1.7 \\
\hline 12 & B3-P-4S9 & & & \multirow{2}{*}{ 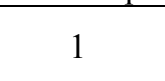 } & 142625 & -0.8 & \multirow{2}{*}{-1.9} \\
\hline 13 & B3-P-4S10 & & & & 139125 & -3 & \\
\hline
\end{tabular}


Table 5-35 Strength of Unaged and Aged Reinforced Concrete Cylinder Specimens

\begin{tabular}{|c|c|c|c|c|c|c|c|}
\hline No & Designation & $\begin{array}{l}\text { Type of } \\
\text { Aging }\end{array}$ & $\begin{array}{l}\text { Number of } \\
\text { Months of } \\
\text { Aging }\end{array}$ & $\begin{array}{l}\text { Number } \\
\text { of Wraps }\end{array}$ & $\begin{array}{l}\text { Axial Strength } \\
\text { (lbs) }\end{array}$ & $\begin{array}{c}\text { Percent Change } \\
\text { in Strength - } \\
\text { Compared to } \\
\text { Unaged } \\
\text { Specimen }\end{array}$ & $\begin{array}{l}\text { Average } \\
\text { percent } \\
\text { Change in } \\
\text { Strength }\end{array}$ \\
\hline 1 & B3-R-4C1 & \multirow{3}{*}{ Unaged } & \multirow{3}{*}{$\mathbf{0}$} & No wrap & 148725 & --- & \multirow{3}{*}{---} \\
\hline 2 & B3-R-4C2 & & & \multirow[t]{2}{*}{ 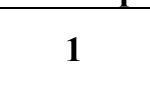 } & 165100 & --- & \\
\hline 3 & B3-R-4C3 & & & & 174650 & --- & \\
\hline 4 & B3-R-4S1 & \multirow{5}{*}{$\begin{array}{l}\text { Elevated } \\
\text { Temperature }\end{array}$} & \multirow{2}{*}{1} & \multirow{2}{*}{1} & 157450 & -7 & \multirow{2}{*}{-9.5} \\
\hline 5 & B3-R-4S2 & & & & 148675 & -12 & \\
\hline 6 & B3-R-4S3 & & \multirow{3}{*}{2} & No Wrap & 146750 & -1.3 & -1.3 \\
\hline 7 & B3-R-4S4 & & & \multirow{2}{*}{1} & 154600 & -8 & \multirow{2}{*}{-9.5} \\
\hline 8 & B3-R-4S5 & & & & 151025 & -11 & \\
\hline 9 & B3-R-4S6 & \multirow{5}{*}{$\begin{array}{l}\text { Freeze- } \\
\text { Thaw }\end{array}$} & \multirow{2}{*}{1} & \multirow{2}{*}{1} & 166525 & -1.9 & \multirow{2}{*}{-1.7} \\
\hline 10 & B3-R-4S7 & & & & 167325 & -1.5 & \\
\hline 11 & B3-R-4S8 & & \multirow{3}{*}{2} & No Wrap & 14613 & -5 & -1.7 \\
\hline 12 & B3-R-4S9 & & & \multirow{2}{*}{1} & 158425 & -6 & \multirow{2}{*}{-5} \\
\hline 13 & B3-R-4S10 & & & & 162250 & -4 & \\
\hline
\end{tabular}

- Non-wrapped plain concrete specimens showed an increase in strength of $1.2 \%$ in elevated temperature conditions and an increase of $1.7 \%$ in freeze thaw conditions over a period of 2 month aging.

- Non-wrapped reinforced concrete specimens showed a decrease in strength of $1.3 \%$ in elevated temperature conditions and decrease of $1.4 \%$ in freeze thaw conditions over a period of 2 month aging.

- Plain concrete specimens showed an increase in strength (Table 5-35). This is due to curing for longer periods.

- Elevated temperature condition resulted in higher reduction in strength than the specimens subjected to freeze thaw conditions (Table 5-35).

- Specimens in freeze thaw condition showed a slight increase in strength in the first month of aging. 


\subsubsection{Strip Specimens}

Twenty carbon strip specimens, non-aged and aged in elevated temperature and freeze thaw conditions for 1 and 2 months were tested in tension. The decrease in strength of the CFRP wrap due to aging was determined (Table 5-36). The stiffness of the specimens, which was calculated by plotting the stress strain graphs, is given in Table 5-30. Specimens were named as T-U-0C1, where $\mathrm{T}, \mathrm{U}$ and $\mathrm{C}$ stand for tension specimen, unaged and Control while 0 and $\mathrm{C} 1$ stand for 0 months of aging and control specimen number 1 . The aged specimens are named as T-E-1S1 where T, E and S stand for tension specimen, Elevated temperature aging and 1S1 stands for 1 month of aging and specimen1.

Table 5-36 Strength of Unaged and Aged Tension Strip Specimens

\begin{tabular}{|c|c|c|c|c|c|c|c|}
\hline No & Designation & $\begin{array}{l}\text { Type of } \\
\text { Aging }\end{array}$ & $\begin{array}{l}\text { Number of } \\
\text { Months of } \\
\text { Aging }\end{array}$ & $\begin{array}{l}\text { Axial Strength } \\
\text { (kips) }\end{array}$ & $\begin{array}{l}\text { Average Strength } \\
\text { (kips) }\end{array}$ & $\begin{array}{l}\text { Change in } \\
\text { Strength }\end{array}$ & $\begin{array}{c}\text { Percent } \\
\text { decrease } \\
\text { of } \\
\text { Strength }\end{array}$ \\
\hline 1 & T-U-0C1 & \multirow{3}{*}{ Unaged } & \multirow{3}{*}{$\mathbf{0}$} & 1.58 & \multirow{3}{*}{1.53} & \multirow{3}{*}{---- } & \multirow{3}{*}{---} \\
\hline 2 & T-U-0C2 & & & 1.52 & & & \\
\hline 3 & T-U-0C3 & & & 1.49 & & & \\
\hline 4 & T-E-1S1 & \multirow{6}{*}{$\begin{array}{l}\text { Elevated } \\
\text { Temperature }\end{array}$} & \multirow{3}{*}{1} & 1.4 & \multirow{3}{*}{1.41} & \multirow{3}{*}{-0.12} & \multirow{3}{*}{-7.8} \\
\hline 5 & T-E-1S2 & & & 1.42 & & & \\
\hline 6 & T-E-1S3 & & & 1.43 & & & \\
\hline 7 & T-E-2S1 & & \multirow{3}{*}{2} & 1.39 & \multirow{3}{*}{1.39} & \multirow{3}{*}{-0.14} & \multirow{3}{*}{-9.1} \\
\hline 8 & T-E-2S2 & & & 1.39 & & & \\
\hline 9 & T-E-2S3 & & & 1.4 & & & \\
\hline 10 & T-F-1S1 & \multirow{6}{*}{$\begin{array}{l}\text { Freeze- } \\
\text { Thaw }\end{array}$} & \multirow{3}{*}{1} & 1.43 & \multirow{3}{*}{1.43} & \multirow{3}{*}{-0.10} & \multirow{3}{*}{-6.5} \\
\hline 11 & T-F-1S2 & & & 1.4 & & & \\
\hline 12 & T-F-1S3 & & & 1.46 & & & \\
\hline 13 & T-F-2S1 & & \multirow{3}{*}{2} & 1.42 & \multirow{3}{*}{1.41} & \multirow{3}{*}{-0.12} & \multirow{3}{*}{-7.8} \\
\hline 14 & T-F-2S2 & & & 1.42 & & & \\
\hline 15 & T-F-2S3 & & & 1.39 & & & \\
\hline
\end{tabular}

- Reduction in strength due to elevated temperature is higher than freezing related aging.

Elevated temperature aging results in 2 months showed a reduction of $9.1 \%$ while the freezing condition showed a reduction of $7.8 \%$. 
Table 5-37 Stiffness of Unaged and Aged Tension Strip Specimens

\begin{tabular}{|c|c|c|c|c|c|}
\hline No & Designation & $\begin{array}{l}\text { Type of } \\
\text { Aging }\end{array}$ & $\begin{array}{l}\text { Number of } \\
\text { Months of } \\
\text { Aging }\end{array}$ & Stiffness (Msi) & Average Stiffness \\
\hline 1 & T-U-0C1 & \multirow{3}{*}{ Unaged } & \multirow{3}{*}{$\mathbf{0}$} & 32.4 & \multirow{3}{*}{32.3} \\
\hline 2 & T-U-0C2 & & & 32.8 & \\
\hline 3 & T-U-0C3 & & & 31.8 & \\
\hline 4 & T-E-1S1 & \multirow{6}{*}{$\begin{array}{c}\text { Elevated } \\
\text { Temperature }\end{array}$} & \multirow{3}{*}{1} & 32.2 & \multirow{3}{*}{32.25} \\
\hline 5 & T-E-1S2 & & & 32.3 & \\
\hline 6 & T-E-1S3 & & & $*$ & \\
\hline 7 & T-E-2S1 & & \multirow{3}{*}{2} & 32.1 & \multirow{3}{*}{32.5} \\
\hline 8 & T-E-2S2 & & & 32.9 & \\
\hline 9 & T-E-2S3 & & & $*$ & \\
\hline 10 & T-F-1S1 & \multirow{6}{*}{$\begin{array}{l}\text { Freeze- } \\
\text { Thaw }\end{array}$} & \multirow{3}{*}{1} & 32.1 & \multirow{3}{*}{32.2} \\
\hline 11 & T-F-1S2 & & & 32.3 & \\
\hline 12 & T-F-1S3 & & & GNF & \\
\hline 13 & T-F-2S1 & & \multirow{3}{*}{2} & 32.5 & \multirow{3}{*}{31.8} \\
\hline 14 & T-F-2S2 & & & 31.2 & \\
\hline 15 & T-F-2S3 & & & $*$ & \\
\hline
\end{tabular}

Gauges not attached for plotting stress strain curves

\subsubsection{Stress/Strain Comparison}

\subsubsection{Concrete Cylinder Specimens}

The stress-strain plots of the specimens subjected to aging in elevated temperature

condition and in freeze thaw conditions are shown in the Appendix B. The stress was calculated as a ratio of the applied load to cross sectional area of the concrete. 


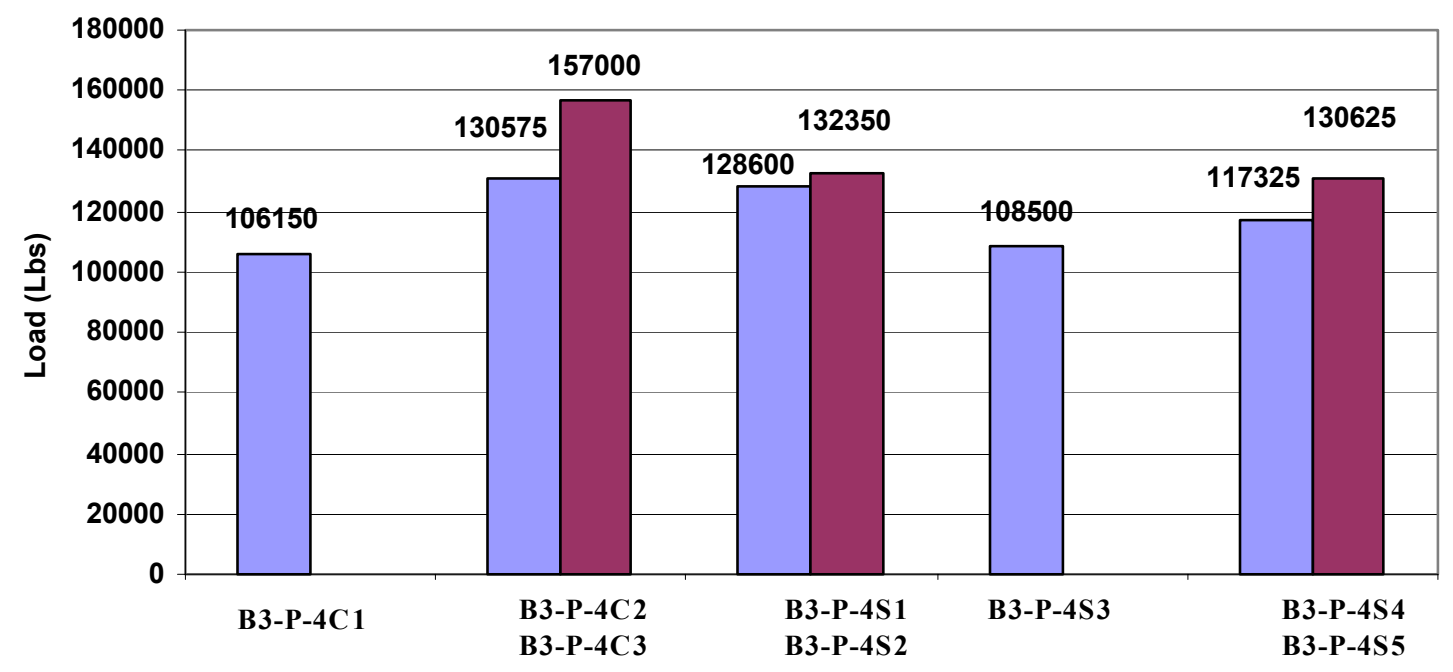

Figure 5-52 Comparison of Maximum Load of Plain Concrete Cylinders Aged in Elevated Temperature refer to Table 5-28 (Aged Plain Concrete Specimens)

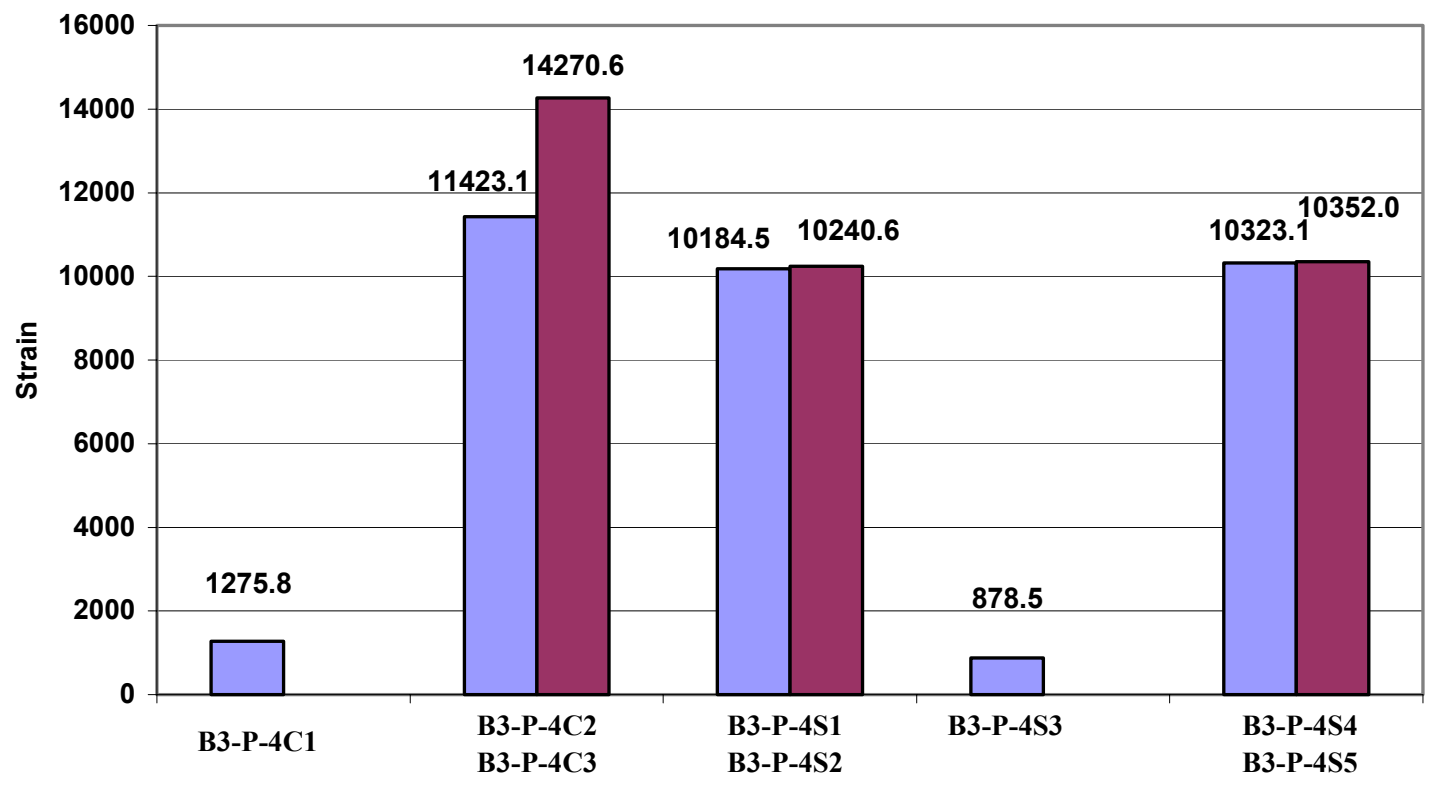

Figure 5-53 Comparison of Maximum Hoop Strain of Plain Concrete Cylinders Aged in Elevated Temperature refer to Table 5-28(Aged Plain Concrete Specimens) 


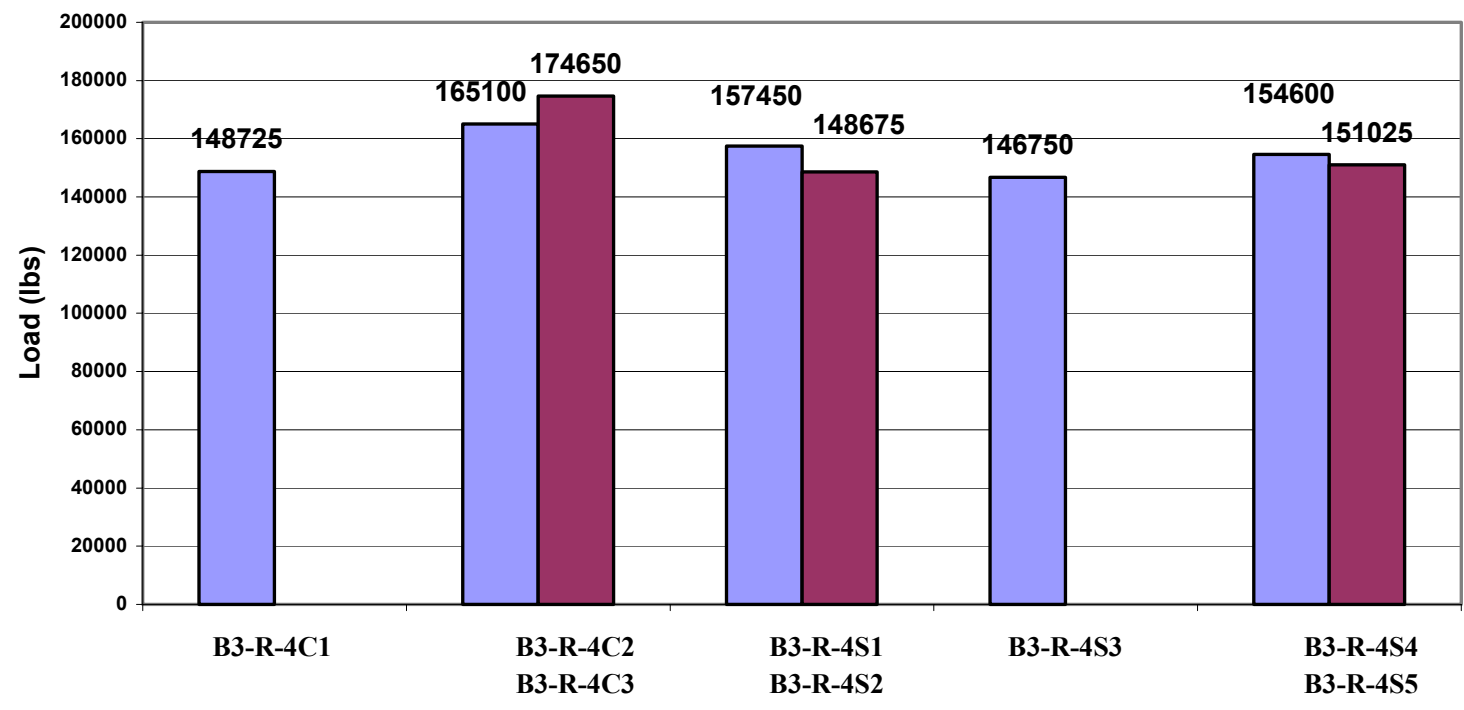

Figure 5-54 Comparison of Maximum Load of Reinforced Concrete Cylinders Aged in Elevated Temperature refer to Table 5-29 (Reinforced Concrete Specimens)

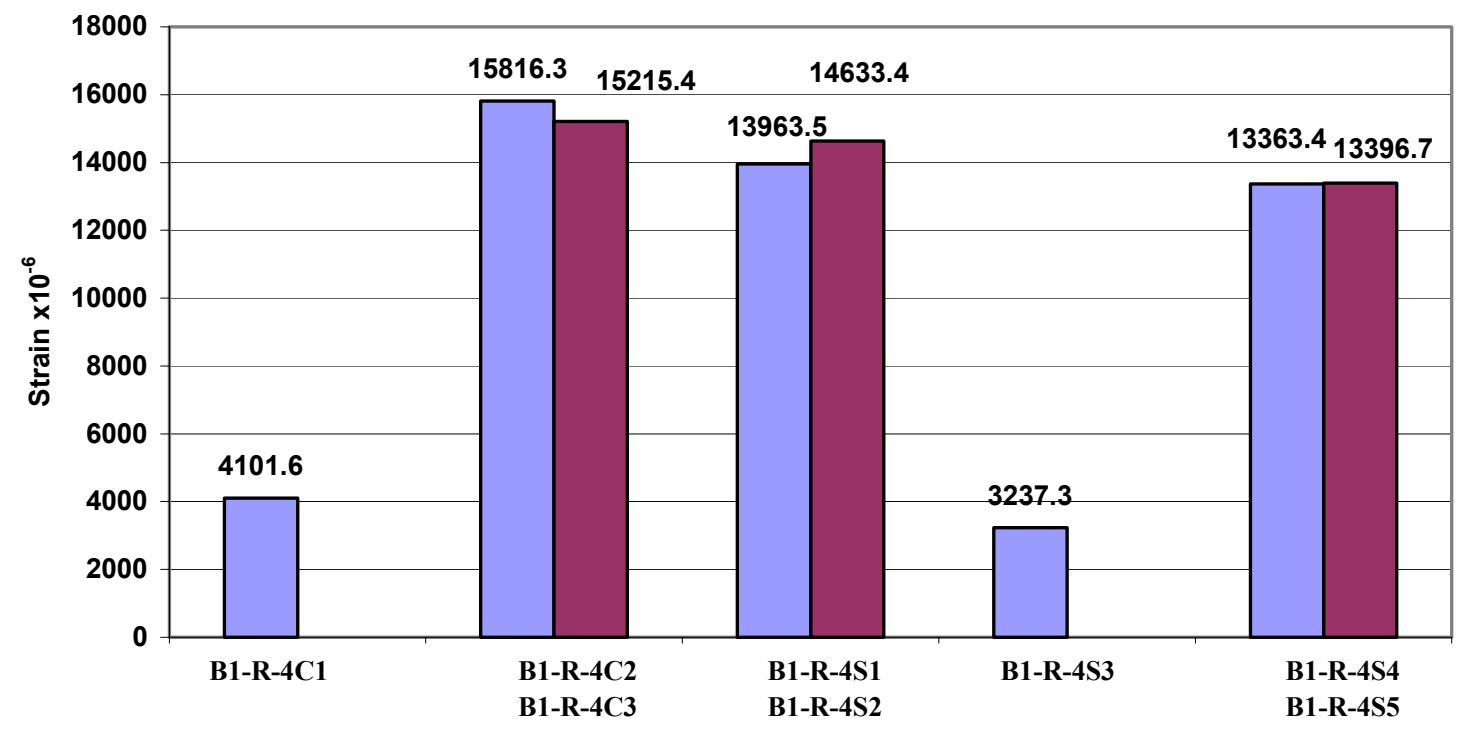

Figure 5-55 Comparison of Strain of Reinforced Concrete Specimens Aged in Elevated Temperature refer to Table 5-29(Reinforced Concrete Specimens) 


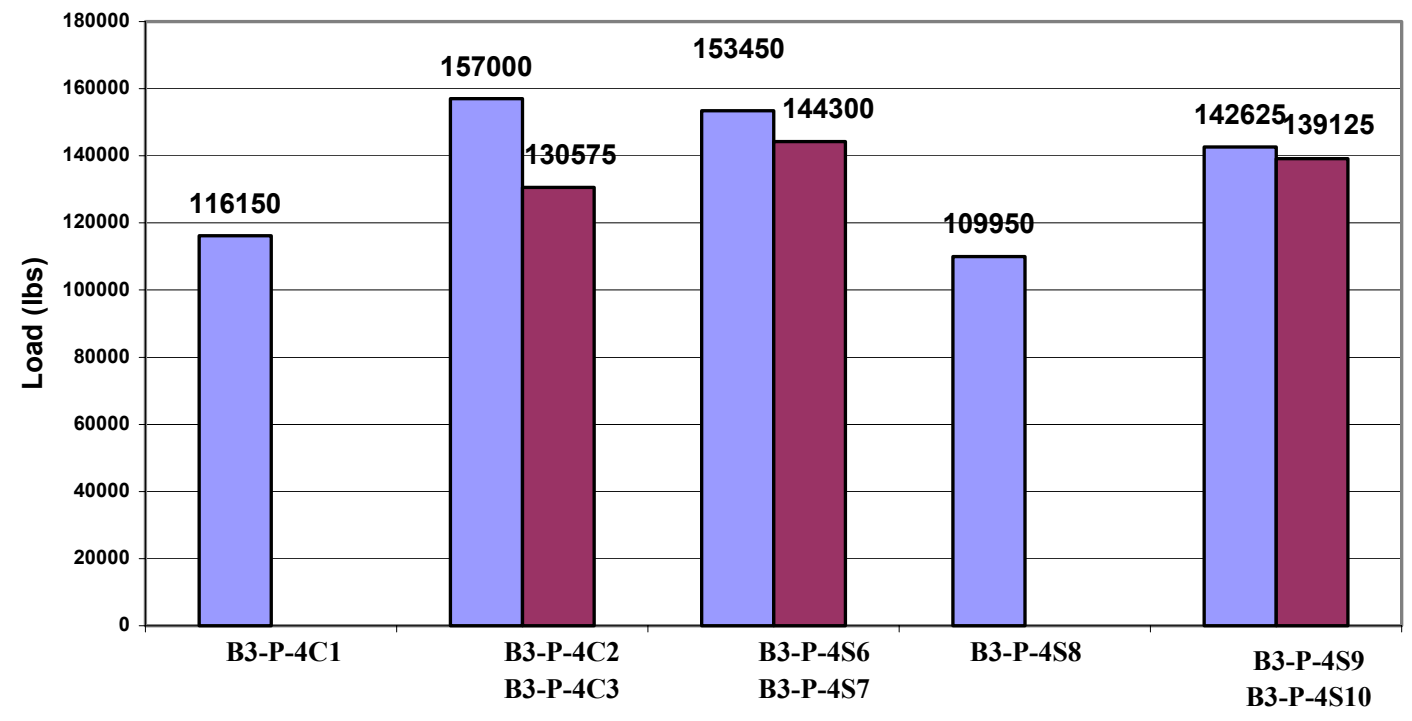

Figure 5-56 Comparison of load of Plain Concrete Cylinder Specimens Subjected to Freeze Thaw Condition refer to Table 5-28 (Plain Concrete Specimens)

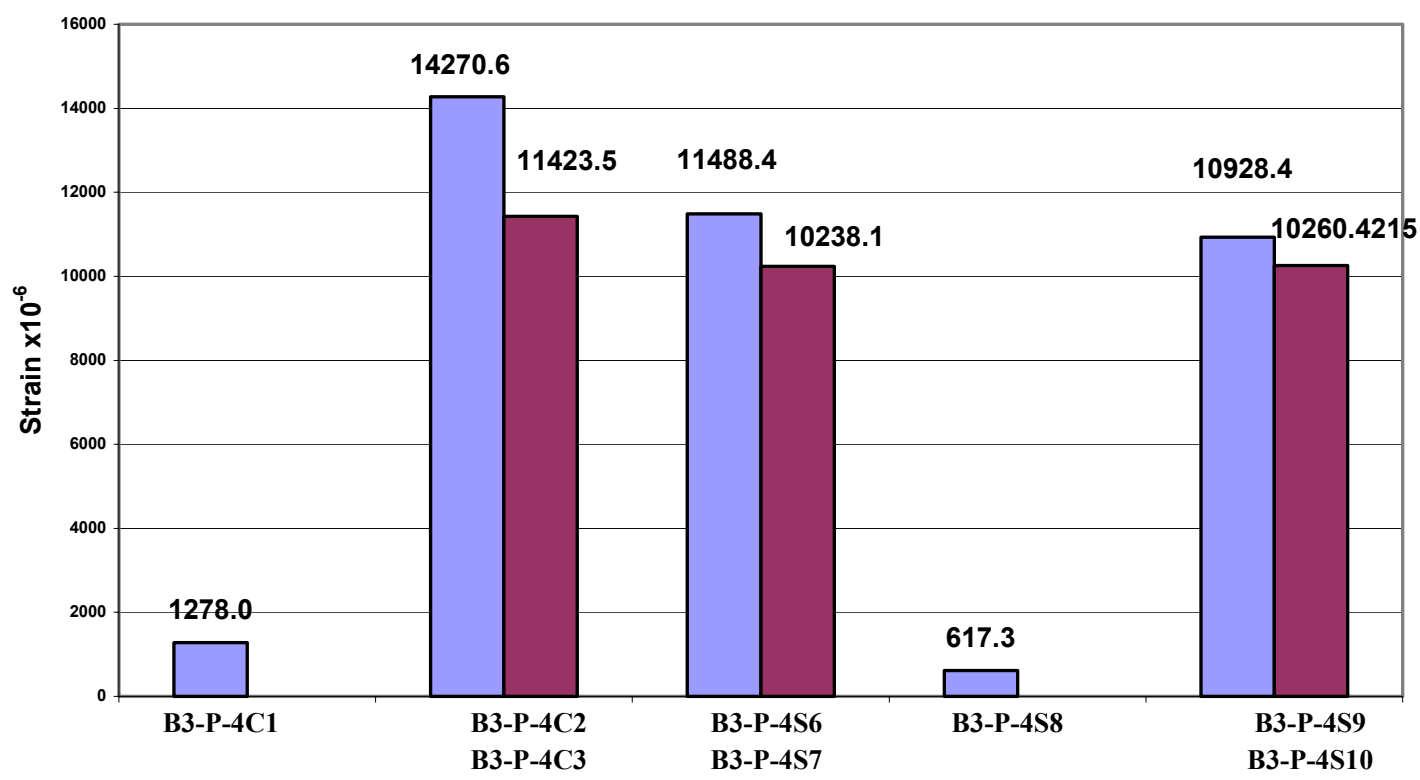

Figure 5-57 Comparison of Strain of Plain Concrete Cylinder Specimens Subjected to Freeze Thaw Condition refer to Table 5-28 (Plain Concrete Specimens) 


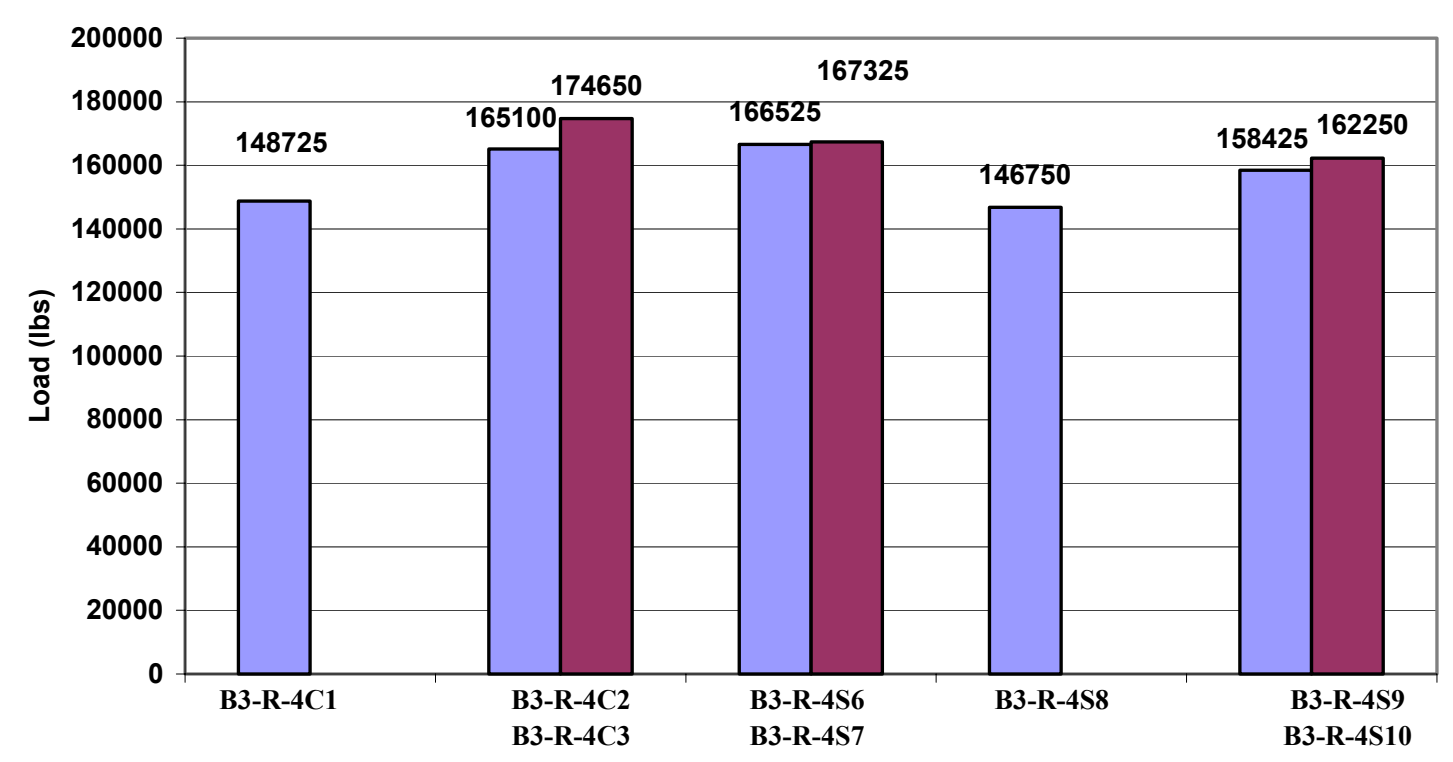

Figure 5-58 Comparison of Load of Reinforced Concrete Cylinder Specimens Subjected to Freeze Thaw Condition refer to Table 5-29 (Reinforced Concrete Specimens)

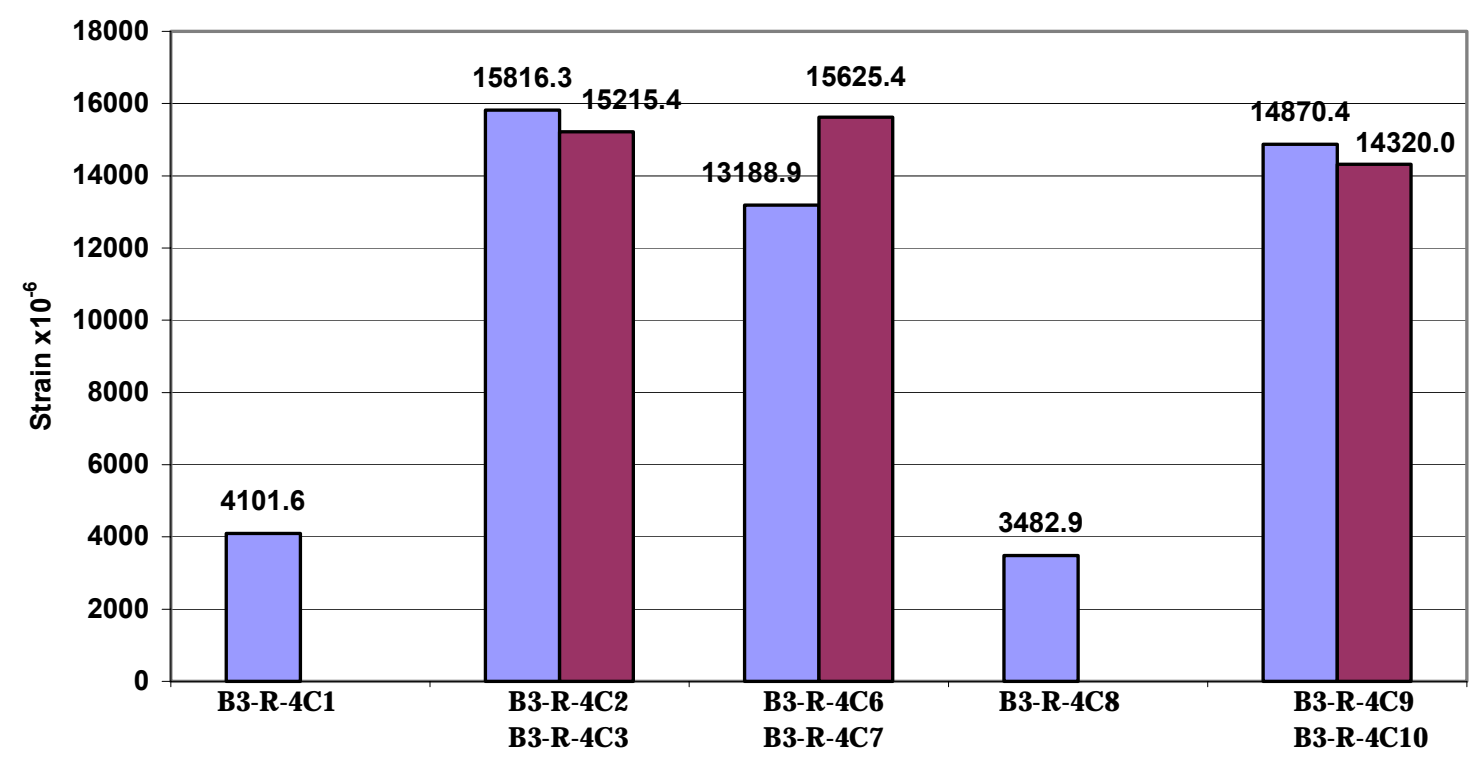

Figure 5-59 Comparison of Strain of Reinforced Concrete Cylinder Specimens Subjected to Freeze Thaw Condition refer to Table 5-29 (Reinforced Concrete Specimens) 


\subsubsection{Strip Specimens}

Five unaged carbon strip specimens were tested with a gauge attached to three of the specimens at the center. Two specimens from each batch of aged strips were attached with gauges at the center and tested. The results of the tests were plotted as stress vs. strain and the stiffness was calculated. The stress vs strain plots and stiffness of the specimens aged in elevated temperature and in freeze thaw conditions are given in Figures 5-60 to 5-62.

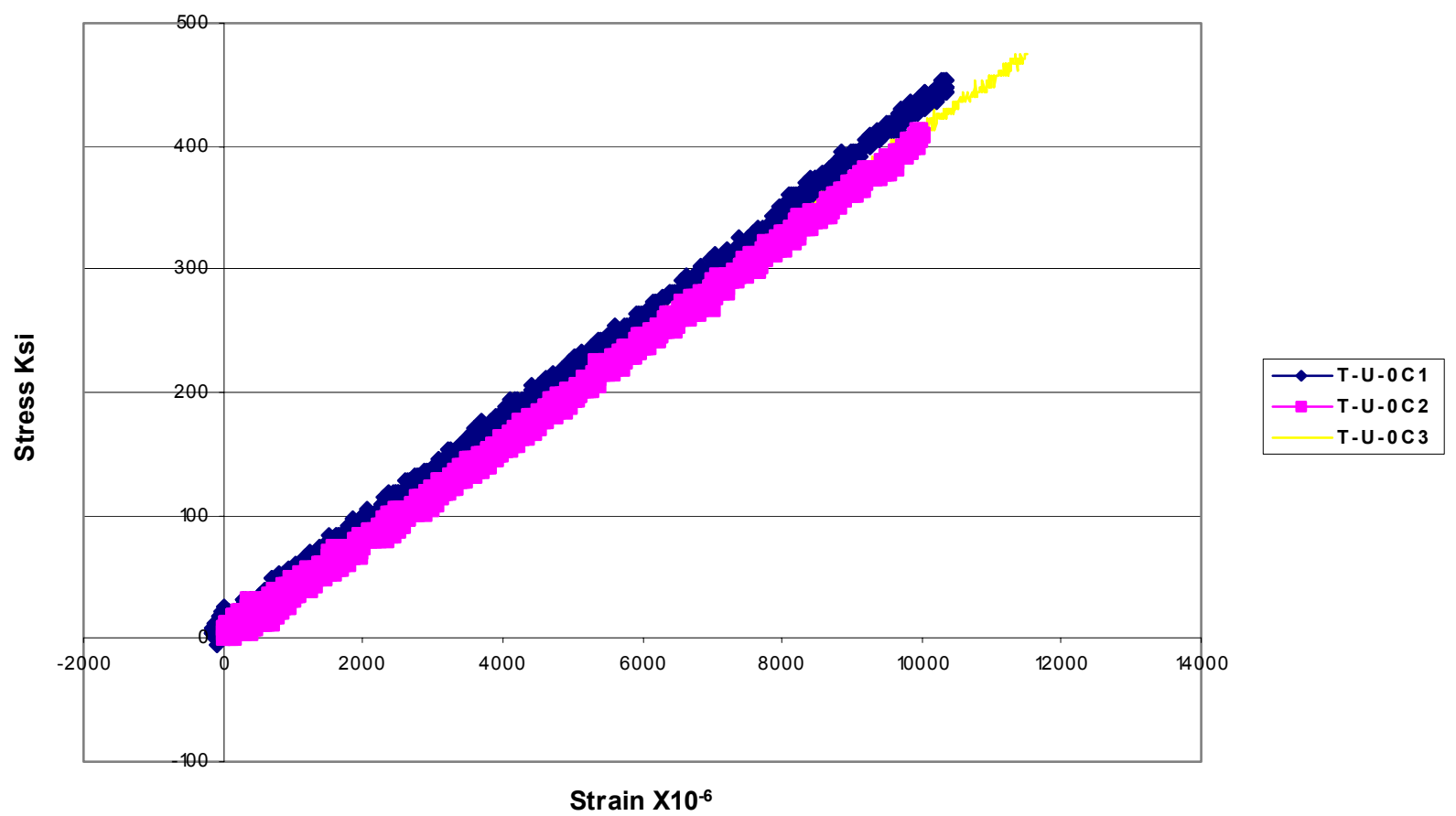

Figure 5-60 Stress Strain Comparison of Unaged Strip Specimen 

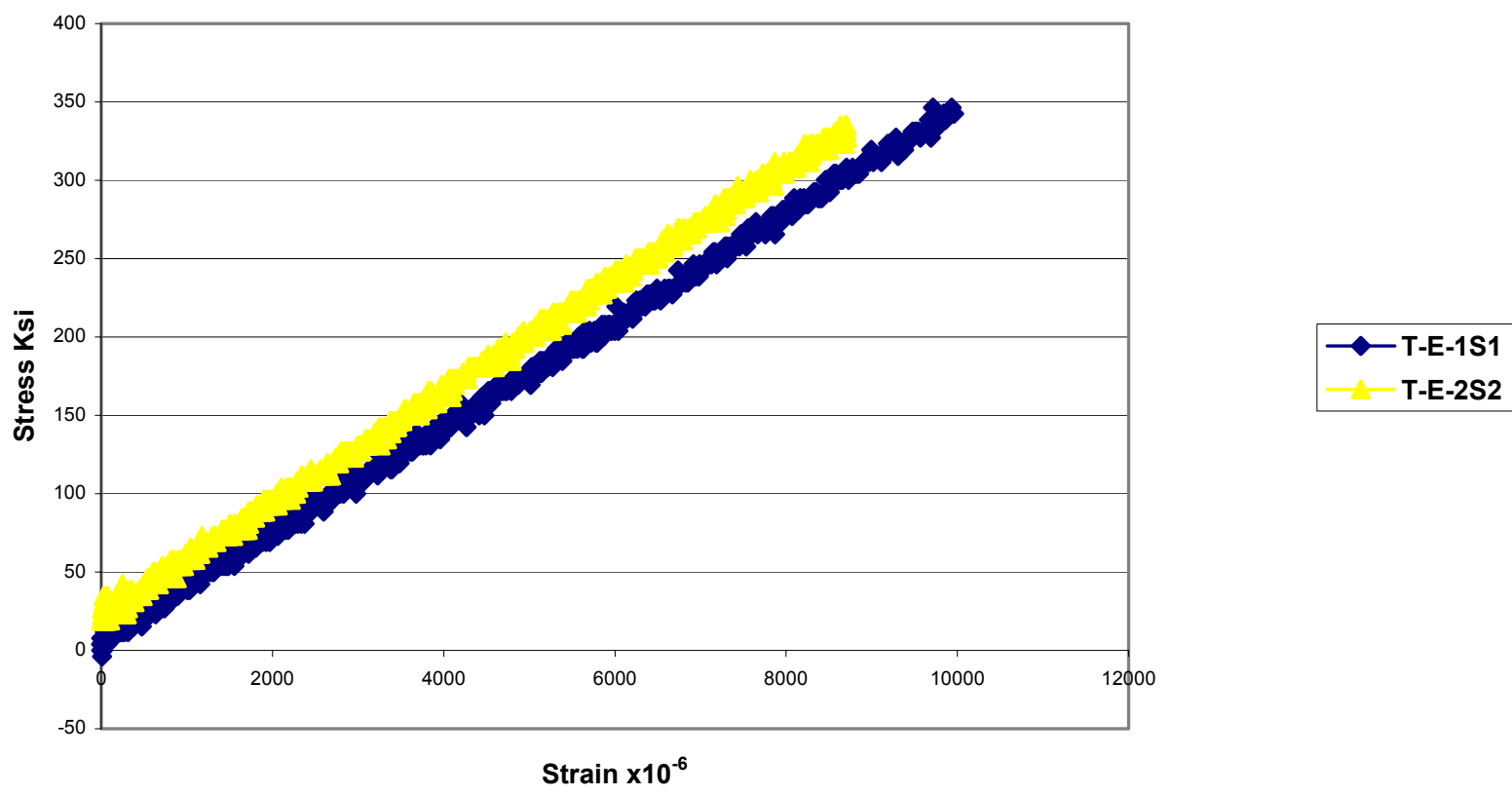

Figure 5-61 Stress Strain Comparison of 1 and 2 Month Aged Strip Specimen - Elevated Temperature

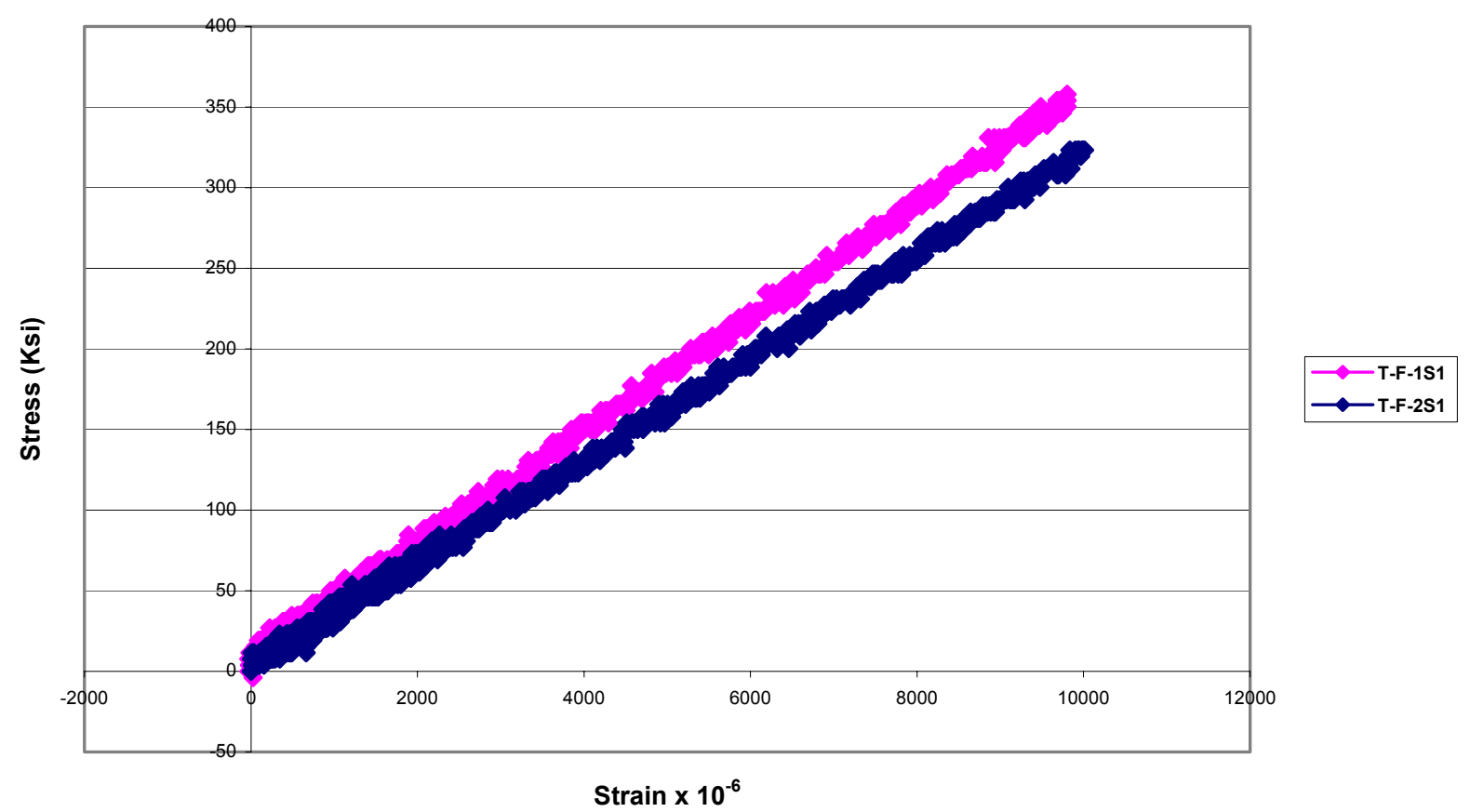

Figure 5-62 Stress Strain Comparison of 1 and 2 Month Aged Strip Specimen - Freeze-Thaw Aging 


\subsubsection{Strains}

The strain was recorded using a strain gauge in the hoop direction. The recorded values of strain have been tabulated in the Table 5-38 and Table 5-39.

Table 5-38 Hoop Strain of Aged and Unaged Plain Concrete Specimens

\begin{tabular}{|c|c|c|c|c|c|c|c|}
\hline No & Designation & Type of Aging & $\begin{array}{l}\text { Number of } \\
\text { Months of } \\
\text { Aging }\end{array}$ & $\begin{array}{l}\text { Number of } \\
\text { Wraps }\end{array}$ & $\begin{array}{l}\text { Hoop } \\
\text { Strain } \\
\times 10^{-6}\end{array}$ & $\begin{array}{c}\text { Percent } \\
\text { Change in } \\
\text { Strain - } \\
\text { Compared to } \\
\text { Unaged } \\
\text { Specimen } \\
\end{array}$ & $\begin{array}{c}\text { Average \% } \\
\text { Change in Strain }\end{array}$ \\
\hline 1 & B3-P-4C1 & \multirow{3}{*}{ Unaged } & \multirow{3}{*}{$\mathbf{0}$} & No Wrap & 1278 & --- & \multirow{3}{*}{--} \\
\hline 2 & B3-P-4C2 & & & \multirow{2}{*}{1} & 11423 & --- & \\
\hline 3 & B3-P-4C3, & & & & 11270 & --- & \\
\hline 4 & B3-P-4S1 & \multirow{5}{*}{$\begin{array}{c}\text { Elevated } \\
\text { Temperature }\end{array}$} & \multirow{2}{*}{1} & \multirow{2}{*}{1} & 10184 & -10 & \multirow{2}{*}{-10} \\
\hline 5 & B3-P-4S2 & & & & 10240 & -10 & \\
\hline 6 & B3-P-4S3 & & \multirow{3}{*}{2} & No Wrap & 878 & -2.2 & -2.2 \\
\hline 7 & B3-P-4S4 & & & \multirow[t]{2}{*}{ ( } & 10323 & -9 & \multirow{2}{*}{-9} \\
\hline 8 & B3-P-4S5 & & & & 7007.2 & $\begin{array}{ll}--- \\
\end{array}$ & \\
\hline 9 & B3-P-4S6 & \multirow{5}{*}{ Freeze-Thaw } & \multirow{2}{*}{1} & \multirow{2}{*}{1} & 11184 & -10 & \multirow{2}{*}{-10} \\
\hline 10 & B3-P-4S7 & & & & 11240 & -10 & \\
\hline 11 & B3-P-4S8 & & \multirow{3}{*}{2} & No Wrap & 617 & -5 & -5 \\
\hline 12 & B3-P-4S9 & & & \multirow{2}{*}{1} & 10323 & -9.6 & \multirow{2}{*}{-9.6} \\
\hline 13 & B3-P-4S10 & & & & 10350 & -9.4 & \\
\hline
\end{tabular}

Table 5-39 Hoop Strain of Aged and Unaged Reinforced Concrete Specimens

\begin{tabular}{|c|c|c|c|c|c|c|c|}
\hline No & $\begin{array}{l}\text { Specimen } \\
\text { Specification }\end{array}$ & Type of Aging & $\begin{array}{l}\text { Number of } \\
\text { Months of } \\
\text { Aging }\end{array}$ & $\begin{array}{c}\text { Number of } \\
\text { Wraps }\end{array}$ & $\begin{array}{l}\text { Hoop Strain } \\
\times 10^{-6}\end{array}$ & $\begin{array}{l}\text { Percent Change } \\
\text { in Strain-- } \\
\text { Compared to } \\
\text { Unaged } \\
\text { Specimen }\end{array}$ & $\begin{array}{c}\text { Average } \\
\% \\
\text { Change } \\
\text { in } \\
\text { Strain }\end{array}$ \\
\hline 1 & B3-R-4C1 & \multirow{3}{*}{ Unaged } & \multirow{3}{*}{$\mathbf{0}$} & No Wrap & 4101.6 & --- & \multirow{3}{*}{---} \\
\hline 2 & B3-R-4C2 & & & \multirow{2}{*}{1} & 15816 & --- & \\
\hline 3 & B3-R-4C3 & & & & 15215 & --- & \\
\hline 4 & B3-R-4S1 & \multirow{5}{*}{$\begin{array}{l}\text { Elevated } \\
\text { Temperature }\end{array}$} & \multirow{2}{*}{1} & \multirow{2}{*}{1} & 13963 & -10 & \multirow{2}{*}{-10} \\
\hline 5 & B3-R-4S2 & & & & 14633 & -10 & \\
\hline 6 & B3-R-4S3 & & \multirow{3}{*}{2} & No Wrap & 3237 & -21 & -21 \\
\hline 7 & B3-R-4S4 & & & \multirow{2}{*}{1} & 13363 & -12 & \multirow{2}{*}{-8.5} \\
\hline 8 & B3-R-4S5 & & & & 14396 & -5 & \\
\hline 9 & B3-R-4S6 & \multirow{5}{*}{ Freeze-Thaw } & \multirow{2}{*}{1} & \multirow{2}{*}{1} & 13188 & -14 & \multirow{2}{*}{-7.3} \\
\hline 10 & B3-R-4S7 & & & & 15625 & -0.7 & \\
\hline 11 & B3-R-4S8 & & \multirow{3}{*}{2} & No Wrap & 3483 & -15 & -15 \\
\hline 12 & B3-R-4S9 & & & \multirow{2}{*}{1} & 14870 & -0.4 & \multirow{2}{*}{-0.36} \\
\hline 13 & B3-R-4S10 & & & & 14352 & -0.32 & \\
\hline
\end{tabular}


- Both elevated temperature and freeze thaw aging resulted in decrease in strains to failure (Table 5-38 and 5-39).

\subsection{Infrared Thermography}

Non Destructive Infrared Thermography tests were done to distinguish the bonded and delaminated areas between fiber and concrete interface. Infrared systems measure the surface temperature and the presence of anomalies can be identified from the temperature profile. These images indicate different surface temperature by making distinction in shades or colors (Halabe, 1995). Delamination or delam is the physical separation or loss of bond between layers. A delamination in the case of wrapped concrete cylinders is typically filled with air. The air acts as a thermal insulator and the difference in temperature between the bonded and delaminated regions can be mapped in the thermal profile. By measuring surface temperature under known heat flow conditions, the subsurface defects can be located (Weil 1989, Weil 1991). The air filled delamination will record a much higher temperature than the bonded regions.

\subsubsection{Thermal Mapping/Profiling}

The concrete cylinders were wrapped with CFRP using epoxy resin. The epoxy had a work time of about 4 hours and after the work time the epoxy starts curing with an exothermic reaction. The infrared thermograms were captured at every half hour and the thermal profile and scale were noted. The specimens were not heated using an external source and the measurements were done to establish the exothermic reaction of concrete. Regions with higher temperature had brighter colors and the regions with lower temperature showed darker colors in 
thermal profiles. The scale of the camera can be set to record the images within a particular temperature. Images of the wrapped cylinders taken every half-hour and the images showing a change in temperature profile are shown in Figs. 5-63 to 5-67.

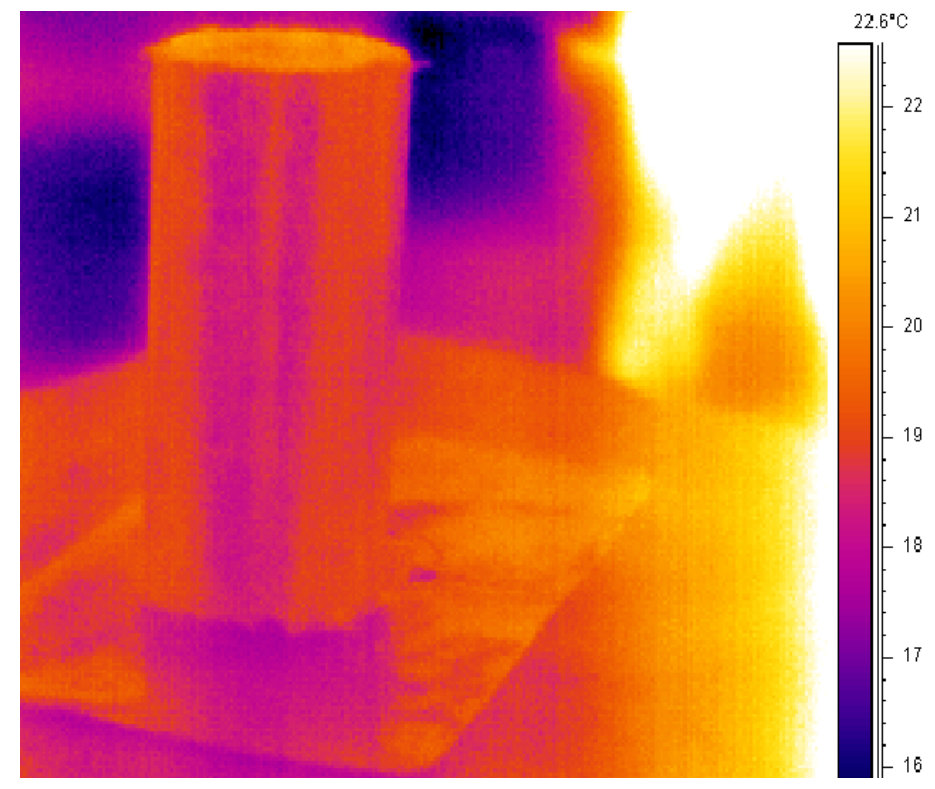

Figure 5-63 Thermogram after 1 hour of wrapping: Reaction has not started

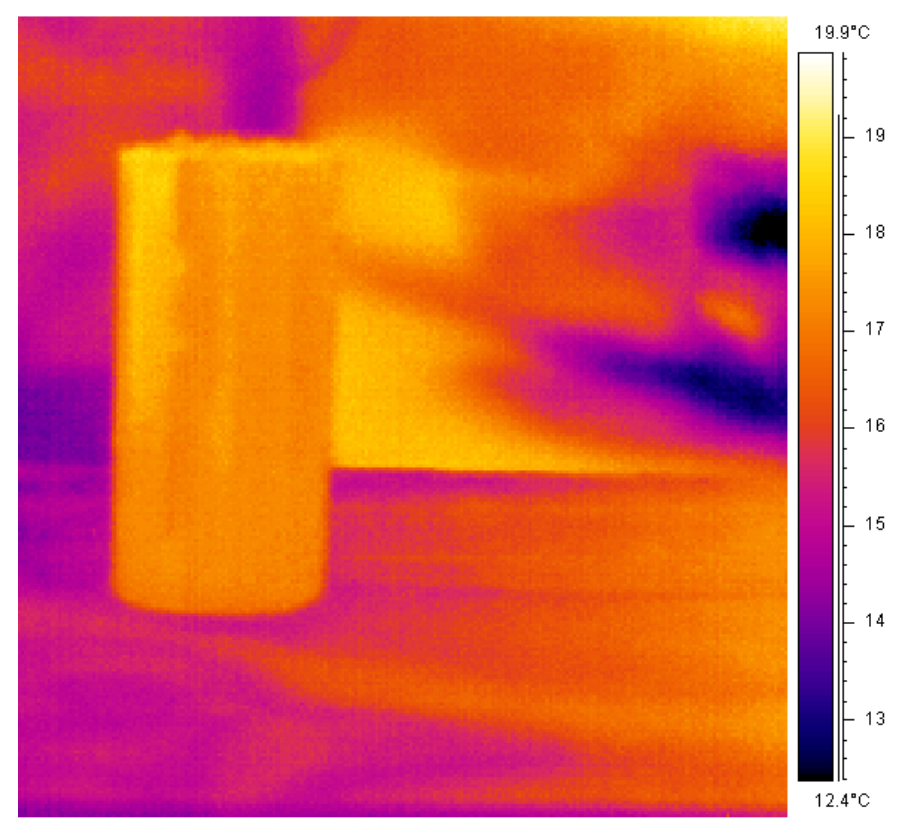

Figure 5-64 Thermogram after 4 hours of wrapping: Exothermic reaction is taking place 


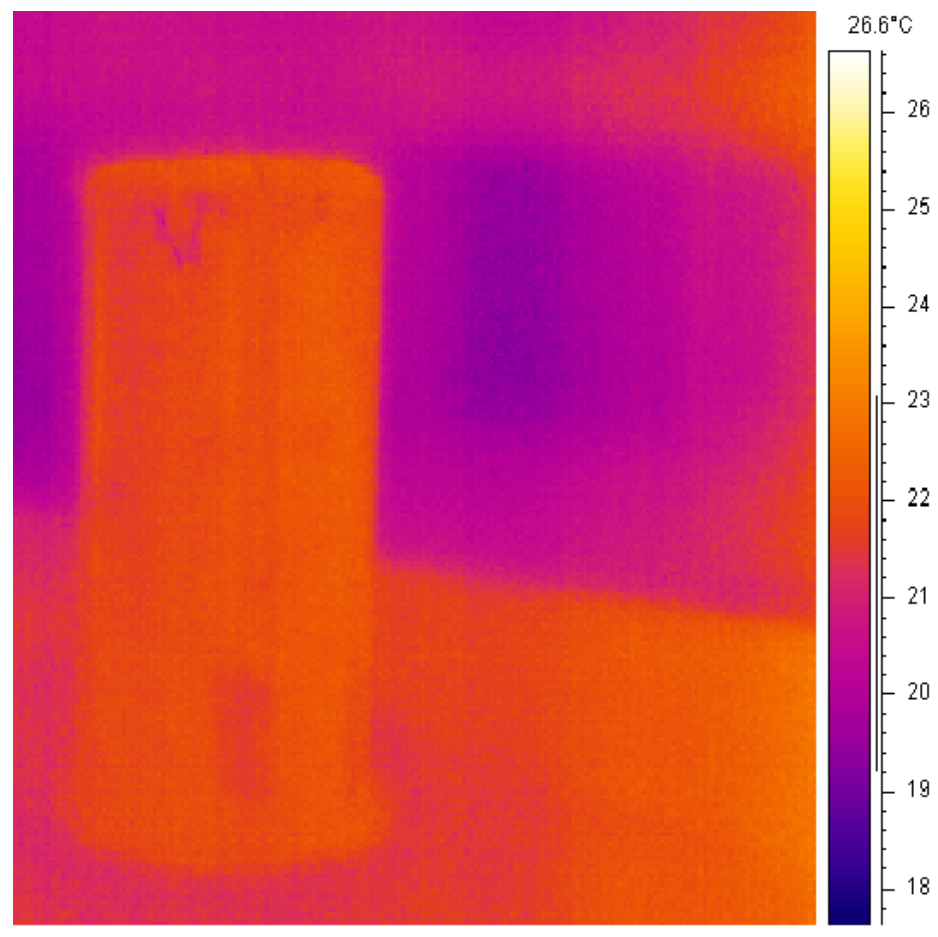

Figure 5-65 Thermogram after 6 Hours of Wrapping: Exothermic Reaction continues

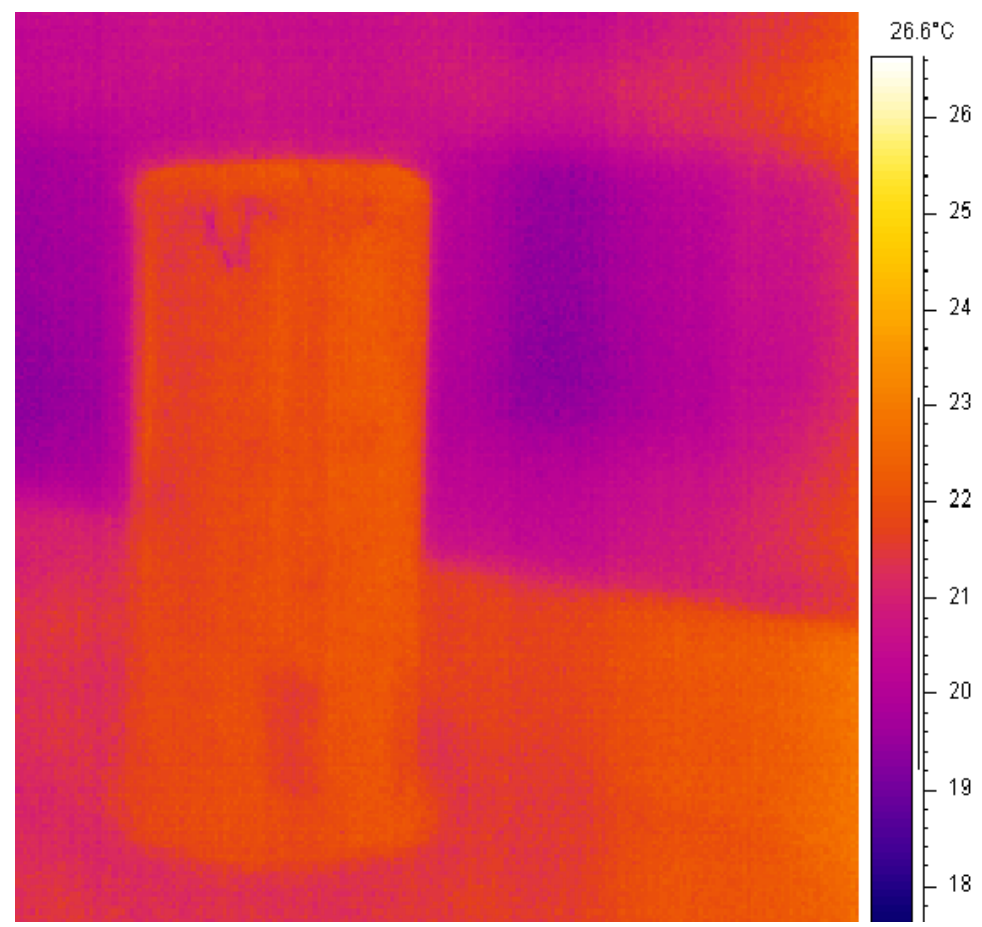

Figure 5-66 Thermogram after 8 hours of wrapping: Cross Linking Continues 


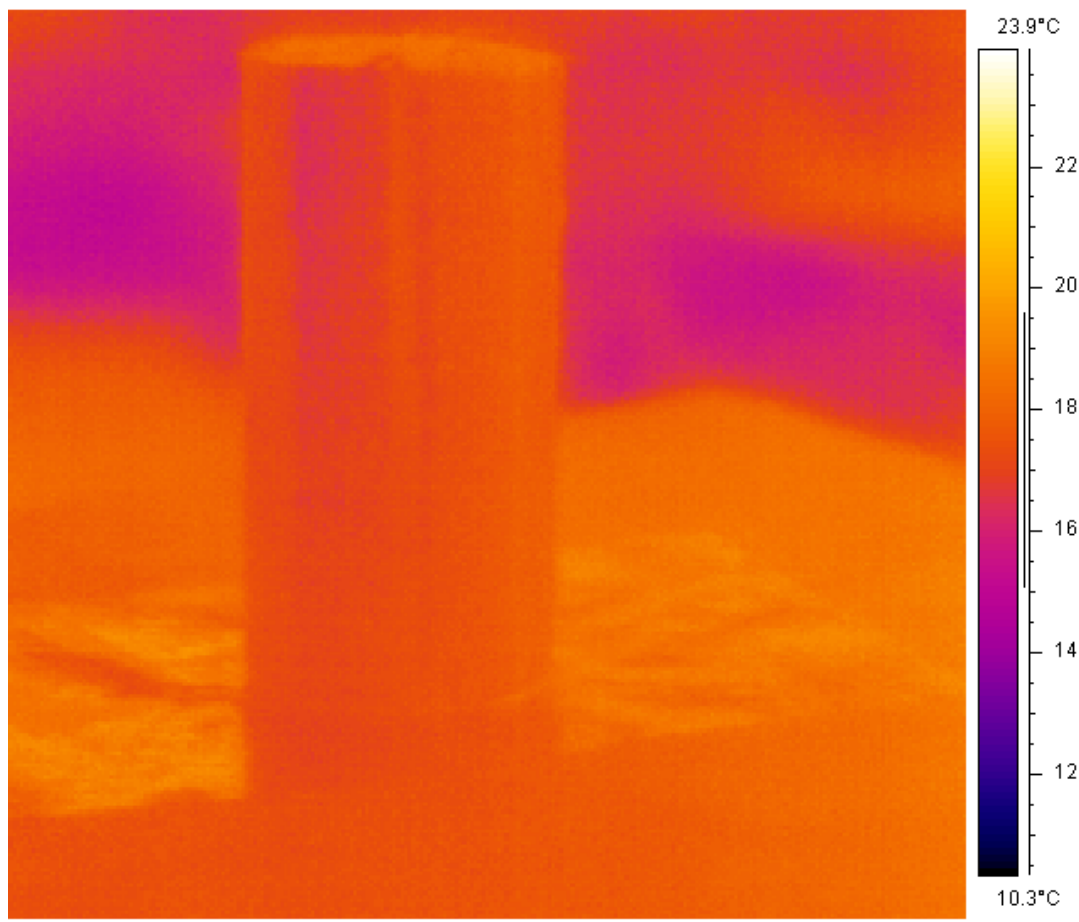

Figure 5-67 Thermogram after 24 hours of Wrapping: Reaction stops

The temperature scale is shown at the side of each infrared thermogram and the scale reads temperatures from a minimum of $10^{\circ} \mathrm{C}$ to a maximum of $24^{\circ} \mathrm{C}$. The scale auto adjusts itself to read the range of exothermic reaction temperature. The initial increase in temperature and the gradual decrease in temperature seen on the thermal scale indicate the rate of exothermic reaction taking place at different time intervals.

- Initially when the thermograms were recorded using the infrared camera, the specimen showed a uniform temperature of about $18.5^{\circ} \mathrm{C}$ indicating no evidence of cross-linking in the resin with 3 hours of working time.

- Temperature increased to $19.9^{\circ} \mathrm{C}$ at about 4 hours after wrapping indicating the ongoing resin cross-linking process. 
- The temperature increased to $24-25^{\circ} \mathrm{C}$ in 6 hours and 8 hours time indicating the cross linking progress of the resin.

- In 24 hours the temperature was about $18^{\circ} \mathrm{C}$ indicating completion of the reaction.

\subsubsection{Test Results}

\subsubsection{Cross linking of the Resin}

The wrapped specimens were heated using an external source, i.e., a quartz heater and the infrared thermograms were captured using the infrared camera. Debonds or the loss of bond between concrete and CFRP wrap interface were marked with a brighter color as delaminations have a higher temperature. The cylinder was placed in front of the camera and each cylinder surface was heated and the thermogram was recorded. All the four quadrant surfaces of the cylinder circumference were checked for defects. Thermograms also showed a higher temperature at the overlap region. This was due to the higher heat retention because of lower heat loss of heat taking place at a lower rate due to increased wrap thickness. It was noted that the carbon wrap lost the applied heat at a faster pace in other regions. Figures 5-68 to 5-71 show the infrared thermograms of the cylinder B2-P-4S1. The cylinder was first checked for any delams using infrared thermography and then tested under compression to failure. The cylinder failed at a load of $130625 \mathrm{lbs}$ and showed an increase of $33.8 \%$ in strength when compared to the non-wrapped specimen. 


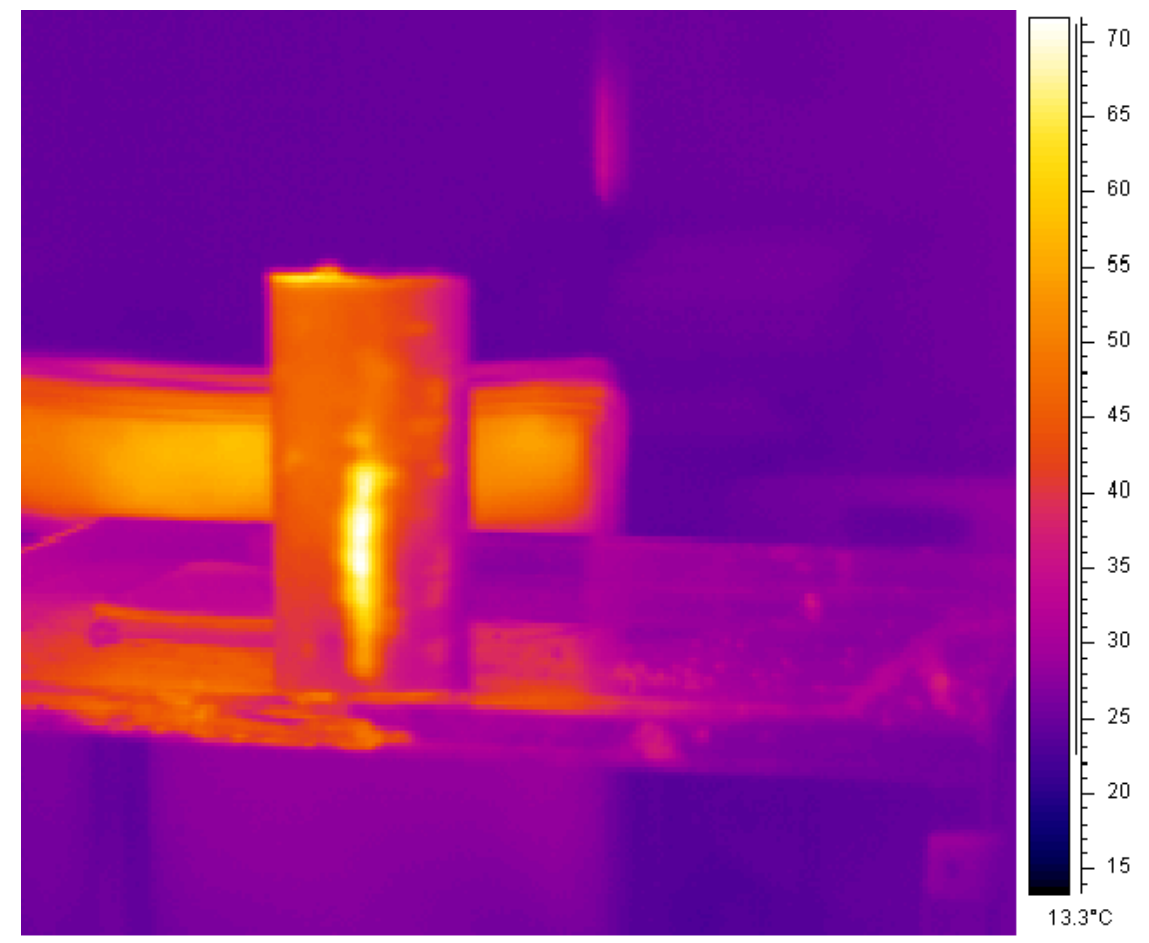

Figure 5-68: Infrared Thermogram of B2-P-4S1 Wrapped Cylinder-Quadrant/Face 1

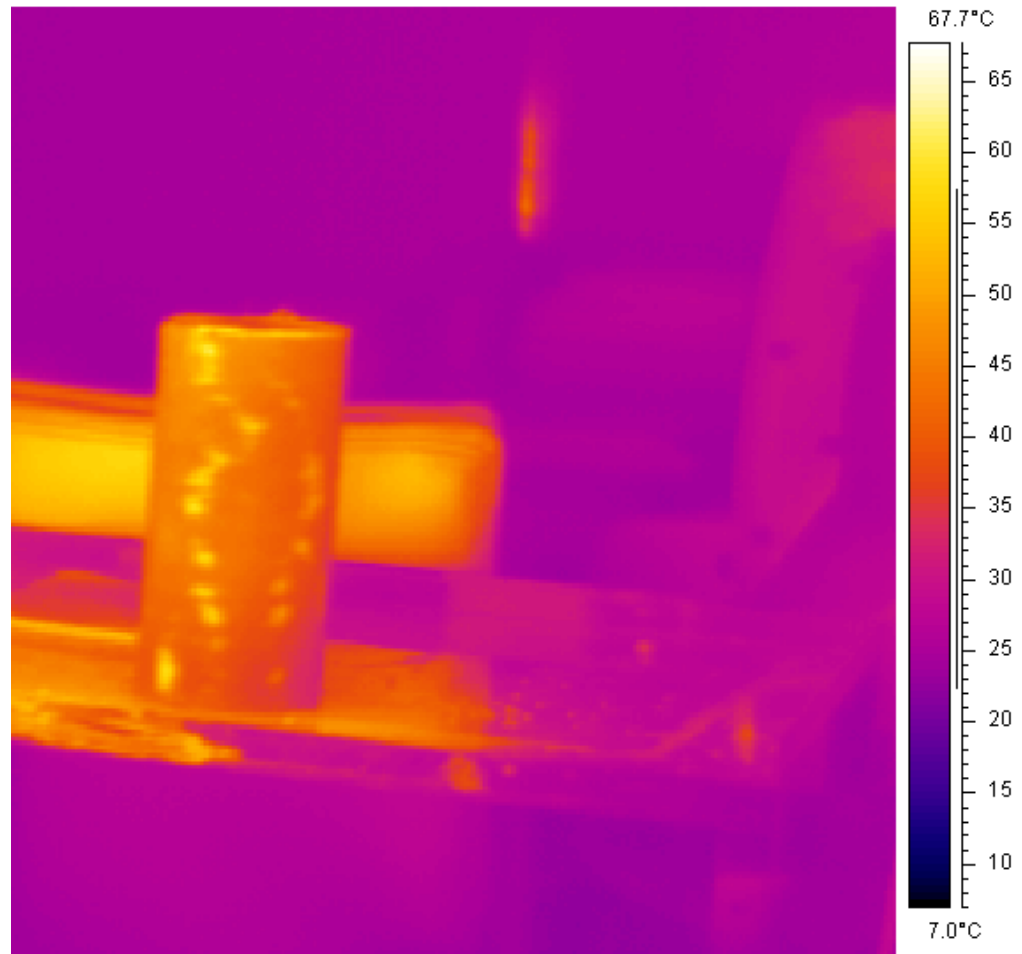

Figure 5-69: Infrared Thermogram of B2-P-4S1 Wrapped Cylinder-Quadrant/Face 2 


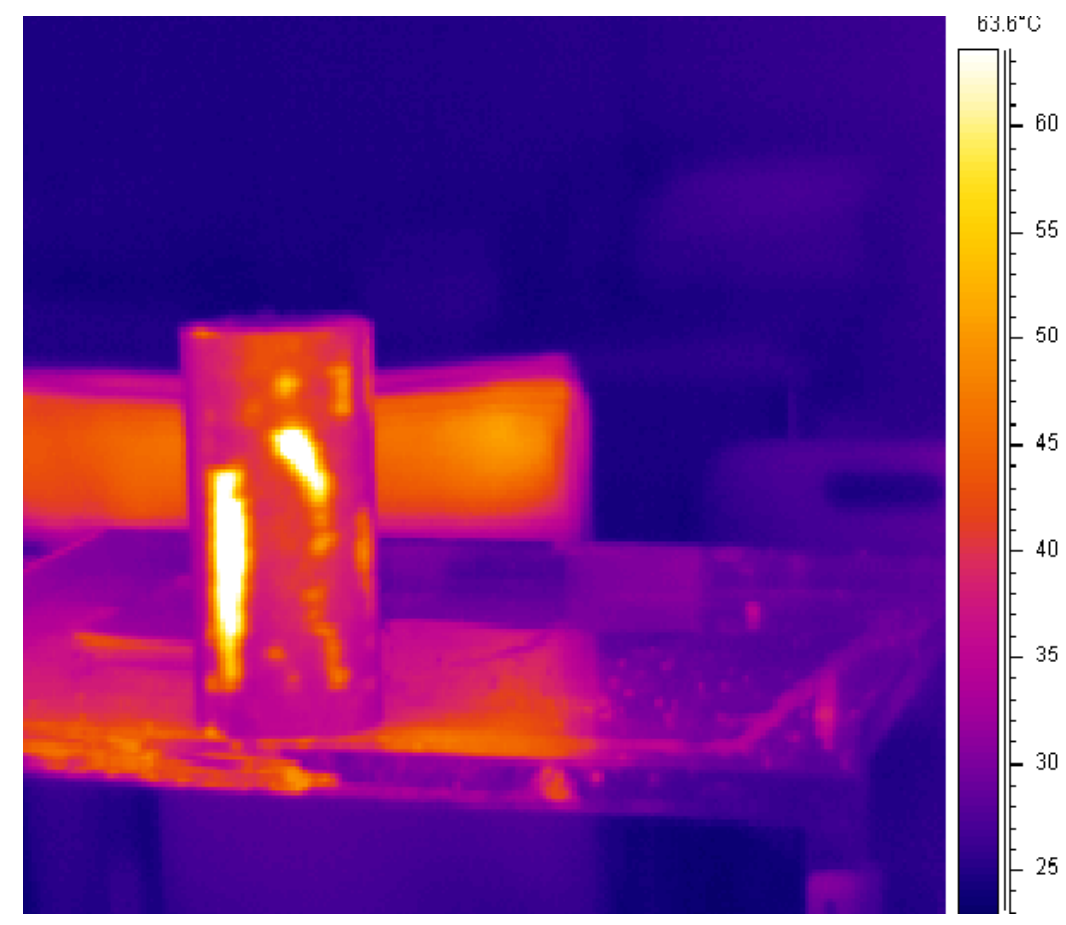

Figure 5-70: Infrared Thermogram of B2-P-4S1 Wrapped Cylinder-Quadrant/Face 3

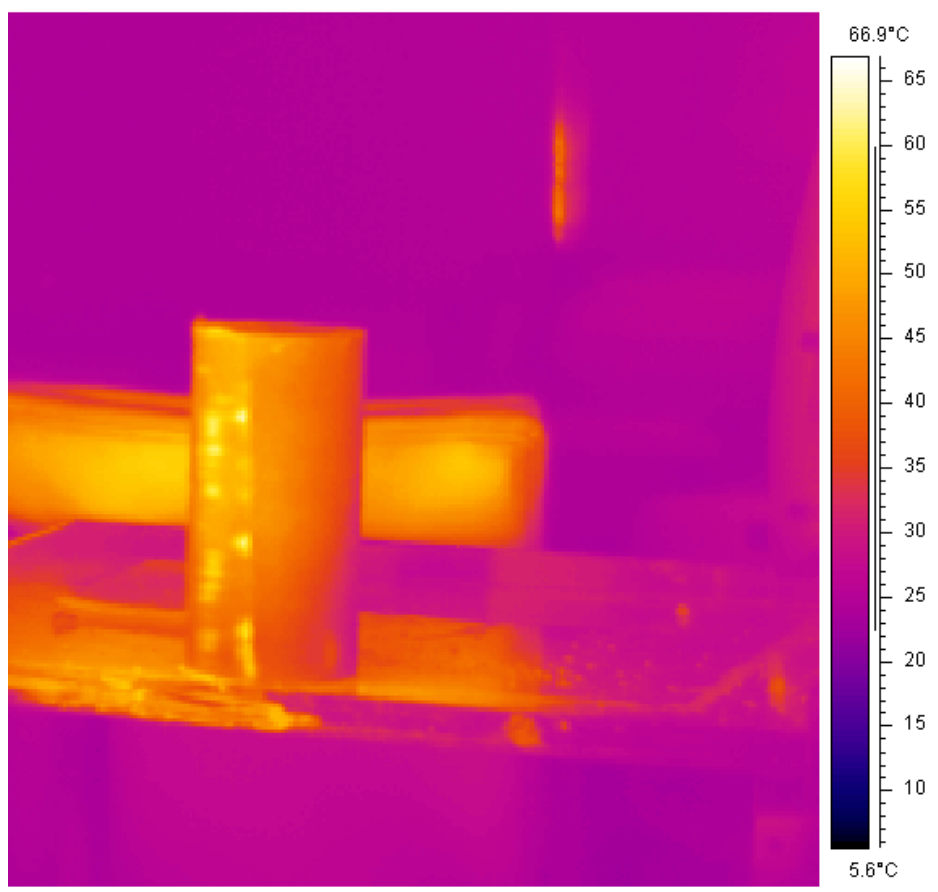

Figure 5-71: Infrared Thermogram of B2-P-4S1 Wrapped Cylinder-Quadrant/Face 4 Overlap of 2" of FRP 
- Brighter spots showed higher temperature hence the presence of debonds, (Halabe et al.1995) as shown in Figures 5-68 to 5- 71.

- Though hand wrapping was done carefully and then the specimens were gently pressed down to prevent air gaps using a plastic spatula. Gaps were observed between the wrap and the specimen (Figures 5-68 to 5- 71).

- The overlap region of FRP showed increased temperature because of the increased thickness of the carbon wrap resulting in increased dissipation time. Hence the region remains hotter than the surrounding region (Figure 5-71).

- It should be noted that small delamination less than $2 \mathrm{in}^{2}$ are permissible while delams greater than $25 \mathrm{in}^{2}$ should be repaired by selectively cutting away the affected area and delams smaller than $25 \mathrm{in}^{2}$ can be repaired by injecting resin, (ACI Committee 440, 2002).

\subsubsection{Aging Test Results}

Wrapped cylinders B3-P-4S11 and B3-R-4S11 were placed in the elevated temperature condition and the specimens B3-P-4S12 and B3-R-4S12 were placed in the freeze thaw cyclic aging conditions. Cylinders were checked to see any increase in delamination area by taking infrared thermograms before they were placed in the chamber and after 1 month and 2 months of accelerated aging. The initial thermograms taken before aging were compared to the thermograms taken after aging.

The images indicated no detectable difference in size of debond in any of the aged specimens when compared to the unaged specimens. Specimens have been placed again in the chamber and the elevated temperature bath and the images will be captured after a period of 10 
months. It is suggested the delaminations should be studied under sustained load conditions as well.

- No increase in size of debond was noted. The brighter spot or the delam which was identified without aging and then after 1 and 2 months of aging in freeze thaw and elevated temperature conditions did not show any detectable increase in size.

\subsection{Summary}

The results from tests conducted to analyze the effects of confinement of concrete cylinders using FRP wrap and the parameters affecting confinement were provided in this chapter. Variation in strength, stiffness and ductility due to number of layers of wrap, fiber orientation, size effect, difference in $f_{c}{ }^{\prime}$, partial confinement as well as partial fiber wetting and partial bonding have been provided. The failure modes of the specimens and infrared thermograms taken to evaluate the bond between concrete and fiber are also described with infrared thermograms. The results obtained to determine each parameter of confinement have been analyzed and discussed. The effects of aging in accelerated conditions of wrapped and nonwrapped specimens were discussed. The infrared thermography tests done to locate the delamination between fiber and concrete are also discussed at the end of each subsection of this chapter. Hence they are not repeated in summary. 


\section{ANALYTICAL EVALUATION}

\subsection{Introduction}

The values of strength due to confinement determined through experimental testing are correlated to different mathematical models given by different researchers. The values are compared with experimental results for both batch $1\left(f_{c}{ }^{\prime}=4500 \mathrm{psi}\right)$ and batch $2\left(f_{c}{ }^{\prime}=8000 \mathrm{psi}\right)$ concrete cylinders. Sample calculations are provided for each model using batch 1 specimens.

\subsection{Analytical Models}

The models of various other researchers with corresponding example calculations are provided along with the strength of plain and reinforced concrete cylinders without wraps.

\section{Strength of plain concrete cylinder}

$f_{c}{ }^{\prime}=4500 \mathrm{psi}$

Area of cylinder $=\pi / 4 *(4)^{2}==12.566 \mathrm{in}^{2}$

Strength of cylinder $=4500 \times$ Area of Cylinder

$$
=4500 \times 12.566=56548.66 \mathrm{lbs} \sim \mathbf{5 6 . 5 4} \text { kips }
$$

Strength of concrete cylinder with longitudinal reinforcement and hoop reinforcement

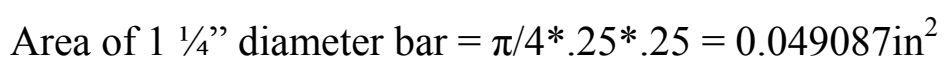

Area of Longitudinal Reinforcement $=4 \times .049087=0.19635 \mathrm{in}^{2}$

Area of Hoop reinforcement $=0.1885 \mathrm{in}^{2}$ 
$f y=40000 \mathrm{psi}$

Strength of $4500 \mathrm{psi}$ cylinder $=4.5^{*}(12.566-0.19632)+40 * 0.19635=70.209$ kips

\section{Analytical calculations were done using existing models from other researchers}

\subsubsection{Model I}

This Model is proposed by ACI Committee 440 (Renato Paretti et al., 2002) calculates the confined compressive strength of concrete as

$$
\begin{aligned}
& f_{c c}= f_{c}^{\prime}\left[2.25 \sqrt{1+7.9 \frac{f_{l}}{f_{c}{ }^{\prime}}}-2 \frac{f_{l}}{f_{c}{ }^{\prime}}-1.25\right] \\
& \text { where, } \\
& f_{c c}{ }^{\prime}=\text { confined compressive strength of concrete }(\mathrm{ksi}) \\
& f_{c}^{\prime}=\text { Compressive strength of concrete (ksi) } \\
& f_{l}=\text { Confining pressure provided by the FRP jacket (ksi) } \\
& f_{l}=\frac{k_{a} \rho_{f} \varepsilon_{f e} E_{f}}{2}(\mathrm{ksi}) \\
& \rho_{f} \text { is the FRP reinforcement ratio } \\
& \varepsilon_{f e} \text { is the effective FRP strain limited to } 0.004 \text { to } 0.75 \varepsilon_{f u} \\
& \mathrm{~K}_{\mathrm{a}}=1 \text { for circular sections (efficiency reduction factor) } \\
& \mathrm{E}_{\mathrm{f}}=33,000,000 \text { psi }
\end{aligned}
$$

\section{Example}

Number of layers $=\mathrm{N}=3$

Diameter of cylinder $=\mathrm{D}=4 "$

Diameter of cylinder + FRP wrap $=D_{o}=4+N * t * 2 \quad$ Where, $\mathrm{t}=$ thickness of FRP wrap $=.11 \mathrm{~mm}=.004$ in 
$\mathrm{D}_{\mathrm{o}}=4+3 * .004 * 2=4.024 \mathrm{in}^{2}$

Area of concrete $=\pi / 4 *(4)^{2}=12.566 \mathrm{in}^{2}$

Area of Concrete + Area of FRP wrap $=\pi / 4 \times(4.024)^{2}=12.73$ in $^{2}$

Area of FRP wrap $=12.73-12.566=0.164 \mathrm{~mm}^{2}$

FRP Reinforcement Ratio $=\rho_{f}=\frac{\text { Area of FRP }}{\text { Area of Concrete }}=\frac{0.16}{12.566}=0.0127$

Effective FRP Stress $=f_{\text {frp }}=90$ to $530 \mathrm{ksi}($ Carbon FRP $)$

Assume $f_{\text {frp }}=495 \mathrm{ksi}$ (from the manufacturer)

$E_{f r p}=33000 \mathrm{Ksi}$

$\varepsilon_{f u}=\frac{f_{f r p}}{E_{f r p}}=\frac{495}{33000}=.015$

$\varepsilon_{f e}=0.75 * 0.015=0.01125\left(0.75 \varepsilon_{f e}\right.$ is used to calculate the maximum value of load to failure

of column)

Confining pressure $f_{l}$ provided by the FRP jacket:

$f_{l}=\frac{k_{a} \rho_{f} \varepsilon_{f e} E_{f}}{2}$

$k_{a}=1$ ( for circular sections)

$f_{l}=\frac{.0127 \times .01125 \times 33000 * 1000}{2}=2419.49 \mathrm{psi}$

$f_{c}^{\prime}=4500 \mathrm{psi}$

$f c c^{\prime}=f^{\prime}{ }_{c} *\left[2.25 \sqrt{1+7.9 \frac{f_{l}}{f_{c}{ }^{\prime}}}-2 \frac{f_{l}}{f_{c}{ }^{\prime}}-1.25\right]$

$f_{c c}^{\prime}=6000 *\left[2.25 \sqrt{1+7.9 \frac{2419.49}{4500}}-2 \frac{2419.49}{4500}-1.25\right]=12729.9$

Area of cylinder $=12.566 \mathrm{in}^{2}$ 
Area of longitudinal reinforcement $=4 \times .049087=0.19635 \mathrm{in}^{2}$

Area of hoop reinforcement $=0.1885 \mathrm{in}^{2} f y=40000 \mathrm{psi}$

PCC: Total Strength $=12.729 * 12.566=159.95 \mathrm{Kips}$

RCC: Total Strength $=12.729(12.566-0.19635)+40 * 0.19635=170.46 \mathrm{kips}$

\subsubsection{Model II}

Model II is a model proposed by Mander (Bogdanovic 2002), and computes the value of confined strength of concrete to be

$$
f_{c c}{ }^{\prime}=f_{c o}{ }^{\prime}\left[-1.254+2.254 \sqrt{1+\frac{7.94 f_{1}}{f_{c o}{ }^{\prime}}}-2 \frac{f_{1}}{f_{c o}{ }^{\prime}}\right]
$$

Where,

$f_{c o}{ }^{\prime}$ is the unconfined concrete strength (ksi)

$f_{c c}{ }^{\prime}$ is the maximum compressive strength of confined concrete (ksi)

$f_{l}$ is the lateral confining stress (ksi)

$$
f_{1}=\frac{2 f_{f r p u} t_{f r p}}{d}(\mathrm{ksi})
$$

$f_{\text {frpu }}$ is the ultimate tensile strength of circular confined concrete strength (ksi)

$t_{f i p}$ is the thickness of the FRP jacket (inches )

$d$ is the diameter of the cylinder (inches)

\section{Example Calculation:}

Number of layers $=\mathrm{N}=3$

Diameter of cylinder $=\mathrm{D}=4$ "

$\mathrm{t}=$ thickness of FRP wrap $=.11 \mathrm{~mm}=.004$ in

$f_{\text {frpu }}=495 \mathrm{ksi}$ 
Lateral confining stress:

$$
\begin{aligned}
& f_{1}=\frac{2 \times 495 \times 1000 \times 3 \times 0.004}{4}=3215.61 \mathrm{psi} \\
& f_{c c}^{\prime}=4500\left[-1.254+2.254 \sqrt{1+\frac{7.94 \times 3215.61}{4500}}-2 \frac{3215.61}{4500}\right]=14128.83 \mathrm{psi}
\end{aligned}
$$

Area of cylinder $=12.566 \mathrm{in}^{2}$

Area of longitudinal reinforcement $=4 \times .049087=0.19635 \mathrm{in}^{2}$

Area of hoop reinforcement $=0.1885 \mathrm{in}^{2}$

$f y=40000 \mathrm{psi}$

PCC $:$ Total Strength $=14128.83 * 12.566=177542.8778 \sim 177.54$ kips

RCC: Total Strength $=14.13(12.566-0.19635)+40 * 0.19635=187.55 \mathrm{kips}$

\subsubsection{Model III}

Model III is a modified model proposed by Neale et al. (Bogdanovic,2002). The value of confined strength of concrete is given as

$f_{c c}{ }^{\prime}=f_{c}{ }^{\prime}\left(1+\alpha_{p c} \omega_{w}\right)$

$f_{c}{ }^{\prime}$ is the unconfined concrete strength (ksi)

$f_{c c}$ ' is the compressive strength of confined concrete (ksi)

$\alpha_{p c}$ is the performance coefficient and is taken as 1

$\omega_{w}$ is the volumetric ratio of FRP strength to concrete strength

$\omega_{w}=\frac{2 f_{1 f r p}}{\phi_{c} f_{c}{ }^{\prime}}$

Where

$F_{1 \text { frp }}$ is the confinement pressure due to FRP reinforcement (ksi)

$\Phi_{c}$ is the resistance factor of concrete 


$$
f_{1 f r p}=\frac{2 N_{b} \phi_{f r p} f_{f r p u} t_{f r p}}{h}
$$

Where

$N_{b}$ is the number of layers of FRP reinforcement

$\Phi_{f r p}$ is resistance factor for FRP reinforcement and is taken to be maximum i.e. $\Phi_{f r p} *=1$

$f_{f r p u}$ is the tensile strength of FRP (ksi)

$t_{f r p}$ is the thickness of the FRP jacket (inches)

$h$ is the diameter of cylinder (inches)

\section{Example Calculation:}

Number of layers $=\mathrm{N}_{\mathrm{b}}=3$

Diameter of cylinder $=\mathrm{h}=4$ "

$\mathrm{t}=$ thickness of FRP wrap $=.11 \mathrm{~mm}=.004$ in

$f_{f r p u}=495 \mathrm{ksi}-$ the tensile strength of FRP

$\Phi_{f r p} *=1$

$f_{1 f r p}=\frac{2 x 3 \times 1 \times 495 \times 1000 x .004}{4}=3215.612 \mathrm{psi}$

$\Phi_{c}=0.85$

$\omega_{w}=\frac{2 \times 3215.612}{.85 \times 4500}=1.6813$

$f_{c}{ }^{\prime}=4500 \mathrm{psi}$

$f_{c c}{ }^{\prime}=4500(1+1 x 1.68)=12066.14 \mathrm{psi}$

Area of cylinder $=12.566 \mathrm{in}^{2}$

Area of longitudinal reinforcement $=4 \times .049087=0.19635 \mathrm{in}^{2}$

Area of hoop reinforcement $=0.1885 \mathrm{in}^{2}$ 
$f y=40000 \mathrm{psi}$

PCC: Total Strength $=12.066 * 12.566=151.62 \mathrm{kips}$

RCC: Total Strength $=12.06(12.566-0.19635)+40 * 0.19635=162.42 \mathrm{kips}$

\subsubsection{Model IV}

Model IV is a model proposed by $\mathrm{Au}, 2000$ and the confined compressive strength of concrete is given as

$$
\begin{aligned}
& f_{c c}{ }^{\prime}=f_{c o}{ }^{\prime}+1.17 f_{c o}{ }^{\prime}\left[\frac{f_{f r p} t_{f r p}}{R f_{c o}{ }^{\prime}}\right]^{0.39} \text { When } 0.4<\frac{f_{f r p} t_{f r p}}{R f_{c o}{ }^{\prime}}<0.7 \\
& f_{c c}{ }^{\prime}=f_{c o}{ }^{\prime}+.39 f_{c o}{ }^{\prime}\left[\frac{f_{f r p} t_{f r p}}{R f_{c o}{ }^{\prime}}\right]^{0.25} \text { When } 0<\frac{f_{f r p} t_{f r p}}{R f_{c o}{ }^{\prime}}<0.4
\end{aligned}
$$

Where

$f_{c o}{ }^{\prime}$ is the unconfined concrete strength (ksi)

$f_{c c}$ ' is the compressive strength of confined concrete (ksi)

$f_{f r p}$ is the tensile strength of FRP (ksi)

$t_{f r p}$ is the thickness of the FRP jacket (inches)

$R$ is the radius of the cylinder (inches)

\section{Example Calculation:}

Number of layers $=\mathrm{N}=3$

Diameter of cylinder $=\mathrm{D}=4$ "

Radius of cylinder $=2 "$

$\mathrm{t}=$ thickness of FRP wrap $=.11 \mathrm{~mm}=.004 \mathrm{in}$ 


$$
\begin{aligned}
& f_{f r p}=495 \mathrm{ksi} \\
& f_{c o}{ }^{\prime}=4500 \mathrm{psi} \\
& \frac{f_{f r p} t_{f r p}}{R f_{c o}{ }^{\prime}}=\frac{495 \times 1000 \times 3 \times .004}{2 \times 4500}=0.7148 \\
& f_{c c}{ }^{\prime}=4500+1.17 \times 4500\left[\frac{495000 \times 3 \times .004}{1.5 \times 4500}\right]^{0.39}=9118.2591 \mathrm{psi}
\end{aligned}
$$

Area of Cylinder $=12.566 \mathrm{in}^{2}$

Area of Longitudinal Reinforcement $=4 \times .049087=0.19635 \mathrm{in}^{2}$

Area of Hoop reinforcement $=0.1885 \mathrm{in}^{2} f y^{\prime}=40000 \mathrm{psi}$

PCC: Total Strength $=9.18 * 12.566=115.35 \mathrm{kips}$

RCC: Total Strength $=9.18(12.566-0.19635)+40 * 0.19635=126.5 \mathrm{kips}$

\subsubsection{Model V}

The calculation of confinement is based on the models proposed by Teng, 2001. The confinement is calculated using the following model

$$
\frac{f_{c c}{ }^{\prime}}{f_{c o}{ }^{\prime}}=1+k_{1} \frac{f_{l}}{f_{c o}{ }^{\prime}}
$$

$f_{c o}$, is the unconfined concrete strength (ksi)

$f_{c c}$ ' is the compressive strength of confined concrete (ksi)

$f_{l}$ is the lateral confining pressure(ksi)

$k_{l}$ is the confinement effectiveness coefficient ( varies in different formula)

$$
\mathrm{f}_{1}=\frac{2 \mathrm{f}_{\text {frp }} \mathrm{t}_{\text {frp }}}{\mathrm{D}}(\mathrm{ksi})
$$


$f_{\text {frp }}$ is the tensile strength of FRP (ksi)

$t_{f r p}$ is the thickness of the FRP jacket (ksi)

\section{Example Calculation:}

Number of layers $=\mathrm{N}=3$

Diameter of cylinder $=\mathrm{D}=4$ "

$\mathrm{t}=$ thickness of FRP wrap $=.11 \mathrm{~mm}=.004 \mathrm{in}$

$f_{f r p}=495 \mathrm{ksi}$

$f_{c o}{ }^{\prime}=4500 \mathrm{psi}$

Lateral confining pressure:

$f_{l}=\frac{2 * 495000 * .004 * 3}{4}=3215.612 \mathrm{psi}$

Table 6-1 Constant K Values from Different Researchers

\begin{tabular}{|c|c|c|}
\hline Number & Author & Value of constant K \\
\hline A & Kharbari and Gao, 1997 & $k_{1}=2.1\left(\frac{f_{l}}{f_{c o}{ }^{\prime}}\right)^{-0.13}$ \\
\hline B & Miyauchi et al., 1999 & $k_{1}=2.98$ \\
\hline C & Toutanji, 1999 & $k_{1}=3.5\left(\frac{f_{l}}{f_{c o}{ }^{\prime}}\right)^{-0.15}$ \\
\hline D & Lam and Teng, 2001 & $k_{1}=2.15$ \\
\hline
\end{tabular}

a) $k_{1}=2.1\left(\frac{f_{l}}{f_{c o}{ }^{\prime}}\right)^{-0.13}$ Kharbari and Gao, 1997

$$
k_{l}=2.1\left(\frac{f_{l}}{f_{c o}{ }^{\prime}}\right)^{-0.13}=2.1\left(\frac{3215.612}{4500}\right)^{-0.13}=2.1937
$$

$\frac{f_{c c}{ }^{\prime}}{4500}=1+2.1937 * \frac{3215.612}{4500} ; f_{c c}{ }^{\prime}=11554.34 \mathrm{psi}$ 
Area of Cylinder $=12.566 \mathrm{in}^{2}$

Area of Longitudinal Reinforcement $=4 \times .049087=0.19635 \mathrm{in}^{2}$

Area of Hoop reinforcement $=0.1885 \mathrm{in}^{2}$

$F y=40000$ psi

PCC: Total Strength $=11.554 * 12.566=145.19 \mathrm{kips}$

RCC: Total Strength $=11.554(12.566-0.19635)+40 * 0.19635=156.18 \mathrm{kips}$

b) $k_{1}=2.98$ Miyauchi et al., 1999

$\frac{f_{c c}{ }^{\prime}}{6000}=1+2.98 * \frac{3215.612}{4500} ; f_{c c}{ }^{\prime}=14082.52 \mathrm{psi}$

Area of cylinder $=12.566 \mathrm{in}^{2}$

Area of longitudinal reinforcement $=4 \times .049087=0.19635 \mathrm{in}^{2}$

Area of hoop reinforcement $=0.1885 \mathrm{in}^{2}$

$f y=40000$ psi

PCC: Total Strength $=14.082 * 12.566=176.95$

RCC $:$ Total Strength $=14.08(12.566-0.19635)+40 * 0.19635=186.99$ kips

c) $k_{1}=3.5\left(\frac{f_{l}}{f_{c o}{ }^{\prime}}\right)^{-0.15}$ Toutanji, 1999

$k_{l}=3.5\left(\frac{3215.612}{4500}\right)^{-0.15}=3.68$

$\frac{f_{c c}{ }^{\prime}}{4500}=1+3.68 * \frac{3215.612}{4500} ; \mathrm{f}_{\mathrm{cc}}{ }^{\prime}=16336.52 \mathrm{psi}$

Area of Cylinder $=12.566 \mathrm{in}^{2}$

Area of longitudinal reinforcement $=4 \times .049087=0.19635 \mathrm{in}^{2}$

Area of hoop reinforcement $=0.1885 \mathrm{in}^{2}$ 
fy $=40000 \mathrm{psi}$

PCC: Total Strength $=16.336 * 12.566=205.28 \mathrm{kips}$

RCC: Total Strength $=16.336(12.566-0.19635-0.1885)+40 * 0.19635+40 * 0.1885=214.45 \mathrm{kips}$

d) $k_{1}=2.15$

This is the model proposed by Lam and Teng, 2001

$\frac{f_{c c}{ }^{\prime}}{4500}=1+2.15 * \frac{3215.61}{4500} ; \mathrm{f}_{\mathrm{cc}}{ }^{\prime}=11413.56 \mathrm{psi}$

Area of cylinder $=12.566 \mathrm{in}^{2}$

Area of longitudinal reinforcement $=4 \times .049087=0.19635 \mathrm{in}^{2}$

Area of hoop reinforcement $=0.1885 \mathrm{in}^{2} f y^{\prime}=40000 \mathrm{psi}$

PCC: Total Strength $=11.413 * 12.566=143.419 \mathrm{kips}$

RCC: Total Strength $=11.41(12.566-0.19635)+40 * 0.19635=154.46 \mathrm{kips}$

\subsubsection{Model VI}

This model is proposed by Mirmiran and Shahawy, 1997 (Chaallal et al., 2000) and is used to calculate the confined strength of concrete.

$$
\begin{gathered}
f_{c c}{ }^{\prime}=f_{c}{ }^{\prime}+3.38 f_{r}^{0.70} \\
f_{r}=\text { confinement pressure } \\
f_{r}=\frac{2 f_{j} t_{j}}{D} \\
f_{j} \text { is the tensile strength of FRP (ksi) } \\
t_{j} \text { is the thickness of FRP (inches) }
\end{gathered}
$$




\section{Example Calculation:}

Number of layers $=\mathrm{N}=3$; Diameter of cylinder $=\mathrm{D}=4$ ”

$\mathrm{t}=$ thickness of FRP wrap $=.11 \mathrm{~mm}=.004 \mathrm{in}$

$f_{j}=495 \mathrm{ksi}$

$f_{r}=\frac{2 \times 495 \times 3 \times .004}{4}=3.215 \mathrm{ksi}$

$f_{c c}{ }^{\prime}=4500 \mathrm{psi}$

$f_{c c}{ }^{\prime}=4.5+3.38^{*}(3.215)^{0.7}=12155.89 \mathrm{psi}$

Area of cylinder $=12.566 \mathrm{in}^{2}$

Area of longitudinal reinforcement $=4 \times .049087=0.19635 \mathrm{in}^{2}$

Area of hoop reinforcement $=0.1885 \mathrm{in}^{2}$

$f y=40000 \mathrm{psi}$

PCC: Total Strength $=12.155 * 12.566=152.74 \mathrm{kips}$

RCC: Total Strength $=12.15(12.566-0.19635)+40 * 0.19635=163.47 \mathrm{kips}$

\subsection{Comparison of Experimental and Analytical Results}

The values of confined strength are calculated from analytical models proposed by various researchers. They are compared with results from the experiments for both batch $1\left(f_{c}{ }^{\prime}=\right.$ 4500psi) and batch $2\left(f_{c}{ }^{\prime}=8000 \mathrm{psi}\right)$ and are tabulated in Tables 7-2 and 7-3. Ratio of the experimental to analytical values greater than 1 indicates theoretical under prediction whereas the ratios smaller than one indicate theoretical over prediction of the concrete confined strength. 
Table 6-2 Experimental Results and Analytical Calculations of Batch 1 (4500 psi) concrete

\begin{tabular}{|c|c|c|c|c|c|c|c|c|c|c|c|c|c|}
\hline \multicolumn{14}{|c|}{ Experimental and Anaytical Results of Confined Strength of Concrete } \\
\hline \multirow{3}{*}{$f_{c}^{\prime}(p s i)$} & \multirow{3}{*}{$\begin{array}{c}\text { Number } \\
\text { of } \\
\text { Layers }\end{array}$} & \multirow{3}{*}{$f_{f i p u}(k s i)$} & \multicolumn{9}{|c|}{ confined strength of concrete (kips) } & \multirow{2}{*}{\multicolumn{2}{|c|}{ Experimental strength (kips) }} \\
\hline & & & \multirow{2}{*}{$\begin{array}{c}\text { Renato } \\
\text { Paretti et } \\
\text { al. (ACI } \\
\text { Committee) }\end{array}$} & \multicolumn{2}{|c|}{ Svecova } & \multirow[b]{2}{*}{ Ching Au } & \multicolumn{4}{|c|}{ Teng } & & & \\
\hline & & & & Mander & Neale & & Kharbari & Miyauchi & Toujanji & Teng & $\begin{array}{c}\text { Omar } \\
\text { Chaalal et } \\
\text { al. }\end{array}$ & \multirow{2}{*}{\multicolumn{2}{|c|}{ Specimen }} \\
\hline \multicolumn{3}{|c|}{ Models } & $\mathbf{I}$ & II & III & !V & $\mathbf{V a}$ & $\mathbf{V b}$ & Ve & Vd & VI & & \\
\hline \multirow{4}{*}{$\begin{array}{l}4500 \\
\text { PCC }\end{array}$} & \multirow{2}{*}{3} & \multirow{2}{*}{495} & \multirow{2}{*}{159.900} & \multirow{2}{*}{177.500} & \multirow{2}{*}{151.627} & \multirow{2}{*}{114.580} & \multirow{2}{*}{145.190} & \multirow{2}{*}{176.959} & \multirow{2}{*}{205.280} & \multirow{2}{*}{143.420} & \multirow{2}{*}{152.740} & B1-P-4S5 & 160.875 \\
\hline & & & & & & & & & & & & B1-P-4S6 & 165.65 \\
\hline & \multirow{2}{*}{1} & \multirow{2}{*}{495} & \multirow{2}{*}{106.724} & \multirow{2}{*}{118.879} & \multirow{2}{*}{88.241} & \multirow{2}{*}{71.950} & \multirow{2}{*}{90.630} & \multirow{2}{*}{96.680} & \multirow{2}{*}{115.007} & \multirow{2}{*}{85.501} & \multirow{2}{*}{101.134} & B1-P-4S1 & 90.05 \\
\hline & & & & & & & & & & & & B1-P-4S2 & 83.87 \\
\hline \multirow{4}{*}{$\begin{array}{l}4500 \\
\text { RCC }\end{array}$} & 2 & 105 & $170-160$ & 107555 & 162000 & 126500 & 156104 & 106001 & 214456 & 154460 & 162170 & B1-R-4S5 & 163.999 \\
\hline & J & 470 & $170.40 J$ & (101.0J & 102.000 & 120.500 & 150.107 & 100. & $21+1.400$ & (10.700 & 100.470 & B1-R-4S6 & 143.174 \\
\hline & & & & & & & & & & & & B1-R-4S1 & 109.524 \\
\hline & 1 & 495 & 118.849 & 130.660 & 100.957 & 85.160 & 103.277 & 109.147 & 120.910 & 98.301 & & B1-R-4S2 & 98.76 \\
\hline
\end{tabular}


Table 6-3 Experimental Results and Analytical Calculations of batch 2 (8000 psi) Concrete

\begin{tabular}{|c|c|c|c|c|c|c|c|c|c|c|c|c|c|}
\hline \multicolumn{14}{|c|}{ Experimental and Anaytical Results of Confined Strength of Concrete } \\
\hline \multirow{3}{*}{$c^{\prime}(p s i)$} & \multirow{3}{*}{$\begin{array}{c}\text { Number } \\
\text { of } \\
\text { Layers }\end{array}$} & \multirow{3}{*}{$f_{f r p u}(k s i)$} & \multicolumn{9}{|c|}{ confined strength of concrete (kips) } & \multirow{2}{*}{\multicolumn{2}{|c|}{ Experimental strength (kips) }} \\
\hline & & & \multirow{2}{*}{$\begin{array}{c}\text { Renato } \\
\text { Paretti et } \\
\text { al. (ACI } \\
\text { Committee) }\end{array}$} & \multicolumn{2}{|c|}{ Svecova } & \multirow[b]{2}{*}{ Ching Au } & \multicolumn{4}{|c|}{ Teng } & & & \\
\hline & & & & Mander & Neale & & Kharbari & Miyauchi & Toujanji & Teng & $\begin{array}{c}\text { Omar } \\
\text { Chaalal et } \\
\text { al. }\end{array}$ & \multirow{2}{*}{\multicolumn{2}{|c|}{ Specimen }} \\
\hline \multicolumn{3}{|c|}{ Models } & $\mathbf{I}$ & II & III & !V & Va & Vb & Ve & Vd & VI & & \\
\hline \multirow{6}{*}{$\begin{array}{l}8000 \\
\text { PCC }\end{array}$} & \multirow{3}{*}{3} & \multirow{3}{*}{495} & \multirow{3}{*}{229.950} & \multirow{3}{*}{257.030} & \multirow{3}{*}{195.610} & \multirow{3}{*}{182.960} & \multirow{3}{*}{196.060} & \multirow{3}{*}{220.950} & \multirow{3}{*}{262.680} & \multirow{3}{*}{197.410} & \multirow{3}{*}{196.740} & B2P-4S7 & 231.9 \\
\hline & & & & & & & & & & & & B2-P-4S8 & 226.5 \\
\hline & & & & & & & & & & & & & \\
\hline & \multirow{3}{*}{1} & \multirow{3}{*}{495} & \multirow{3}{*}{157.130} & \multirow{3}{*}{172.520} & \multirow{3}{*}{132.220} & \multirow{3}{*}{124.240} & \multirow{3}{*}{137.260} & \multirow{3}{*}{140.670} & \multirow{3}{*}{164.260} & \multirow{3}{*}{129.500} & & B2-P-4S1 & 130.625 \\
\hline & & & & & & & & & & & 145.120 & B2-P-4S2 & 132.875 \\
\hline & & & & & & & & & & & & B2-P-4S3 & 135.23 \\
\hline & & & & & & & & & & & & B2-R-4S7 & 224.62 \\
\hline & 3 & 495 & 238.310 & 264.630 & 205.070 & 192.810 & 205.510 & 229.640 & 270.110 & 207.120 & 206.110 & B2-R-4S8 & 226.82 \\
\hline 8000 & & & & & & & & & & & & & \\
\hline $\mathrm{RCC}$ & & & & & & & & & & & & B2-R-4S1 & 162.45 \\
\hline & 1 & 495 & 167.710 & 182.680 & 143.610 & 135.880 & 148.490 & 151.800 & 174.670 & 140.960 & 156.070 & B2-R-4S2 & 144.3 \\
\hline & & & & & & & & & & & & B2-R-4S3 & 161.15 \\
\hline
\end{tabular}


Table 6-4 Comparisons of Experimental Results and Analytical Calculations for (batch1) 4500 psi Concrete

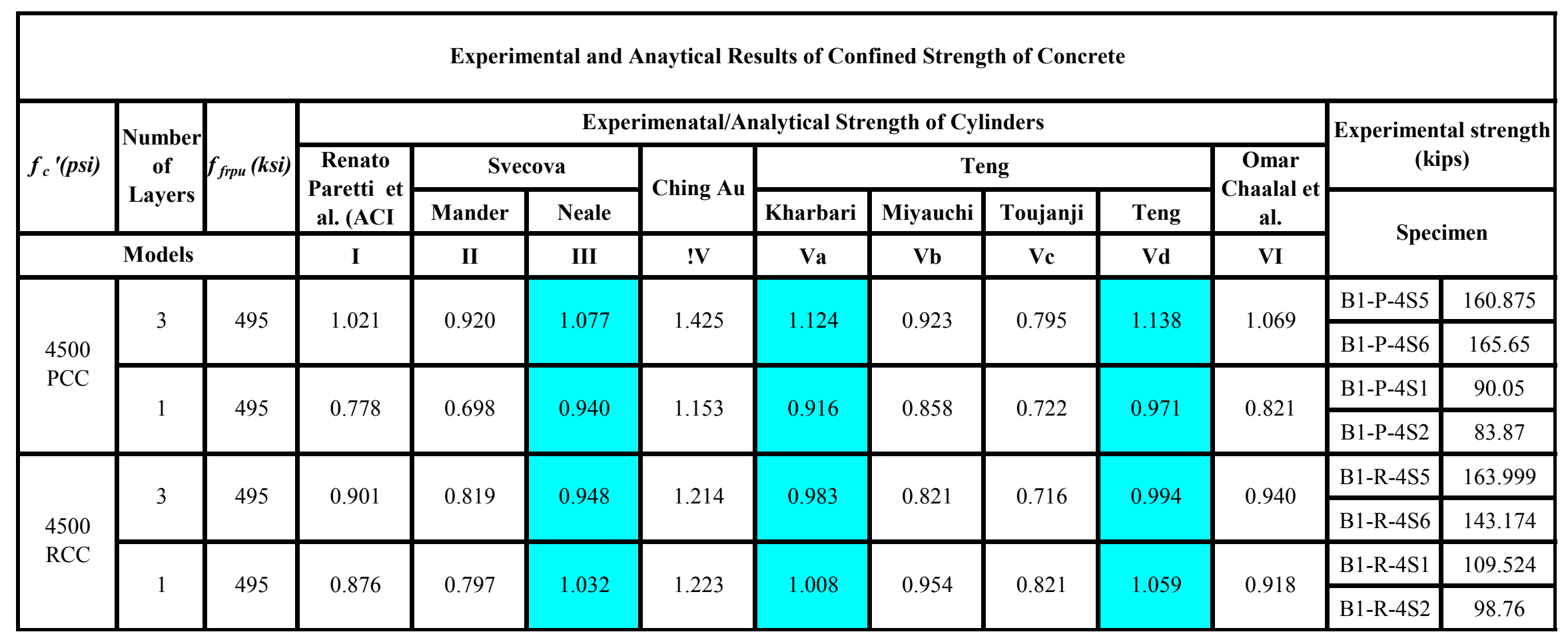

Note: Shaded Portions indicate Models that correlate well with experimental results 
Table 6-5 Comparisons of Experimental Results and Analytical Calculations of (batch2) 8000 psi Concrete

\begin{tabular}{|c|c|c|c|c|c|c|c|c|c|c|c|c|c|}
\hline \multicolumn{14}{|c|}{ Experimental and Anaytical Results of Confined Strength of Concrete } \\
\hline \multirow{3}{*}{$f^{\prime}(p s i)$} & \multirow{3}{*}{$\begin{array}{c}\text { Number } \\
\text { of } \\
\text { Layers }\end{array}$} & \multirow{3}{*}{$f_{\text {frpu }}(k s i)$} & \multicolumn{9}{|c|}{ Experimental/ Analytical Strength of Cylinders } & \multirow{2}{*}{\multicolumn{2}{|c|}{ Experimental strength (kips) }} \\
\hline & & & \multirow{2}{*}{$\begin{array}{c}\text { Renato } \\
\text { Paretti et } \\
\text { al. (ACI } \\
\text { Committee) }\end{array}$} & \multicolumn{2}{|c|}{ Svecova } & \multirow[b]{2}{*}{ Ching Au } & \multicolumn{4}{|c|}{ Teng } & & & \\
\hline & & & & Mander & Neale & & Kharbari & Miyauchi & Toujanji & Teng & $\begin{array}{c}\text { Omar } \\
\text { Chaalal et } \\
\text { al. }\end{array}$ & \multirow{2}{*}{\multicolumn{2}{|c|}{ Specimen }} \\
\hline \multicolumn{3}{|c|}{ Models } & $\mathbf{I}$ & II & III & !V & Va & Vb & Ve & $\mathbf{V d}$ & VI & & \\
\hline \multirow{6}{*}{$\begin{array}{l}8000 \\
\text { PCC }\end{array}$} & \multirow{3}{*}{3} & \multirow{3}{*}{495} & \multirow{3}{*}{0.997} & \multirow{3}{*}{0.892} & \multirow{3}{*}{1.172} & \multirow{3}{*}{1.253} & \multirow{3}{*}{1.169} & \multirow{3}{*}{1.037} & \multirow{3}{*}{0.873} & \multirow{3}{*}{1.161} & \multirow{3}{*}{1.165} & $\mathrm{~B} 2 \mathrm{P}-4 \mathrm{~S} 7$ & 231.9 \\
\hline & & & & & & & & & & & & B2-P-4S8 & 226.5 \\
\hline & & & & & & & & & & & & & \\
\hline & \multirow{3}{*}{1} & \multirow{3}{*}{495} & \multirow{3}{*}{0.846} & \multirow{3}{*}{0.770} & \multirow{3}{*}{1.005} & \multirow{3}{*}{1.070} & \multirow{3}{*}{0.968} & \multirow{3}{*}{0.945} & \multirow{3}{*}{0.809} & \multirow{3}{*}{1.026} & & B2-P-4S1 & 130.625 \\
\hline & & & & & & & & & & & 0.916 & B2-P-4S2 & 132.875 \\
\hline & & & & & & & & & & & & B2-P-4S3 & 135.23 \\
\hline & & & & & & & & & & & & B2-R-4S7 & 224.62 \\
\hline & 3 & 495 & 0.947 & 0.853 & 1.101 & 1.171 & 1.098 & 0.983 & 0.836 & 1.090 & 1.095 & B2-R-4S8 & 226.82 \\
\hline 8000 & & & & & & & & & & & & & \\
\hline $\mathrm{RCC}$ & & & & & & & & & & & & B2-R-4S1 & 162.45 \\
\hline & 1 & 495 & 0.965 & 0.886 & 1.127 & 1.191 & 1.090 & 1.066 & 0.926 & 1.148 & 1.037 & B2-R-4S2 & 140.3 \\
\hline & & & & & & & & & & & & B2-R-4S3 & 161.15 \\
\hline
\end{tabular}

Note: Shaded Portions indicate Models that correlate well with experimental results 


\subsection{Discussions}

The experimental values were compared with the analytical models and three of the models provided better correlation with the experimental results. Other analytical models over predicted or under predicted the values of confined concrete strength.

- The models proposed by Kharbari and Gao 1997, Lam and Teng, 2001 and the modified model proposed by Neale et al.2000, provided good correlation and typically within $10 \%$ of the experimental value and not exceeding $20 \%$.

- The model proposed by $\mathrm{Au}, 2000$ provided under predicted and models by Mander, (1998) and Toutanji (1999) provided over prediction.

- The model proposed by Neale et al (2000) consists of parameters that are directly related to compressive strength of concrete, number and thickness of fiber wrap, and diameter of the cylinder. It should be noted that all constants are taken as one.

- Kharbari and Gao's model provides a constant $\mathrm{k}$ that represents the ratio between lateral confining pressure and unconfined concrete strength, which provided good correlation with experimental results on laboratory scale specimens.

- The model proposed by Mander is traditionally used for steel confined concrete. 


\section{CONCLUSIONS AND RECOMMENDATIONS}

\subsection{Introduction}

Concrete cylinder specimens with and without internal steel reinforcement were fully and partially bonded with CFRP sheets to study the effect of external confinement. The effects of confinement were studied with respect to fiber orientation, cylinder strength $\left(f_{c}{ }^{\prime}\right)$, number of fiber wraps, cross sectional area of concrete cylinders, height and location of wrapping, degree of fiber wetting and bonding and degree of bonding fabric onto concrete. In addition to studying the behavior of wrapped concrete cylinders under compression, responses of wrapped specimens under accelerated aging conditions; i.e. elevated temperature and freeze thaw conditions was evaluated. Possible delamination/debonding between FRP and concrete interface during hand lay-up or due to aging were studied using non-destructive infrared thermography technique. A total of 139 cylinder specimens were tested to determine effects of wrapping CFRP on concrete cylinders including 30 (6 control specimens and 24 aged) specimens to evaluate accelerated aging effects. Additional 25 CFRP strip specimens were tested (5 control specimens and 20 aged) under elevated temperature and freeze thaw conditions). Responses such as ultimate strength, stiffness, strain, ductility and failure patterns were determined under varying parameters and compressive load condition. Comparisons were also carried out to determine the effect of wrapping and aging on concrete cylinders and FRP strip specimens. Conclusions are provided in terms of

- Effect of confinement (Section 8.2)

- Size effect due to concrete cross section (Section 8.3)

- Effect due to number of wraps (Section 8.4) 
- Effect of wrap height and location (Section 8.5)

- Effect of degree of fabric wetting (Section 8.6)

- Bond and contact nature of wrap (Section 8.7)

\subsection{Effect of Confinement}

\subsubsection{Ultimate Load}

Strength increase up to 3 times was achieved with 3 layers of $0^{\circ}$ wraps and the increase depends on number of layers and fabric orientation. Compared to $0^{\circ}$ fabric +45 and $\pm 45^{\circ}$ wrap provided small strength increase. In addition,

$>$ Contribution of internal steel reinforcement to axial strength was about 10 kips for low (batch $1, f_{c}^{\prime}=4500 \mathrm{psi}$ ) and high (batch $2, f_{c}^{\prime}=8000 \mathrm{psi}$ ) concrete strength cylinders.

$>$ Increase in strength due to wrapping was 1.5-2 times the strength of non-wrapped cylinder for specimens with one wrap and 2.5-3 times for specimens with 3 layers of wrap.

$>$ In the case of $45^{\circ}$ wrap there was no notable increase in strength. However strength increases in of specimens wrapped with $\pm 45^{\circ}$ wrap was about 1.1 of the non-wrapped specimen.

\subsubsection{Axial and Hoop Failure Strain}

Axial strain increase for $0^{\circ}$ fabric wrapped cylinder was found to be up to 3 and 4 times for 1 and 3 layers, whereas hoop strain increases were found to be up to 10 to 15 times, respectively, for one and three layers. 
Axial strain increases for $45^{\circ}$ and $\pm 45^{\circ}$ fabric wrapped cylinder were found to be of a range from 1 to 3 times of non wrapped specimens, whereas hoop strain increases ranged from 8 and 20 times.

\subsubsection{Stiffness}

Initial axial stiffness (slope of stress-strain curve up to 0.002 strain) of single layer $0^{\circ}$ wrapped specimens stiffness increases by 1.06 to 1.1 times the non wrapped specimens whereas cylinders with three $0^{\circ}$ layer wrap increased 1.12 to 1.2 times.

$>$ Specimens wrapped with single layer $45^{\circ}$ specimens showed the least increase in axial and hoop stiffness.

$>$ Specimens with $\pm 45^{\circ}$ wrap showed increased stiffness in the axial direction (1.17 to 1.2$)$ and in the hoop direction (1.2 -1.3 times).

Stiffness drop of about 10 times was noted from initial slope $\mathrm{m}_{1}$ to slope after bifurcation point $\mathrm{m}_{2}$.

$>$ CFRP wrapped concrete specimens showed a bilinear stress strain curve. Initial slope of the stress strain curve was linear to an axial strain value corresponding to -0.002 . During second part of the bilinear curve (after strain of 0.002) the wrap started carrying higher load with a reduction in the stress strain slope.

\subsubsection{Failure Modes}

Cylinders with $0^{\circ}$ and $\pm 45^{\circ}$ wraps exhibited significantly enhanced ductility. Cylinders wrapped with $0^{\circ}$ fabrics exhibited sudden wrap rupture and concrete crushing failure whereas $\pm 45^{\circ}$ fabric wrapped cylinders exhibited relatively gradual failure with increased 
hoop strains. With increase in number of $0^{\circ}$ fabrics, fabric rupture was observed to be more sudden with explosive sound.

\subsubsection{Ductility}

$>$ Specimens wrapped with $0^{\circ}$ fiber showed 3-5 and 8-10 times increase in total energy absorption for single and three layers of wrap, respectively, in the axial direction and 1015 times and 15-20 times increase in energy in the hoop direction, for single and three layers, respectively.

Specimens wrapped with single layers of $45^{\circ}$ and $\pm 45^{\circ}$ fiber show about 1-2 times and 35 times increase in energy in the axial direction and 8-10 times and 15-20 times increase in energy in the hoop direction, respectively

\subsection{Size Effect due to Concrete Cross Section}

\subsubsection{Ultimate Load}

Smaller size cylinders showed better strength increase and the size effect reduced with increasing number of layers.

With 1 layer of FRP wrap, 3"x6", 4"x 8" and 6"x 12" plain cylinder specimens of batch 4 $\left(f_{c}^{\prime}=8000 \mathrm{psi}\right)$ wrapped with 1 layer of CFRP showed 1.29, 1.35 and 1.12 times increase in strength respectively, whereas 3 "x6" and 4"x 8" specimens wrapped with 3 layer of CFRP showed 2.31 and 2.15 times increase in strength respectively when compared to the non wrapped specimens. 
With 1 layer of wrap smaller size cylinders carried $15.1 \%$ more strength than larger cylinders whereas with 3 layers of wrap strength increase in smaller size cylinders was $7.4 \%$.

\subsubsection{Failure Strain}

In small size specimens the strain increase per layer was more than in larger cylinders.

\section{Axial}

$>3$ "x6", 4"x 8" and 6"x 12" plain concrete specimens wrapped with 1 layer of CFRP show an increase in strain of $2.79,3.4$ and 3.6 respectively when compared to the non wrapped specimens.

$>3$ "x6" and 4"x 8" specimens wrapped with 3 layer of CFRP show an increase in strain of 5.03 and 4.88 respectively when compared to the non wrapped specimens

Increase in strain for one layer is 2.79 while the increase in strain per layer of specimen wrapped with 3 wraps is 1.67 . The increase in strain per layer is not as good as increase in strain of a single wrapped specimen.

\section{Hoop}

3"x6", 4"x 8" and 6"x 12" specimens wrapped with 1 layer of CFRP show an increase in strain of $6.8,22$, and 20.1 respectively when compared to the non wrapped specimens.

$>$ 3"x6", and 4"x 8" specimens wrapped with 3 layer of CFRP show an increase in strain of 14.9 and 24.45 respectively when compared to the non wrapped specimens. 


\subsection{Effect due to Number of Wraps}

\subsubsection{Strength}

As number of layers increased, strength increase per layer of wrap decreased.

Increase in axial strength due to 1, 3 and 6 layers of wrapping 1.29, 2.39 and 3.04 times respectively compared to the non-wrapped cylinders. However per layer related strength increase for 1, 3 and 6 layers wrapped was 27.22, 43.7\% and 33.9\% the non-wrapped strength, respectively indicating reduction in effectiveness of wrap with increasing number of wraps.

\subsubsection{Failure Strain}

Increase in strain per layer is reduced for a given stress level with increasing number of layers. Ductility improves significantly per layer of wrap.

$>$ Increase in axial strain due to wrapping 1,3 and 6 layers of fiber onto the concrete specimen is $2.79,5.03$ and 5 times respectively in comparison to the non-wrapped specimen.

Increase in hoop strain due to wrapping 1,3 and 6 layers of fiber onto the concrete specimen is $6.8,14.9$ and 23.45 times respectively in comparison to the non-wrapped specimen. 


\subsection{Effects of Wrapping Height and Location}

\subsubsection{Strength}

Cylinders wrapped with 0 ", 1/2", and 1" gap at top and bottom showed 1.7, 1.38 and 1.16 times strength increase of non wrapped specimens, respectively, indicating the importance of wrapping near beam-column junctions. Further, when the gap was increased to $1 \frac{1}{2}$ " at top and bottom, wrapped cylinder exhibited a different failure mode, wherein concrete above the wrap was crushed and displaced at a lower load than a nonwrapped cylinder.

Specimens wrapped for 1 " and $1 \frac{1 / 2}{2}$ height at top and bottom only leaving a gap in the middle of a cylinder showed strength increase of 1.29 and 1.45 times the non-wrapped cylinder strength. Test results indicate importune of confining edges near load application/ transfer points. Results also indicate a need to ensure concrete section integrity through wrapping at beam column junctions through wrapping at beam column junctions so that additional confining action is achieved at middle portions of a column section.

\subsubsection{Strain}

\section{Axial}

Axial strain increases in specimens wrapped completely with and $1 / 2$ " gap for wrap at the top and bottom are about $6 \%$ more than non-wrapped specimens. Specimens with 1" or more gap at top and bottom showed relatively lower axial and hoop strain increases 
compared to non-wrapped specimen indicating lack of their effectiveness in confining the cylinder resulting in stress concentration and a different failure mode.

\section{Hoop}

Hoop strain increases in fully wrapped specimens wrapped with completely and those with $1 / 2$ " gap for wrap at top and bottom about $16 \%$ more than non-wrapped specimens. Specimens with 1" or more gap at top and bottom showed relatively hoop strain increases compared to non-wrapped specimen indicating lack of their effectiveness in confining the cylinder resulting in stress concentration and a different failure mode.

\subsubsection{Failure Patterns}

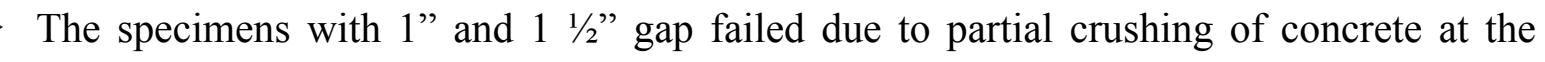
exposed top and bottom regions, at an angle of about $45^{\circ}$. The wrapped middle portion remained intact. Specimens wrapped with 1" and $1 \frac{1}{2}$ " fiber at top and bottom only without middle portion wrapped failed with the specimen crushing at the center and failure progressing upward. The wrapped upper portions remained intact.

\subsection{Effect of Degree of Fabric Wetting}

\subsubsection{Strength}

Strength increase in completely wet and fully bonded specimen was 1.66. Specimens wrapped with fabric wetted and bonded at 3 and 2 positions to the cylinder showed strength increase of 1.37 and 1.17, respectively, as compared to non-wrapped specimen. 


\subsubsection{Strain}

Increase in axial and hoop strains of specimens completely and partially wet and bonded at 3 positions was almost equal while the specimen wet and bonded at 2 positions showed reduced strains.

\section{Axial}

$>$ The increase in strain for fully bonded specimen was 3.72, for specimen wrapped with resin at 3 positions were 3.17 and for specimens wrapped with resin at 2 positions was 1.37 compared to non-wrapped specimen.

\section{Hoop}

The increase in strain for fully bonded specimen was 10.02 , specimen wrapped with resin at 3 positions was 10.7 and specimen wrapped with resin at 2 positions is 4.14 times when compared to non-wrapped specimen.

\subsubsection{Total Energy}

Specimens completely wet and fully bonded have much higher energy than those that were partially wet and bonded at 2 or 3 locations.

$>$ Fully wetted and bonded specimens showed 7.2 times increase in energy in the axial direction compared to non-wrapped specimens while partially wetted specimens show 4.94 and 1.64 times increase in energy respectively. 
Fully wetted and bonded specimens showed 16.2 times increase in energy in the hoop direction compared to non-wrapped specimens while partially wetted specimens show 11.19 and 4.8 times increase in energy respectively.

\subsection{Degree of wrap Bonding/Contact with Concrete}

\subsubsection{Strength}

Strength increases in completely bonded specimens was about 1.52 as compared to nonwrapped specimens. In comparison, specimens wrapped with only $31.8 \%$ and $21.2 \%$ bonding showed strength increases of 1.48 and 1.23 respectively.

\subsubsection{Strain}

At the bonded region, specimens showed lower axial strain than those at the non-bonded regions. Though strength increases were achieved with lesser degree of bonding, increase in axial strains at the unbonded location as compared to bonded location indicate possible buckling and bending forces that may interfere with the overall efficiency of wrap during long term loading. Hoop strain followed the same pattern at both bonded and unbonded regions (Figure 5-50). Total energy absorption is lower in partially bonded specimens.

\subsection{Axial Compression Tests to determine the Effects of Aging}

\subsubsection{Strength}

- Over two months of aging, maximum strength reduction was $11.5 \%$ in elevated temperature and $5 \%$ in freeze-thaw conditions in wrapped cylinders. 


\subsubsection{Strain}

- Over two months of aging, maximum strain reduction was $10 \%$ in elevated temperature and $10 \%$ in freeze-thaw conditions in wrapped cylinders.

\subsubsection{Strength/Stiffness of Strip Specimens}

- Reduction in strength of specimens subjected to elevated temperature is $7.8 \%$ for 1 month period and $9.1 \%$ for 2 -months period.

- Reduction in strength of specimens subjected to freeze thaw aging is $6.5 \%$ for 1 -month period and $7.8 \%$ for 2 -months period.

- No change in stiffness of the aged specimens was noted.

\subsection{Infrared Thermography Tests}

Infrared thermography testing detected the exothermic reaction during resin curing process and also delamination areas. Based on thermograms, neither elevated temperature aging nor freeze-thaw aging resulted in any additional delamination.

\subsection{Analytical and Experimental Comparison}

Currently available models can be used to closely predict the axial strength of wrapped specimens. Models from Kharbari (1997), Teng (2001) and the modified model proposed by Neale et al, (2000) correlate well to the experimental values. However it was also noted that 
some of the other available models either under predicted or over predicted the experimental results.

\subsection{Recommendations for Future research}

- Aging of specimens should be continued to correlate accelerated aging to natural aging.

- Specimens should be wrapped with glass fiber and the effects of confinement should be compared.

- More tests should be done to determine if increase in strength due to confinement is bond or contact critical.

- The increase in confinement related strength should be studied for number of layers ranging from 3 to 10 or higher including wrap thickness effects with respect to concrete section dimensions.

- Concrete substrate properties and quality in terms of surface finish, mortar richness, preexisting cracking should also be studied.

- Cylinders with additional compressive strengths and number of layers should be tested and correlated with wrapped prototype columns to suggest realistic confinement models. 


\section{REFERENCES}

1. ACI Committee 440, "Guide for the Design and Construction of Externally Bonded FRP Systems for Strengthening Concrete Structures.” American Concrete Institute, 2002

2. Ahmed, D. S., Green, M. F., and Hope, B. B., "Efficiency of FRP wraps on Corrosion Damaged Concrete Cylinders," Proceedings of the $3^{\text {rd }}$ conference on Advanced Composite Materials in Bridges and Structures, pg 679-686, 2000.

3. Au Ching, "Behavior of Fiber Reinforced Plastic-An Introduction" http:/www.mit.edu/people/auching/home.html, 2000

4. Bogdanovic, A, "Strengthening Circular Concrete Columns using FRP Sheets Applications.” Composite Materials in Civil Engineering 23.735, 2002.

5. CDCC, "Durability of Concrete Beams with Fiber Wraps," Proceedings of the second International Conference on Durability of Fiber Reinforced Polymer (FRP) Composite for Construction, Montreal (Quebec), Canada, May, 1998

6. CDCC, "Durability of Concrete Beams with Fiber Wraps," Proceedings of the second International Conference on Durability of Fiber Reinforced Polymer (FRP) Composite for Construction, Montreal (Quebec), Canada, May, 2002. 
7. Chaallal Omar, Dubreuil Francois, and Shahawy Mohsen, "Behavior of CFRP wrapped Concrete Columns under Compression and Bending Conditions." Proceedings of the third Conference on Advanced Composite Materials on Bridges and Structures, 2000, pp. 601-608.

8. Fernandes, J.F., Aire, C.M.U., Gettu, R., and Almeida P., A., O. “An Experimental Study of Confined Concrete for the Design of Composite Columns." Composites in Construction, 2001.

9. Francesco M., Myers J. J., Murthy S. S., "Performance of FRP Confined Concrete Subjected to Accelerated Environmental Conditioning." CDCC, pp 87-98, 2002.

10. Halabe, B. Uadaya., Hota, V.S. GangaRao, and Petro, H. Samer, "Nondestructive Evaluation Methods for Highway Bridge Superstructures.” Constructed Facilites Center, 1995.

11. Homan, S.M. and Sheikh, S.A. "Durability of fiber Reinforced Polymers used in Concrete Structures," Proceedings of the Third International Conference on Advanced Composite Materials in Bridges and Structures, Ottawa (Ontario) Canada, pp. 751-758, August, 2000. 
12. Hota, V.S. GangaRao, Vijay P.V., and Faza, S., "Behavior of Concrete Beams Wrapped with Carbon Tow Sheet," CFC Report No. 95-196, April 95, Submitted to Tonen Corporation, Japan.

13. Karbhari, M., Kawashima, A. Hoshikuma, J. 1997, “A Study on Confinement Effect of Concrete Cylinders by Carbon Fiber Sheets", Non Metallic (FRP) Reinfrocement for Concrete Structures, Proceedings of the Third International Symposium, V. 1 Oct, pp. 209-216

14. Kshirsagar Sachin, "Durability of Fiber Reinforced Composite Wrap System for the Rehabilitation of Concrete Structures.” Thesis submitted to the Faculty of West Virginia University in partial fulfillments of the requirements for the degree of Master of Science in Civil Engineering, 1998.

15. Legeron, F., and Paultre, P. "Uniaxial Confinement Model for Normal and High Strength Concrete Columns." Journal of Structural Engineering, ASCE Vol. 129, No. 2, 2003.

16. Lopez Anindo, R., Trouman, D.T. and Busel, J.P. "Fabrication and Installation of Modular FRP Composite Bridge Deck"”, Paper submitted for ICE' 98, Nashiville, TN, 1998.

17. Lorenzis Laura. "A Comparative Study of Models on Confinement of Concrete Cylinders with FRP Wrap.” Department of Innovation Engineering, Italy. 
18. Mander, J.B., Priestley, M.J.N., and Park, R., "Theoretical stress strain model for confined concrete.” Journal of structural engineering, ASCE, 114(8), pp. 1804-1826

19. Masia Mark J., Trevor N. Gale, and Nigel G. Shrive, "Size Effects in Axially Loaded Square-Section Concrete Prisms Strengthened using Carbon Fiber Reinforced Polymer Wrapping.” National Research Council Canada, 2004

20. Matthys, S. Taerwe, L. and Audenaert, K. "Tests on Axially Loaded Concrete Columns Confined by Fiber Reinforced Polymer Sheet Wrapping." Fourth International Symposium on Fiber Reinforced Polymer Reinforcement for Reinforced Concrete Structures, 1999, pg. 217-228.

21. Mirmiran, A., and Shahawy, M. (1997). "Behavior of Concrete Columns Confined by Fiber Composites." Journal of Structural Engineering, ASCE, 123(5), pp. 583-590.

22. Miyauchi, K. Rochette, P. Labossiere, P., "Confinement of Concrete Cylinders with CFRP", Proceedings First International Conference on Composite Infrastructures, Tuscon, Arizona pp. 829-841.

23. Mohamed A. I., Yehai, N. A. B., and Heikai A. H., "Durability Investigation of FRP Composites Wrap for Concrete Columns in Salt Solution.” CDCC 2002. 
24. Nanni, A. Norris, M.S. and Bradford, N.M. "Lateral Confinement of Concrete using FRP Reinforcement.” Fiber Reinforced- Plastic Reinforcement for Concrete Structures, International Symposium, 1993, pp. 193-209

25. Paretti Renato, and Nanni Antonio, “Axial Testing of Concrete Columns Confined with Carbon FRP: Effect of Fiber Orientation.” 2002.

26. Park, R. and Pauley, T. "Reinforced Concrete Structures." John Wiley \& Sons, 1975.

27. Pessiki, S., Harries, K.A., Kestner, J.T., Sause, R., and Ricles, J.M. "Axial Behavior of Reinforced Concrete Columns Confined with FRP Jackets.” Journal of Composite Construction, 2001, 5(4), 237-245.

28. Picher, F. Rochette, P. and Labossiere, P. "Confinement of concrete cylinders with CFRP.” Fiber Composites in Infrastructure, 1996 pp. $829-841$.

29. Rousakis, T. and Tepfers, T. "Behavior of Concrete Confined by High E-Modulus Carbon FRP Sheets subjected to Monotonic and Cyclic Compressive Load." http://www.betong.se/info/tepfers2.pdf 2002.

30. Teng, T.G. Chen, J.F. Smith, S.T. and Lam, L. "FRP-Strengthened RC Structures", 2001. 
31. Toutanji H. A. and Rey, F. "Performance of Concrete Columns Strengthened with Advanced Composites subjected to Freeze-Thaw Conditions," Durabilty of Fiber Reinforced Polymer Composites for Construction, Montreal (Quebec) Canada, pp. 351$360,1998$.

32. Toutanji, H.A. "Stress Strain Characteristics of Concrete Columns Externally Confined with Advanced Fiber Composite Sheets.” ACI Materials Journal 96(3), 1999, pp 397404.

33. Vasudevan, Archana "Application of digital infrared thermography for nondestructive evaluation of composite bridge components." Thesis submitted to the Faculty of West Virginia University in partial fulfillments of the requirements for the degree of Master of Science in Civil Engineering, 2004.

34. Weil, G.J. "Detecting the Defects." ASCE Civil Engineering Magazine, 1989, pp. 74-77.

35. Weil, G.J. "Infrared Thermographic Techniques." CRC Handbook on Nondestructive Testing.” Edited by Malhotra, V.M., and Carino, N.J. Boca Raton, 1991, pp. 305-316. 


\section{APPENDIX A}

Stress-Strain Diagrams of Wrapped and Non-Wrapped Columns with and without Internal Steel Reinforcement 


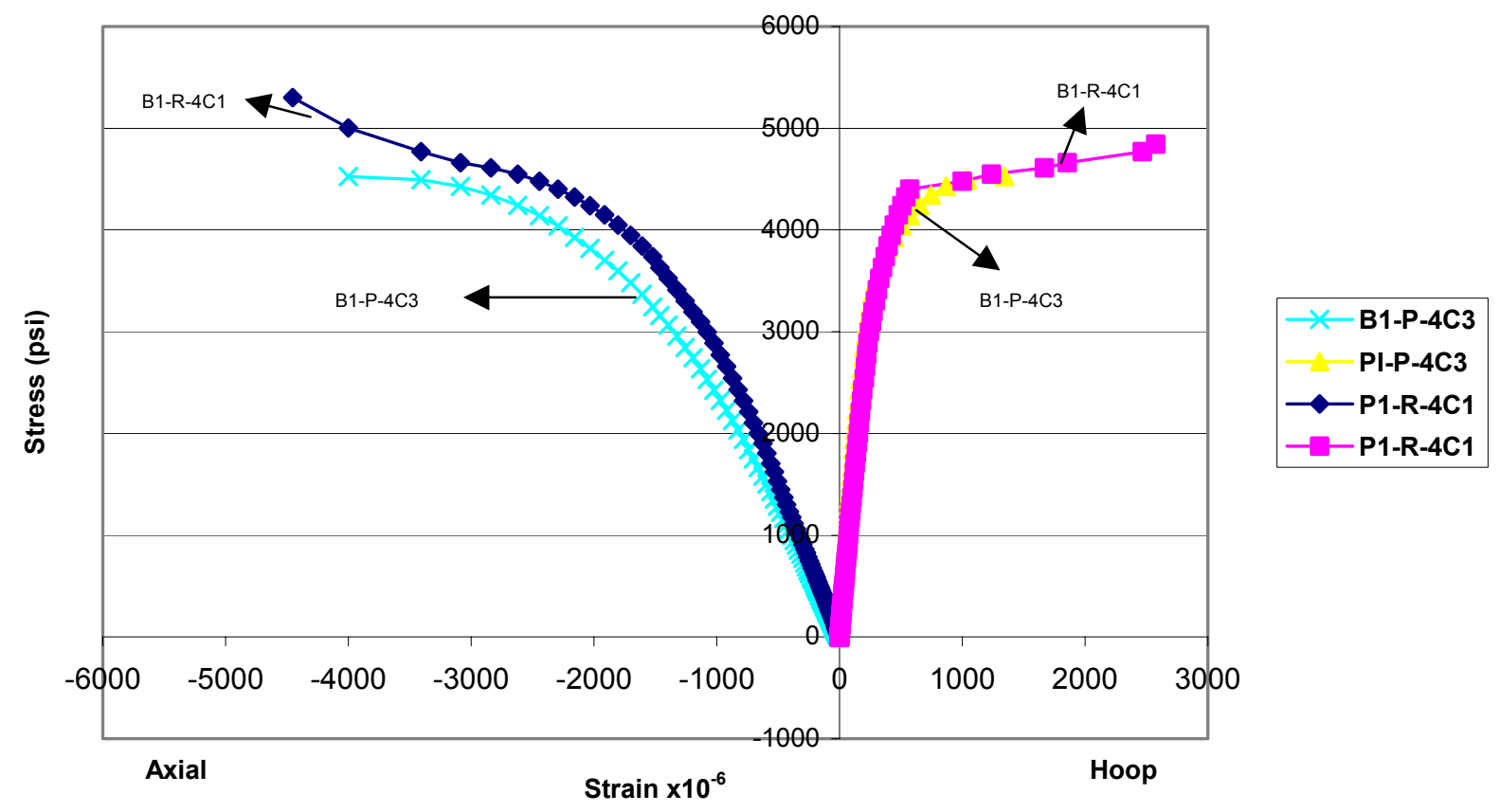

Fig. A. 1 Stress-Strain Curve of Non Wrapped Batch 1 Plain and Reinforced Column Specimens

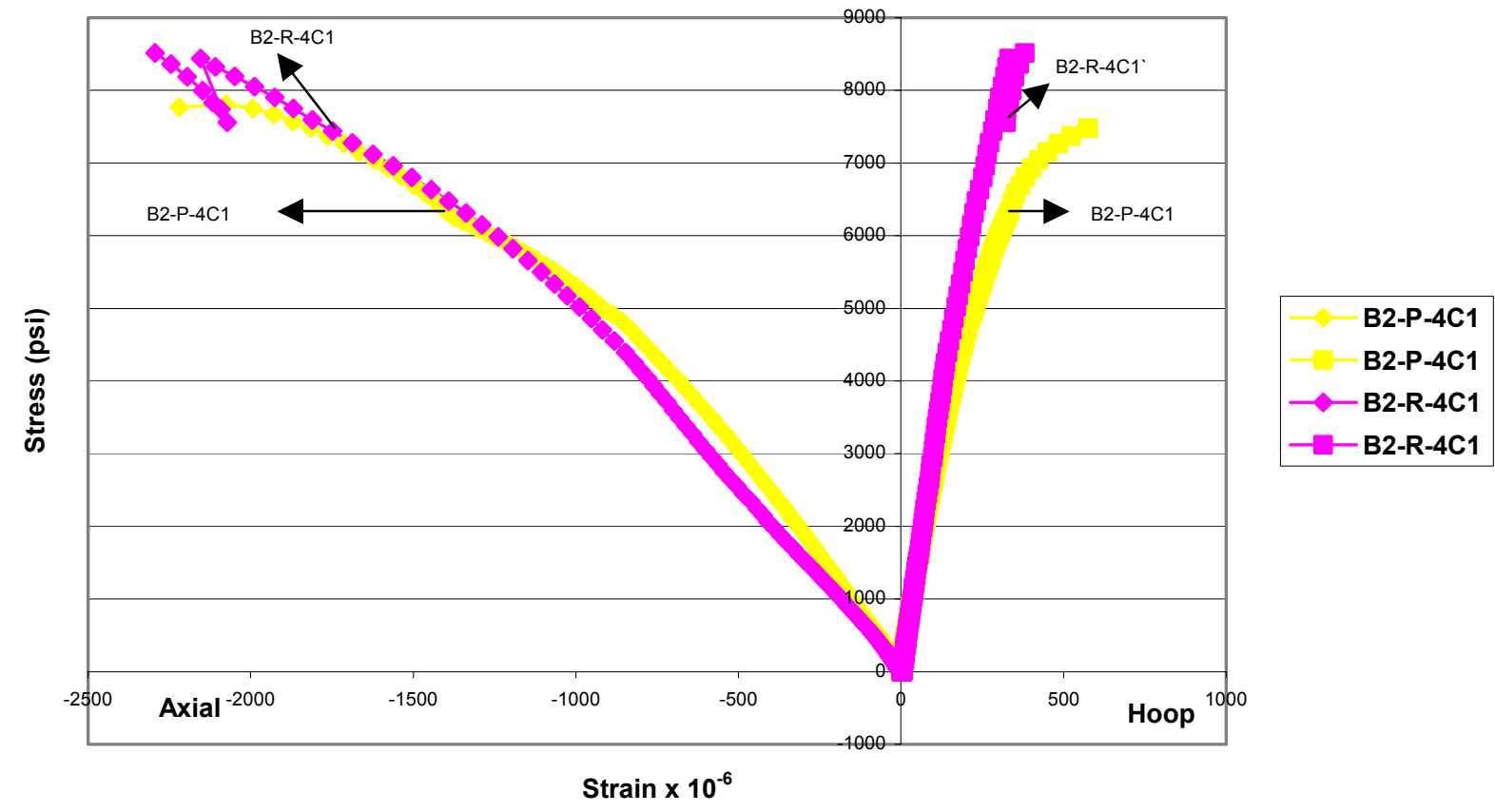

Fig. A. 2 Stress-Strain Curve of Non Wrapped Batch 2 Plain and Reinforced Column Specimens 


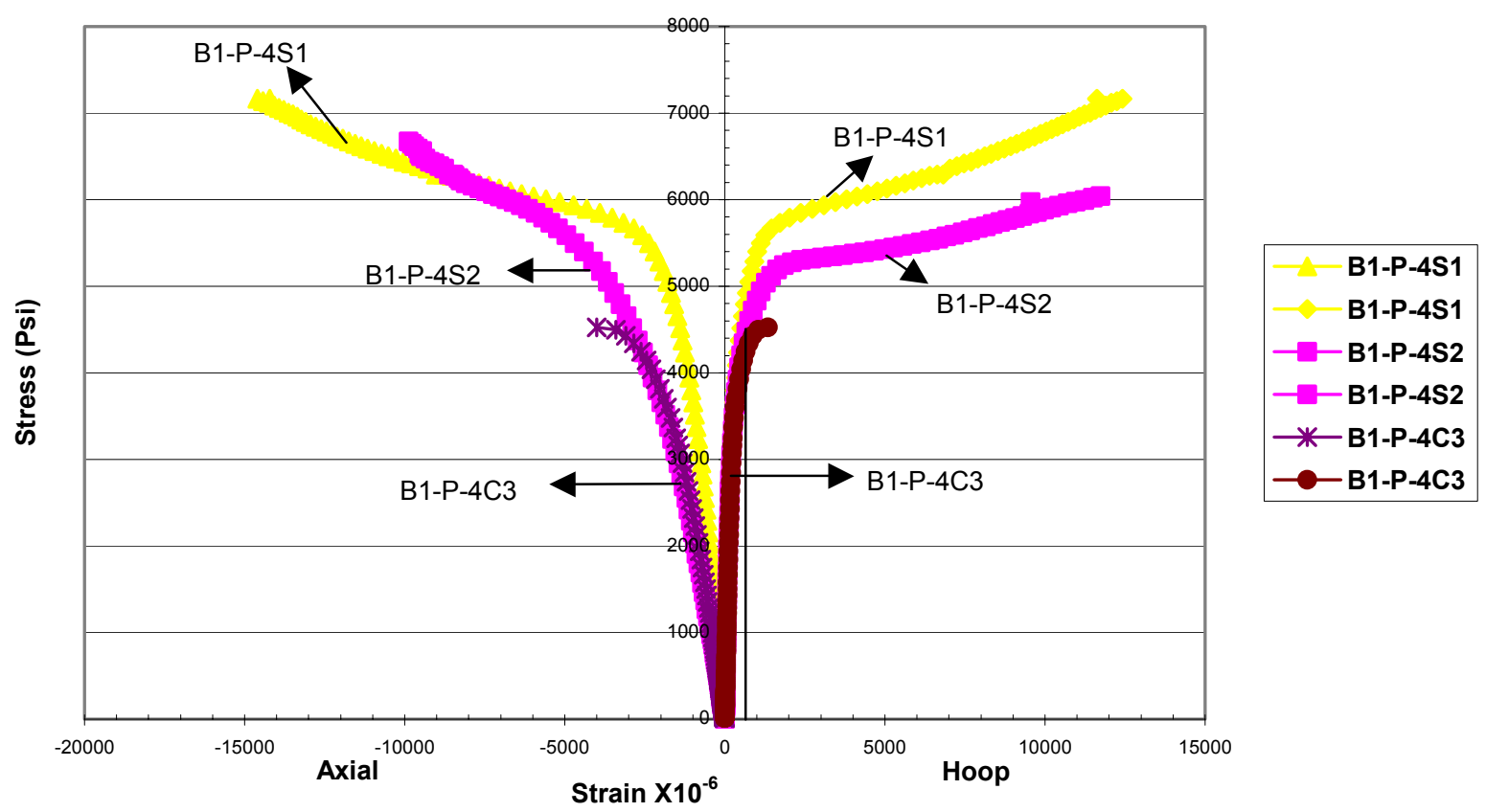

Fig. A. 3 Stress-Strain Comparison of 1 layer - $0^{\circ}$ Wrapped PCC Specimen with Control Specimen Batch 1

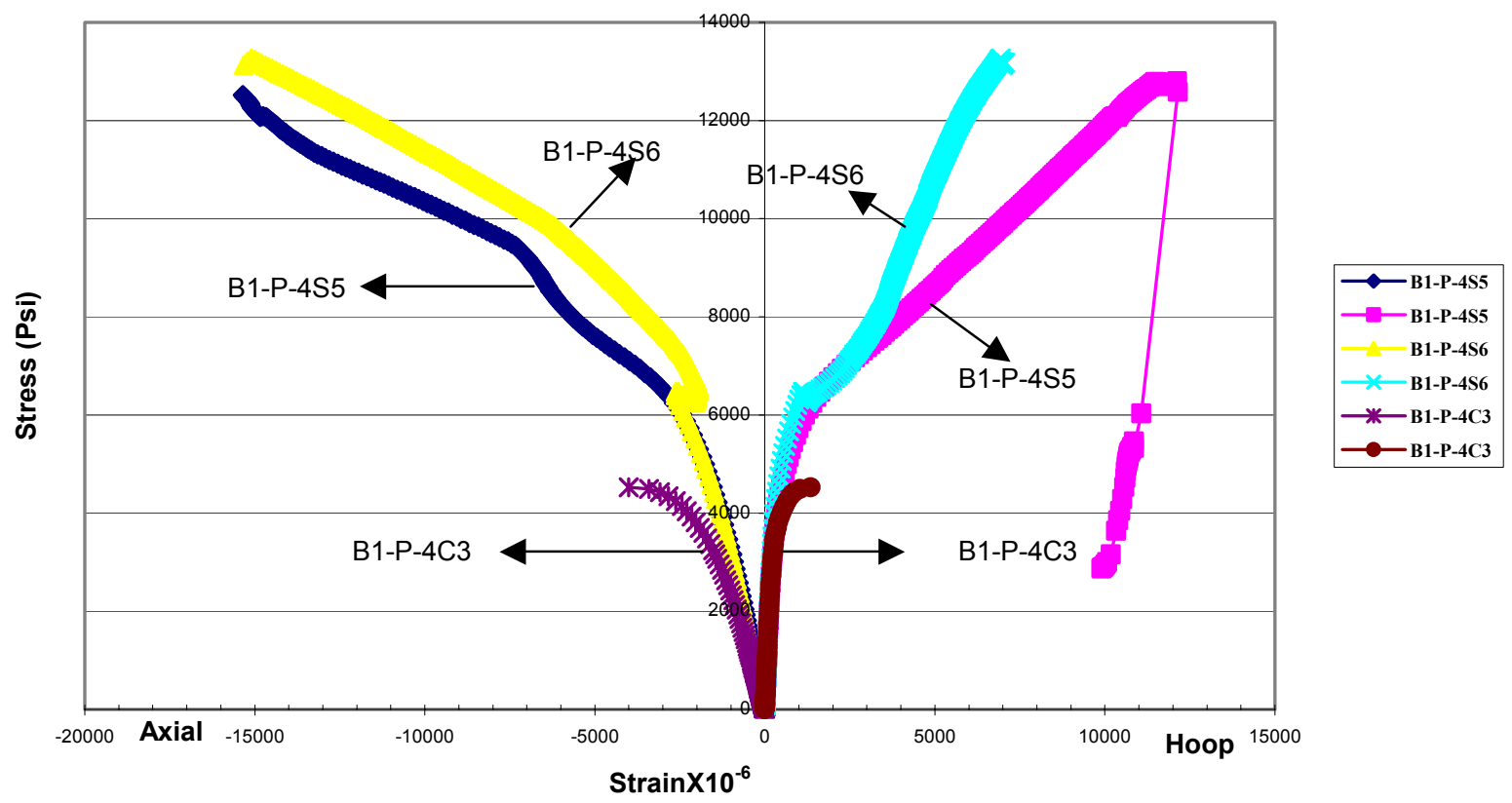

Fig. A. 4 Stress-Strain Comparison of 3 Layer - $0^{\circ}$ wrapped PCC Specimen with Control Specimen - Batch 1 


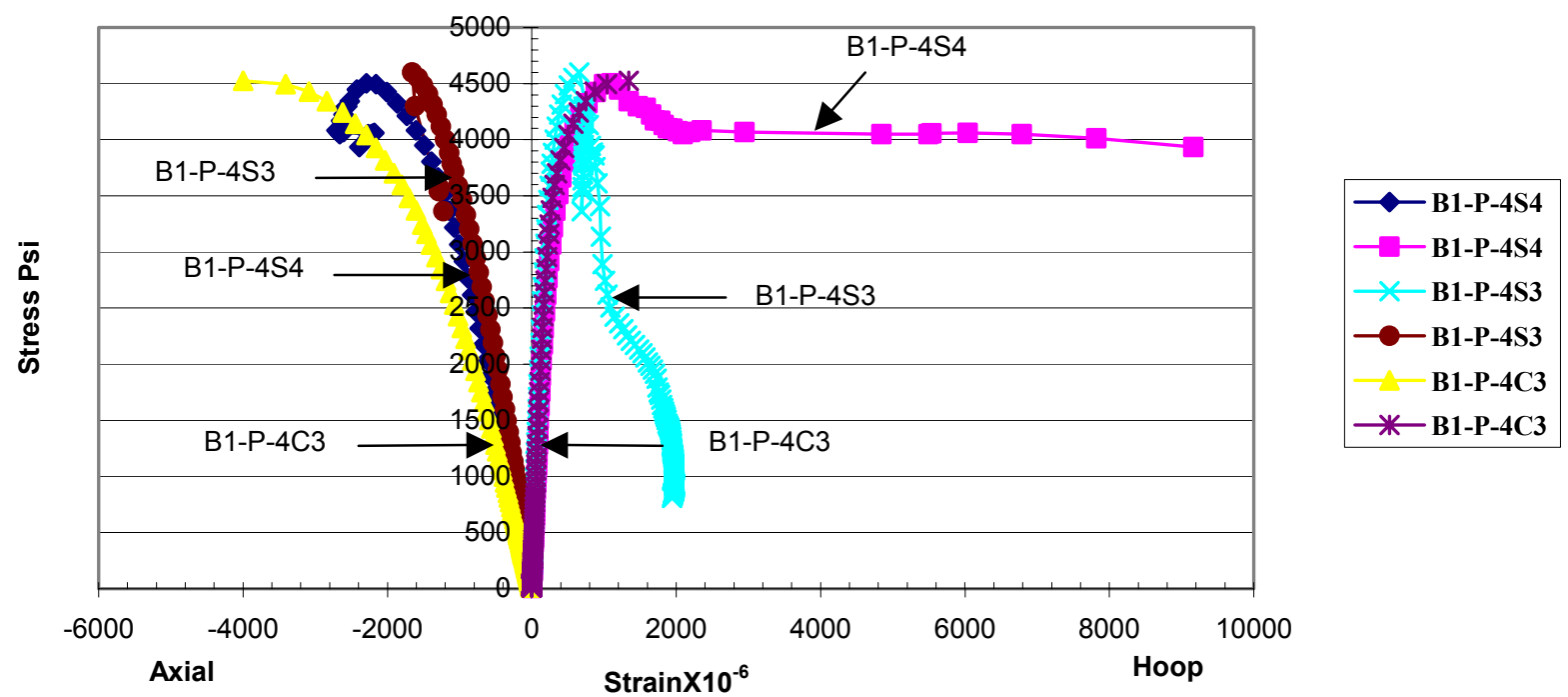

Fig. A. 5 Stress-Strain Comparison of 1 Layer $-45^{\circ}$ Wrapped PCC Specimen with Control Specimen - Batch 1
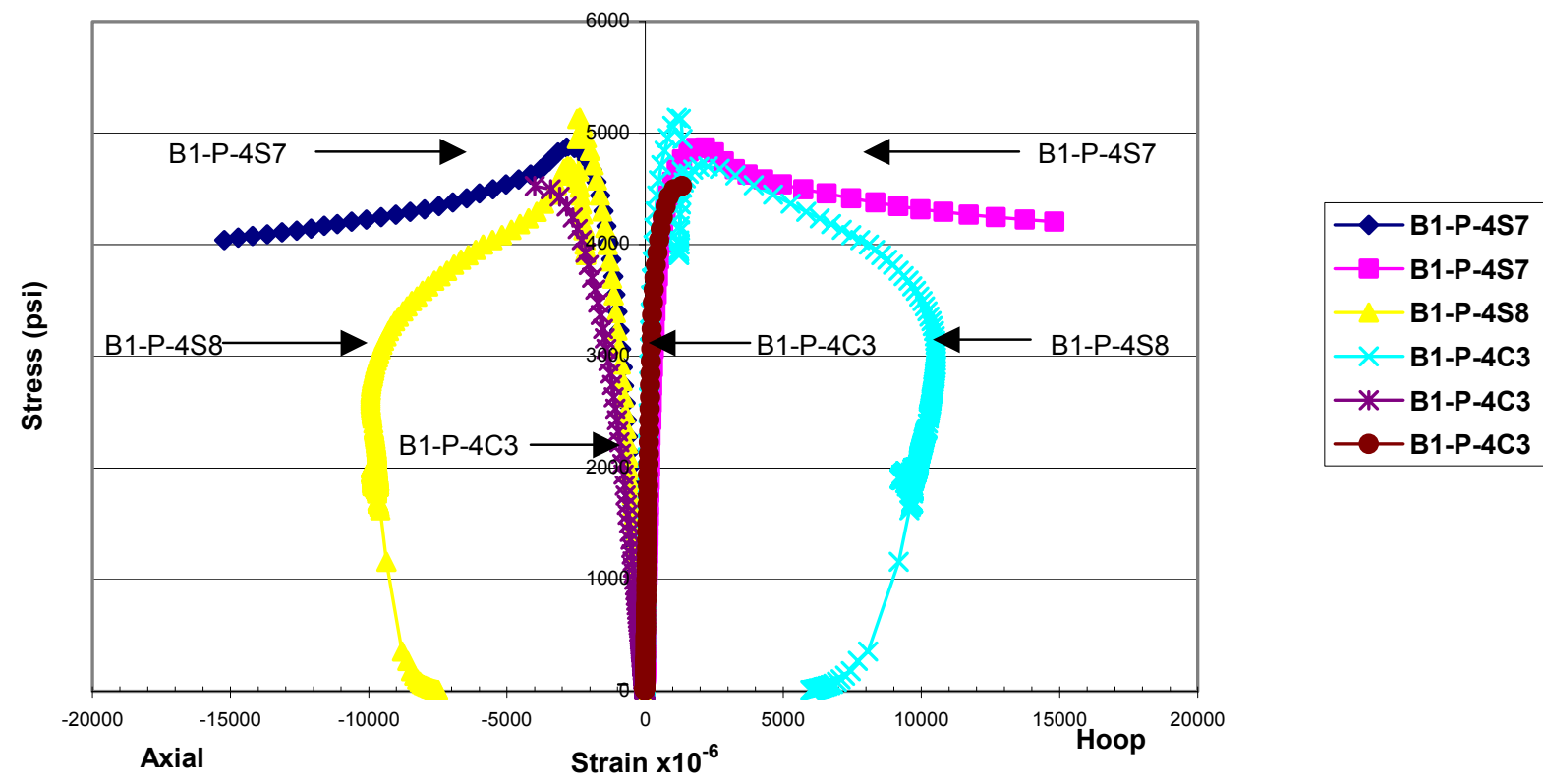

Fig. A. 6 Stress- Strain Comparison of 2 Layer $\pm 45^{\circ}$ Wrapped PCC Specimen with Control Specimen - Batch 1 


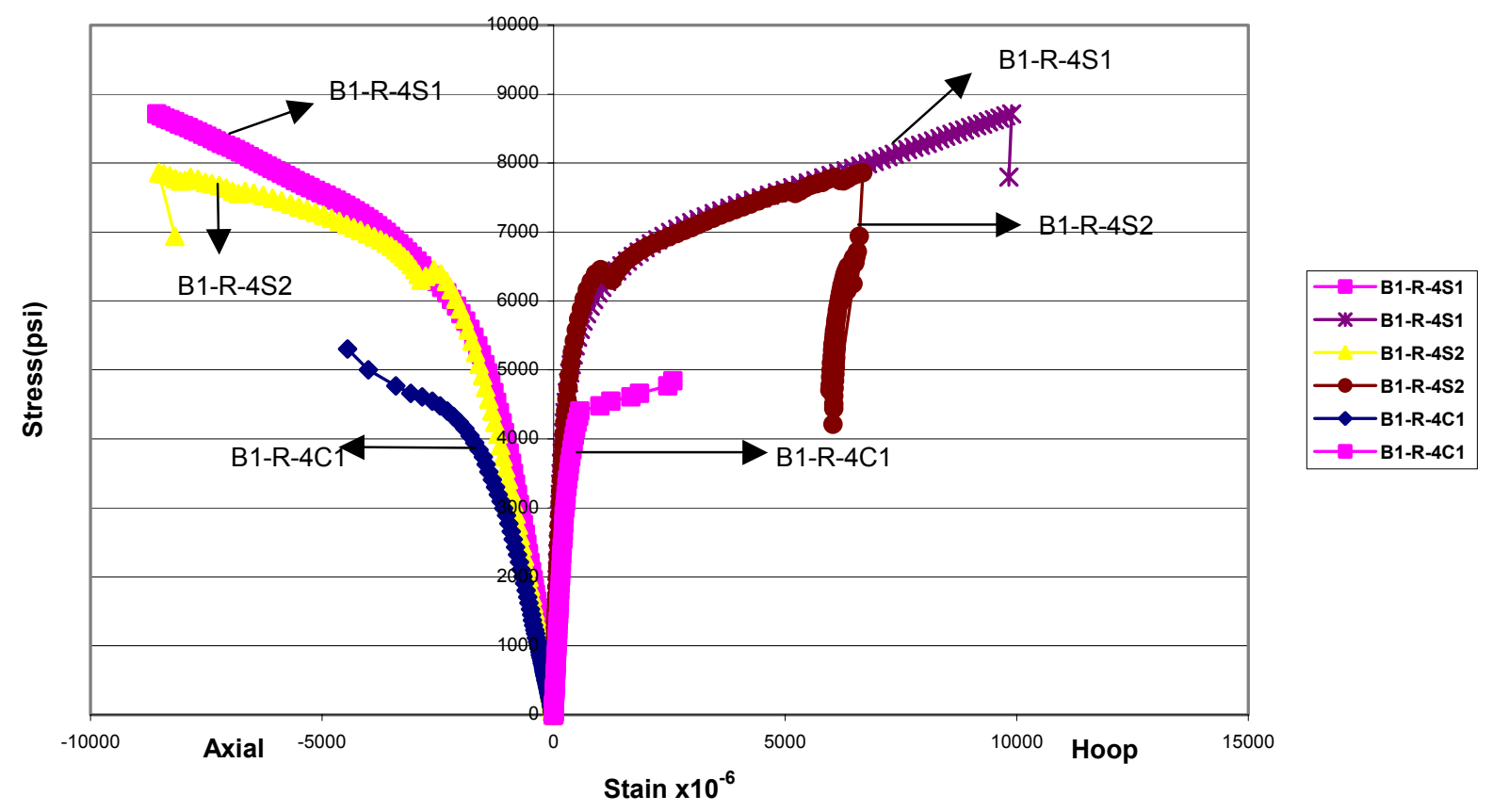

Fig. A. 7 Stress Strain Comparison of 1 Layer- $0^{\circ}$ Wrapped RCC Specimen with Control Specimen - Batch 1
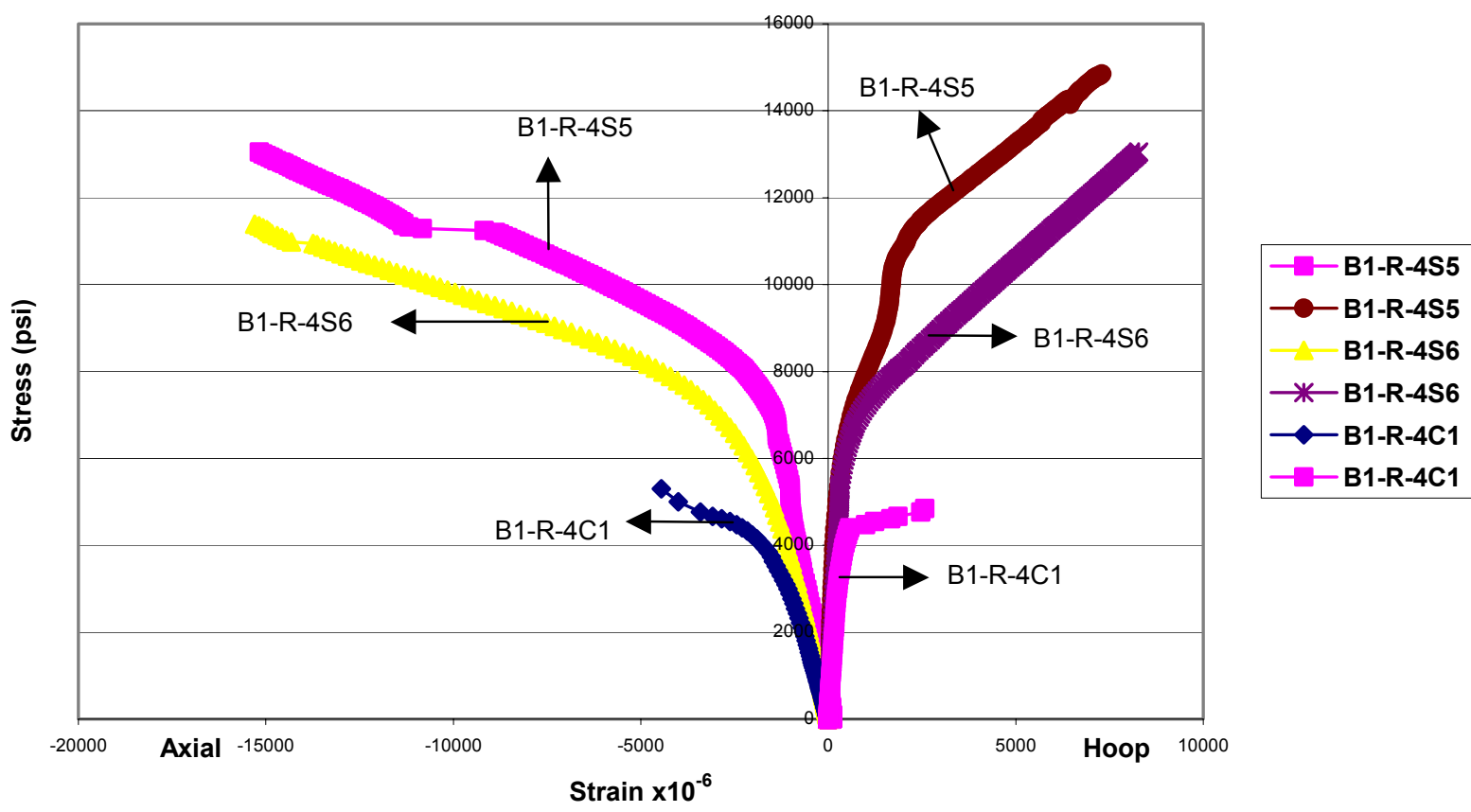

Fig. A. 8 Stress-Strain Comparison of 3 Layer $-0^{\circ}$ Wrapped RCC Specimen with Control Specimen - Batch 1 


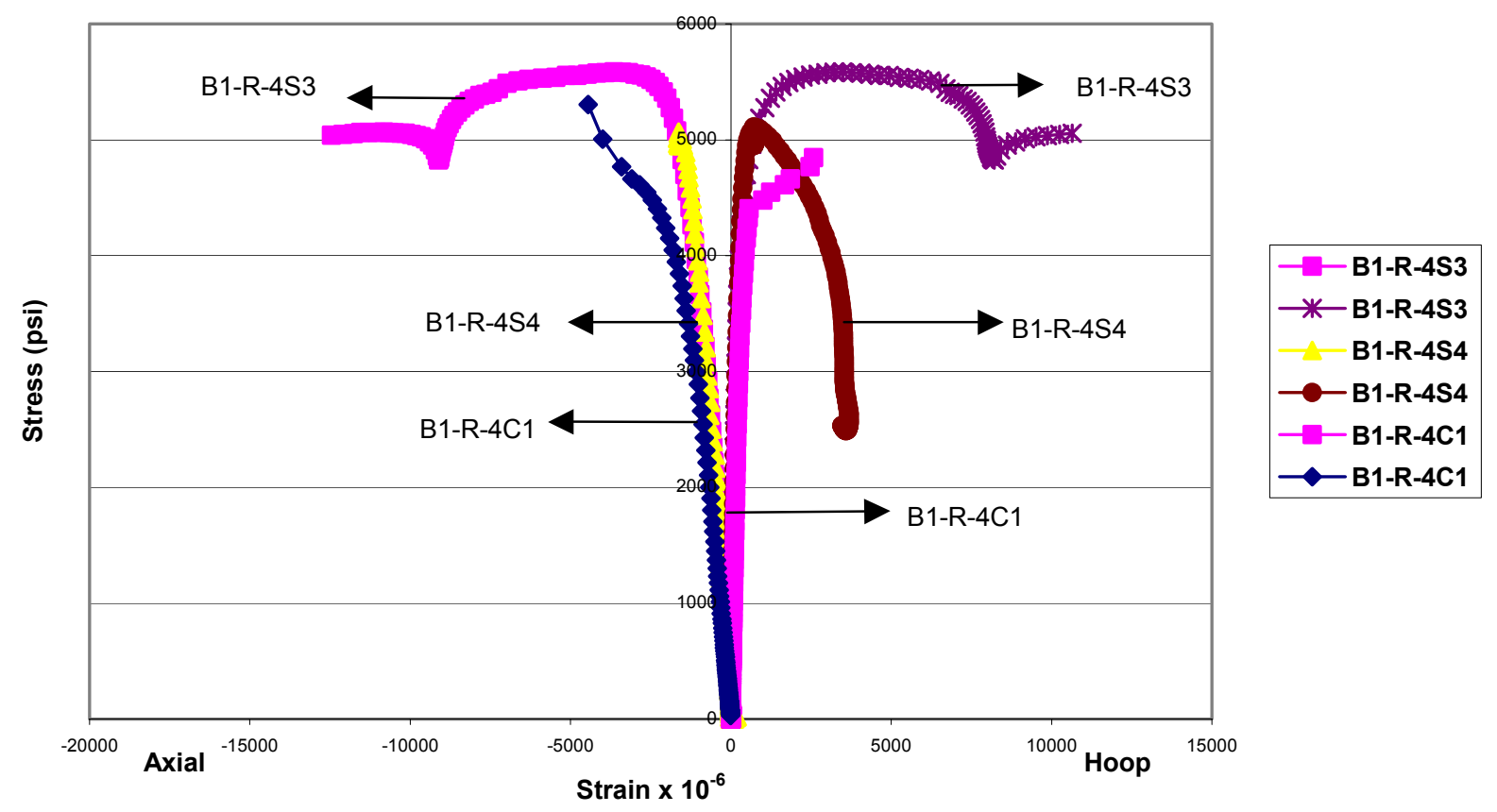

Fig. A. 9 Load Strain Comparison of 1 Layer $-45^{\circ}$ Wrapped RCC Specimen with Control Specimen - Batch 1
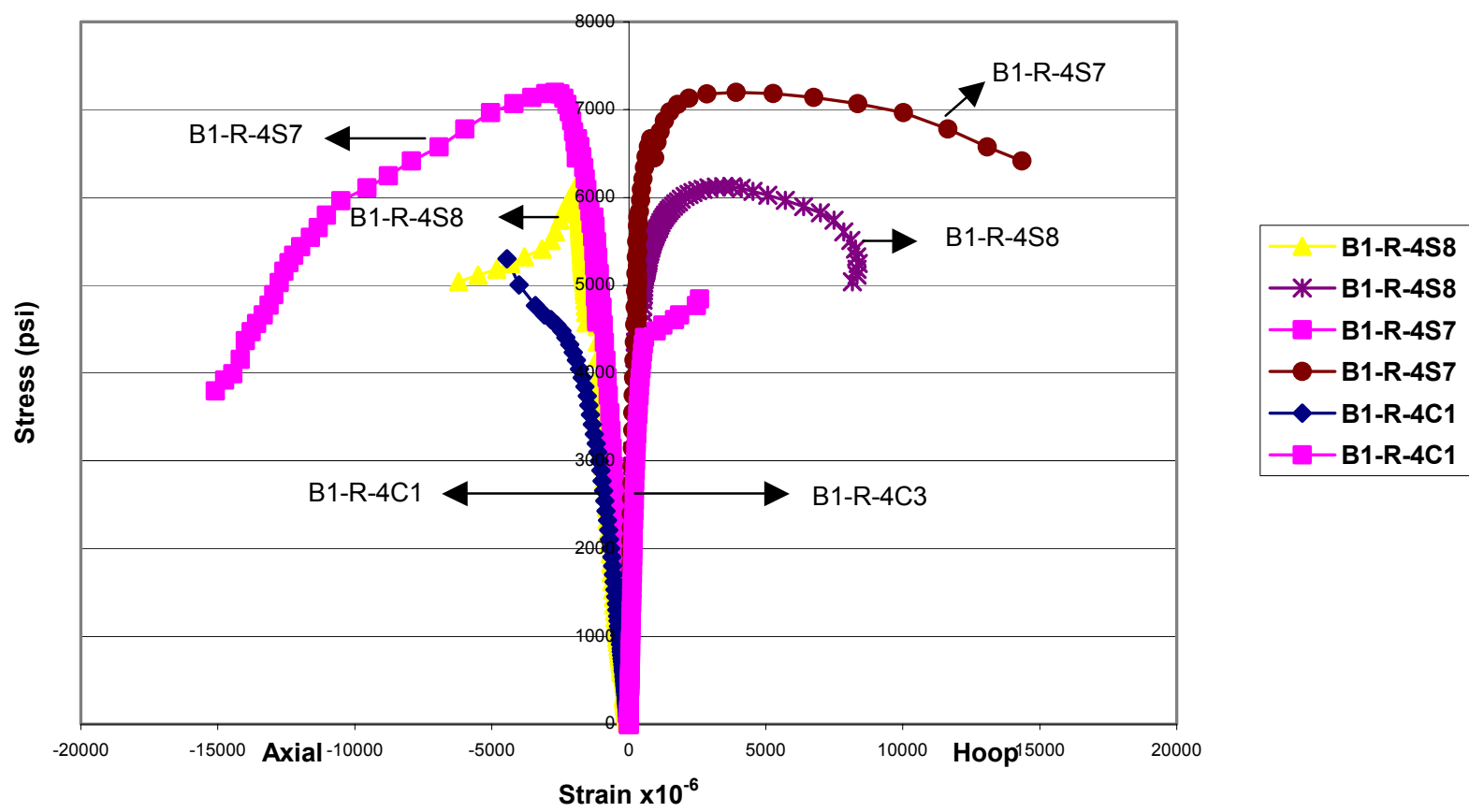

Fig. A. 10 Stress Strain Comparison of 2 Layer $\pm 45^{\circ}$ Wrapped RCC Specimen with Control Specimen- Batch 1 


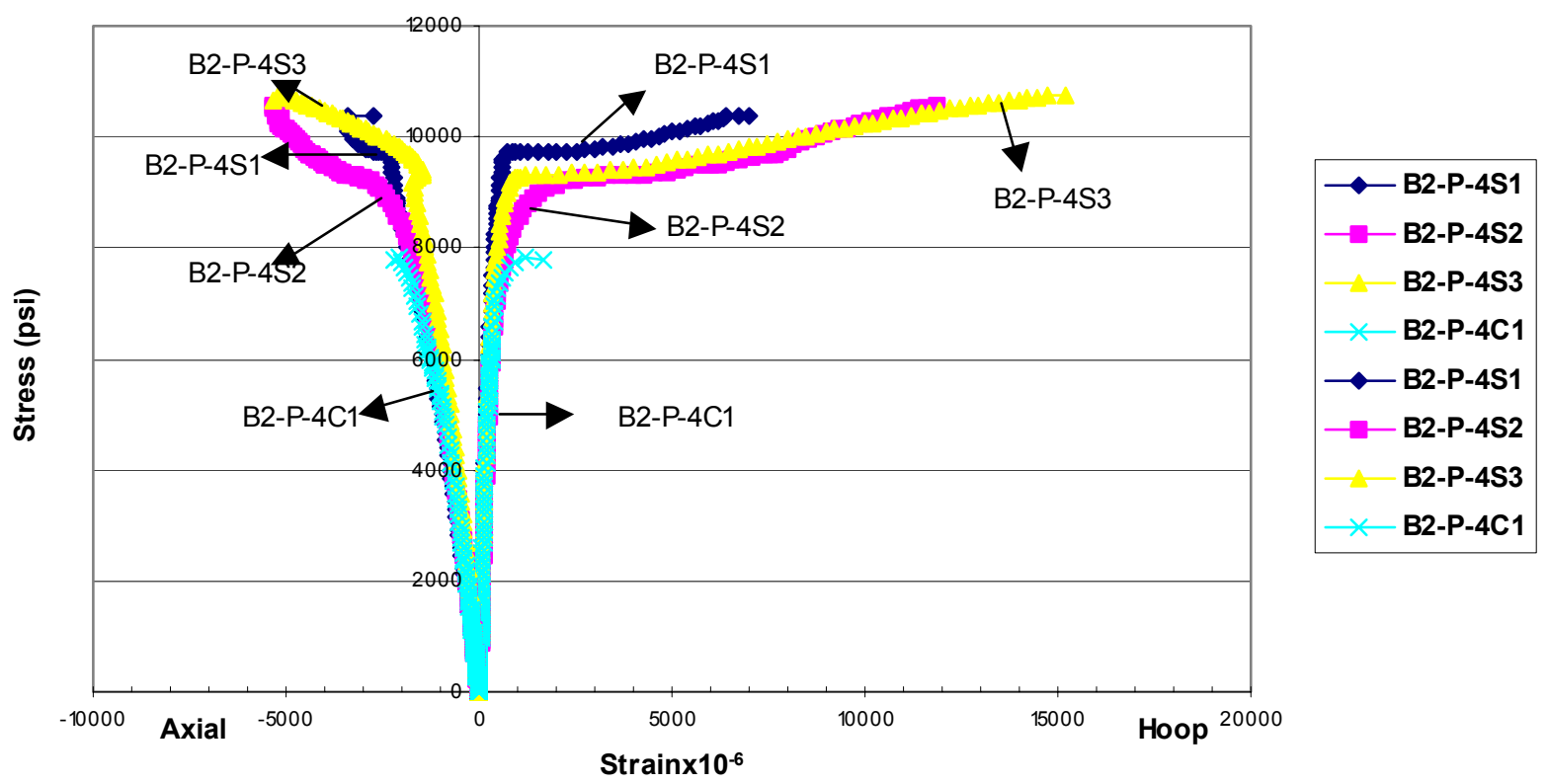

Fig. A. 11 Stress - Strain Comparison of 1 layer - $0^{\circ}$ Wrapped PCC Specimen with Control Specimen - Batch 2

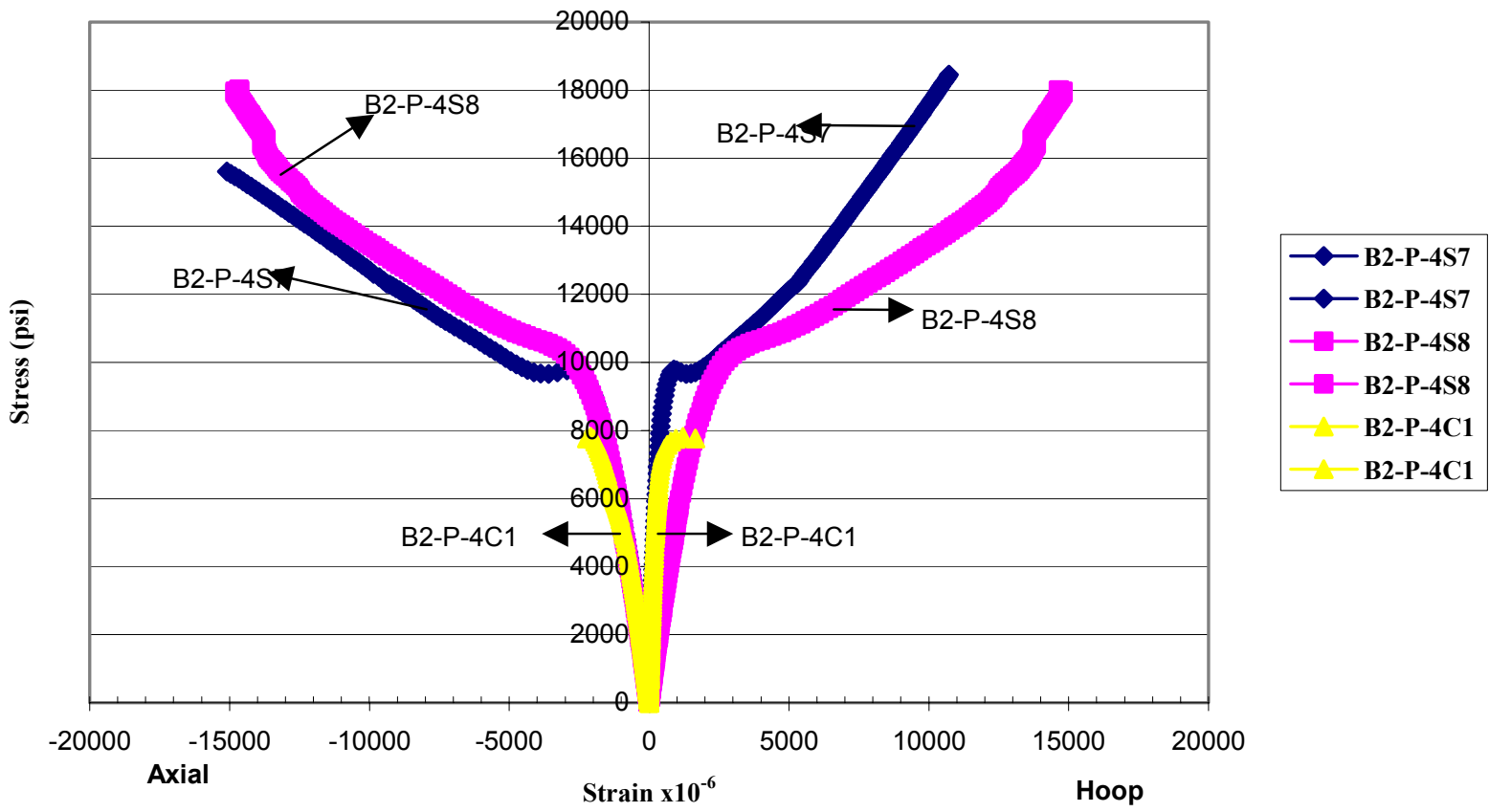

Fig. A. 12 Stress -Strain Comparison of 3 layers $-0^{\circ}$ Wrapped PCC Specimen with Control Specimen - Batch 2 


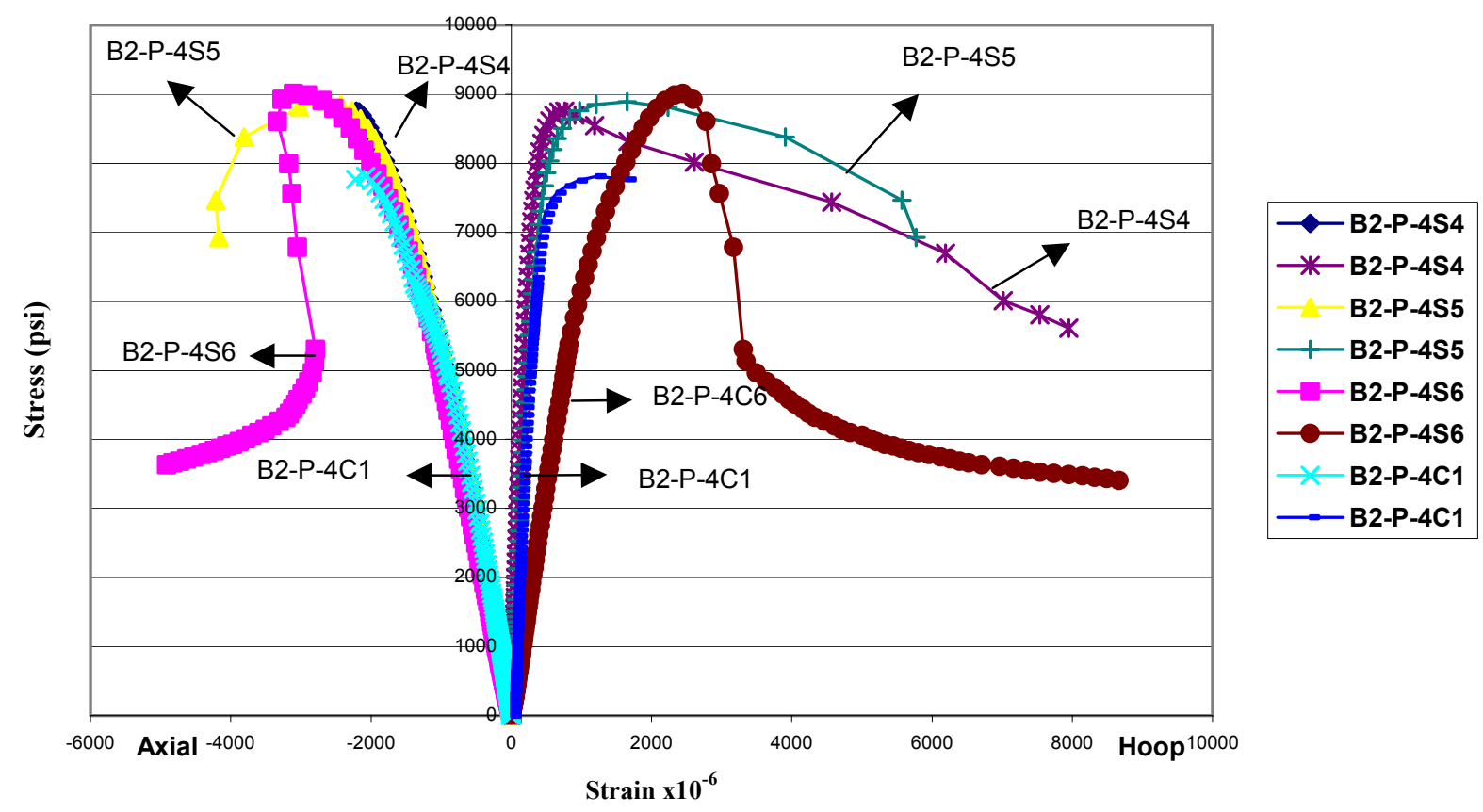

Fig. A. 13 Stress Strain Comparison of 1 layer $45^{\circ}$ Wrapped PCC Specimen with Control Specimen - Batch 2

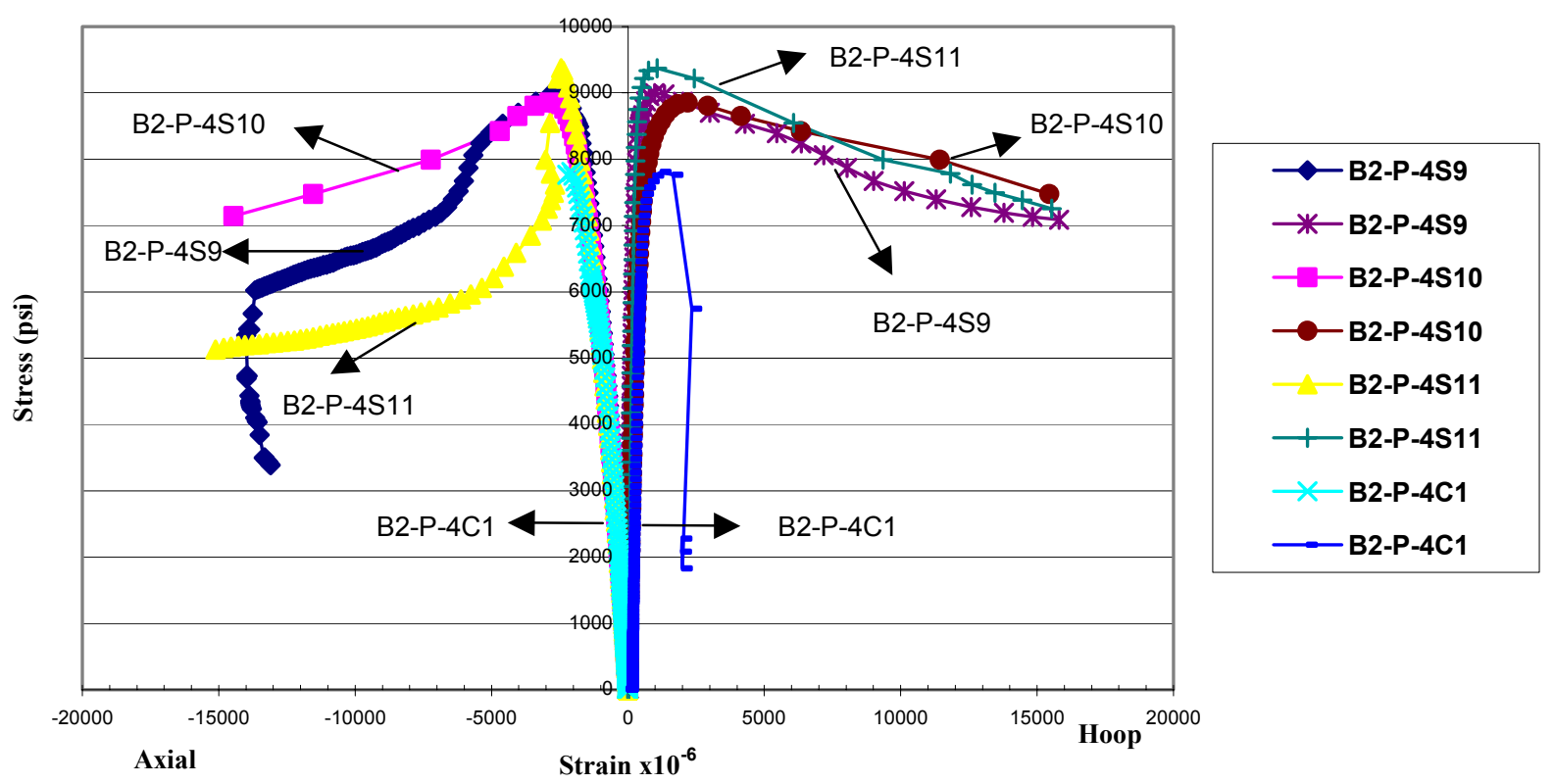

Fig. A. 14 Stress Strain Comparison of 2 Layer $\pm 45^{\circ}$ Wrapped PCC Specimen with Control Specimen- Batch 2 


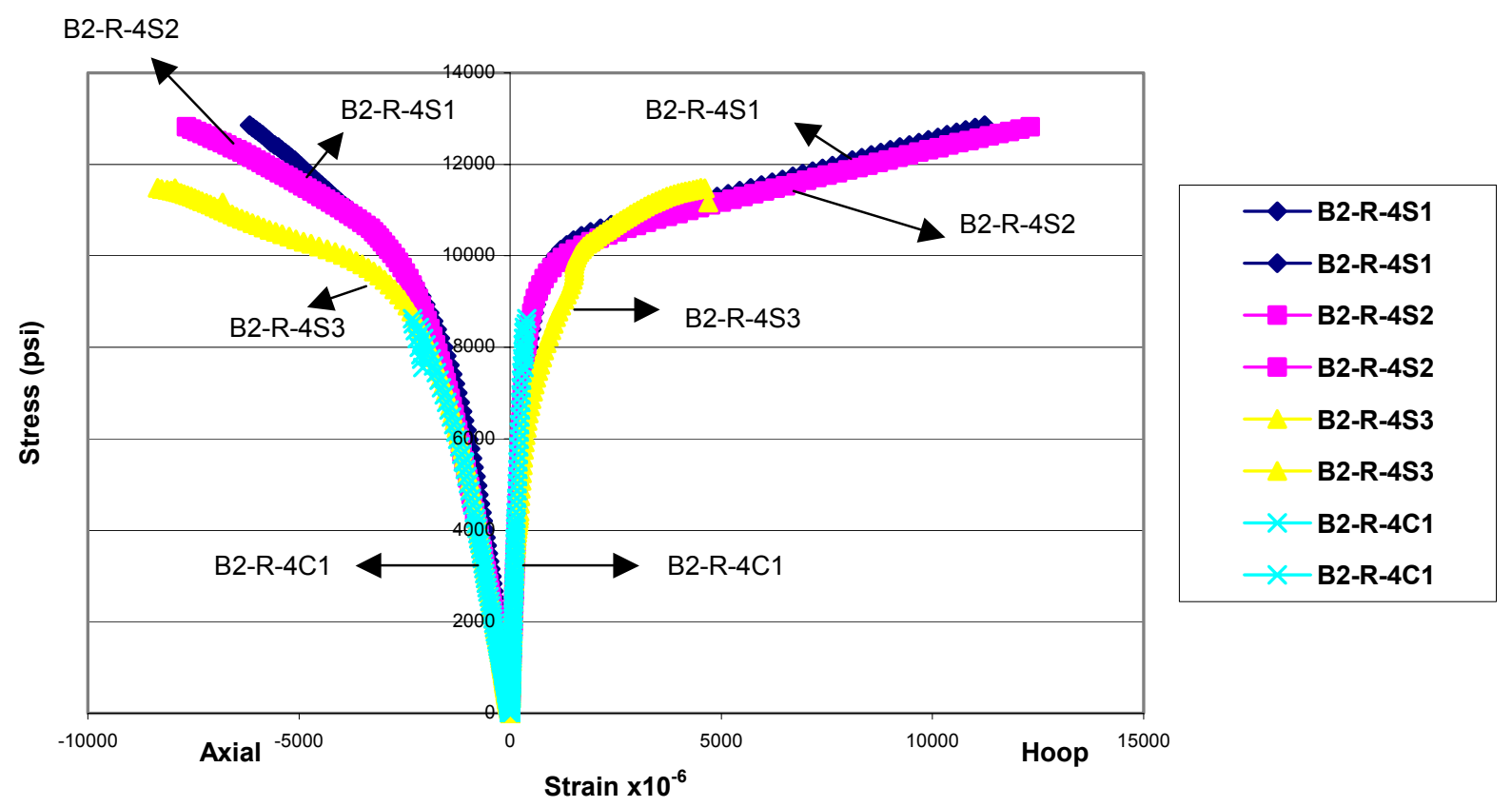

Fig. A. 15 Stress Strain Comparison of 1 layer $-0^{\circ}$ Wrapped RCC Specimen with Control Specimen - Batch 2

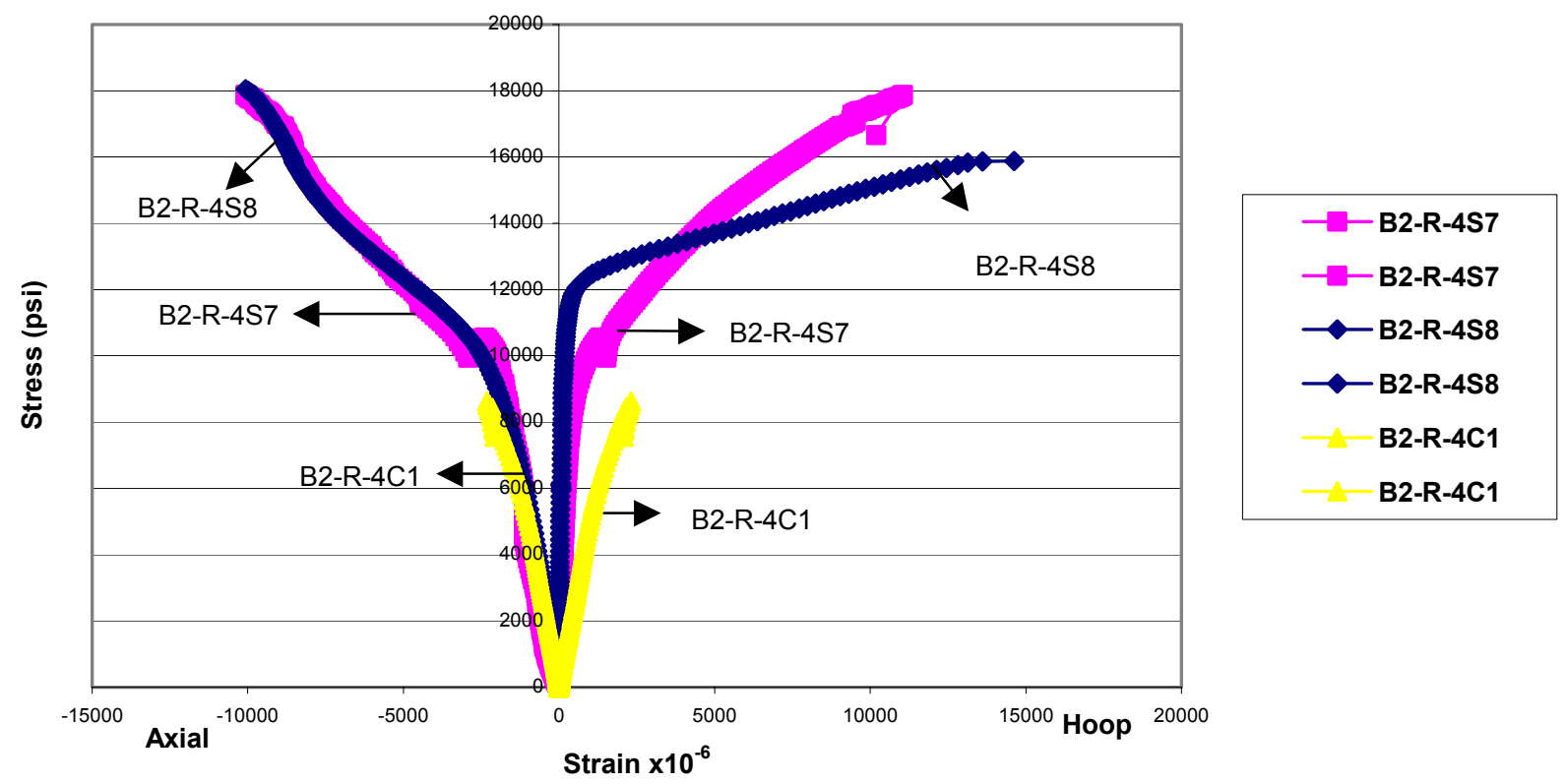

Fig. A. 16 Load Strain Comparison of 3 layer - $0^{\circ}$ Wrapped RCC Specimen with Control Specimen - Batch 2 


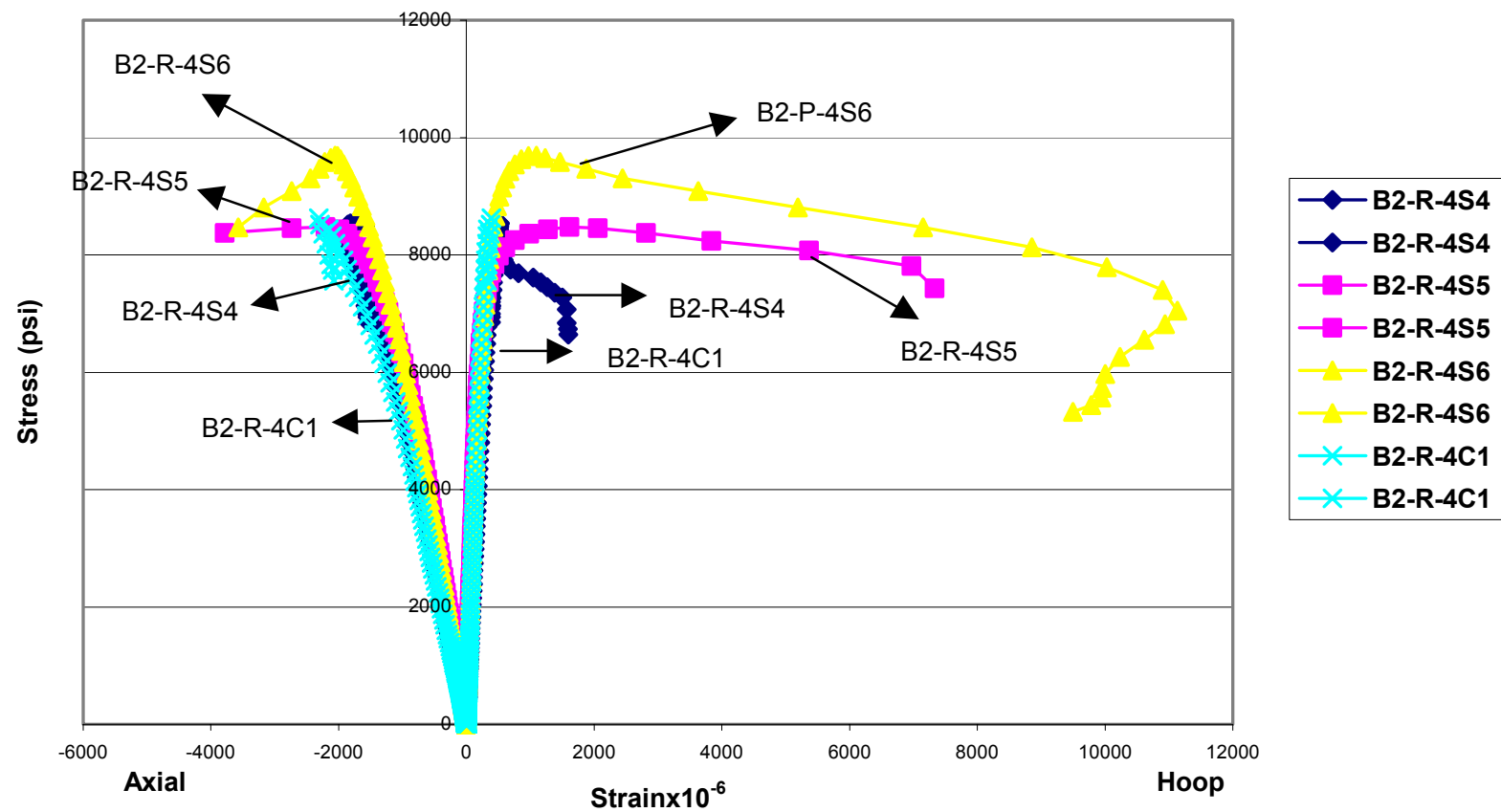

Fig. A. 17 Load Strain Comparison of 1 layer $45^{\circ}$ Wrapped RCC Specimen with Control Specimen Batch 2

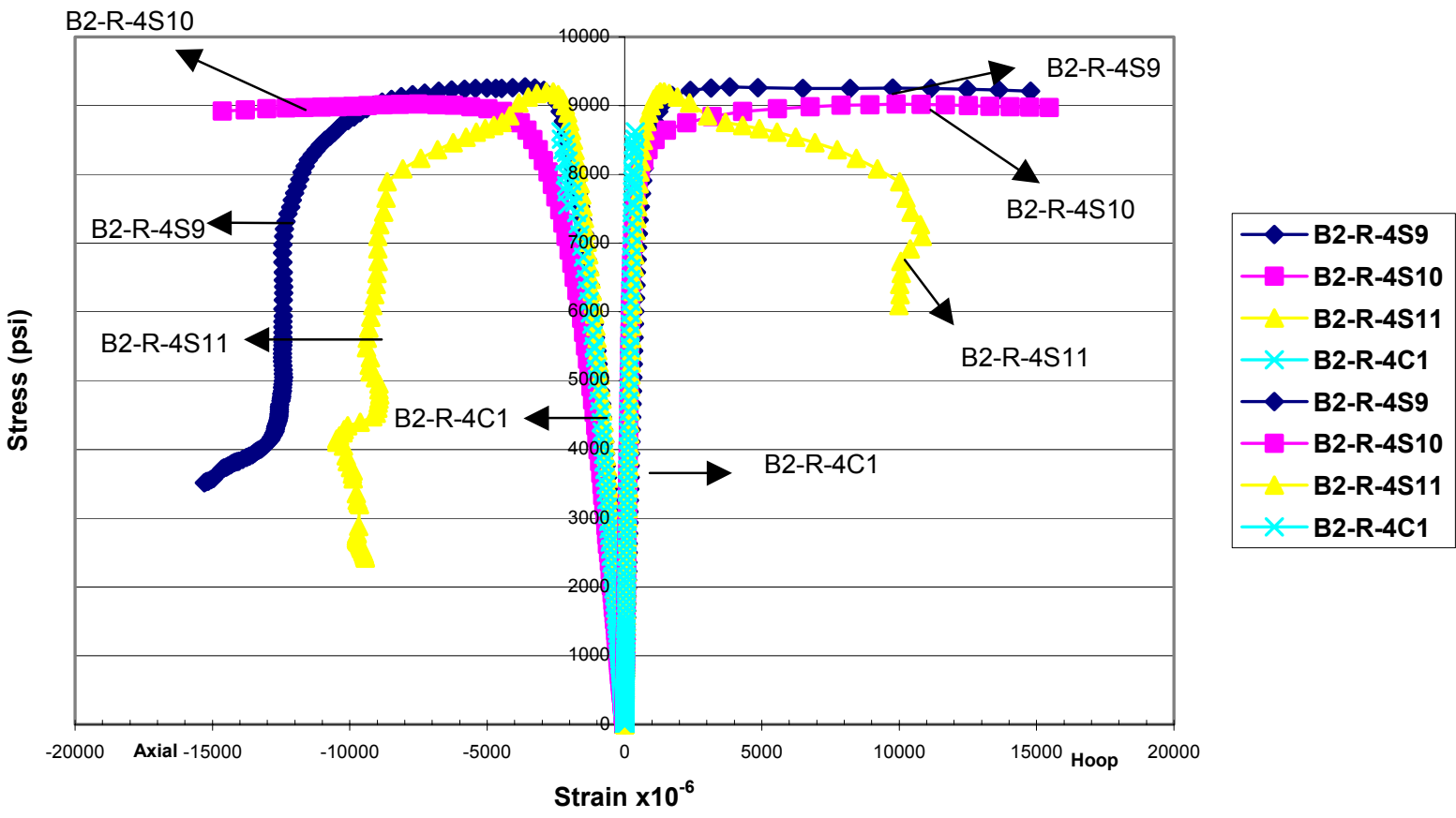

Fig. A. 18 Stress - Strain Comparison of 2 Layer $\pm 45^{\circ}$ Wrapped PCC Specimen with Control Specimen- Batch 2 


\section{APPENDIX B}

Tables on Deformability Factor (batch $1-f_{c}{ }^{\prime}=4500$ psi and batch $2-f_{c}{ }^{\prime}=8000 \mathrm{psi}$ ) 
Table B- 1 Comparison of energy for wrapped PCC Specimens with fibers running in $0^{\circ}$ direction (Batch 1- $\left.f_{c}{ }^{\prime}=4500 \mathrm{psi}\right)$

\begin{tabular}{|c|c|c|c|c|c|c|c|c|c|}
\hline \multirow{2}{*}{$\begin{array}{l}\text { Gauge } \\
\text { Direction }\end{array}$} & \multirow{2}{*}{ Specification } & \multirow{2}{*}{$\begin{array}{l}\text { No. of } \\
\text { Layers }\end{array}$} & \multirow{2}{*}{$\begin{array}{l}\text { Total } \\
\text { Area }\end{array}$} & \multirow{2}{*}{$\begin{array}{l}\text { Area } \\
\text { under } \\
.0008 \\
\text { Strain }\end{array}$} & \multirow{2}{*}{$\begin{array}{c}\text { Area } \\
\text { under } \\
.002 \\
\text { Strain }\end{array}$} & \multirow{2}{*}{$\begin{array}{c}\text { Area } \\
\text { under } \\
.003 \\
\text { strain }\end{array}$} & \multicolumn{3}{|c|}{ Ratio of Areas } \\
\hline & & & & & & & 0.0008 & 0.002 & 0.003 \\
\hline \multirow{3}{*}{ Axial } & B1-P-4C3 & --- & 13.06 & .85 & 4.54 & 7.86 & 15.36 & 2.87 & 1.66 \\
\hline & B1-P-4S1 & \multirow{2}{*}{1} & 83.159 & 1.3 & 4.81 & 9.766 & 63.96 & 17.28 & 8.51 \\
\hline & B1-P-4S2 & & 45.27 & 0.926 & 6.856 & 9.026 & 48.88 & 6.6 & 5.01 \\
\hline \multirow{3}{*}{ Hоop } & B1-P-4C3 & --- & 5.108 & 0.13 & 0.83 & 2.43 & 39.29 & 6.15 & 2.1 \\
\hline & B1-P-4S1 & \multirow{2}{*}{1} & 72.88 & 0.28 & 3.14 & 6.59 & 260.28 & 23.2 & 11.05 \\
\hline & B1-P-4S2 & & 62.02 & 0.12 & 0.86 & 2.63 & 516.83 & 72.11 & 23.58 \\
\hline \multirow{3}{*}{ Axial } & B1-P-4C3 & --- & 13.06 & .85 & 4.54 & 7.86 & 15.36 & 2.8 & 1.66 \\
\hline & B1-P-4S5 & \multirow{2}{*}{3} & 132.73 & 2.59 & 6.24 & 11.77 & 51.24 & 21.2 & 11.27 \\
\hline & B1-P-4S6 & & 147.45 & 2.42 & 5.76 & 13.36 & 60.92 & 25.5 & 11.04 \\
\hline \multirow{3}{*}{ Hoop } & B1-P-4C3 & --- & 5.108 & 0.13 & 0.83 & 2.43 & 39.29 & 6.15 & 2.1 \\
\hline & B1-P-4S5 & \multirow[b]{2}{*}{3} & 112.2 & 0.197 & 3.59 & 7.9 & 569.54 & 31.25 & 14.2 \\
\hline & B1-P-4S6 & & 61.6 & 0.155 & 2.45 & 19.25 & 397.41 & 25.14 & 3.2 \\
\hline
\end{tabular}

Table B- 2 Comparison of energy for wrapped PCC Specimens with fibers running in $4^{\circ}$ direction (Batch 1- $f_{c}{ }^{\prime}=4500 \mathrm{psi}$ )

\begin{tabular}{|c|c|c|c|c|c|c|c|c|c|}
\hline \multirow{2}{*}{$\begin{array}{c}\text { Gauge } \\
\text { Direction }\end{array}$} & \multirow{2}{*}{ Specification } & \multirow{2}{*}{$\begin{array}{c}\text { Non } \\
\text { Of } \\
\text { Layers }\end{array}$} & \multirow{2}{*}{$\begin{array}{l}\text { Total } \\
\text { Area }\end{array}$} & \multirow{2}{*}{$\begin{array}{l}\text { Area } \\
\text { under } \\
.0008 \\
\text { Strain }\end{array}$} & \multirow{2}{*}{$\begin{array}{c}\text { Area } \\
\text { under } \\
.002 \\
\text { Strain }\end{array}$} & \multirow{2}{*}{$\begin{array}{c}\text { Area } \\
\text { under } \\
.003 \\
\text { strain }\end{array}$} & \multicolumn{3}{|c|}{ Ratio of Areas } \\
\hline & & & & & & & .0008 & .002 & .003 \\
\hline \multirow{3}{*}{ Axial } & B1-P-4C3 & --- & 13.056 & 0.77 & 4.54 & 7.6 & 16.9 & 2.87 & 1.71 \\
\hline & B1-P-4S3 & \multirow{2}{*}{1} & 4.715 & 1.367 & --- & --- & 3.44 & --- & --- \\
\hline & B1-P-4S4 & & 8.5767 & 1.106 & 5.527 & --- & 7.75 & 1.55 & -- \\
\hline \multirow{3}{*}{ Hoop } & B1-P-4C3 & --- & 5.108 & 0.13 & 0.83 & 2.43 & 39.29 & 6.15 & 2.1 \\
\hline & B1-P-4S3 & \multirow{2}{*}{1} & 5.61 & 0.36 & --- & --- & 15.5 & --- & --- \\
\hline & B1-P-4S4 & & 36.679 & 0.4 & 2.9 & --- & 91.69 & 12.64 & --- \\
\hline \multirow[t]{3}{*}{ Axial } & B1-P-4C3 & -- & 13.056 & 0.77 & 4.54 & 7.6 & 16.95 & 2.87 & 1.7 \\
\hline & B1-P-4S7 & \multirow{2}{*}{2} & 63.58 & 0.92 & 6.45 & 11.59 & 69.1 & 9.85 & 5.4 \\
\hline & B1-P-4S8 & & 37.04 & 0.93 & 5.87 & 10.39 & 39.82 & 6.31 & 3.56 \\
\hline \multirow[t]{3}{*}{ Hoop } & B1-P-4C3 & --- & 5.108 & 0.13 & 0.83 & 2.43 & 39.29 & 6.15 & 2.1 \\
\hline & B1-P-4S7 & \multirow{2}{*}{2} & 64.68 & 0.32 & 3.99 & 8.9 & 202.125 & 16.2 & 7.2 \\
\hline & B1-P-4S8 & & 44.61 & 0.19 & 2.55 & 7.65 & 234.78 & 17.4 & 5.8 \\
\hline
\end{tabular}


Table B- 3 Comparison of energy for wrapped RCC Specimens with fibers running in zero direction (Batch 1- $f_{c}{ }^{\prime}=4500 \mathrm{psi}$ )

\begin{tabular}{|c|c|c|c|c|c|c|c|c|c|}
\hline \multirow{2}{*}{$\begin{array}{c}\text { Gauge } \\
\text { Directio } \\
\text { n }\end{array}$} & \multirow{2}{*}{ Specification } & \multirow{2}{*}{$\begin{array}{l}\text { No. of } \\
\text { Layers }\end{array}$} & \multirow{2}{*}{$\begin{array}{l}\text { Total } \\
\text { Area }\end{array}$} & \multirow{2}{*}{$\begin{array}{l}\text { Area } \\
\text { under } \\
.0008 \\
\text { Strain }\end{array}$} & \multirow{2}{*}{$\begin{array}{c}\text { Area } \\
\text { under } \\
.002 \\
\text { Strain }\end{array}$} & \multirow{2}{*}{$\begin{array}{c}\text { Area } \\
\text { under } \\
.003 \\
\text { strain }\end{array}$} & \multicolumn{3}{|c|}{ Ratio of Areas } \\
\hline & & & & & & & .0008 & .002 & .003 \\
\hline \multirow{3}{*}{ Axial } & B1-R-4C1 & -- & 4.37 & 1.07 & --- & --- & 4.08 & --- & -- \\
\hline & B1-R-4S1 & \multirow{2}{*}{1} & 56.8 & 1.3 & 7.17 & 13.07 & 43.69 & 7.9 & 4.3 \\
\hline & B1-R-4S2 & & 53.54 & 1.1 & 6.205 & 12.88 & 48.67 & 8.6 & 4.15 \\
\hline \multirow{3}{*}{ Hoop } & B1-R-4C1 & --- & 2.24 & 0.25 & --- & --- & 8.96 & --- & --- \\
\hline & B1-R-4S1 & \multirow{2}{*}{1} & 72.25 & 0.51 & 3.09 & 9.45 & 141.67 & 23.38 & 7.6 \\
\hline & B1-R-4S2 & & 61.78 & 0.48 & 2.47 & 7.57 & 128.7 & 25.01 & 8.16 \\
\hline \multirow{3}{*}{ Axial } & B1-R-4C1 & --- & 4.37 & 1.07 & --- & -- & 4.08 & --- & --- \\
\hline & B1-R-4S5 & \multirow{2}{*}{3} & 151.26 & 1.75 & 9.8 & 17.81 & 86.4 & 15.43 & 8.49 \\
\hline & B1-R-4S6 & & 130.43 & 1.1 & 7.15 & 12.64 & 118.57 & 18.24 & 10.3 \\
\hline \multirow{3}{*}{ Hoop } & B1-R-4C1 & --- & 2.24 & 0.25 & --- & --- & 8.96 & --- & --- \\
\hline & B1-R-4S5 & \multirow{2}{*}{3} & 80.09 & 0.45 & 10.02 & 17.59 & 177.9 & 7.9 & 4.55 \\
\hline & B1-R-4S6 & & 80.14 & 0.15 & 15.02 & 30.78 & 534.26 & 5.33 & 2.6 \\
\hline
\end{tabular}

Table B- 4 Comparison of energy for wrapped RCC Specimens with fibers running in $45^{\circ}$ direction (Batch 1- $f_{c}{ }^{\prime}=4500 \mathrm{psi}$ )

\begin{tabular}{|c|c|c|c|c|c|c|c|c|c|}
\hline \multirow{2}{*}{$\begin{array}{c}\text { Gauge } \\
\text { Direction }\end{array}$} & \multirow{2}{*}{ Specification } & \multirow{2}{*}{$\begin{array}{l}\text { No. of } \\
\text { Layers }\end{array}$} & \multirow{2}{*}{$\begin{array}{l}\text { Total } \\
\text { Area }\end{array}$} & \multirow{2}{*}{$\begin{array}{c}\text { Area } \\
\text { under } \\
.0008 \\
\text { Strain }\end{array}$} & \multirow{2}{*}{$\begin{array}{c}\text { Area } \\
\text { under } \\
.002 \\
\text { Strain }\end{array}$} & \multirow{2}{*}{$\begin{array}{c}\text { Area } \\
\text { under } \\
.003 \\
\text { strain }\end{array}$} & \multicolumn{3}{|c|}{ Ratio of Areas } \\
\hline & & & & & & & .0008 & .002 & .003 \\
\hline \multirow{3}{*}{ Axial } & B1-R-4C1 & --- & 4.27 & 1.07 & & --- & 3.99 & --- & --- \\
\hline & B1-R-4S3 & \multirow{2}{*}{1} & 63.44 & 1.25 & 6.77 & 12.24 & 50.75 & 9.37 & 5.18 \\
\hline & B1-R-4S4 & & & & & & --- & --- & --- \\
\hline \multirow{3}{*}{ Hoop } & B1-R-4C1 & --- & 2.24 & 0.25 & & & 8.96 & --- & --- \\
\hline & B1-R-4S3 & \multirow{2}{*}{1} & 81.44 & 0.86 & 6.38 & 14.13 & 94.69 & 12.76 & 5.76 \\
\hline & B1-R-4S4 & & & & & & --- & --- & --- \\
\hline \multirow{3}{*}{ Axial } & B1-R-4C1 & --- & 4.27 & 1.07 & & --- & 3.99 & --- & --- \\
\hline & B1-R-4S7 & \multirow{2}{*}{2} & 45.73 & 1.05 & 5.74 & 11.27 & 43.55 & 7.9 & 4.05 \\
\hline & B1-R-4S8 & & 87.91 & 2.00 & 8.6 & 15.75 & 43.955 & 10.22 & 5.58 \\
\hline \multirow{3}{*}{ Hoop } & B1-R-4C1 & --- & 2.24 & 0.25 & & & 8.96 & --- & --- \\
\hline & B1-R-4S7 & \multirow{2}{*}{2} & 44.13 & 0.14 & 4.41 & 28.2 & 315.21 & 10.06 & 1.56 \\
\hline & B1-R-4S8 & & 98.4 & 0.4 & 6.23 & 35.8 & 246 & 15.79 & 2.74 \\
\hline
\end{tabular}


Table B- 5 Comparison of Energy Values for PCC Specimens wrapped with fibers in Hoop direction (Batch 2- $f_{c}{ }^{\prime}=8000$ psi)

\begin{tabular}{|c|c|c|c|c|c|c|c|c|c|}
\hline \multirow{2}{*}{$\begin{array}{c}\text { Gauge } \\
\text { Direction }\end{array}$} & \multirow{2}{*}{ Specification } & \multirow{2}{*}{$\begin{array}{l}\text { No. of } \\
\text { fiber } \\
\text { layers }\end{array}$} & \multirow{2}{*}{$\begin{array}{l}\text { Total } \\
\text { Area }\end{array}$} & \multirow{2}{*}{$\begin{array}{c}\text { Area } \\
\text { under } \\
0.0008 \\
\text { Strain }\end{array}$} & \multirow{2}{*}{$\begin{array}{c}\text { Area } \\
\text { under } \\
0.002 \\
\text { Strain }\end{array}$} & \multirow{2}{*}{$\begin{array}{c}\text { Area } \\
\text { under } \\
0.003 \\
\text { Strain }\end{array}$} & \multicolumn{3}{|c|}{ Ratio of Areas } \\
\hline & & & & & & & 0.0008 & 0.002 & 0.003 \\
\hline \multirow{4}{*}{ Axial } & B2-P-4C1 & --- & 11.28 & 2.08 & 9.52 & --- & 5.4 & 1.18 & --- \\
\hline & B2-P-4S1 & \multirow{3}{*}{1} & 22.89 & 1.91 & 9.42 & 19.94 & 11.98 & 2.42 & 1.14 \\
\hline & B2-P-4S2 & & 41.99 & 2.1 & 10.49 & 19.22 & 19.99 & 4.00 & 2.18 \\
\hline & B2-P-4S3 & & 45.27 & 2.2 & 12.05 & 21.44 & 20.57 & 3.75 & 2.11 \\
\hline \multirow{4}{*}{ Hoop } & B2-P-4C1 & --- & 11.26 & 0.53 & 5.83 & --- & 21.24 & 1.93 & --- \\
\hline & B2-P-4S1 & \multirow{3}{*}{1} & 67.39 & 0.41 & 2.17 & 43.61 & 164.36 & 31.05 & 1.54 \\
\hline & B2-P-4S2 & & 111.203 & 0.59 & 5.92 & 22.22 & 188.47 & 18.78 & 5.00 \\
\hline & B2-P-4S3 & & 149.146 & 0.64 & 6.13 & 86.05 & 233.04 & 24.33 & 1.7 \\
\hline \multirow{3}{*}{ Axial } & B2-P-4C1 & --- & 11.28 & 2.08 & 9.52 & --- & 5.4 & 1.18 & --- \\
\hline & B2-P-4S7 & \multirow{2}{*}{3} & 168.89 & 2.09 & 10.43 & 19.65 & 80.8 & 16.19 & 8.59 \\
\hline & B2-P-4S8 & & 172.50 & 1.79 & 10.19 & 19.71 & 96.36 & 16.9 & 8.75 \\
\hline \multirow{3}{*}{ Hoop } & B2-P-4C1 & --- & 11.26 & 0.53 & 5.83 & --- & 21.2 & 1.93 & --- \\
\hline & B2-P-4S7 & \multirow{2}{*}{3} & 136.86 & 0.46 & 3.17 & 7.36 & 297.52 & 43.17 & 18.59 \\
\hline & B2-P-4S8 & & 85.63 & 0.128 & 0.87 & 2.38 & 668.9 & 98.42 & 35.97 \\
\hline
\end{tabular}

Table B- 6 Comparison of Energy Values for PCC Specimens wrapped with fibers in $45^{\circ}$ direction (Batch $2-f_{c}{ }^{\prime}=\mathbf{8 0 0 0 p s i )}$

\begin{tabular}{|c|c|c|c|c|c|c|c|c|c|}
\hline \multirow{2}{*}{$\begin{array}{l}\text { Gauge } \\
\text { Direction }\end{array}$} & \multirow{2}{*}{ Specification } & \multirow{2}{*}{$\begin{array}{l}\text { No. of } \\
\text { fiber } \\
\text { layers }\end{array}$} & \multirow{2}{*}{$\begin{array}{l}\text { Total } \\
\text { Area }\end{array}$} & \multirow{2}{*}{$\begin{array}{c}\text { Area } \\
\text { under } \\
0.0008 \\
\text { Strain }\end{array}$} & \multirow{2}{*}{$\begin{array}{l}\text { Area } \\
\text { under } \\
0.002 \\
\text { Strain }\end{array}$} & \multirow{2}{*}{$\begin{array}{l}\text { Area } \\
\text { under } \\
0.003 \\
\text { Strain }\end{array}$} & \multicolumn{3}{|c|}{ Ratio of Areas } \\
\hline & & & & & & & 0.0008 & 0.002 & 0.003 \\
\hline \multirow{4}{*}{ Axial } & B2-P-4C1 & --- & 11.28 & 2.08 & 9.52 & --- & 5.4 & 1.18 & --- \\
\hline & B2-P-4S4 & \multirow{3}{*}{1} & 12.08 & 1.825 & 9.5 & --- & 6.61 & 1.27 & $\begin{array}{l}--- \\
--\end{array}$ \\
\hline & B2-P-4S5 & & 25.66 & 1.61 & 9.207 & 17.96 & 15.93 & 2.7 & 1.42 \\
\hline & B2-P-4S6 & & 28.6 & 1.92 & 9.51 & 18.93 & 14.89 & 3.00 & 1.5 \\
\hline \multirow{4}{*}{ Hoop } & B2-P-4C1 & --- & 11.26 & 0.53 & 5.83 & --- & 21.24 & 1.9 & --- \\
\hline & B2-P-4S4 & \multirow{3}{*}{1} & 57.82 & 0.33 & 2.57 & --- & 175.21 & 22.49 & --- \\
\hline & B2-P-4S5 & & 42.58 & 1.2 & 7.79 & 24.3 & 35.48 & 5.46 & 1.7 \\
\hline & B2-P-4S6 & & 46.58 & 0.48 & 3.68 & 17.5 & 97.04 & 12.65 & 2.66 \\
\hline \multirow{4}{*}{ Axial } & B2-P-4C1 & --- & 11.28 & 2.08 & 9.52 & --- & 5.42 & 1.18 & --- \\
\hline & B2-P-4S9 & \multirow{3}{*}{2} & 124.52 & 0.368 & 3.56 & 10.51 & 338.36 & 34.97 & 11.8 \\
\hline & B2-P-4S10 & & 125.3 & 0.583 & 6.73 & 16.58 & 214.92 & 18.61 & 7.55 \\
\hline & B2-P-4S11 & & 127.8 & 0.27 & 2.1 & --- & 473.33 & 60.85 & --- \\
\hline \multirow{4}{*}{ Hoop } & B2-P-4C1 & --- & 11.26 & 0.53 & 5.83 & --- & 21.24 & 1.93 & ---- \\
\hline & B2-P-4S9 & \multirow{3}{*}{2} & 96.03 & 2.01 & 10.59 & 18.27 & 47.77 & 9.07 & 5.2 \\
\hline & B2-P-4S10 & & 108.99 & 2.01 & 10.38 & 17.63 & 54.22 & 10.5 & 6.18 \\
\hline & B2-P-4S11 & & 87.54 & 1.84 & 10.21 & 18.22 & 47.57 & 8.57 & 4.8 \\
\hline
\end{tabular}


Table B- 7 Comparison of Energy Values for RCC Specimens wrapped with fibers in Hoop direction (Batch 2- $f_{c}{ }^{\prime}=8000$ psi)

\begin{tabular}{|c|c|c|c|c|c|c|c|c|c|}
\hline \multirow{2}{*}{$\begin{array}{c}\text { Gauge } \\
\text { Direction }\end{array}$} & \multirow{2}{*}{ Specification } & \multirow{2}{*}{$\begin{array}{l}\text { No. of } \\
\text { fiber } \\
\text { layers }\end{array}$} & \multirow{2}{*}{$\begin{array}{l}\text { Total } \\
\text { Area }\end{array}$} & \multirow{2}{*}{$\begin{array}{c}\text { Area } \\
\text { under } \\
0.0008 \\
\text { Strain }\end{array}$} & \multirow{2}{*}{$\begin{array}{c}\text { Area } \\
\text { under } \\
0.002 \\
\text { Strain }\end{array}$} & \multirow{2}{*}{$\begin{array}{l}\text { Area } \\
\text { under } \\
0.003 \\
\text { Strain }\end{array}$} & \multicolumn{3}{|c|}{ Ratio of Areas } \\
\hline & & & & & & & 0.0008 & 0.002 & 0.003 \\
\hline \multirow{4}{*}{ Axial } & B2-R-4C1 & --- & 11.81 & 1.64 & 9.2 & --- & 7.2 & 1.28 & --- \\
\hline & B2-R-4S1 & \multirow{3}{*}{1} & 57.55 & 2.23 & 11.22 & 21.55 & 25.8 & 5.12 & 2.67 \\
\hline & B2-R-4S2 & & 73.93 & 1.78 & 10.07 & 19.63 & 41.53 & 7.34 & 3.76 \\
\hline & B2-R-4S3 & & 57.52 & 1.7 & 9.7 & 18.24 & 33.8 & 5.9 & 3.15 \\
\hline \multirow{4}{*}{ Hoop } & B2-R-4C1 & --- & 2.03 & 0.27 & 1.37 & --- & 7.51 & 1.48 & --- \\
\hline & B2-R-4S1 & \multirow{3}{*}{1} & 125.86 & 0.55 & 3.85 & 13.33 & 228.83 & 32.69 & 9.44 \\
\hline & B2-R-4S2 & & 165.86 & 0.36 & 2.84 & 16.58 & 460.72 & 58.4 & 10.00 \\
\hline & B2-R-4S3 & & 45.12 & 0.60 & 5.3 & 10.39 & 75.2 & 8.51 & 4.34 \\
\hline \multirow{3}{*}{ Axial } & B2-R-4C1 & --- & 11.81 & 1.64 & 9.2 & --- & 7.2 & 1.28 & --- \\
\hline & B2-R-4S7 & \multirow{2}{*}{3} & 118.84 & 1.88 & 10.36 & 20.56 & 63.21 & 11.47 & 5.78 \\
\hline & B2-R-4S8 & & 118.148 & 0.99 & 9.38 & 19.81 & 119.34 & 12.59 & 5.98 \\
\hline \multirow{3}{*}{ Hoop } & B2-R-4C1 & --- & 2.03 & 0.27 & 1.37 & --- & 7.5 & 1.48 & --- \\
\hline & B2-R-4S7 & \multirow{2}{*}{3} & 207.52 & 0.76 & 6.99 & 16.71 & 273.05 & 29.66 & 12.41 \\
\hline & B2-R-4S8 & & 154.68 & 1.7 & 7.21 & 13.13 & 90.98 & 21.45 & 11.78 \\
\hline
\end{tabular}

Table B- 8 Comparison of Energy Values for RCC Specimens wrapped with fibers in $45^{\circ}$ direction (Batch 2- $f_{c}{ }^{\prime}=$ 8000psi)

\begin{tabular}{|c|c|c|c|c|c|c|c|c|c|}
\hline \multirow{2}{*}{$\begin{array}{c}\text { Gauge } \\
\text { Direction }\end{array}$} & \multirow{2}{*}{ Specification } & \multirow{2}{*}{$\begin{array}{l}\text { No. of } \\
\text { fiber } \\
\text { layers }\end{array}$} & \multirow{2}{*}{$\begin{array}{l}\text { Total } \\
\text { Area }\end{array}$} & \multirow{2}{*}{$\begin{array}{c}\text { Area } \\
\text { under } \\
0.0008 \\
\text { Strain }\end{array}$} & \multirow{2}{*}{$\begin{array}{l}\text { Area } \\
\text { under } \\
0.002 \\
\text { Strain }\end{array}$} & \multirow{2}{*}{$\begin{array}{c}\text { Area } \\
\text { under } \\
0.003 \\
\text { Strain }\end{array}$} & \multicolumn{3}{|c|}{ Ratio of Areas } \\
\hline & & & & & & & 0.0008 & 0.002 & 0.003 \\
\hline \multirow{4}{*}{ Axial } & B2-R-4C1 & --- & 11.81 & 1.64 & 9.19 & --- & 7.2 & 1.28 & --- \\
\hline & B2-R-4S4 & \multirow{3}{*}{1} & 8.27 & 1.77 & --- & --- & 4.67 & --- & --- \\
\hline & B2-R-4S5 & & 26.00 & 2.22 & 10.85 & 25.5 & 11.74 & 2.39 & 1.01 \\
\hline & B2-R-4S6 & & 25.48 & 2.16 & 11.72 & 22.38 & 11.79 & 2.17 & 1.13 \\
\hline \multirow{4}{*}{ Hoop } & B2-R-4C1 & --- & 2.03 & 0.27 & 1.37 & --- & 7.51 & 1.48 & --- \\
\hline & B2-R-4S4 & \multirow{3}{*}{1} & 10.79 & 0.48 & --- & --- & 22.47 & --- & --- \\
\hline & B2-R-4S5 & & 58.77 & 0.48 & 9.35 & 22.29 & 122.43 & 6.28 & 2.63 \\
\hline & B2-R-4S6 & & 84.8 & 0.52 & 7.31 & 46.19 & 163.07 & 11.6 & 1.83 \\
\hline \multirow{4}{*}{ Axial } & B2-R-4C1 & --- & 11.81 & 1.64 & 9.19 & --- & 7.2 & 1.28 & --- \\
\hline & B2-R-4S9 & \multirow{3}{*}{2} & 114.41 & 1.9 & 10.14 & 18.42 & 60.2 & 11.28 & 6.21 \\
\hline & B2-R-4S10 & & 119.55 & 1.44 & 7.91 & 15.02 & 83.02 & 15.11 & 7.95 \\
\hline & B2-R-4S11 & & 73.49 & 2.05 & 10.32 & 21.2 & 35.8 & 7.12 & 3.4 \\
\hline \multirow{4}{*}{ Hoop } & $\mathrm{B} 2-\mathrm{R}-4 \mathrm{C} 1$ & --- & 2.03 & 0.27 & 1.37 & --- & 7.51 & 1.48 & --- \\
\hline & B2-R-4S9 & \multirow{3}{*}{2} & 133.27 & 0.62 & 4.97 & 187.3 & 214.95 & 26.81 & 0.71 \\
\hline & B2-R-4S10 & & 136.14 & 0.21 & 4.33 & 18.2 & 648.28 & 31.44 & 7.4 \\
\hline & B2-R-4S11 & & 84.56 & 0.54 & 5.01 & 12.48 & 156.59 & 16.87 & 6.77 \\
\hline
\end{tabular}




\section{APPENDIX C}

Stress-Strain Diagrams of Wrapped and Non-Wrapped Columns with and without Internal Steel Reinforcement Subjected to Accelerated Aging 


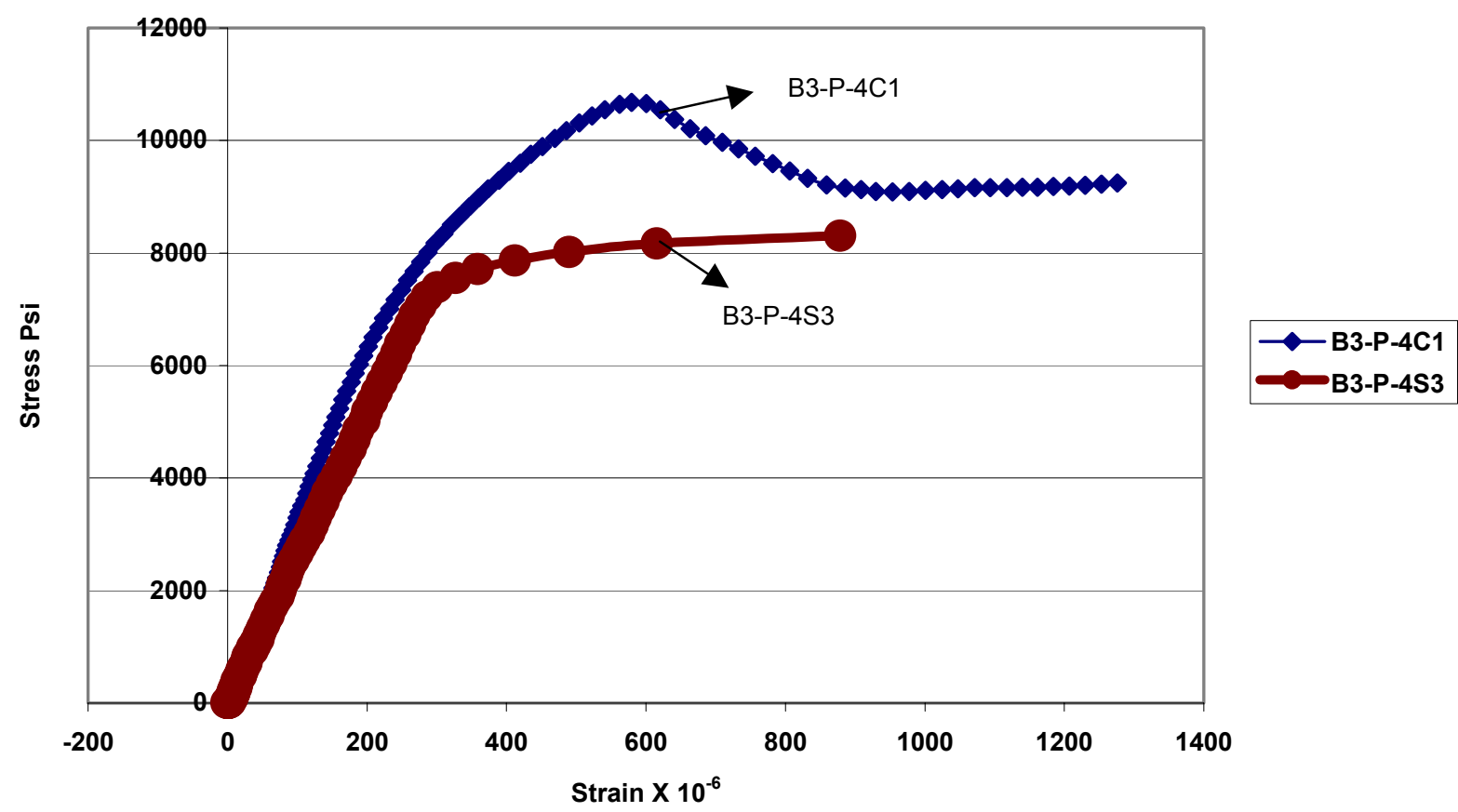

Fig C. 1 Comparison of Stress- Strain of Non Wrapped Plain Concrete Specimens Aged in Elevated Temperature Condition

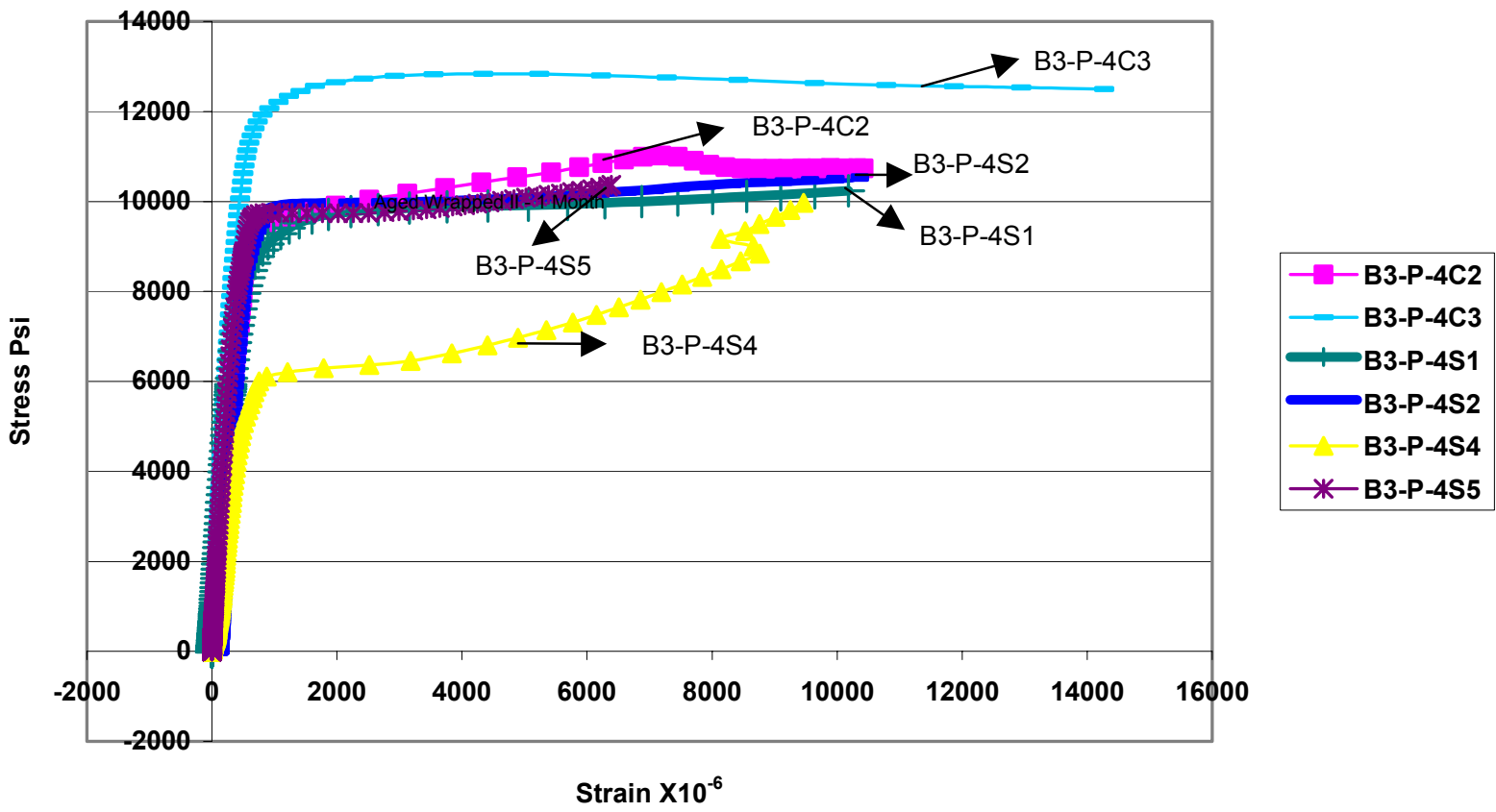

Fig C. 2 Comparison of Stress- Strain of Wrapped Plain Concrete Specimens Aged in Elevated Temperature Condition 


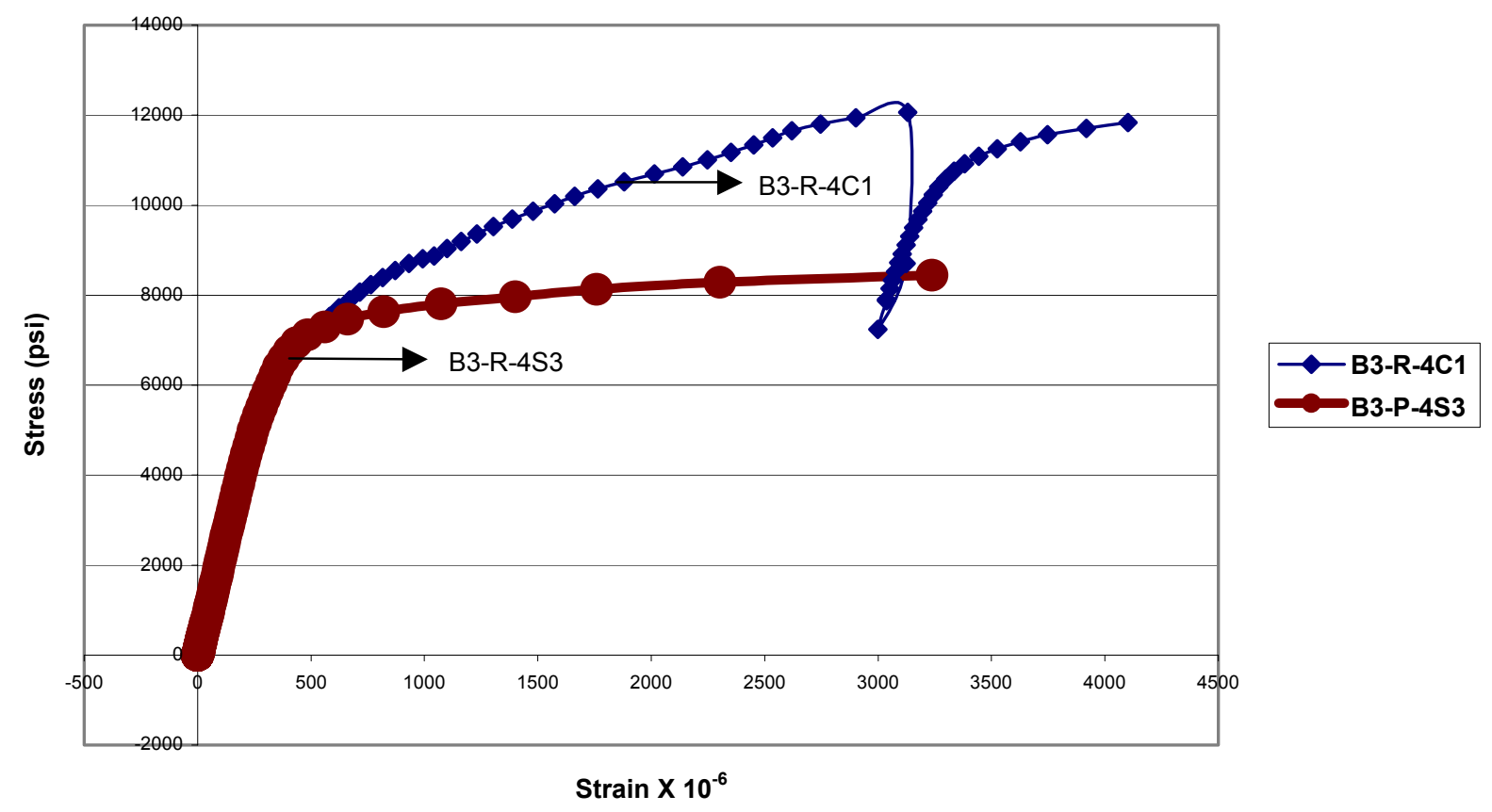

Fig C. 3 Comparison of Stress- Strain of Non Wrapped Reinforced Concrete Specimens Aged in Elevated Temperature Condition

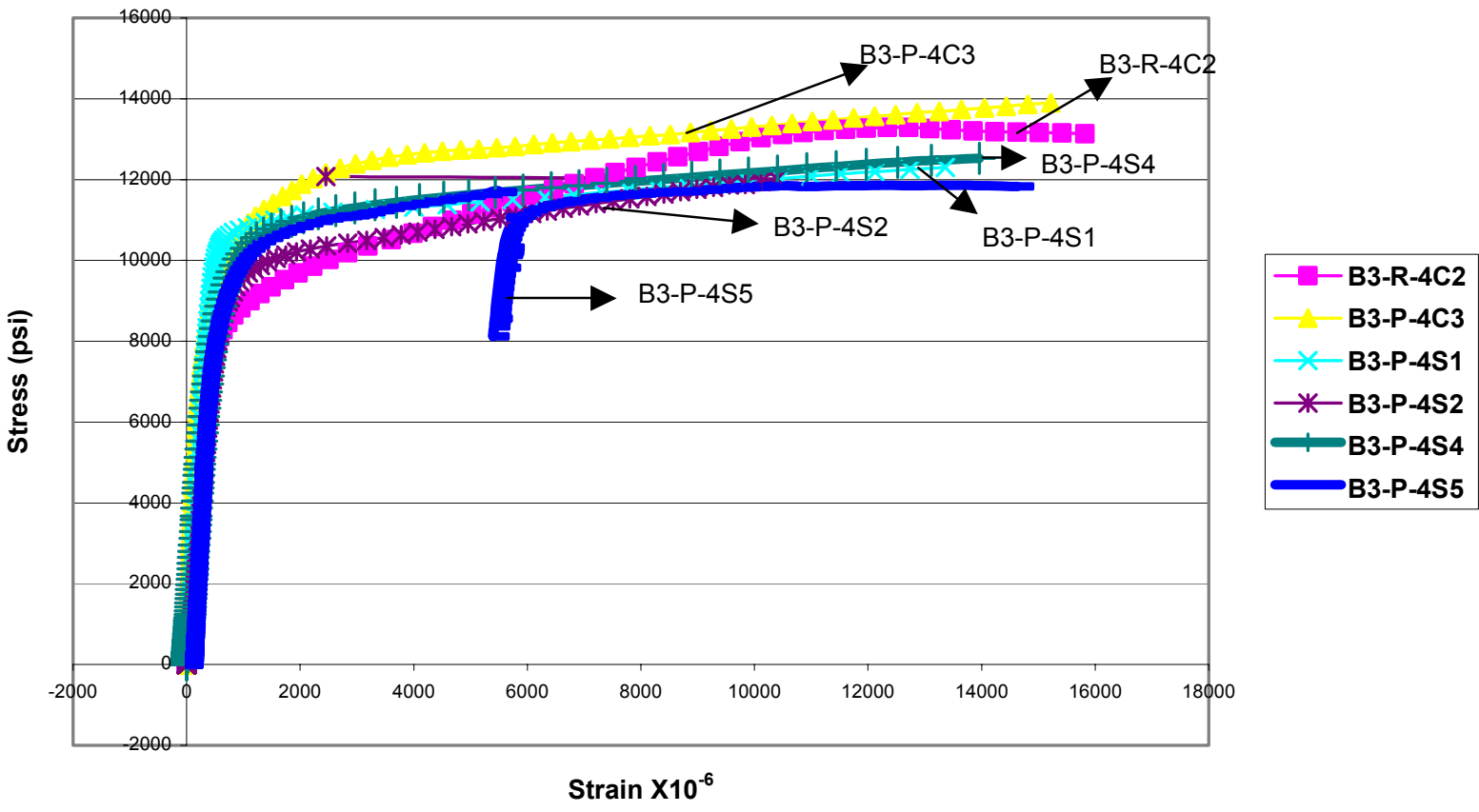

Fig C. 4 Comparison of Stress- Strain of Wrapped Reinforced Concrete Specimens Aged in Elevated Temperature Condition 


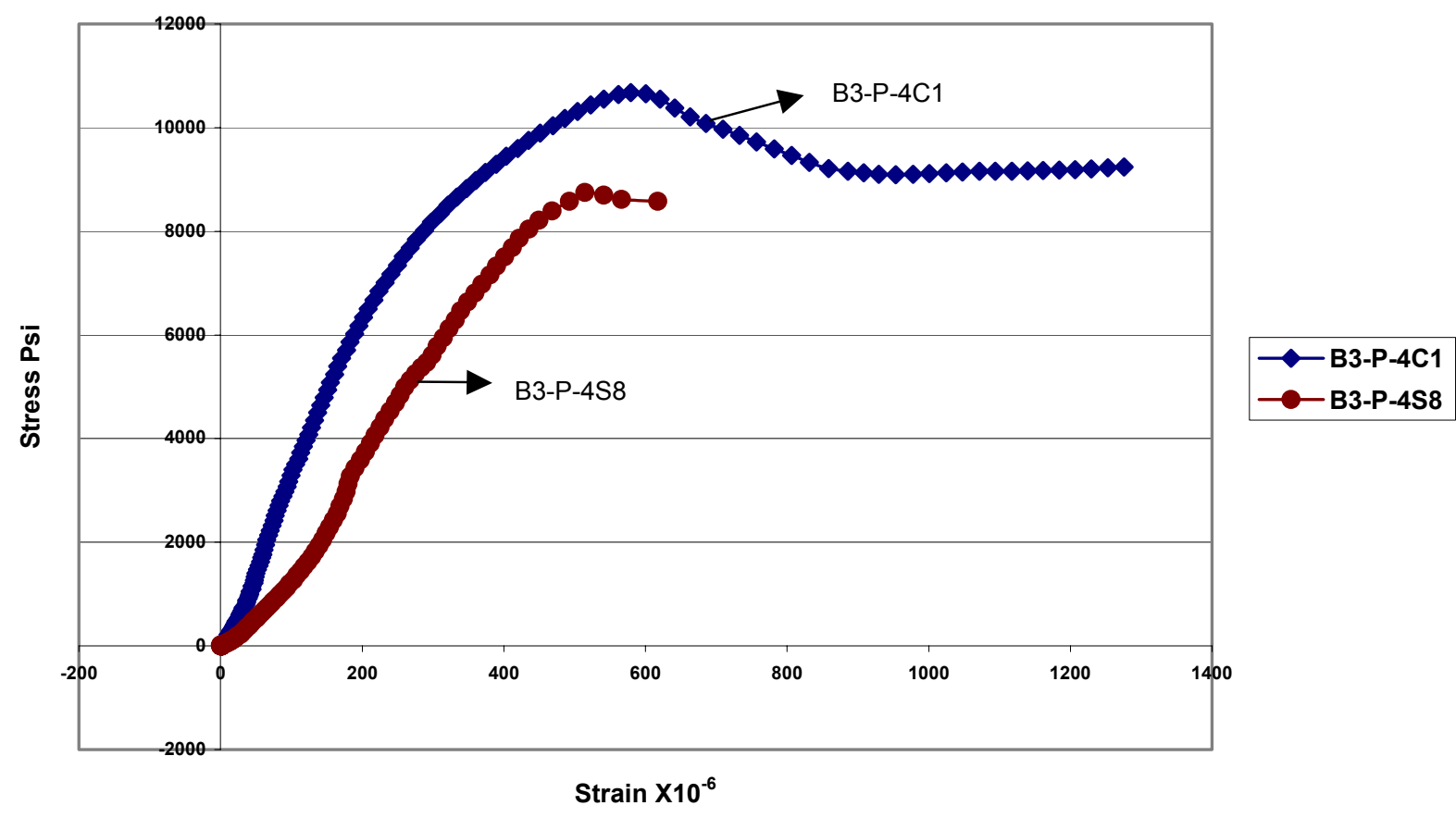

Fig C. 5 Comparison of Stress- Strain of Non Wrapped Plain Concrete Specimens Aged in FreezeThaw Condition

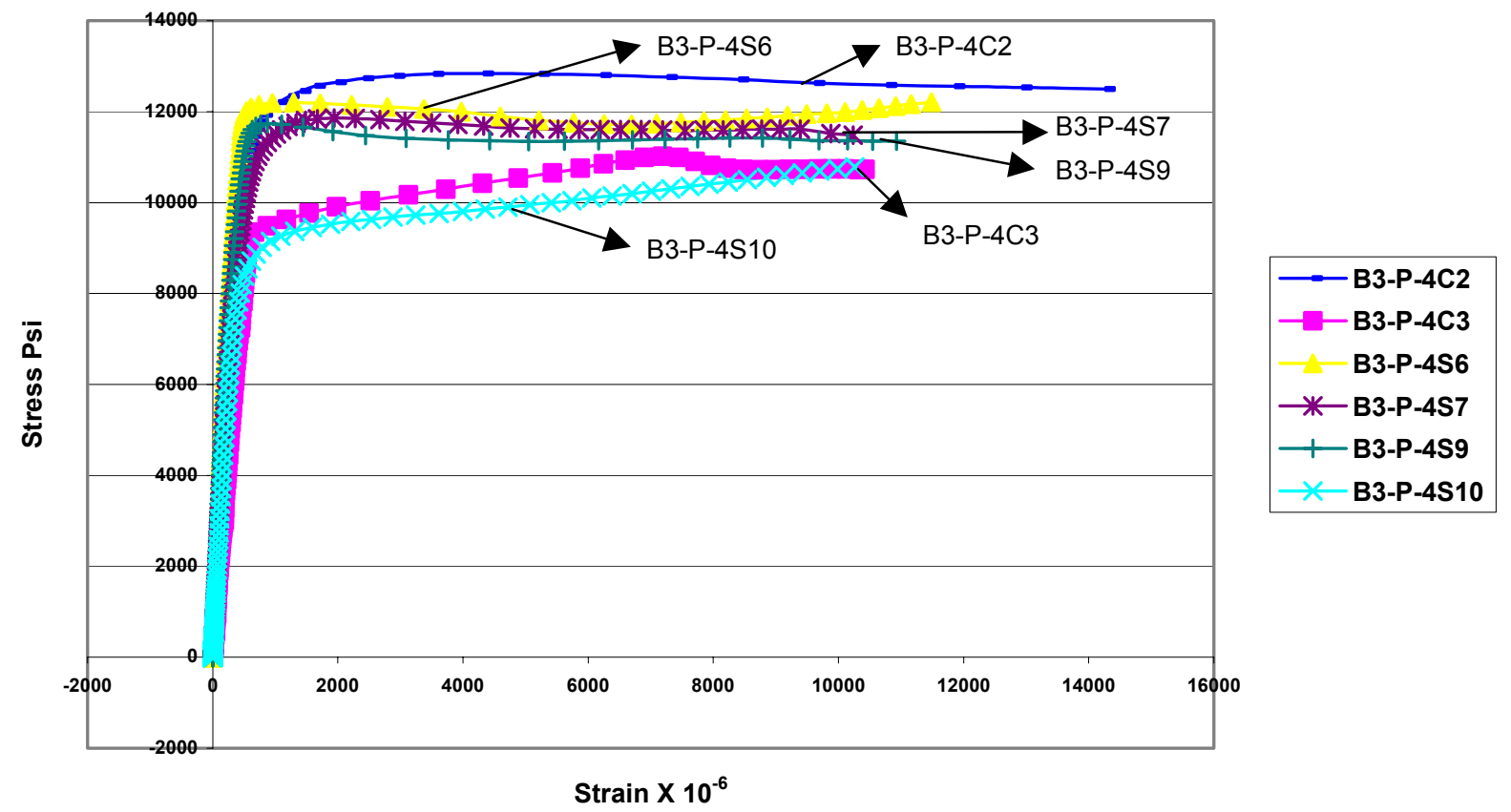

Fig C. 6 Comparison of Stress- Strain of Wrapped Plain Concrete Specimens Aged in Freeze-Thaw Condition 


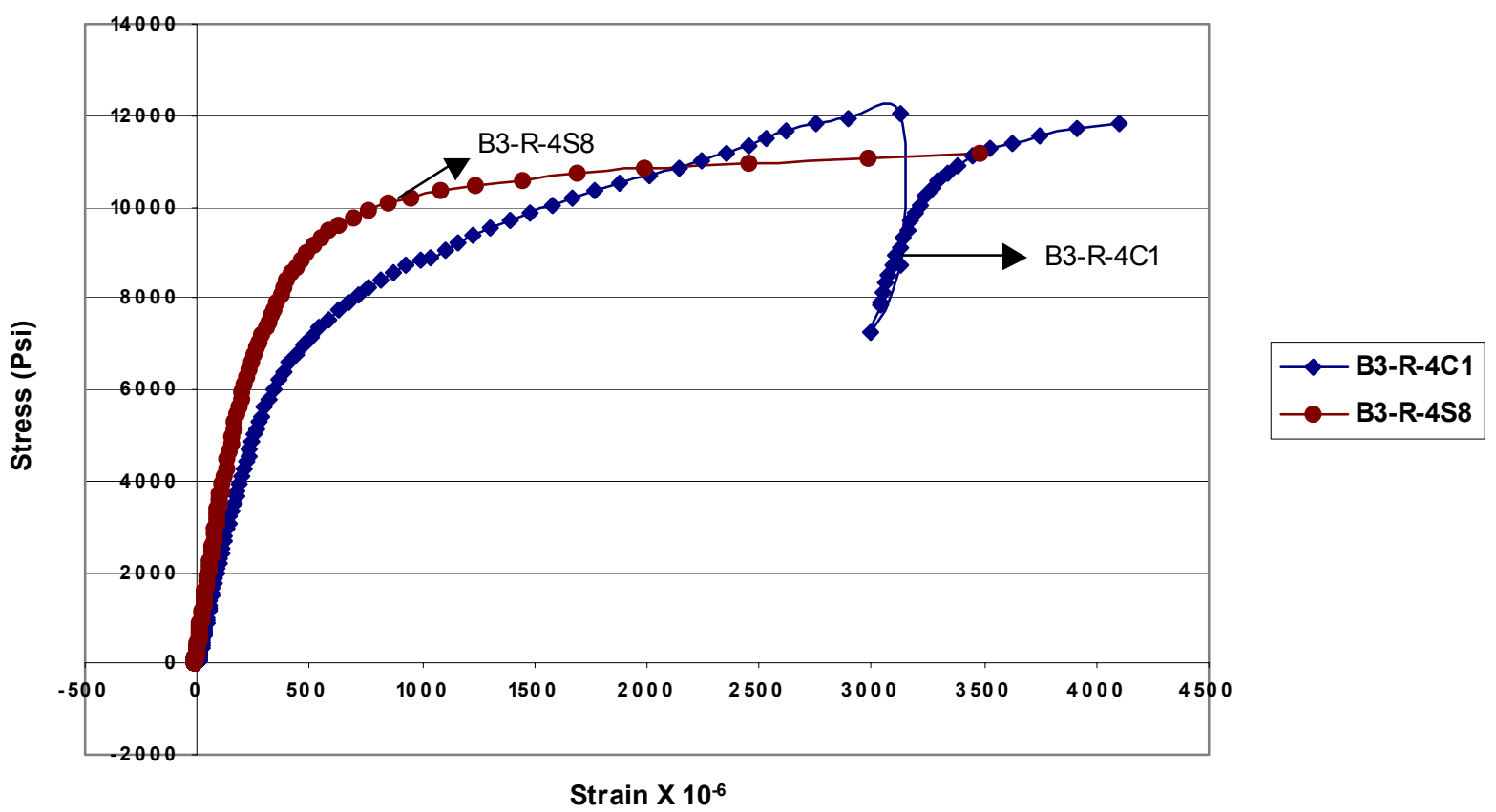

Fig C. 7 Comparison of Stress- Strain of Non Wrapped Reinforced Concrete Specimens Aged in Freeze-Thaw Condition

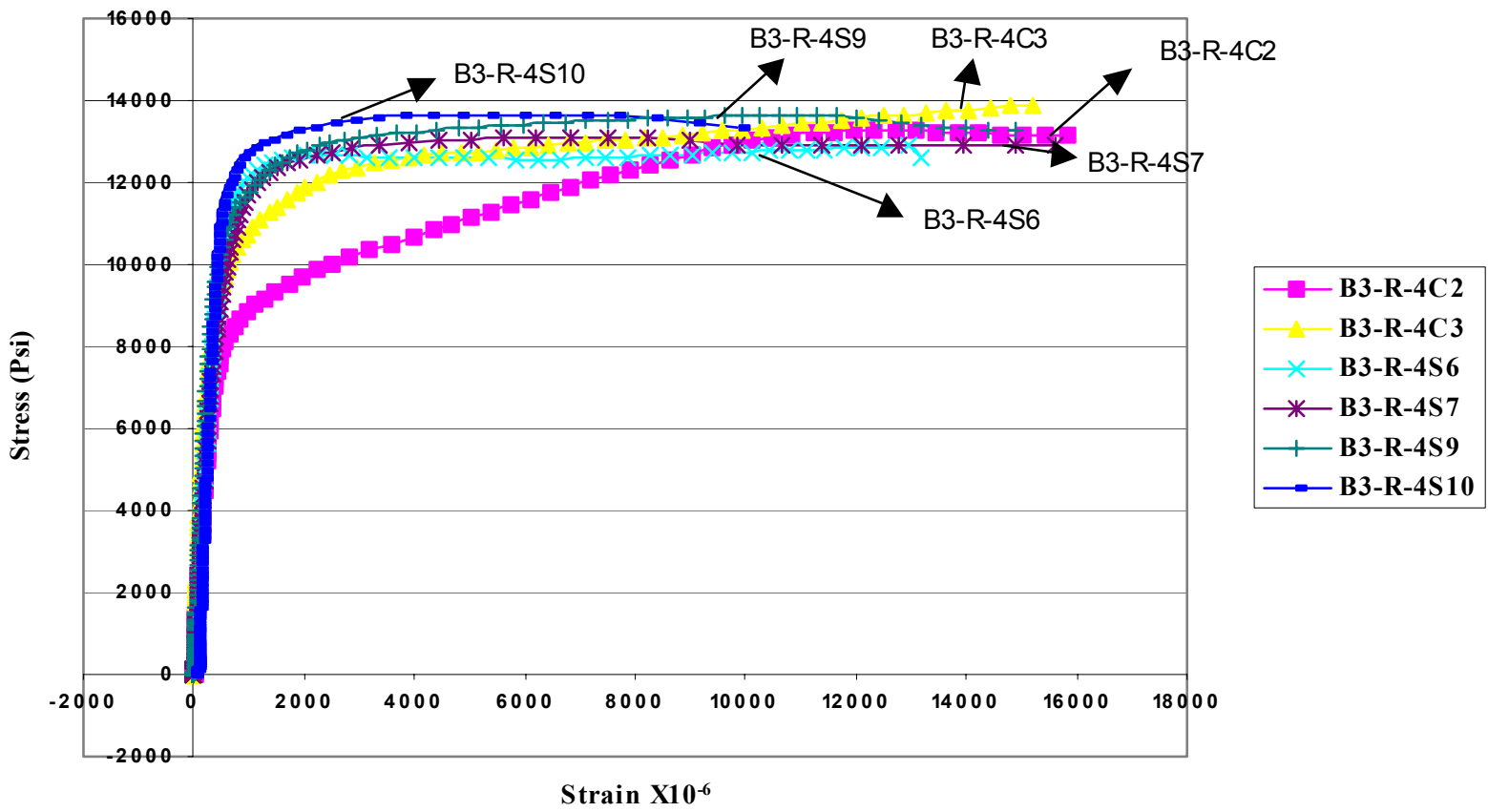

Fig C. 8 Comparison of Stress- Strain of Wrapped Reinforced Concrete Specimens Aged in FreezeThaw Condition 


\section{APPENDIX D}

Analytical Calculation of Stiffness and Analysis of Failure Mode of Partially Wrapped Specimen 


\section{Stiffness Calculations}

The stiffness of unconfined and confined concrete cylinders was calculated and the results were correlated to the experimental values.

The lateral confining pressure of the FRP wrap is given as

$$
\begin{aligned}
f_{l} & =\frac{2 f_{f r p} t_{f r p}}{2} \text { where } \\
f_{f r p} & =\varepsilon_{\mathrm{h}} * E_{f r p}
\end{aligned}
$$

Taking the thickness of FRP as 0.004 " and diameter of cylinder as 4 " the value of $f_{l}$ was calculated. The hoop strain, $\varepsilon_{\mathrm{h}}$ was calculated using Poisson ratio values $\gamma_{\mathrm{cc}}=0.2,0.25,0.3$.

$$
\begin{aligned}
& \varepsilon_{\mathrm{h}}=\frac{\gamma_{\mathrm{cc}}}{2 \mathrm{E}_{\mathrm{FRP}}\left(\frac{1-\gamma_{\mathrm{cc}}}{\mathrm{E}_{\mathrm{cc}}}\right)\left(\frac{\mathrm{t}}{\mathrm{d}}\right)+1} \varepsilon_{\mathrm{cc}} \text { (Ref. Legeron and Paultre, 2002) } \\
& \gamma_{\mathrm{cc}}=0.2,0.25,0.3 \\
& \mathrm{E}_{\mathrm{FRP}}=33,000,000 \mathrm{psi} \\
& \mathrm{t}=0.004 " \\
& \mathrm{~d}=4 " \\
& \varepsilon_{\mathrm{cc}}=0.0001 \text { to } 0.003 \text {. The hoop strain was calculated for each of the values of axial }
\end{aligned}
$$

strain from 0.001 to 0.003 .

Table D- 1 Hoop Strain of Confined Concrete

\begin{tabular}{|c|c|c|c|}
\hline Confined Strain of Concrete & $\gamma_{\mathrm{cc}}=0.2$ & $\gamma_{\mathrm{cc}}=0.25$ & $\gamma_{\mathrm{cc}}=0.3$ \\
\hline 0.001 & 0.000192044 & 0.000240654 & 0.000289506 \\
\hline 0.002 & 0.000384089 & 0.000481307 & 0.000579012 \\
\hline 0.003 & 0.000576133 & 0.000721961 & 0.000868518 \\
\hline
\end{tabular}


After calculating the hoop strain due to wrap the hoop stress was calculated using $f_{f r p}=$ $\varepsilon_{h}{ }^{*} E_{f r p}$

Table D- 2 Stress in Fiber

\begin{tabular}{|c|c|c|c|}
\hline Confined Strain of Concrete & $\gamma_{\mathrm{cc}}=0.2$ & $\gamma_{\mathrm{cc}}=0.25$ & $\gamma_{\mathrm{cc}}=0.3$ \\
\hline 0.001 & 6337.46359 & 7941.57 & 9553.69 \\
\hline 0.002 & 12674.92 & 15883.15 & 19107.39 \\
\hline 0.003 & 19012.39 & 23824.72 & 28661.09 \\
\hline
\end{tabular}

and the lateral stress $f_{l}$ was calculated using the formula $f_{l}=\frac{2 f_{f r p} t_{f r p}}{d}$.

Table D- 3 Lateral Confining Stress $f_{l}$ (psi)

\begin{tabular}{|c|c|c|c|}
\hline Confined Strain of Concrete & $\gamma_{\mathrm{cc}}=0.2$ & $\gamma_{\mathrm{cc}}=0.25$ & $\gamma_{\mathrm{cc}}=0.3$ \\
\hline 0.001 & 38.02 & 47.64 & 57.32 \\
\hline 0.002 & 76.04 & 95.29 & 114.64 \\
\hline 0.003 & 114.07 & 142.94 & 171.96 \\
\hline
\end{tabular}

Once the lateral stress was calculated the axial stress due to confinement was calculated using the formula

$$
\frac{f_{c c}{ }^{\prime}}{f_{c o}{ }^{\prime}}=1+k_{1} \frac{f_{l}}{f_{c o}{ }^{\prime}}
$$

Where

$\mathrm{k}_{1}=2.15$ (Teng et. al., 2001)

$$
f_{c o}{ }^{\prime}=\left[2\left(\frac{\varepsilon_{c}}{\varepsilon_{c}{ }^{\prime}}\right)-\left(\frac{\varepsilon_{c}}{\varepsilon_{c}{ }^{\prime}}\right)^{2}\right] f_{c}{ }^{\prime}
$$


$f_{c o}{ }^{\prime}$ is the confined compressive strength of concrete at each value of strain which of 0.001 to 0.003 . $\varepsilon_{c}$ include strain values varying from 0.001 to 0.003 while $\varepsilon_{c}{ }^{\prime}$ is the strain value of 0.002 .

$$
f_{c}^{\prime}=4500 \mathrm{psi}
$$

Table D- 4 Confined Stress of Concrete $f_{c c}$ '(psi)

\begin{tabular}{|c|c|c|c|}
\hline Confined Strain of Concrete & $\gamma_{\mathrm{cc}}=0.2$ & $\gamma_{\mathrm{cc}}=0.25$ & $\gamma_{\mathrm{cc}}=0.3$ \\
\hline 0.001 & 3456.74 & 3463.53 & 3477.11 \\
\hline 0.002 & 4663.50 & 4704.89 & 4746.48 \\
\hline
\end{tabular}

Calculated stress of the specimen can be equated to the stiffness using the relation stress $/$ strain $=$ E. The strain is taken to be a constant. Hence when calculating the increase in stiffness of wrapped and non-wrapped specimen, ratio between stress of the non-wrapped to wrapped specimen is the same as the ratio between the stiffness. Thus the ratio between the calculated values of stress of wrapped and non-wrapped specimens are given in Table D-5.

Table D- 5 Comparison of Confined to Unconfined Stiffness

\begin{tabular}{|c|c|c|c|}
\hline Confined Strain of Concrete & $\gamma_{\mathrm{cc}}=0.2$ & $\gamma_{\mathrm{cc}}=0.25$ & $\gamma_{\mathrm{cc}}=0.3$ \\
\hline 0.001 & 1.018 & 1.02 & 1.024 \\
\hline 0.002 & 1.03 & 1.05 & 1.07 \\
\hline
\end{tabular}

The increase in stiffness was calculated and the values were correlated to the experimental values. In the case of 3 wraps the increase in stiffness was about 1.2 times the unconfined concrete at a strain value of 0.003 . 


\section{Partially wrapped specimens failure mode}

The failure pattern of the specimens subjected to compressive loading was verified using the Coulomb Failure Criterion. It states that shear strength consists of 2 components: Cohesion and Friction (Fernandes, 2001).

$$
\tau_{\mathrm{cr}}=\mathrm{c}+\sigma \tan (\phi)
$$

$\mathrm{C}$ is cohesion parameter and $\phi$ is internal angle of friction.

In this study cohesion remains the same for both unconfined and partially confined i.e. wrapped only at the center with no wrap at top and bottom, as the concrete was made in the same batch. The angle of internal friction varies from a non-wrapped to a partially wrapped specimen. The partially wrapped specimen has a lower angle of friction and hence the reduction in shear strength, which was noted in the failure mode of partially, wrapped specimens. The specimens failed in the non-wrapped region and the failure plane makes a lower angle than the failure plane of the non-wrapped specimen.

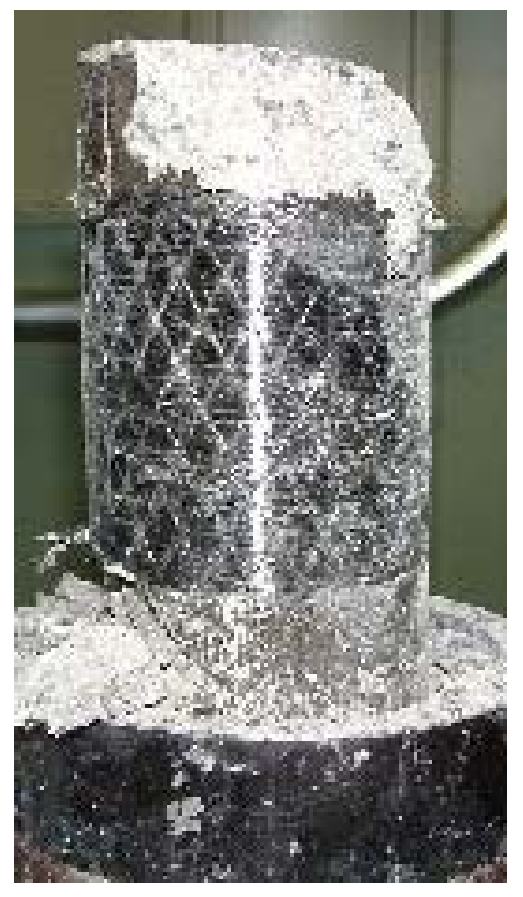

Figure D- 1 Partially Wrapped Specimen - Failure Pattern 
Considering theory of elasticity, the stress components $\sigma$ and $\tau$ acting on a plane whose normal makes an angle $\theta$ with the direction of the failure plane

$$
\begin{aligned}
& \sigma=1 / 2\left(\sigma_{1}+\sigma_{3}\right)+1 / 2\left(\sigma_{1}-\sigma_{3}\right) \cos 2 \theta \\
& \tau=1 / 2\left(\sigma_{1}-\sigma_{3}\right) \sin 2 \theta
\end{aligned}
$$

$\theta$ for non-wrapped segment of the partially wrapped specimens is lower than in nonwrapped specimens due to dimension and aspect ratio of non-wrapped height to diameter. Hence the strength of partially wrapped specimens is lower than non-wrapped specimens due to this change in failure mode. Further study is necessary to validate these findings observed in few cylinders. 